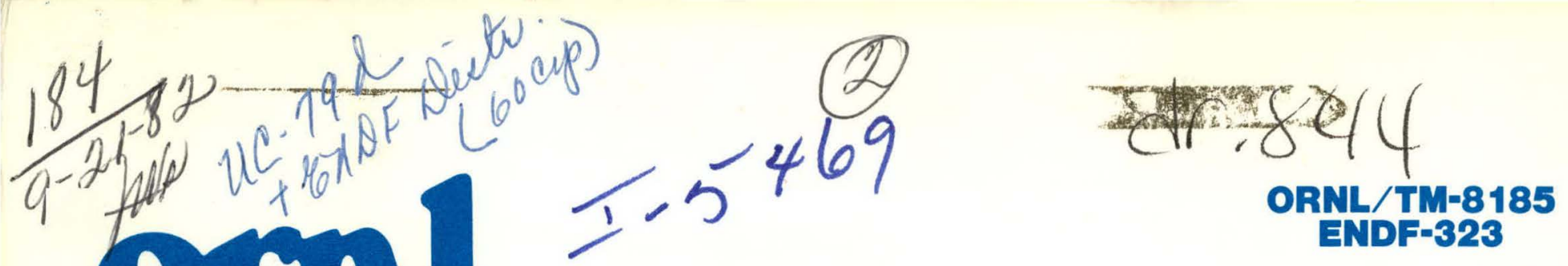

orin

OAK

RIDGE

NATIONAL

LABORATORY

Nancy M. Larson

UNION

CARBIDE

\title{
User's Guide for BAYES: \\ A General-Purpose Computer Code for Fitting a Functional Form to Experimental Data
}

\section{MASTER}



OPERATED BY

UNION CARBIDE CORPORATION FOR THE UNITED STATES DEPARTMENT OF ENERGY 


\section{DISCLAIMER}

This report was prepared as an account of work sponsored by an agency of the United States Government. Neither the United States Government nor any agency Thereof, nor any of their employees, makes any warranty, express or implied, or assumes any legal liability or responsibility for the accuracy, completeness, or usefulness of any information, apparatus, product, or process disclosed, or represents that its use would not infringe privately owned rights. Reference herein to any specific commercial product, process, or service by trade name, trademark, manufacturer, or otherwise does not necessarily constitute or imply its endorsement, recommendation, or favoring by the United States Government or any agency thereof. The views and opinions of authors expressed herein do not necessarily state or reflect those of the United States Government or any agency thereof. 


\section{DISCLAIMER}

Portions of this document may be illegible in electronic image products. Images are produced from the best available original document. 


\section{Printed in the United States of America. Available from National Technical Information Service \\ U.S. Department of Commerce \\ 5285 Port Royal Road, Springfield, Virginia 22161 \\ NTIS price codes-Printed Copy: A15 Microfiche A01}

This report was prepared as an account of work sponsored by an agency of the United States Government. Neither the United States Government nor any agency thereof, nor any of their employees, makes any warranty, express or implied, or assumes any legal liability or responsibility for the accuracy, completeness, or usefulness of any information, apparatus, product, or process disclosed, or represents that its use would not infringe privately owned rights. Reference herein to any specific commercial product, process, or service by trade name, trademark, manufacturer, or otherwise, does not necessarily constitute or imply its endorsement, recommendation, or favoring by the United States Government or any agency thereof. The views and opinions of authors expressed herein do not necessarily state or reflect those of the United States Government or any agency thereof. 


\section{ORNL/TM- -8185}

DE82. 021092

ORNL/TM-8185

ENDF-323

Contract No. W-7405-eng-26

Engineering Physics Division and Physics Division

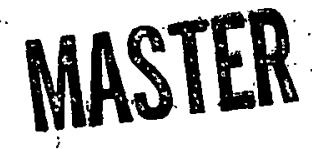

User's Guide for BAYES: A General-Purpose Computer Code
for Fitting a Functional Form to Experimental Data

Nancy M. Larson

Computer Sciences

Date Published - August 1982

OAK RIDGE NATIONAL LABORATORY

Oak Ridge, Tennessee 37830

operated by

UNION C.ARBIDE CORPORATTON

for the

DEPARTMENT OF ENERGY




i

THIS PAGE

WAS INTENTIONALLY

LEFT BLANK 
LIST OF TABLES. . . . . . . . . . . . . . . . . . . V v ACKNOWLEDGMENTS . . . . . . . . . . . . . . . . . . . . ABSTRACT. . . . . . . . . . . . . . . . . . . . 1

I. INTRODUCTION. . . . . . . . . . . . . . . . . . . 3

II. DERIVATION OF BAYES' EQUATIONS. . . . . . . . . . . 5

III. IMPLEMENTATION OF BAYES' EQUATIONS. . . . . . . . . . . 11

1. Solving the Equations .. . . . . . . . . . 11

IV. DETAILS OF THE COMPUTER CODE. . . . . . . . . . . . 15

1. General Comments. . . . . . . . . . . . 15

2. User-Supplied Subroutines ........... 17

3. Output Routines.............. 22

4. Black-Box Routines. . . . . . . . . . . 25

5. Bayes Routines. . . . . . . . . . . . . 25

6. Variable-Dimensioned Arrays . . . . . . . . 28

V. EXAMPLES. . . . . . . . . . . . . . . . . . 29

Example 1. Fit a Functional Form to Experimental Data. $\quad 30$

The Problem . . . . . . . . . . . . . 30

The Solution............... . . . 30

Specific Case . . . . . . . . . . . . . . 30

Example 2. Combine Independent Data Sets . . . . . 48

The Problem................ . . 48

The solution. . . . . . . . . . . . . 48

Specific Case ................. . . . 48

Example 3. Background Subtraction. . . . . . . 67

The Problem ................ . . 67

The First Solution. . . . . . . . . . . 67

The Second Solution............... 68

Specific Case ................. 68

Example 4. Normalization ............ 89

The Problem .................. 89

The First Solution. . . . . . . . . . . . 89

The Second Solution... . . . . . . . . 9 90

Spccific Case .................. . 9 90

Example 5. Angular Distribution. ......... 114

The Problem............... 114

The Solution. . . . . . . ....... . 114

Specific Case .................... 115

VI. THE COMPANION CODE LEAST. . . . . . . . . . . . 137

VII. SUMMARY . . . . . . . . . . . . . . . 147

REFERENCES. . . . . . . . . . . . . . . . . 149

APPENDIX A. ALGEBRAIC DETAILS. . . . . . . . . . . . 151

1. Deriving Bayeo' Equations ...... . . . . . . 1.52

2. Iteration Scheme. . . . . . . . . . ... 156

3. Derivation of Least-Squares from Bayes' Equations . 157

4. Use of Data Covariance to Indicate Coherent Data

Corrections . . . . . . . . . . . . 158

5. Covariance Matrix for Differential Cross Sections. 159 
APPENDIX B. NOTATION USED IN BAYES . . . . . . . . . . . 163

APPENDIX C. FøRTRAN LISTING OF BAYES MAIN PROGRAM AND

OTHER ROUTINES . . . . . . . . . . . . 169

APPENDIX D. FØRTRAN LISTING OF ROUTINES UNIQUE TO

PROGRAM LEAST. . . ............. . . 189

APPENDIX E. FØRTRAN LISTING OF OUTPUT ROUTINES . . . . . . 205 
Table IV.1. Description of the Four Subprograms Which

a User Must Supply. . . . . . . . . . . . . . 20

Table IV.2. Description of Output Subroutines. . . . . . 23

Table V.1.1. ORELA PDP-10 File EX1.DAT, Containing Data

Required for Example 1. . . . . . . . . . . . 32

Table V.1.2. User-Supplied Subroutines for Example 1, Found on File EX1.F4 on the DRELA PDP-10............ 33

Table V.1.3. Teletype Commands and User Responses to Program Prompts for Example 1... . . . . . . . . . 36

Table V.1.4. Output Resulting from Use of the Commands Shown in Table V.1.3.................... 37

Table V.1.5. Teletype Commands and User Responses to Program Prompts for Example 1, Using Automatic Numerical Derivative Option. . . . . . . . . . . . . . . . . .

Table V.1.6. Output Resulting from Use of the Commands Shown in Table V.1.5., with Calls to Subroutines DUTDAT, ØUTREL, ఐUTCHL, ØUTREB, ØUTCHB, ØUTGMG, ØUTTH and ØUTG Suppressed to Minimize Output. . . . . . . . . . 46

Table V.1.7. File BAYES.øUT, Which Suppresses Calls to the Subroutines Listed in the File. . . . . . . . . 47

Table V.2.1. Input Data For Example 2. . . . . . . . 51

Table V.2.2. User-Supplied Subroutines for Example 2, Found on File EX2.F4 on the ORELA PDP-10........... 52

Table V.2.3. Modified Versions of Subroutines ØUTDAT, ØUTTH, ØUTG, and øUTREL, for Use in Example 2. . . . . . . 56

Table V.2.4. Teletype Commands and User Responses to Program Prompts for Example 2............... 60

Table V.2.5. Output Resulting from the Use of Commands Given in Table V.2.4................ 61

Table V.2.6. Data and Covariance Matrix for the Combination of the Two Data Sets Shown in Table V.2.1......... 65

Table V.2.7. Output Obtained by Including All Five Data Points Simultaneously ................. 
Table V.3.1. ØRELA PDP-10 File EX31.DAT, Containing "Raw" Data Required for Example 3.............

Table V.3.2. User-Supplied Subroutines for Example 3, First Method of Solution. . . . . . . . . . . . 73

Table V.3.3. Teletype Commands and User Responses to Program Prompts for Example 3, First Solution . . . . . . . . .

Table V.3.4. Output Resulting from Use of Commands Shown in Table V.3.3................. 78

Table V.3.5. User-Supplied Subroutines for Example 3, Second Method of Solution. . . . . . . . . . . . . .

Table V.3.6. Teletype Command 3 and User Responses to Program Prompts for Example 3, Second Solution. . . . . . . .

Table V.3.7. Output Resulting from the Use of Commands Shown in Table V.3.6..................

Table V.3.8. Teletype Commands and User Responses to Program Prompts for Example 3, Second Soluton, with Data Supplied Half at a Time. . . . . . . . . . . . . . .

Table V.3.9. Output Resulting from the Use of Commands Shown in Table V.3.8..................

Table V.4.1. ØRELA PDP-10 File EX41.DAT, Containing "Raw" Data Used for Example 4 ...............

Table V.4.2. User-Supplied Subroutines for the First Method of Solution for Example 4 ..............

Table V.4.3. Teletype Commands and User Responses to Program Prompts for Example 4, First Method of Solution ......

Table V.4.4. Output Resulting from the Use of Commands Given in Table V.4.3................ 100

Table V.4.5. Uoer-Supplied Subroutines for the Seoond Method of Solution for Example 4. . . . . . . . . 104

Table V.4.6. Teletype Commands and User Responses to Program Prompts for Example 4, Second Method of Solution . . . . . 108

Table V.4.7. Output Resulting from the Use of Commands Given in Table V.4.6. ................ 109 
Table V.4.8. Teletype Commands and User Responses to Program Prompts for Example 4. Second Method of Solution, Where Subsets of the Data are Analyzed Sequentially . . . . . 110

Table V.4.9. Output Resulting from the Use of Commands Given in Table V.4.8. ............... Ill

Table V.5.1. ØRELA PDP-10 File EX5.DAT, Containing Data for Example 5. . . . . . . . . . . . . 117

Table V.5.2. Starting Values for the Parameters for Eximple 5, Stored in File EX5.PAR ............. 118

Table V.5.3. User-Supplied Subroutines for Example 5, Stored in File EX5.F4. . . . . . . . . . . . . .

Table V.5.4. Teletype Commands and User Responses to Program Prompts for Example 5.............. 123

Table V.5.5. Output Resulting from the Use of Commands Given in Table V.5.4. . . . . . . . . . . . . . 124

Table V.5.6. Results Which are Obtained for Example 5 by Assuming that the Data Covariance Matrix is Diagonal. . . 131

Table VI.1. Output from Least-Squares Analysis of Data Given in Example 1. . . . . . . . . . . . . 139

Table VI.2. Output from Least-Squares Analysis of Combined Data Set for Example 2. .............. 141

Table VI.3. Output from Least-Squares Analysis of Data Set for Example 3, First Method of Solution . . . . . . . 142

Table VI.4. Output from Least-Squares Analysis of Data Set for Example 3, Second Method of Solution. . ...... 143

Table VI.5. Output for Least-Squares Analysis of Data Set for Example 4, First Method of Solution........ 145

Table VI.6. Output from Least-Squares Analysis of Data Set for Example 4, Second Method of Solution. . . . . . 146 
THIS PAGE

WAS INTENTIONALLY

LEFT BLANKK 


\section{ACKNOWLEDGMENTS}

The author acknowledges contributions from a multitude of people, without whose aid this project might never have been brought to fruition. First and foremost, Francis Perey provided invaluable insight into the correct use of Bayes' method. Reg Gwin, in his struggles to use an early version of BAYES, suggested several modifications to increase the versatility and thus the utility of the code. Other early users of BAYES (David Hetrick, Peter Fu, Kirk Dickens, and Duane Larson) provided both encouragement and inspiration for the examples used in this report. The financial and moral support of the entire ORELA staff is greatly appreciated.

Finally, thanks go to Betty Waddell and Bobbie Roth who patiently typed the several iterations of this report. 


\begin{abstract}
This report is intended as a user's manual for a general-purpose computer program BAYES to solve "Bayes' equations" for updating parameter values, uncertainties, and correlations. Bayes' equations are derived from Bayes' theorem, using linearity and normality assumptions. The method of solution is described, and details are given for adapting the code for a specific purpose. Numerous examples are given, including problem description and solution method, FØRTRAN coding, and sample input and output. A companion code LEAST, which solves the usual least-squares equations rather than Bayes' equations but which encourages nondiagonal data weighting, is also described.
\end{abstract}


THIS PAGE

WAS INTENTIONALLY

LEFT BLANK 


\section{INTRODUCTION}

In a recent report [LA80] on a multilevel R-matrix code (SAMMY) for analysis of experimental neutron data, we described the use of Bayes' method for obtaining estimates of parameters of a model by fitting experimental data. In this report we describe a "skeleton" code (BAYES) which can be used to solve Bayes' equations for an arbitrary problem, much as one would use a generalized least-squares solver.

A discussion of the philosophy regarding the use of Bayes' theorem is presented in the earlier report and will not be repeated here. Rather, in Section II we present a straightforward derivation of Bayes' equations, carefully delineating the assumptions required for that derivation. For further details, the reader is referred to the forthcoming article on Bayes' method [PE82].

In Section III we describe the manner in which Bayes' equations are implemented in the computer code BAYES. In Section IV other portions of BAYES are discussed in sufficient detail to permit ready modification for specific applications.

Section $V$ is expected to be the most important section for anyone wishing to employ Bayes' method in his own work. Here we present examples of problems which might be attacked with Bayes' method. A description of a problem is given, followed by a discussion of the various approaches one could take to the problem. The FORTRAN coding which the user would supply is given for each approach discussed. Also shown are sample input and output. 
In Section VI we describe a companion program (LEAST), identical to BAYES except that it is used to solve the least-squares equations rather than Bayes' equations. Applications of LEAST to the examples of Section V are also given in Section VI.

Five appendices complete this report. Appendix A gives those algebraic details which were judged too complex to be included within the text. Appendix B contains an alphabetized table of notation used in BAYES. The FøRTRAN listing of subroutines unique to BAYES is given in Appendix $C$, of those unique to LEAST in Appendix $D$, and of the output routines in Appendix E. 


\section{DERIVATION OF BAYES' EQUATIONS}

In this section the formulae implemented in the code BAYES to obtain the values of the parameters and their uncertainties using Bayes' theorem are derived. Bayes' theorem may be written in the form

$$
p(P \mid D X) \propto p(P \mid X) p(D \mid P X)
$$

where

(1) P represents the parameters of whatever physical theory is to be used to describe the data and D represents the new experimental data which the theory is expected to describe.

(2) X represents "background" or "prior" information such as the data from which prior knowledge of the parameters $P$ was derived. $X$ is assumed to be independent of $D$.

(3) $p(P \mid D X)$ is the probability for the value of the parameters conditional upon the new data $D$ and is what we seek. It is conventional to call $p(P \mid D X)$ the posterior probability. When $P$ represents several parameters, $p(P \mid D X)$ is a joint probability density function (joint $p d f)$. The expectation values of $P$ times $p(P \mid D X)$ are taken as the new estimates for the parameters; the associated covariance matrix gives us a measure of how well the parameters are determined and of the parameters' inter-dependencies.

(4) $p(D \mid P X)$ is the probability density function for observing the data D given that the parameters $P$ are correct. It is a function of the parameters $P$ of the model and is proportional to the likelihood function of the data $D$. 
(5) $p(P \mid X)$ is the joint pdf for the value of the parameters $P$ of the model, prior to consideration of the new data $D$; it is known as the prior joint pdf. The expectation values of $P$ times $p(P \mid X)$ are the prior estimates for the values of the parameters; the associated covariance matrix gives a measure of how well the parameters are known before consideration of the new data.

(6) The constant of proportionality in Eq. (II.1) can be determined from the normalization condition.

Let $P=\left\{P_{k}\right\}$ for $k=1$ to $k$ be the set of all parameters of the theoretical model to be considered. The joint $\operatorname{pdf} p(P \mid X)$ is assumed to be a joint normal pdf having as expectation value the vector $\bar{p}$ and the covariance matrix $M$. Under this assumption the pdf may be written

$$
p(P \mid X) \propto \exp \left[-1 / 2(P-P)^{t} M^{-1}(P-\bar{P})\right]
$$

where the superscript $t$ denotes the transpose.

The experimental data is represented by a data vector $D$ whose components $D_{i}$ are the $L$ data points. The experimental cundltions are assumed to be such that the data $D$ (i.e. the $D_{i}^{\prime} s$ ) have a joint normal distribution with mean $T=T(P)$ and covariance matrix $V$. The likelihood function is then

$$
p(D \mid P X) \propto \exp \left[-1 / 2(D-T)^{t} v^{-1}(D-T)\right]
$$

In this equation, the covariance matrix $\mathrm{V}$ represents not only the experimental "errors" of the data, but also any theoretical "errors" resulting from approximations used in calculating $T$. Obviously $V$ need not be diagonal. 
Combining Eqs. (II.1), (II.2), and (II.3) gives an expression for the pdf of $P$ after consideration of new data $D$ (i.e., for $p(P \mid D X)$ ), expressed in terms of the "true" value $T$. What is needed, however, is an expression for $p(P \mid D X)$ expressed in terms of the parameters $P$. This is obtained formally by considering $\mathrm{T}$ a function of $\mathrm{P}$, performing a Taylor expansion about $\bar{P}$ (the expectation value of $p(P \mid X)$ ), and keeping only the linear terms:

$$
T(P) \simeq \bar{T}+G(P-\bar{P})
$$

where $\bar{T}$ is equal to $T(\bar{P})$. The elements of $G$ are the partial derivatives of $T_{n}$ with respect to the parameters $P_{k}$, evaluated at $P=\bar{P}$ :

$$
G_{n k}=\left.\frac{\partial T_{n}}{\partial P_{k}}\right|_{P=\bar{P}} \begin{aligned}
& \text { for } n=1,2, \ldots, L \\
& \text { and } k=1,2, \ldots, K
\end{aligned}
$$

Since $T$ is a vector of dimension $L$ (equal to the number of data points), and $P$ is a vector of dimension $K$ (equal to the number of parameters), this "sensitivity matrix" $G$ is of dimension $L \times K$.

Sluhst.ituting Eq, (II.4) into Eq. (II.3) and using Eq. (II.2), we obtain for the posterior joint pdf (Eq. (II.1)):

$$
\begin{aligned}
& p(P \mid D X) \propto \exp \left[-1 / 2\left\{(P-\bar{P})^{t} M^{-1}(P-\bar{P})+\right.\right. \\
&\left.\left.(D-\bar{T}-G(P-\bar{P}))^{t} V^{-1}(D-\bar{T}-G(P-\bar{P}))\right\}\right]
\end{aligned}
$$


Because of the three basic assumptions we have made, i.e..

i) the prior joint pdf is a joint normal,

ii) the likelihood function is a joint normal, and

iii) the true value is a linear function of the parameters,

the posterior joint pdf is also a joint normal. Denoting its expectation value by $\bar{p}^{\prime}$ and its covariance matrix by $M^{\prime}$, we may write:

$$
p(P \mid D X) \propto \exp \left[-1 / 2\left(P-\bar{P}^{\prime}\right)^{t} M^{\prime}=1\left(P-\bar{P}^{\prime}\right)\right] \text {. }
$$

As shown in Appendix A, equating the linear and quadratic terms of the exponents in Eqs. (II.6) and (II.7) yields our final results, hereafter referred to as Bayes' equations:

$$
\begin{aligned}
& P^{\prime}-\bar{P}=M G^{t}(N+V)^{-1}(D-T), \\
& M-M^{\prime}=M G^{t+}(N+V)^{-1} G M,
\end{aligned}
$$

where the $\mathrm{L} \times \mathrm{L}$ matrix $\mathrm{N}$ is defined as

$$
N=G M G^{t}
$$

The matrix $\mathrm{N}$ is the covariance matrix of the joint pdf for the true value of the data based upon our prior pdf for the value of the parameters.

In the limit where the matrix $M$ is diagonal and its elements tend to infinity, Bayes' equations become the familiar least-squares equations. Algebraic details are given in Appendix A. 
Because the linearity condition (Eq. (II.4)) may be only approximately correct, it is necessary to alter Bayes' equations slightly to permit iteration to an accurate solution. (Details are given in Appendix A.) It is the iterative form of Bayes' equations which is implemented in the code BAYES.

Finally, we note that the derivation of Eqs. (II.8) through (II. 10) which we present in Appendix $A$ is not the only possible derivation. Alternative derivations can be found in [MA80] and [GA73]. 


\section{THIS PAGE}

\section{WAS INTENTIONALLY}

\section{LEFT BLANK}




\section{IMPLEMENTATION OF BAYES' EQUATIONS}

\section{Solving the Equations}

Implementation of Bayes' equations is straightforward. From Appendix A, the iterative form of these equations is

$$
\bar{P}^{(n+1)}=\bar{P}+M G^{(n) t}\left(N^{(n)}+V\right)^{-1}\left(D-T^{(n)}-G^{(n)}\left(5^{5}-\bar{P}^{(n)}\right)\right)
$$

and

$$
M^{(n+1)}=M-M G^{(n) t}\left(N^{(n)}+V\right)^{-1} G^{(n)} M \text {, }
$$

where

$$
N^{(n)}=G^{(n)}{ }_{M G}^{(n) t} \text {. }
$$

Solving Eqs. (III.1) and (III.2) is equivalent to solving

$$
A X=Y
$$

$K+1$ times (where $K$ is the number of parameters for the problem), with $A$ the $\mathrm{L} \times \mathrm{L}$ symmetric matrix $\mathrm{N}+\mathrm{V}$ (where $\mathrm{L}$ is the number of data points), and $\mathrm{Y}$ a column matrix equal to $\left(D-\bar{T}^{(n)}-G^{(n)}\left(\bar{P}_{-} \bar{P}^{(n)}\right)\right.$ ) in Eq. (III.1) or equal to each of the $K$ columns of the rectangular matrix $G^{(n)} M$ in Eq. (III.2). The results for $X$ are then multiplied by $M G(n) t$ for use in És. (III.1) and (III.2)

In order to ensure reasonable accuracy in the solution of Eq. (III.4), we perform a scaling operation on matrix A prior to solution of the equation. Note that Eq. (III.4) is mathematically equivalent to the equation

$$
A^{\prime} X^{\prime}=Y^{\prime}
$$


where $A^{\prime}=C A C, X^{\prime}=C^{-1} X$, and $Y^{\prime}=C Y$, with $C$ any $L \times L$ nonsingular matrix. In particular, we choose $C$ to be the diagonal matrix whose elements are the inverse of the diagonal elements of $A$. The matrix $A^{\prime}$ then has 1.0 everywhere on the diagonal, and the numerical solution of Eq. (III.5) is likely to be more accurate than that of Eq. (III.4). A detailed discussion of scaling as preparation for solution of matrix equations is given in Section I.7 of the Linpack IIsers' Guide [Dø79].

Solution of Eq. (III.5) is obtained in two steps. First matrix $A^{\prime}$ is factorized into the form

$$
A^{\prime}=U B U^{t}
$$

where $B$ is a block-diagonal matrix and $U$ is the product of elementary unit triangular and permutation matriees. The inveroco of $U$ and $B$ are lien immediately available, and the solution $X^{\prime}$ is simply

$$
X^{\prime}=\left(U^{-1}\right)^{t} B^{-1} U^{-1} Y^{\prime}
$$

LINFACK subruatine DPPCD is used to factorize A' according to Eq. (III.6). Tuls need bé done only one time, and the $(K+1)$ solutions $X^{\prime}$ are then found using LINPACK routine DPPSL.

In program BAYES, subroutine NEWPAR oversees the operations nut.1 ined above for obtaining updated parameter values and parameter covariance matrix elements.

Two other functions, not directiy related to solution of Bayes' equations, are performed in subroutine NEWPAR. The first is to test for convergence, the second to generate $x^{2}$ and/or weighted residuals. 
Convergence of the solution is tested as follows: the new value of each parameter is compared to its value at the previous iteration. When all NPAR parameters agree to within a specified tolerance, iteration ceases. Specifically, let $t$ be the tolerance or "convergence fraction" as specified in the teletype input (see Section V, Examples); iteration ceases when

$$
\left|\bar{P}^{(n+1)}-\bar{P}^{(n)}\right|<t\left|\bar{P}^{(n)}\right|
$$

for every varied parameter.

Both least-squares and "Bayesian" $x^{2}$ and weighted residuals may be generated in NEWPAR. The least-squares residuals are defined as

$$
R_{L S}=V^{-1}\left(D-T^{(n)}\right)
$$

and $\chi^{2}$ as

$$
x_{L S}^{2}=\left(D-\bar{T}^{(n)}\right)^{t} V^{-1}\left(D-\bar{T}^{(n)}\right) .
$$

The Bayesian weighted residuals are defined by

$$
R_{B}=\left(N^{(n)}+V\right)^{-1}\left(D-T^{(n)}-G^{(n)}\left(\bar{P}-\bar{P}^{(n)}\right)\right)
$$

and $\chi^{2}$ by

$$
\begin{gathered}
x_{B}^{2}=\left(D-\bar{T}^{(n)}-G^{(n)}\left(\bar{P}-\bar{P}^{(n)}\right)\right)^{t}\left(N^{(n)}+V\right)^{-1} \\
x\left(D-\bar{T}^{(n)}-G^{(n)}\left(\bar{P}-\bar{P}^{(n)}\right)\right) .
\end{gathered}
$$




\section{THIS PAGE}

\section{WAS INTENTIONALLY LEFT BLANK}




\section{DETAILS OF THE COMPUTER CODE}

\section{General Comments}

Program BAYES will likely be modified by each user to suit his special purposes. For that reason we have endeavored to make the FøRTRAN coding as readable as possible, perhaps at the expense of computer efficiency. All arrays required by BAYES are of fixed size; error messages appear at execution time when array bounds are exceeded. (Dynamic allocation of array storage is employed in version ZBAYES, described in subsection 6 below.) Comment cards abound throughout the program. Double precision is used in BAYES; though it is not strictly necessary, experience has shown that this is the safer course, especially since numerical "derivatives" are rarely sufficiently accurate in single precision.

For a simple problem, the user must supply only three subroutines: one to initialize parameters and parameter covariances, a second to specify the experimental data and data covariances, and a third to calculate theoretical values. An optional fourth subroutine would generate partial derivatives, though BAYES is capable of generating numerical differences as approximations to the partial derivatives if the user so desires.

Tnput formats are controlled by the individual user via the subroutines discussed above, which are described in more detail below. The code BAYES, however, handles many of the bookkeeping problems internally: (1) To vary only selected members of a parameter list, and hold the others constant, the user need only set a flag for the varied parameters. (2) Though covariance matrices are stored in "packed" form to minimize storage, the user is asked to specify the matrices in the customary twodimensional form. 
All output provided by BAYES is done in routines whose names begin with the letters øUT. Often a user will not need all possible kinds of output, in which case he may simply suppress the call to that routine by preparing a file called BAYES.ØUT. This file contains one card per suppressed subroutine, with the subroutine's name in columns 1 through 6 . For example, listing the values of the partial derivatives will be needed only during the "debugging" stage, so in normal operation file BAYES.ØUT contains a line with "ØUTG (blank) (blank)" in columns 1 through 6. See, e.g., Example 1 in Section V.

Outpul ruutlnes may réquire modification for some problems. See, e.g., Example 2 in Section $V$, for which the independent variable is not energy but rather alphanumeric information. Appropriate output formats must be provided by the user for this type of variable.

The one other modification which will often be required is in array dimensions. Such changes of dimension should be made with great care: (1) The appropriate limit NDATMX (maximum number nf data points), NPARMX (maximum number of varied parameters), or NNPARM (maximum total number of parameters) must be changed in the DATA statement following the COMMON statements in the main program. (2) Dimensions must be changer in COMMON/DAT/,/PAR/,/BOTH/, and /YRPAR/ in every subroutine in the entire program. The dimension of VARDAT and EN in CØMMØN/DAT/ should be set equal to $((\operatorname{NDATMX} *(\operatorname{NDATMX}+1)) / 2)$, and the dimension of VARPAR and VARNEW in CØMMØN/PAR/ should be set to $(($ NPARMX*(NPARMX+1))/2). (3) If NPARMX is changed, the "DIMENSION PARVAR" statement in subroutine PPARAM must be changed. (4) If NDATMX is changed, the "DIMENSIØN DATCØV" statement in subroutines SETDAT and FIXV must be changed. 
Array sizes in BAYES are currently set at NDATMX $=51$, NPARMX $=25$, and NNPARM $=26$. The error message which appears if these limits are exceeded specifies which COMMONS need to be modifed.

Subsections 2 through 5 of this section contain descriptions of the four different categories of subroutines which together comprise the BAYES code. Routines in each category are stored in separated files on disk NML2, Project-Programmer Number (PPN) $[100,1006]$, on the ORELA PDP-10 computer, and can be copied from these to other PPN's. Users not on that computer should contact the Radiation Shielding Information Center [RA82] for access to the code. It is expected (though not guaranteed) that conversion of BAYES (or LEAST) for use on other computer systems should not be difficult, since little PDP-10-specific FORTRAN has been employed.

Subsection 6 describes version ZBAYES, in which arrays are not of. fixed dimensions.

2. User-Supplied Subroutines

Three routines must be provided by the users for every problem. The first is subroutine SETPAR, which initializes parameters and parameter covariances, and flags those parameters which are to be varied. (Note: if no parameter is flagged, BAYES assumes all parameters are to be varied.) Users unfamiliar with Bayes' method may question what are appropriate values for the covariance matrix elements; often a reasonable procedure is to set off-diagonal elements equal to zero and diagonal elements equal to the square of the uncertainty on the parameter. For example, if previous 
experiments have shown that the parameter cannot vary by more than $10 \%$, then the diagonal element is $(0.1 \times P)^{2}$. If there is no prior evidence constraining the parameter to a certain size, the diagonal element may be initialized at $(1.0 \times \mathrm{P})^{2}$ or even greater. Strictly speaking, a more correct approach in this case would be to use the least-squares method; however, that is not practical if prior information exists for some parameters but not for others, or if multiple data sets are to be analyzed sequentially.

The second user-supplied routine is subroutine SETDAT, which specifies the experimental data, the values of the independent variable or variables labeling each data point, and the data covariance matrix elements. For guidance in setting the values of data covariances, the user is referred to the examples in Section $V$. Note that in many cases it is not appropriate to assume that the data covariance matrix is diagonal.

The third routine is function THEØ(KDAT), which generates the theoretical value to which experimental data point KDAT is to be compared.

For many problems, BAYES can generate numerical differences to approximate the partial derivative of the theoretical value with respect to each of the parameters. However, in most instances the user should provide analytical derivatives in function DERIV, since the numerical difference option consumes considerable computer time. Where possible, the numerical difference option should be used for debug purposes, to test both algebra and coding in function DERIV.

FORTRAN listings of the four routines SETPAR, SETDAT, THED, and DERIV are given in Section $\mathrm{V}$ for each example covered in that section; Table IV. 1 summarizes the information the user must supply in the four routines. In 
modifying the routines for his problem, the user should take care to change only the executable statements and not CØMMØN blocks or EQUIVALENCE statements. (It may, of course, be necessary to change array dimensions if limits are exceeded.) If the automatic numerical difference option is to be used exclusively, function DERIV can be a "dummy" routine of the form DØUBLE PRECISIØN FUNCTIØN DERIV RETURN END 
Table IV.1. Description of the Four Subprograms Which a User Must Supply.

\begin{tabular}{lll}
\hline Routine & Variable or & Meaning \\
& Array to be & \\
Initialized
\end{tabular}

\begin{tabular}{|c|c|c|}
\hline \multirow{4}{*}{$\begin{array}{l}\text { Subroutine } \\
\text { SETPAR }\end{array}$} & NPARAM & total number of parameters \\
\hline & $\begin{array}{l}\operatorname{PARAM}(i), \text { for } \\
i=1 \text { to NPARAM }\end{array}$ & $\bar{P}_{i}$ for all $i$ \\
\hline & $\begin{array}{l}\operatorname{IFPAR}(i) \text {, for } \\
i=1 \text { to NPARAM }\end{array}$ & $\begin{array}{l}1 \text { if parametor number i is } \\
\text { to be varied, } 0 \text { otherwise }\end{array}$ \\
\hline & $\begin{array}{l}\operatorname{PARC} \oslash V(k, i) \text { for } \\
k \text { and } i=1 \text { to } \\
\text { NPARAM }\end{array}$ & $\begin{array}{l}M_{\text {ki }} \text { (only } k \leq i \text { need be } \\
\text { specified, since the } \\
\text { array is symmetric) }\end{array}$ \\
\hline \multirow{5}{*}{$\begin{array}{l}\text { Subroutine } \\
\text { SETDAT }\end{array}$} & NDAT & number nf rat.a moints \\
\hline & $E(i)$, for $i=1$ to NDAT & $\begin{array}{l}\text { the first independent variable } \\
\text { (often energy) }\end{array}$ \\
\hline & $E 2(i)$ for $i=1$ to NDAT & $\begin{array}{l}\text { the second independent variable, } \\
\text { if needed }\end{array}$ \\
\hline & $\operatorname{DATA}(i)$ for $i=1$ to NDAT & experimental data \\
\hline & $\begin{array}{l}\operatorname{DATC} \oslash V(k, i) \text { for } \\
k \text { and } i=1 \text { to NDAl }\end{array}$ & $\begin{array}{l}v_{k i} \text { (only } k \leq i \text { need be } \\
\text { specified, 3ince the array } 10 \\
\text { symmetric); Note that the } \\
\text { uncertainty on data point } i \\
\text { is } \sqrt{v_{i i}}\end{array}$ \\
\hline
\end{tabular}


Table IV.1. (Continued)

\begin{tabular}{lll}
\hline Routine & $\begin{array}{l}\text { Variable or } \\
\text { Array to be } \\
\text { Initialized }\end{array}$ & Meaning \\
\hline
\end{tabular}

Double

Precision

Function

THEØ

Double

Precision

Function

DERIV
THEØ (KDAT)

$\bar{T}^{(n)}($ KDAT) $=$ theory for

data point KDAT, evaluated at

parameter $y$ yalues PARAM

(i.e., $\mathrm{P}^{(n)}$ )

$G_{i j}^{n}=\frac{\partial T_{i}}{\partial P_{j}}$

i.e., the partial derivative of the theory with respect to parameter number $j=K P A R$, for data point $i=K D A T$, evaluated at parameter values PARAM (i.e. $\overline{\mathrm{P}}(h)$ ) 
3. Output Routines

Output from BAYES is generated only in routines whose names begin with the letters ØUT. These routines are listed in Table IV. 2 and stored as file ØUT.FØR on the ORELA PDP-10 computer. Any of these routines may be modified by the user to provide output more suitable to his needs. A summary of what is printed in each routine is given in Table IV.2. FØRTRAN listing is provided in Appendix E.

Unit 6 is the logical unit number for output from BAYES. On the PDP10, this causes output to be printed in a file having extension LPT, which can then be typed or QUEUED to the line printer. When the file BAYES.ØUT does not specify suppression of the call to subroutine ØUTGMG, the extensive output from that routine appears in file FOR28.DAT. 
TABLE IV.2. Description of Output Subroutines

\begin{tabular}{|c|c|c|}
\hline $\begin{array}{l}\text { Subroutine } \\
\text { Name }\end{array}$ & $\begin{array}{l}\text { Name of array } \\
\text { printed in } \\
\text { that routine }\end{array}$ & Meaning \\
\hline ØUTALL & (None) & $\begin{array}{l}\text { (read file BAYES.øUT to } \\
\text { learn which output is to } \\
\text { be suppressed) }\end{array}$ \\
\hline $\left.\begin{array}{l}\emptyset \mathrm{UTCHB} \\
\emptyset \mathrm{UTCHL}\end{array}\right\}$ & $\mathrm{CHI}$ & 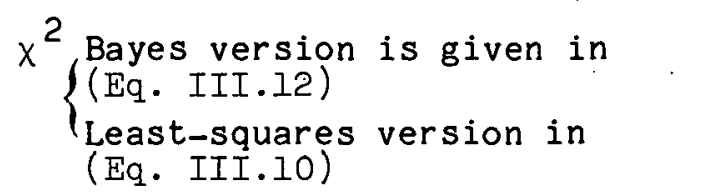 \\
\hline$\emptyset$ UTDAT & $\begin{array}{l}\text { E } \\
\text { DATA } \\
\text { VARDAT }\end{array}$ & $\begin{array}{l}\text { energies (independent variables). } \\
\text { experimental data. } \\
\text { covariance matrix (output as } \\
\text { standard deviation plus } \\
\text { correlation matrix) }\end{array}$ \\
\hline$\emptyset U T G$ & $\begin{array}{l}E \\
G\end{array}$ & $\begin{array}{l}\text { energies } \\
\text { partial derivatives }\end{array}$ \\
\hline ØUTGMG & GMG & (for debug only) \\
\hline ØUTPAR & $\begin{array}{l}\text { PARM } \\
\text { VARPAR }\end{array}$ & $\begin{array}{l}\text { initial values for varied } \\
\text { parameters } \\
\text { initial values for parameter } \\
\text { covariance matrix }\end{array}$ \\
\hline ØUTP 1 & $\begin{array}{l}\text { PØLD } \\
\text { PARM }\end{array}$ & $\begin{array}{l}\text { old values of parameters } \\
\text { updated values of parameters }\end{array}$ \\
\hline ØUTP2 & $\begin{array}{l}\text { PØLD } \\
\text { PARM } \\
\text { VARNEW }\end{array}$ & $\begin{array}{l}\text { old values of parameters } \\
\text { updated values of parameters } \\
\text { updated covariance matrix }\end{array}$ \\
\hline $\left.\begin{array}{l}\emptyset U T R E B \\
\emptyset U T R E L\end{array}\right\}$ & $\begin{array}{l}\text { E } \\
\text { DUM }\end{array}$ & $\begin{array}{l}\text { energies } \\
\text { weighted residuals } \\
\left\{\begin{array}{l}\text { Bayes version from (Eq. III.II) } \\
\text { Least-squares version from }\end{array}\right. \\
\quad(\mathrm{Eq} . \text { III.9) }\end{array}$ \\
\hline ØUTTH & $\begin{array}{l}\text { E } \\
\text { DATA } \\
\text { TH }\end{array}$ & $\begin{array}{l}\text { energies } \\
\text { data } \\
\text { theoretical values }\end{array}$ \\
\hline
\end{tabular}


TABLE IV.2. (Continued)

\begin{tabular}{lll}
\hline $\begin{array}{l}\text { Subroutine } \\
\text { Name }\end{array}$ & $\begin{array}{l}\text { Name of array } \\
\text { printed in } \\
\text { that routine }\end{array}$ & Meaning \\
\hline ØUTV & $\mathrm{V}$ & covariance matrix $\mathrm{V}_{\mathrm{ki}}$ \\
ØUTYV & PARCøV & covariance matrix $\mathrm{M}_{\mathrm{ki}}$ \\
ØUTYPR & $\begin{array}{l}\text { PARAM } \\
\text { PARCøV }\end{array}$ & $\begin{array}{l}\text { complete set of parameters } \\
\text { uncertainties and correlations } \\
\text { (i.e. covariance matrix) }\end{array}$ \\
\hline
\end{tabular}




\section{Black-Box Routines}

The method of solution of Bayes' equations (described in Section III) requires a significant amount of matrix manipulation. BAYES uses the L.T.NPACK [DØ79] routines DPPCD, DPPSL, and others called by those two, to perform these manipulations. These routines may safely be treated as a "black box" and therefore are not listed in this report. They are available on the PDP-10 in file DPPXX.FøR.

Automatic generation of numerical differences as approximations to analytic derivatives is accomplished by a call to subroutine DO4NML, which is a double-precision modification of the Numerical Algorithms Group routine DO4AAF [NAG]. This routine and those called by it are available on the PDP-10 in file DO4NML.FOR.

\section{Bayes Routines}

The remaining subroutines of the code BAYES are stored in file BAYES.FØR on the PDP-10 and listed in Appendix C. This includes all routines in solid boxes in the tree diagram shown in Fig. IV.1.

The main program functions as an overseer, calling appropriate subroutines to perform the actual calculations. The only modification a user should make in the main program is to change dimensions of the arrays.

Other subroutines included in this segment will not likely require modification by the casual user. Briefly, these routines are: 
PPARAM, which performs bookkeeping operations to convert between the complete parameter set and the varied parameter set.

FIXV, which rearranges storage of data covariance matrix.

THEØRY, which oversees evaluation of theoretical values and partial derivatives.

FUN, an auxiliary program required by the automatic numerical derivative routine.

NEWPAR, which, along with SCALE, MUL, and MUL2, solves Bayes' equations and generates weighted residuals and $\chi^{2}$ vạues. UPDATE, which updates parameter values in the complete parameter set. RESTRT, which reinitializes arrays in order to analyze another data set. 


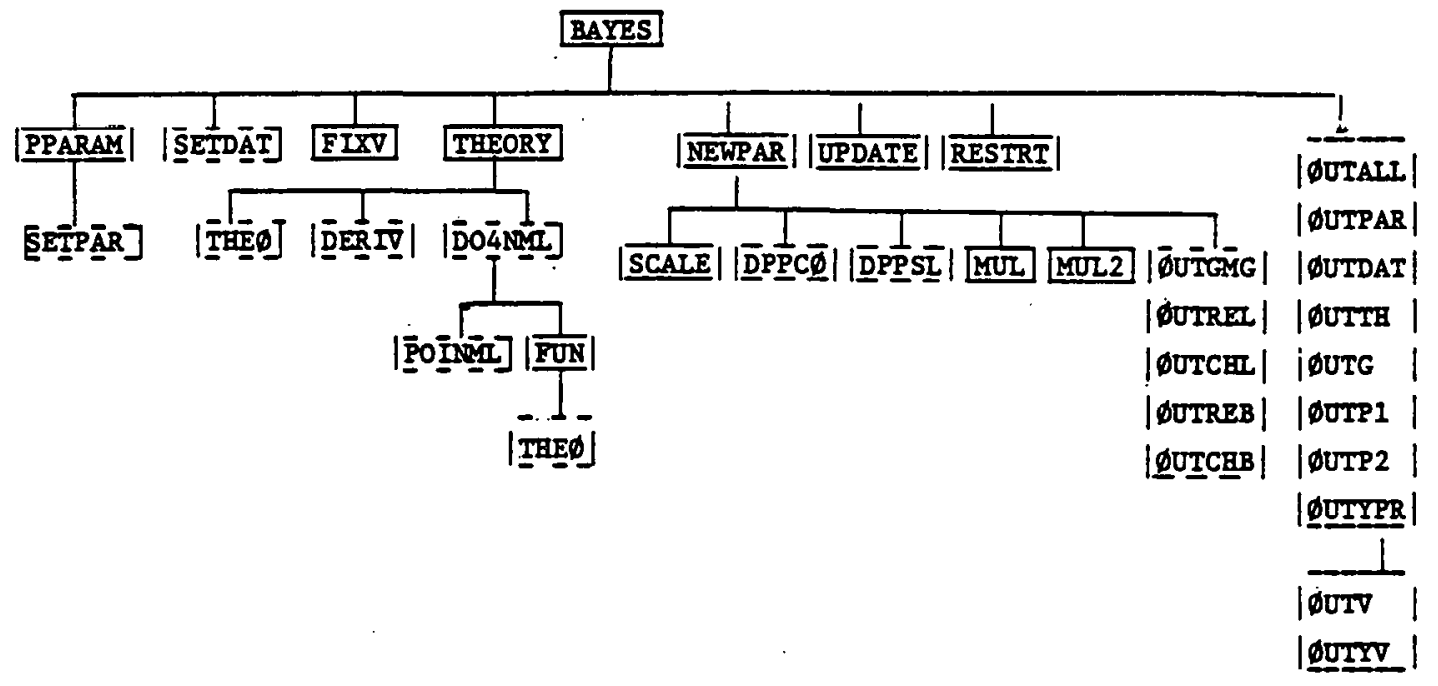

Fig. IV.1. Tree Diagram of Subroutines in BAYES. 


\section{Variable-Dimensioned Arrays}

Experienced computer programmers may find fixed array dimensions burdensome; therefore, an alternative version ZBAYES has been prepared. ZBAYES is identical to BAYES, except that array storage is allocated as it is needed, using calls to function IDIMEN to fix REAL*8 arrays, and calls to JDIMEN to fix INTEGER arrays. Thus, for example, the statement

$$
\text { IDATA = IDIMEN (NDAT) }
$$

causes NDAl words to be sel aside in array $\Lambda$ in CØMMøN/EXPAND/NREAL, INTEG, A, IA. Here $A$ is a double precision array of dimension NREAL, and IA is an integer array of dimension INTEG. Calls to a subroutine which uses array DATA are then written as

$$
\text { CALL SUB(A(IDATA)). }
$$

Unce DAl'A is no lunber dieded, its opace may bo released via

$$
I=\operatorname{IDIMEN}(-\operatorname{IDATA}) \text {. }
$$

It should be noted that this also releases everything allocated after DATA. The dimension of array $A$ is specified by NREAL, and of IA by INTEG. A warning message is printed if these limits are exceeded, in which case the user needs simply to increase the size and recompile the main rouline. No 1 isting of ZBAYES is provided within this report. ORELA PDP-10 users may obtain the necessary files from NML2: [100,1006]; filenames are identical to those specified for BAYES, with pref1x $Z$ appended. Other users should contact RSIC [RA82]. Conversion of ZBAYES for use on other computers should involve no major difficulties. 


\section{EXAMPLES}

Perhaps the clearest way to illustrate how a skeleton program such as BAYES might be used is by providing a number of examples. In this section we describe five different problems, identify one or more possible solutions to each problem, and list the FØRTRAN coding used to obtain the solutions. Sample input and output are provided for each case.

PDP-10 filenames are given for both data and user-supplied subroutines, for each of the four examples. ORELA PDP-10 users can access these files from disk NML2, project-programmer number $[100,1006]$. Output files are not saved, since they can be readily regenerated and compared to the listings provided here. Output is on unit 6 , and will appear in a file named ???.LPT on the ORELA PDP-10. 
Example 1. Fit a Functional Form to Experimental Data

The Problem:

The analytic expression $f(E, P)$, where $E$ is the independent variable

and $\mathrm{P}$ is one or more parameters, is expected to provide a reasonable fit to a set of experimental data $D$. Find the parameters $\bar{P}^{\prime}$, and the corresponding covariance matrix $\mathrm{M}^{\prime}$, which provide the best fit.

\section{The Solution:}

The solution is straightforward. Set

$$
T_{i}=\rho\left(E_{i}, \bar{P}\right)
$$

and

$$
G_{i j}=\left.\frac{\partial f}{\partial P_{j}}\right|_{E=E_{i}} \quad P=\bar{P}
$$

and solve Bayes' equations for $\bar{P}^{\prime}$ and $M^{\prime}$.

\section{Spec1f1c Case:}

Let the function $f(E, P)$ be given by

$$
f(E, P)=\left(P_{1} E\right)^{2}+P_{2} E+P_{3}
$$


Initial values for the parameters are assumed to be known to within $10 \%$, from some "previous experiment." The current "experiment " provides 21 (artificially generated) uncorrelated data points, as listed in Table V.1.1 (the PDP-10 file EX1.DAT). The PDP-10 file EX1.F4 shown in Table V.1.2 contains the user-supplied subroutines for this problem. Appropriate commands to execute this program are given in Table V.1.3, along with user responses to program prompts. The corresponding output file is given in Table V.1.4.

Teletype input for using the automatic numerical derivative option is shown in Table V.1.5, with corresponding output in Table V.1.6. In this case we have suppressed most of the output by generating the file BAYES. OUT as shown in Table V.1.7. 
Table V.1.1. ØRELA PDP-10 File EXI.DAT, Containing Data Required for Example 1.

\begin{tabular}{lll}
\hline Energy & Data & Relative Error \\
\hline 10.00 & 154.00 & 0.01 \\
11.00 & 151.90 & 0.01 \\
12.00 & 152.00 & 0.01 \\
1.3 .00 & 154.30 & 0.01 \\
14.00 & 158.80 & 0.01 \\
15.00 & 165.50 & 0.01 \\
16.00 & 174.40 & 0.01 \\
17.00 & 185.50 & 0.01 \\
18.00 & 198.80 & 0.01 \\
19.00 & 214.30 & 0.01 \\
20.00 & 232.00 & 0.01 \\
21.00 & 251.90 & 0.01 \\
22.00 & 274.00 & 0.01 \\
23.00 & 298.30 & 0.01 \\
24.00 & 324.80 & 0.01 \\
25.00 & 353.50 & 0.01 \\
26.00 & 384.40 & 0.01 \\
27.00 & 417.50 & 0.01 \\
28.00 & 457.80 & 0.01 \\
29.00 & 490.30 & 0.01 \\
30.00 & 530.00 & 0.01 \\
& & \\
\hline
\end{tabular}


Table V.1.2. User-Supplied Subroutines for Example 1, Found on File EX1.F4 on the ØRELA PDP-10.

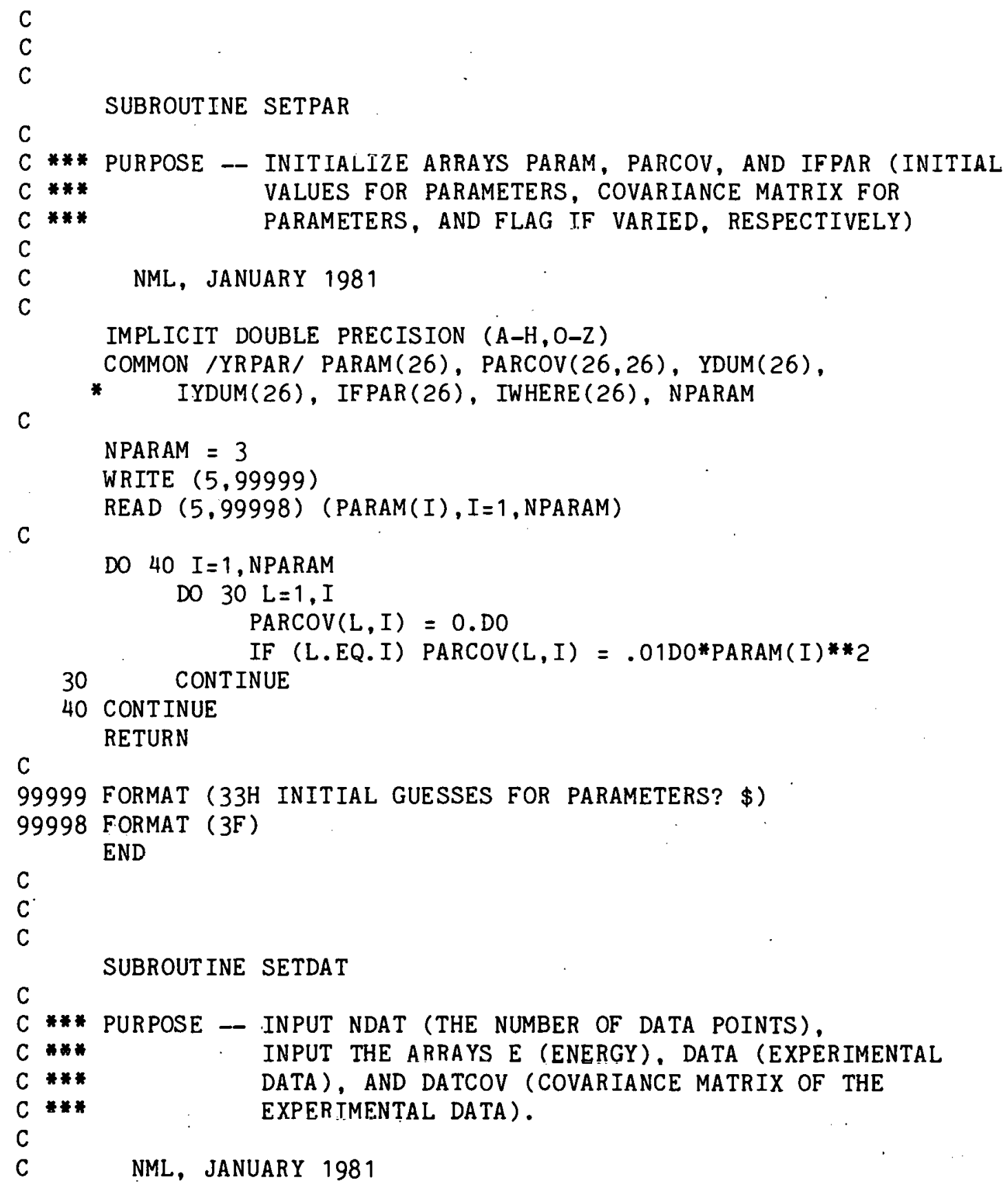

C

C

$C$

SUBROUT INE SETPAR

C *** PURPOSE -- INITIALIZE ARRAYS PARAM, PARCOV, AND IFPAR (INITIAL

$C * * * \quad$ VALUES FOR PARAMETERS, COVARIANCE MATRIX FOR

$C * * *$ PARAMETERS, AND FLAG IF VARIED, RESPECTIVELY)

$\mathrm{C}$

C NML, JANUARY 1981

C

IMPLICIT DOUBLE PRECISION (A-H,O-Z)

COMMON /YRPAR/ PARAM(26), PARCOV $(26,26), \operatorname{YDUM}(26)$,

C

* IYDUM(26), IFPAR(26), TWHERE (26), NPARAM

C

NPARAM $=3$

WRITE $(5,99999)$

READ $(5,99998)$ (PARAM( $I), I=1$, NPARAM)

DO $40 \quad I=1$, NPARAM

DO $30 \mathrm{~L}=1, \mathrm{I}$

$\operatorname{PARCOV}(L, I)=0 . D O$

30 CONT INUE

IF (L.EQ.I) $\operatorname{PARCOV}(L, I)=.01 D O * \operatorname{PARAM}(I) * 2$

40 CONTINUE

RETURN

C

99999 FORMAT (33H INITIAL GUESSES FOR PARAMETERS? \$)

99998 FORMAT (3F)

END

C.

C

C

SUBROUT INE SETDAT

C

C *** PURPOSE -- INPUT NDAT (THE NUMBER OF DATA POINTS),

$C$ *** INPUT THE ARRAYS E (ENERGY), DATA (EXPERIMENTAL

C *** DATA), AND DATCOV (COVARIANCE MATRIX OF THE

C ** EXPERTMENTAL DATA).

C NML, JANUARY 1981 
Table V.1.2. (Continued)

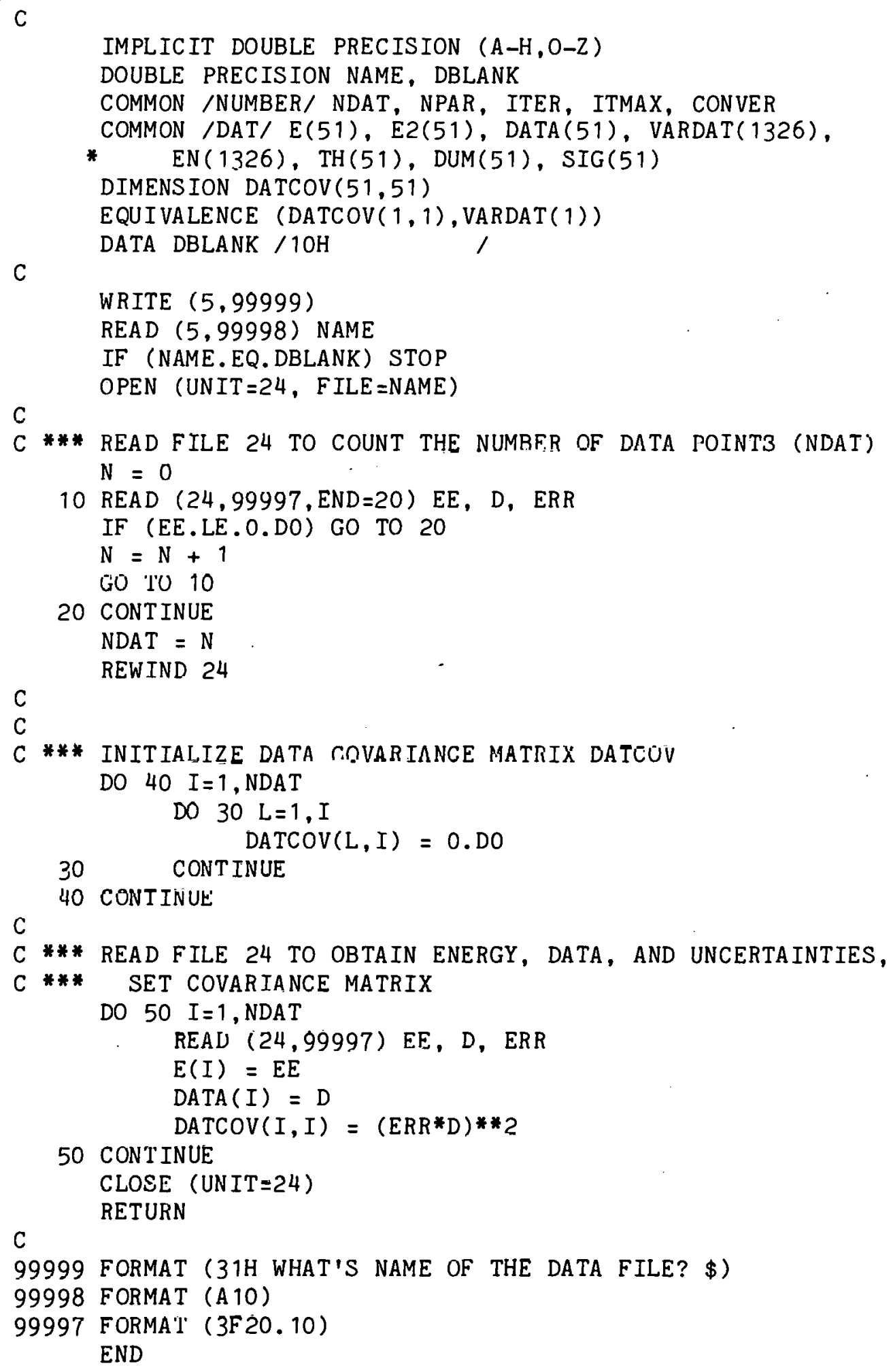

C

IMPLICIT DOUBLE PRECISION $(A-\mathrm{H}, \mathrm{O}-\mathrm{Z})$

DOUBLE PRECISION NAME, DBLANK

COMMON /NUMBER/ NDAT, NPAR, ITER, ITMAX, CONVER

COMMON /DAT/ E(51), E2(51), DATA(51), VARDAT(1326),

* EN(1326), TH(51), DUM(51), SIG(51)

DIMENSION DATCOV $(51,51)$

EQU I VALENCE (DATCOV $(1,1), \operatorname{VARDAT}(1))$

C

DATA DBLANK / 10H

WRITE $(5,99999)$

READ (5,99998) NAME

IF (NAME.EQ.DBLANK) STOP

OPEN (UNIT $=24$, FILE $=$ NAME)

C

C *** READ FILE 24 TO COUNT THE NUMBFR OF DATA POINT3 (NDAT)

$\mathrm{N}=0$

10 READ $(24,99997, E N D=20)$ EE, D, ERR

IF (EE.LE.O.DO) GO TO 20

$\mathrm{N}=\mathrm{N}+1$

GO TO 10

20 CONTINUE

NDAT $=N$

REWIND 24

C

C

C *** INITIALIZE DATA COVARIANCE MATRIX DATCÜV

DO $40 I=1$, NDAT

DO $30 \mathrm{~L}=1, \mathrm{I}$

$\operatorname{DATCOV}(L, I)=0 . D O$

30 CONTINUE

40 CONTINUE

C

C *** READ FILE 24 TO OBTAIN ENERGY, DATA, AND UNCERTAINTIES,

$C * * *$ SET COVARIANCE MATRIX

DO $50 I=1, N D A T$

READ $(24,99997)$ EE, D, ERR

$E(I)=E E$

$\operatorname{DATA}(I)=D$

$\operatorname{DATCOV}(I, I)=\left(E R R^{*} D\right) * * 2$

50 CONT INUE

CLOSE (UNIT $=24$ )

RETURN

C

99999 FORMAT (31H WHAT'S NAME OF THE DATA FILE? \$)

99998 FORMAT (A 10)

99997 FORMA' (3F 20.10)

END 
Table V.1.2. (Continued)

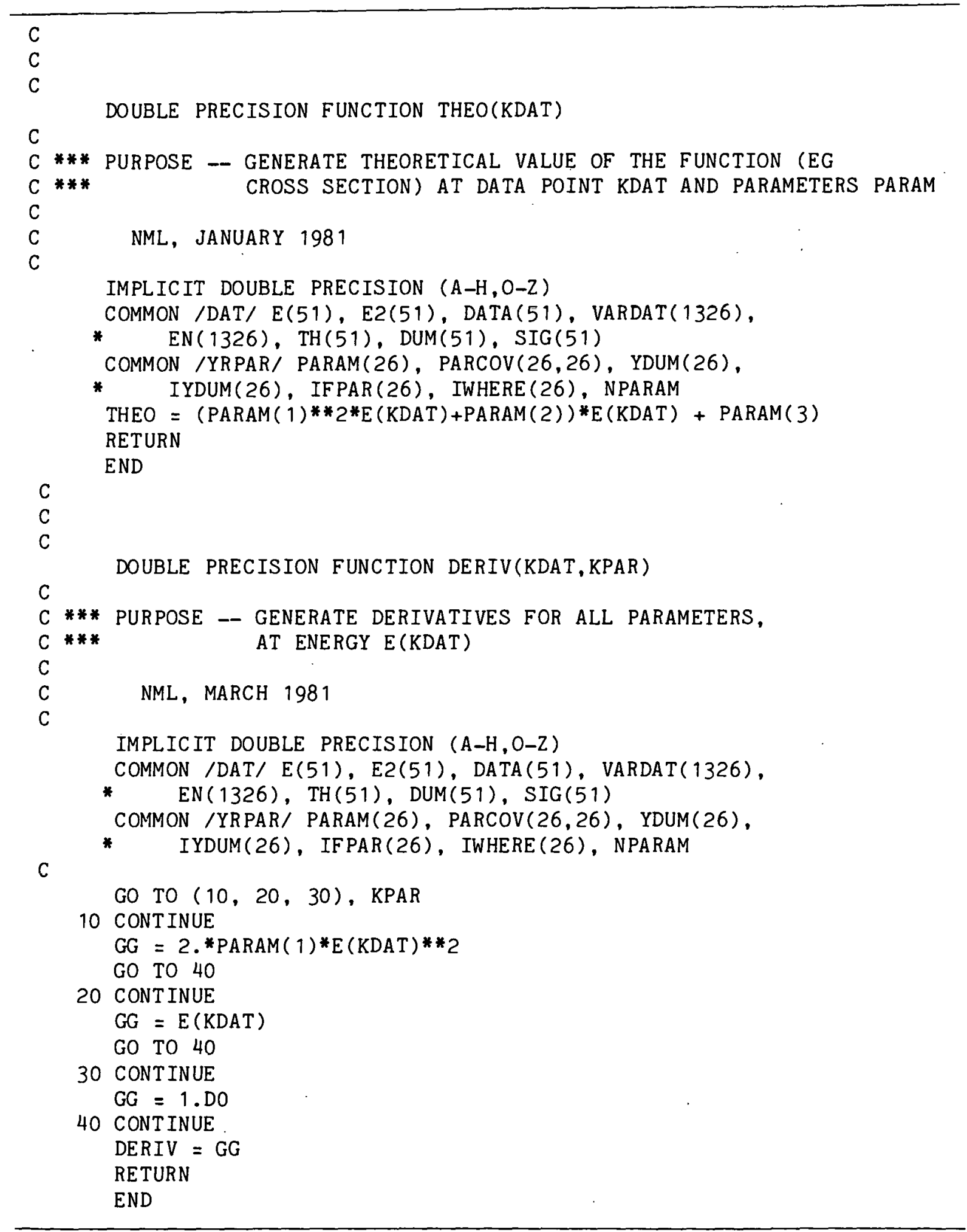


Table V.1.3. Teletype Commands and User Responses to Program Prompts for Example 1. Underlined portions are supplied by the user; a downward arrow indicates carriage return.

.EX BAYES, EX1, SHOW, DPPXX, D04NML $\downarrow$

HOW MANY ITERATIONS? WHAT IS CONVERGENCE FRACTION? $5, .001 \downarrow$

DO YOU WISH TO USE AUTOMATIC NUMERICAL DERIVATIVES? $\underline{\mathrm{N} \downarrow}$

INITIAL GUESS FOR PARAMETERS? 1., -25.,300.t

WHAT'S NAME OF THE DATA FILE? EX1.DAT $\downarrow$

WIAT'S NAME OF THE DATA FILE? $\underline{\phi}$

STOP 
Table V.1.4. Output Resulting from Use of the Commands Shown in Table V.1.3.

MAXIMUM NUMBER OF ITERATIONS IS 5

CONVERGENCE FACTOR IS 0.001000

******INPUT PARAMETER VALUES

$\begin{array}{rrr} & \text { PARAMETER } & \text { UNCERTA INTY } \\ 1 & 1.000000 & 0.100000 \\ 2 & -25.000000 & 2.500000 \\ 3 & 300.000000 & 30.000000\end{array}$

****** INPUT DATA VALUES

$\begin{array}{rrrr} & \text { DATA POINT } & \text { VALUE } & \text { UNCERTAINTY } \\ 1 & 10.000000 & 154.000000 & 1.540000 \\ 2 & 11.000000 & 151.900000 & 1.519000 \\ 3 & 12.000000 & 152.000000 & 1.520000 \\ 4 & 13.000000 & 154.299999 & 1.543000 \\ 5 & 14.000000 & 158.799999 & 1.588000 \\ 6 & 15.000000 & 165.500000 & 1.655000 \\ 7 & 16.000000 & 174.400000 & 1.744000 \\ 8 & 17.000000 & 185.500000 & 1.855000 \\ 9 & 18.000000 & 198.799999 & 1.988000 \\ 10 & 19.000000 & 214.299999 & 2.143000 \\ 11 & 20.000000 & 232.000000 & 2.320000 \\ 12 & 21.000000 & 251.900000 & 2.519000 \\ 13 & 22.000000 & 274.000000 & 2.740000 \\ 14 & 23.000000 & 298.299999 & 2.983000 \\ 15 & 24.000000 & 324.799999 & 3.248000 \\ 16 & 25.000000 & 353.500000 & 3.535000 \\ 17 & 26.000000 & 384.400002 & 3.844000 \\ 18 & 27.000000 & 417.500000 & 4.175000 \\ 19 & 28.000000 & 452.799999 & 4.528000 \\ 20 & 29.000000 & 490.299999 & 4.903000 \\ 21 & 30.000000 & 530.000000 & 5.300000\end{array}$


Table V.1.4. (Continued)

***** THEORETICAL CALCULATION

$\begin{array}{rccc} & \text { ENERGY } & \text { DATA } & \text { THEORY } \\ 1 & 10.000000 & 154.000000 & 150.000000 \\ 2 & 11.000000 & 151.900000 & 146.000000 \\ 3 & 12.000000 & 152.000000 & 144.000000 \\ 4 & 13.000000 & 154.299999 & 144.000000 \\ 5 & 14.000000 & 158.799999 & 146.000000 \\ 6 & 15.000000 & 165.500000 & 150.000000 \\ 7 & 16.000000 & 174.400000 & 156.000000 \\ 8 & 17.000000 & 185.500000 & 164.000000 \\ 9 & 18.000000 & 198.799999 & 174.000000 \\ 10 & 19.000000 & 214.299999 & 186.000000 \\ 11 & 20.000000 & 232.000000 & 200.000000 \\ 12 & 21.000000 & 251.900000 & 216.000000 \\ 13 & 22.000000 & 274.000000 & 234.000000 \\ 14 & 23.000000 & 298.299999 & 254.000000 \\ 15 & 24.000000 & 324.799999 & 276.000000 \\ 16 & 25.000000 & 353.500000 & 300.000000 \\ 17 & 26.000000 & 384.400002 & 326.000000 \\ 18 & 27.000000 & 417.500000 & 354.000000 \\ 19 & 28.000000 & 452.799999 & 384.000000 \\ 20 & 29.000000 & 490.299999 & 416.000000 \\ 21 & 3 n .0 n n n n 0 & 539.000000 & 15 n .00 n n n \cap\end{array}$

PARTIAL DERIVATIVES

ENERGY

$1.0000000+01$

1. $100000 D+01$

$1.200000 \mathrm{D}+01$

1. $300000 \mathrm{D}+01$

1. $400000 \mathrm{D}+01$

$1.500000 D+01$

$1.600000 D+01$

1. $700000 \mathrm{D}+01$

$1.8000000+01$

$1.900000 \mathrm{D}+01$

2. $000000 D+01$

2. $100000 \mathrm{D}+01$

2. $200000 D+01$

2. $300000 \mathrm{D}+01$

2. $400000 \mathrm{D}+01$

2. $500000 \mathrm{D}+01$

2. $600000 D+01$

2. $700000 D+01$

2. $800000 \mathrm{D}+01$

2. $900000 D+01$

3. $000000 \mathrm{D}+01$
1

$2.00000 \mathrm{D}+02$

2. $42000 \mathrm{D}+02$

2. $88000 \mathrm{D}+02$

3. $38000 \mathrm{D}+02$

3. $92000 \mathrm{D}+02$

4. 50000D+02

5. $12000 D+02$

$5.78000 D+02$

6. $48000 D+02$

$7.22000 D+02$

8. $00000 \mathrm{D}+02$

8. 82000D+02

$9.68000 \mathrm{D}+02$

$1.05800 \mathrm{D}+03$

1. $15200 D+03$

$1.25000 D+03$

1. $35200 D+03$

1. $45800 \mathrm{D}+03$

1. $56800 \mathrm{D}+03$

1. $68200 \mathrm{D}+03$

$1.80000 D+03$
2

$1.000000+01$

1. $10000 \mathrm{D}+01$

1. $20000 D+01$

1. $30000 D+01$

1. $40000 D+01$

1. $50000 D+0.1$

1. $60000 D+01$

1. $70000 D+01$

$1.80000 D+01$

1. $90000 D+01$

2. $00000 D+01$

2. $10000 \mathrm{D}+01$

2. $20000 D+01$

2. $30000 \mathrm{D}+01$

2. $40000 \mathrm{D}+01$

2. $50000 D+01$

2. $60000 D+01$

2. $70000 \mathrm{D}+01$

2. $80000 D+01$

2. $90000 \mathrm{D}+01$

3. $00000 \mathrm{D}+01$
3

1. $00000 D+00$

$1.00000 D+00$

$1.00000 \mathrm{D}+00$

$1.00000 D+00$

$1.00000 \mathrm{D}+00$

$1.00000 \mathrm{D}+00$

$1.00000 D+00$

$1.00000 D+00$

$1.00000 D+00$

$1.00000 \mathrm{D}+00$

$1.00000 \mathrm{D}+00$

$1.00000 \mathrm{D}+00$

$1.00000 \mathrm{D}+00$

$1.00000 D+00$

$1.00000 D+00$

$1.00000 D+00$

$1.00000 \mathrm{D}+00$

$1.00000 D+00$

$1.00000 D+00$

$1.00000 \mathrm{D}+00$

$1.00000 \mathrm{D}+00$ 
Table V.1.4. (Continued)



***** BAYESIAN CHI SQUARED AT FORMER VALUES OF PARAMETERS IS

0.272653

CHI SQUARED DIVIDED BY DEGREES OF FREEDOM IS 0.015147 
Table V.1.4. (Continued)

***** INTERMEDIATE RESULTS

$\begin{array}{ccc} & \text { OLD PARAM } & \text { NEW PARAMETERS } \\ 1 & 1.000000 & 1.049677 \\ 2 & -25.000000 & -25.177087 \\ 3 & 300.000000 & 295.814766\end{array}$

***** THEORETICAL CALCULATION

$\begin{array}{rccc} & \text { ENERGY } & \text { DATA } & \text { THEORY } \\ 1 & 10.000000 & 154.000000 & 154.226069 \\ 2 & 11.0 n n n \cap 0 & 151.000000 & 152.187239 \\ 3 & 12.000000 & 152.000000 & 152.352052 \\ 4 & 13.000000 & 154.299999 & 154.720509 \\ 5 & 14.000000 & 158.799999 & 159.292611 \\ 6 & 15.000000 & 165.500000 & 166.068354 \\ 7 & 16.000000 & 174.400000 & 175.047741 \\ 8 & 17.000000 & 185.500000 & 186.230772 \\ 9 & 18.000000 & 198.799999 & 199.617447 \\ 10 & 19.000000 & 214.299999 & 215.207765 \\ 11 & 20.000000 & 232.000000 & 233.001726 \\ 12 & 21.000000 & 251.900000 & 252.999331 \\ 13 & 22.000000 & 274.000000 & 275.200580 \\ 14 & 23.000000 & 298.299999 & 299.605472 \\ 15 & 24.000000 & 324.799999 & 326.214008 \\ 16 & 25.000000 & 353.500000 & 355.026187 \\ 17 & 26.000000 & 384.400002 & 386.042010 \\ 18 & 27.000000 & 417.500000 & 419.261476 \\ 19 & 28.000000 & 452.799999 & 454.684586 \\ 20 & 29.000000 & 490.299999 & 492.311340 \\ 21 & 30.000000 & 530.000000 & 532.141737\end{array}$


Table V.1.4. (Continued)

****** PARTIAL DERIVATIVES

$\begin{array}{rcccc} & \text { ENERGY } & 1 & 2 & \cdots \\ 1 & 1.000000 \mathrm{D}+01 & 2.09935 \mathrm{D}+02 & 1.00000 \mathrm{D}+01 & 1.00000 \mathrm{D}+00 \\ 2 & 1.100000 \mathrm{D}+01 & 2.54022 \mathrm{D}+02 & 1.10000 \mathrm{D}+01 & 1.00000 \mathrm{D}+00 \\ 3 & 1.200000 \mathrm{D}+01 & 3.02307 \mathrm{D}+02 & 1.20000 \mathrm{D}+01 & 1.00000 \mathrm{D}+00 \\ 4 & 1.300000 \mathrm{D}+01 & 3.54791 \mathrm{D}+02 & 1.30000 \mathrm{D}+01 & 1.00000 \mathrm{D}+00 \\ 5 & 1.400000 \mathrm{D}+01 & 4.11473 \mathrm{D}+02 & 1.40000 \mathrm{D}+01 & 1.00000 \mathrm{D}+00 \\ 6 & 1.500000 \mathrm{D}+01 & 4.72355 \mathrm{D}+02 & 1.50000 \mathrm{D}+01 & 1.00000 \mathrm{D}+00 \\ 7 & 1.600000 \mathrm{D}+01 & 5.37435 \mathrm{D}+02 & 1.60000 \mathrm{D}+01 & 1.00000 \mathrm{D}+00 \\ 8 & 1.700000 \mathrm{D}+01 & 6.06713 \mathrm{D}+02 & 1.70000 \mathrm{D}+01 . & 1.00000 \mathrm{D}+00 \\ 9 & 1.800000 \mathrm{D}+01 & 6.80191 \mathrm{D}+02 & 1.80000 \mathrm{D}+01 & 1.00000 \mathrm{D}+00 \\ 10 & 1.900000 \mathrm{D}+01 & 7.57867 \mathrm{D}+02 & 1.90000 \mathrm{D}+01 & 1.00000 \mathrm{D}+00 \\ 11 & 2.000000 \mathrm{D}+01 & 8.39742 \mathrm{D}+02 & 2.00000 \mathrm{D}+01 & 1.00000 \mathrm{D}+00 \\ 12 & 2.100000 \mathrm{D}+01 & 9.25815 \mathrm{D}+02 & 2.10000 \mathrm{D}+01 & 1.00000 \mathrm{D}+00 \\ 13 & 2.200000 \mathrm{D}+01 & 1.01609 \mathrm{D}+03 & 2.20000 \mathrm{D}+01 & 1.00000 \mathrm{D}+00 \\ 14 & 2.300000 \mathrm{D}+01 & 1.11056 \mathrm{D}+03 & 2.30000 \mathrm{D}+01 & 1.00000 \mathrm{D}+00 \\ 15 & 2.400000 \mathrm{D}+01 & 1.20923 \mathrm{D}+03 & 2.40000 \mathrm{D}+01 & 1.00000 \mathrm{D}+00 \\ 16 & 2.500000 \mathrm{D}+01 & 1.31210 \mathrm{D}+03 & 2.50000 \mathrm{D}+01 & 1.00000 \mathrm{D}+00 \\ 17 & 2.600000 \mathrm{D}+01 & 1.41916 \mathrm{D}+03 & 2.60000 \mathrm{D}+01 & 1.00000 \mathrm{D}+00 \\ 18 & 2.700000 \mathrm{D}+01 & 1.53043 \mathrm{D}+03 & 2.70000 \mathrm{D}+01 & 1.00000 \mathrm{D}+00 \\ 19 & 2.800000 \mathrm{D}+01 & 1.64589 \mathrm{D}+03 & 2.80000 \mathrm{D}+01 & 1.00000 \mathrm{D}+00 \\ 20 & 2.900000 \mathrm{D}+01 & 1.76556 \mathrm{D}+03 & 2.90000 \mathrm{D}+01 & 1.00000 \mathrm{D}+00 \\ 21 & 3.000000 \mathrm{D}+01 & 1.88942 \mathrm{D}+03 & 3.00000 \mathrm{D}+01 & 1.00000 \mathrm{D}+00\end{array}$

***** LEAST-SQUARES WEIGHTED RESIDUALS AT FORMER VALUES OF PARAMETERS

\begin{tabular}{|c|c|c|}
\hline & NERGY & RESIDUAL \\
\hline 1) & 10.0000 & $35 \mathrm{D}-02$ \\
\hline 2) & 11.0000 & $8 D-01$ \\
\hline 3) & 12.0000 & $-1.52377 D-01$ \\
\hline 4) & 13.0000 & $-1.76622 D-01$ \\
\hline 5) & 14.0000 & $-1.95345 \mathrm{D}-01$ \\
\hline 6) & 15.0000 & $-2.07502 \mathrm{D}-01$ \\
\hline 7) & 16.0000 & $-2.12965 D-0$ \\
\hline 8) & 17.0000 & $-2.12370 \mathrm{D}-01$ \\
\hline 9) & 18.0000 & $-2.06836 \mathrm{D}-01$ \\
\hline 10) & 19.0000 & $-1.97665 \mathrm{D}-01$ \\
\hline 11) & 20.0000 & $-1.86111 \mathrm{D}-01$ \\
\hline 12) & 21.0000 & $-1.73250 D-01$ \\
\hline
\end{tabular}

ENERGY RESIDUAL

( 13) $22.0000-1.59915 D-01$

( 14 ) $23.0000-1.46711 \mathrm{D}-01$

( 15) $24.0000-1.34036 D-01$

( 16) $25.0000-1.22132 \mathrm{D}-01$

( 17) $26.0000-1.11124 D-01$

( 18) $27.0000-1.01056 \mathrm{D}-01$

( 19) $28.0000-9.19186 \mathrm{D}-02$

( 20 ) $29.0000-8.36685 \mathrm{D}-02$

( 21) $30.0000-7.62455 \mathrm{D}-02$
**** LEAST-SQUARES CHI SQUARED AT FORMER VALUES OF PARAMETERS IS 3.042660 CHI SQUARED DIVIDED BY DEGREES OF FREEDOM - IS 0.169037


Table V.1.4. (Continued)

***** BAYESIAN WEIGHTED RESIDUALS AT FORMER VALUES OF PARAMETERS

\begin{tabular}{|c|c|c|}
\hline \multicolumn{2}{|c|}{ ENERGY } & RESIDUAL \\
\hline 1) & 10.0000 & $7.98260 \mathrm{D}-03$ \\
\hline 2) & 11.0000 & $16770 D-03$ \\
\hline 3) & 12.0000 & $1.24752 \mathrm{D}-03$ \\
\hline 4) & 13.0000 & $-1.40679 D-03$ \\
\hline 5) & 14.0000 & $-3.32483 D-03$ \\
\hline 6) & 15.0000 & 03 \\
\hline 7) & 16.0000 & $-4.88783 \mathrm{D}-0$ \\
\hline 8) & 17.0000 & $-4.74093 \mathrm{D}$ \\
\hline 9) & 18.0000 & $-4.19167 D-03$ \\
\hline 10) & 19.0000 & $-3.40165 D-03$ \\
\hline 11 & 20.0000 & $-2.50467 \mathrm{D}$ \\
\hline & & -1.5989 \\
\hline
\end{tabular}

\begin{tabular}{|c|c|c|}
\hline \multicolumn{2}{|c|}{ ENERGY } & RESIDUAL \\
\hline 13) & 22.0000 & $-7.47717 \mathrm{D}-04$ \\
\hline 14) & 23.0000 & $1.27230 \mathrm{D}-05$ \\
\hline 15) & 24.0000 & $6.67007 D-04$ \\
\hline 16) & 25.0000 & $1.21289 D-03$ \\
\hline 17) & 26.0000 & $1.65624 \mathrm{D}-03$ \\
\hline & 27 & $696 D$ \\
\hline 19 & 28.0000 & $2.27718 \mathrm{D}-03$ \\
\hline & 9.0000 & $3.47889 \mathrm{D}-03$ \\
\hline & 30.000 & $2.62336 \mathrm{D}-03$ \\
\hline
\end{tabular}

***** BAYESIAN CHI SQUARED AT FORMER VALUES OF PARAMETERS IS

CHI SQUARED DIVIDED BY DEGREES OF FREEDOM IS

0.014506

INTERMEDIATE RESULTS

$\begin{array}{ccc} & \text { OLD PARAM } & \text { NEW PARAMETERS } \\ 1 & 1.000000 & 1.048524 \\ 2 & -25.000000 & -25.178821 \\ 3 & 300.000000 & 295.829072\end{array}$

THEORETICAL CALCULATION

FNERGY

10.000000

11.000000

12.000000

13.000000

1.4 .000000

15.000000

16.000000

17.000000

18.000000

19.000000

20.000000

21.000000

22.000000

23.000000

24.000000

25.000000

26.000000

27.000000

28.000000

29.000000

30.000000
DAT $\Lambda$ 154.000000 151.900000 152.000000 154,299999 158.799999 165.500000 174.400000 185.500000 198.799999 214.299999 232.000000 251.900000 274.000000 298.299999 324.799999 353.500000 384.400002 417.500000 452.799999 490.299999 530.000000
TIIEORY

153.981201 151.889852 151.997309 154.303573 158.808644 165.512522 174.415206 185.516698 198.816996 214.316101 232.014013 251.910731 274.006257 298.300589 324.793728 353.485674 384.376426 417.465986 452.754352 490.241525 529.927505 
Table V.1.4. (Continued)

PARTIAL DERIVATIVES

$\begin{array}{rcccc} & \text { ENERGY } & 1 & 2 & 3 \\ 1 & 1.000000 \mathrm{D}+01 & 2.09705 \mathrm{D}+02 & 1.00000 \mathrm{D}+01 & 1.00000 \mathrm{D}+00 \\ 2 & 1.100000 \mathrm{D}+01 & 2.53743 \mathrm{D}+02 & 1.10000 \mathrm{D}+01 & 1.00000 \mathrm{D}+00 \\ 3 & 1.200000 \mathrm{D}+01 & 3.01975 \mathrm{D}+02 & 1.20000 \mathrm{D}+01 & 1.00000 \mathrm{D}+00 \\ 4 & 1.300000 \mathrm{D}+01 & 3.54401 \mathrm{D}+02 & 1.30000 \mathrm{D}+01 & 1.00000 \mathrm{D}+00 \\ 5 & 1.400000 \mathrm{D}+01 & 4.11022 \mathrm{D}+02 & 1.40000 \mathrm{D}+01 & 1.00 .00 \mathrm{D}+00 \\ 6 & 1.500000 \mathrm{D}+01 & 4.71836 \mathrm{D}+02 & 1.50000 \mathrm{D}+01 & 1.00010 \mathrm{D}+00 \\ 7 & 1.600000 \mathrm{D}+01 & 5.36844 \mathrm{D}+02 & 1.60000 \mathrm{D}+01 & 1.0000 \mathrm{~N}+00 \\ 8 & 1.700000 \mathrm{D}+01 & 6.06047 \mathrm{D}+02 & 1.70000 \mathrm{D}+01 & 1.00000 \mathrm{D}+00 \\ 9 & 1.800000 \mathrm{D}+01 & 6.79444 \mathrm{D}+02 & 1.80000 \mathrm{D}+01 & 1.00000 \mathrm{D}+00 \\ 10 & 1.900000 \mathrm{D}+01 & 7.57035 \mathrm{D}+02 & 1.90000 \mathrm{D}+01 & 1.00000 \mathrm{D}+00 \\ 11 & 2.000000 \mathrm{D}+01 & 8.38820 \mathrm{D}+02 & 2.00000 \mathrm{D}+01 & 1.00000 \mathrm{D}+00 \\ 12 & 2.100000 \mathrm{D}+01 & 9.24799 \mathrm{D}+02 & 2.10000 \mathrm{D}+01 & 1.00000 \mathrm{D}+00 \\ 13 & 2.200000 \mathrm{D}+01 & 1.01497 \mathrm{D}+03 & 2.20000 \mathrm{D}+01 & 1.00000 \mathrm{D}+00 \\ 14 & 2.300000 \mathrm{D}+01 & 1.10934 \mathrm{D}+03 & 2.30000 \mathrm{D}+01 & 1.00000 \mathrm{D}+00 \\ 15 & 2.400000 \mathrm{D}+01 & 1.20790 \mathrm{D}+03 & 2.40000 \mathrm{D}+01 & 1.00000 \mathrm{D}+00 \\ 16 & 2.500000 \mathrm{D}+01 & 1.31066 \mathrm{D}+03 & 2.50000 \mathrm{D}+01 & 1.00000 \mathrm{D}+00 \\ 17 & 2.600000 \mathrm{D}+01 & 1.41760 \mathrm{D}+03 & 2.60000 \mathrm{D}+01 & 1.00000 \mathrm{D}+00 \\ 18 & 2.700000 \mathrm{D}+01 & 1.52875 \mathrm{D}+03 & 2.70000 \mathrm{D}+01 & 1.00000 \mathrm{D}+00 \\ 19 & 2.800000 \mathrm{D}+01 & 1.64409 \mathrm{D}+03 & 2.80000 \mathrm{D}+01 & 1.00000 \mathrm{D}+00 \\ 20 & 2.900000 \mathrm{D}+01 & 1.76362 \mathrm{D}+03 & 2.90000 \mathrm{D}+01 & 1.00000 \mathrm{D}+00 \\ 21 & 3.000000 \mathrm{D}+01 & 1.88734 \mathrm{D}+03 & 3.00000 \mathrm{D}+01 & 1.00000 \mathrm{D}+00\end{array}$

***** LEAST-SQUARES WEIGHTED RESIDUALS AT FORMER VALUES OF PARAMETERS

\begin{tabular}{|c|c|c|}
\hline \multicolumn{2}{|c|}{ ENERGY } & RESIDUAL \\
\hline 1) & 10.0000 & $7.92658 D-03$ \\
\hline 2) & 11.0000 & $9804 \mathrm{D}-03$ \\
\hline 3) & 12.0000 & 1. $16473 \mathrm{D}-03$ \\
\hline 4) & 13.0000 & $-1.50108 \mathrm{D}-03$ \\
\hline 5) & 14.0000 & $-3.42808 D-03$ \\
\hline 6) & $15: 0000$ & $-4.57159 D-03$ \\
\hline 7) & 16.0000 & $-4.99965 \mathrm{D}-03$ \\
\hline 8) & 17.0000 & $-4.85250 D-03$ \\
\hline 9) & 18.0000 & $-4.30057 D-03$ \\
\hline 10) & 19.0000 & $-3.50607 D-03$ \\
\hline 11) & 20.0000 & $-2.60339 D-03$ \\
\hline 12) & 21.0000 & $-1.69123 D-0$ \\
\hline
\end{tabular}

ENERGY RESIDUAL

( 13) $22.0000-8.33360 \mathrm{D}-04$

( 14$) 23.0000-6.62532 D-05$

( 15) $24.0000 \quad 5.94473 \mathrm{D}-04$

( 16) $25.0000 \quad 1.14645 \mathrm{D}-03$

(17) $26.0000 \quad 1.59546 \mathrm{D} .03$

(18) $27.00001 .95140 D-03$

( 19) $28.0000 \quad 2.22638 \mathrm{D}-03$

( 20) $29.0000 \quad 2.43242 \mathrm{D}-03$

( 21) $30.00002 .58080 \mathrm{D}-03$

***** LEAST-SQUARES CIII 3QUARED AT FORMER VALUES OF PARAMETERS IS 0.001191 CHI SQUARED DIVIDED BY DEGREES OF FREEDOM IS 0.000066 
Table V.1.4. (Continued)

***** BAYESIAN WEIGHTED RESIDUALS AT FORMER VALUES OF PARAMETERS

\begin{tabular}{|c|c|c|}
\hline \multicolumn{2}{|c|}{ ENERGY } & RESIDUAL \\
\hline 1) & 10.0000 & $7.99345 \mathrm{D}-03$ \\
\hline 2) & 11.0000 & $4.47432 \mathrm{D}-03$ \\
\hline 3) & 12.0000 & $1.25021 \mathrm{D}-03$ \\
\hline 4) & 13.0000 & $-1.40741 D-03$ \\
\hline 5) & 14.0000 & 32791D-03 \\
\hline 6) & $15: 0000$ & 6708 \\
\hline 7) & 16.0000 & $-4.89315 D-03$ \\
\hline 8) & 17.0000 & $-4.74624 \mathrm{D}-03$ \\
\hline 9) & 18.0000 & $-4.19647 \mathrm{D}-03$ \\
\hline 10) & 19.0000 & $-3.40564 \mathrm{D}-03$ \\
\hline 11) & 20.0000 & $-2.50769 \mathrm{D}-03$ \\
\hline 12) & 21.000 & $-1.60092 \mathrm{D}$ \\
\hline
\end{tabular}

$\begin{array}{ccc}\text { ENERGY } & \text { RESIDUAL } \\ (13) & 22.0000 & -7.48777 D-04 \\ (14) & 23.0000 & 1.25300 D-05 \\ (15) & 24.0000 & 6.67567 D-04 \\ (16) & 25.0000 & 1.21409 D-03 \\ (17) & 26.0000 & 1.65796 D-03 \\ (18) & 27.0000 & 2.00909 D-03 \\ (19) & 28.0000 & 2.27964 D-03 \\ (20) & 29.0000 & 2.48159 D-03 \\ (21) & 30.0000 & 2.62624 D-03\end{array}$

***** BAYESTAN CHI SQUARED AT FORMER VALUES OF PARAMETERS IS

0.261097

CHI SQUARED DIVIDED BY DEGREES OF FREEDOM IS 0.014505

******* NEW VALUES FOR PARAMETERS

$\begin{array}{cccc} & \text { POLD } & \text { PNEW } & \text { UNCERTA INTY } \\ 1 & 1.000000 & 1.048523 & 0.007940 \\ 2 & -25.000000 & -25.178796 & 0.607752 \\ 3 & 300.000000 & 295.828865 & 5.208788\end{array}$

$2 \quad 6.077518 \mathrm{D}-01 \quad-99 \quad 100$

$3 \cdot 5.208788 \bar{D}+00 \quad 95 \cdot-99 \quad 100$ 
Table V.1.5. Teletype Commands and User Responses to Program Prompts for Example 1, Using Automatic Numerical Derivative Option:

.EX BAYES, EX1, SHOW, DPPXX, D04NML $\downarrow$

HOW MANY ITERATIONS? WHAT IS CONVERGENCE FRACTION? 5,.001

DO YOU WISH TO USE AUTOMATIC NUMERICAL DERIVATIVES?

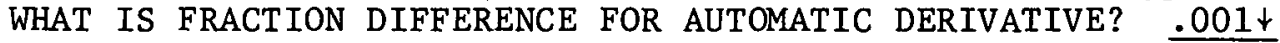

INITIAL GUESS FOR PARAMETERS? 1.,-25.,30.0.t

WILAT'S NAME OF TIIE DATA FILE? EX1.DAT $\downarrow$

WHAT'S NAME OF THE DATA FILE? $\Perp$

STOP 
Table V.1.6. Output Resulting from Use of the Commands Shown in Table V.1.5, with Calls to Subroutines ØUTDAT, ØUTREL, ØUTCHL, ØUTREB, ఏUTCHB, ØUTGMG, ØUTTH and ØUTG Suppressed to Minimize Output.

MAXIMUM NUMBER OF ITERATIONS IS 5

CONVERGENCE FACTOR IS 0.001000

AUTOMATIC DERIVATIVE USES STEP SIZE 0.00100

*****INPUT PARAMETER VALUES

$\begin{array}{rrc} & \text { PARAMETER } & \text { UNCERTAINTY } \\ 1 & 1.000000 & 0.100000 \\ 2 & -75.0 \text { MNONO0 } & 2.500000 \\ 3 & 300.000000 & 30.000000\end{array}$

***** INTERMEDIATE RESULTS

$\begin{array}{ccc} & \text { OLD PARAM } & \text { NEW PARAMETERS } \\ 1 & 1.000000 & 1.049677 \\ 2 & -25.000000 & -25.177087 \\ 3 & 300.000000 & 295.814766\end{array}$

***** INTERMEDIATE RESULTS

\begin{tabular}{|c|c|c|c|}
\hline & OLD PARAM & \multicolumn{2}{|c|}{ NEW PARAMETERS } \\
\hline 1 & 1.000000 & 1.048524 & \\
\hline 2 & -25.000000 & -25.178821 & \\
\hline 3 & 300.000000 & 295.829072 & \\
\hline & NEW VALUES & FOR PARAMETERS & \\
\hline & POLD & PNEW & UNCERTA INTY \\
\hline 1 & 1.000000 & 1.048523 & 0.007940 \\
\hline 2 & -25.000000 & -25.178796 & 0.607752 \\
\hline 3 & 300.000000 & 295.828865 & 5.208788 \\
\hline
\end{tabular}

STD. DEV. CORRELATION

$\begin{array}{rrrrr}1 & & 1 & 2 & 3 \\ 2 & 6.940102 D-03 & 100 & & \\ 3 & 5.2087518 D-01 & -99 & 100 & \\ & & \end{array}$


Table V.1.7. File BAYES.ØUT, Which Suppresses Calls to the Subroutines Listed in the File.

$\begin{array}{ll}\text { OUTDAT } & \text { INPUT DATA IS NOT PRINTED } \\ \text { OUTREL } & \text { LEAST-SQUARES RESIDUALS ARE NOT PRINTED } \\ \text { OUTEHL } & \text { LEAST-SQUARES CHI-SQUARED IS NOT PRINTED } \\ \text { OUTREB } & \text { BAYESTAN RESTDIJA.S ARF NOT PRINTED } \\ \text { OUTCHB } & \text { BAYESIAN CHI-SQUARED IS NOT PRINTED } \\ \text { OUTTH } & \text { THEORETICAL VALUES ARE NOT PRINTED } \\ \text { OUTG } & \text { PARTIAL DERIVATIVES ARE NOT PRINTED } \\ \text { OUTGMG } & \text { MATRIX.GMG IS NOT LISTED IN FILE FOR28.DAT }\end{array}$


Example 2. Combine Independent Data Sets

The Problem:

Two or more experimental data sets contain the same or related information but were obtained from independent sources. Combine the data sets to obtain the best value for each quantity on which any information is available.

\section{The Solution:}

The model parameters $P$ are set equal to the quantities of interest. When the information in the data set is a measurement of one specific quantity, the theoretical value $T$ is equal to the parameter $(T=P)$; the derivative with respect to that parameter is unity $(G=1.0)$ and the derivative with respect to all other parameters is zero. When the information in the data set is a measurement of relationships between two or more quantitites (e.g., a relative cross section), theoretical values and derivatives are adjusted accordingly.

\section{Specific Case:}

Data set 1 consists of the total cross section for neutrons of fixed energy impinging on target element $A$, the cross section for element $B$ relative to $\mathrm{A}$, and uncertainties and correlations on both numbers. Data set 2 contains results of an independent measurement of the cross sections for element $B$, the cross section for element $A$ relative to $B$, the cross section for element $C$ relative to $B$, and the associated uncertainties and correlations. Find the resulting best estimate of the cross sections for 
$A, B$, and $C$, and the uncertainties and correlations.. (Note: the program GLUCS [HE80] was written to solve problems similar to this in evaluation of neutron cross sections for the Evaluated Nuclear Data File (ENDF) files. GLUCS uses a preliminary version of BAYES for solution of Bayes' equations.)

Let the model parameters be $\sigma_{A}, \sigma_{B}$, and $\sigma_{C}$, the cross sections for elements $A, B$, and $C$, respectively. The data are now a function of two independent parameters (i.e., the element types) rather than one (energy, in the previous example). The data sets might be typed in files as shown in Table V.2.1. The first two columns give the element types; where they differ, the data refer to the ratio of first to second. Where they agree, the data is an absolute cross section. Following the blank line, the data covariance matrix is given.

The theoretical value $\mathrm{T}$ depends on the element types involved. For example, in data set 1 the first theoretical value is $T_{1}=\sigma_{A}$ and the second is $\mathrm{T}_{2}=\sigma_{\mathrm{B}}{ }^{\prime \sigma}{ }_{\mathrm{A}}$. The partial derivative matrix is then

$$
G=\left[\begin{array}{lll}
1 & 0 & 0 \\
-\sigma_{B} / \sigma_{A}^{2} & 1 / \sigma_{A} & 0
\end{array}\right]
$$

where data points correspond to rows and parameters to columns.

The PDP-10 file EX2.F4 shown in Table V.2.2 contains the four usersupplied subroutines needed to solve this problem. Table V.2.3 shows the modified versions of ØUTDAT, ФUTTH, ФUTG, and ØUTREL, required to obtain sensible output in this case where the one independent variable (e.g., energy) is replaced by two independent variables which are, moreover, 
alphanumeric. This table is part of file EX2øUT.F4, which also contains the remaining (unmodified) output subroutines.

For this example, no prior information is known for the parameter values. To approximate this situation for program BAYES, the diagonal elements of the parameter covariance matrix are initialized at $(1.0 \times \mathrm{P})^{2}$.

Commands to execute this program and responses to program prompts are shown in Table V.2.4. The output file is shown in Table V.2.5. Identical results (to six significant digits in the parameters, and three in the uncertainties) are obtained by reversing the order of तat.a input. an equivalent approach is to generate the combined data file EX23.DAT, shown in Table V.2.6, and execute the program with this data set only. The output file from this run is shown in Table V.2.7. Note that final values obtained for the three quantities of interest $\left(\sigma_{A}, \sigma_{B}\right.$, and $\sigma_{C}$, or equivalently $P_{1}, P_{2}$, and $P_{3}$ ) and their covariance matrix are identical no matter what method of data input is used. 
Table V.2.1. Input Data for Example 2. Data Set 1 is Contained in PDP-10 File EX21.DAT, Data Set 2 in EX22.DAT

\begin{tabular}{|c|c|c|c|c|}
\hline \multicolumn{2}{|c|}{ Data Set 1} & \multicolumn{3}{|c|}{ Data Set 2} \\
\hline & $10 \cdot 30$ & $\mathrm{BB}$ & 11.50 & \\
\hline \multirow[t]{2}{*}{$\mathrm{BA}$} & 1.20 & $A B$ & 0.80 & \\
\hline & & $\mathrm{CB}$ & 1.40 & \\
\hline \multicolumn{5}{|l|}{0.7} \\
\hline \multirow[t]{3}{*}{.03} & 0.05 & .04 & .02 & .01 \\
\hline & & .02 & .08 & .03 \\
\hline & & .01 & .03 & .08 \\
\hline
\end{tabular}


Table V.2.2. User-Supplied Subroutines for Example 2, Found on File EX2.F4 on the ØRELA P.DP-10.




Table V.2.2. (Continued)

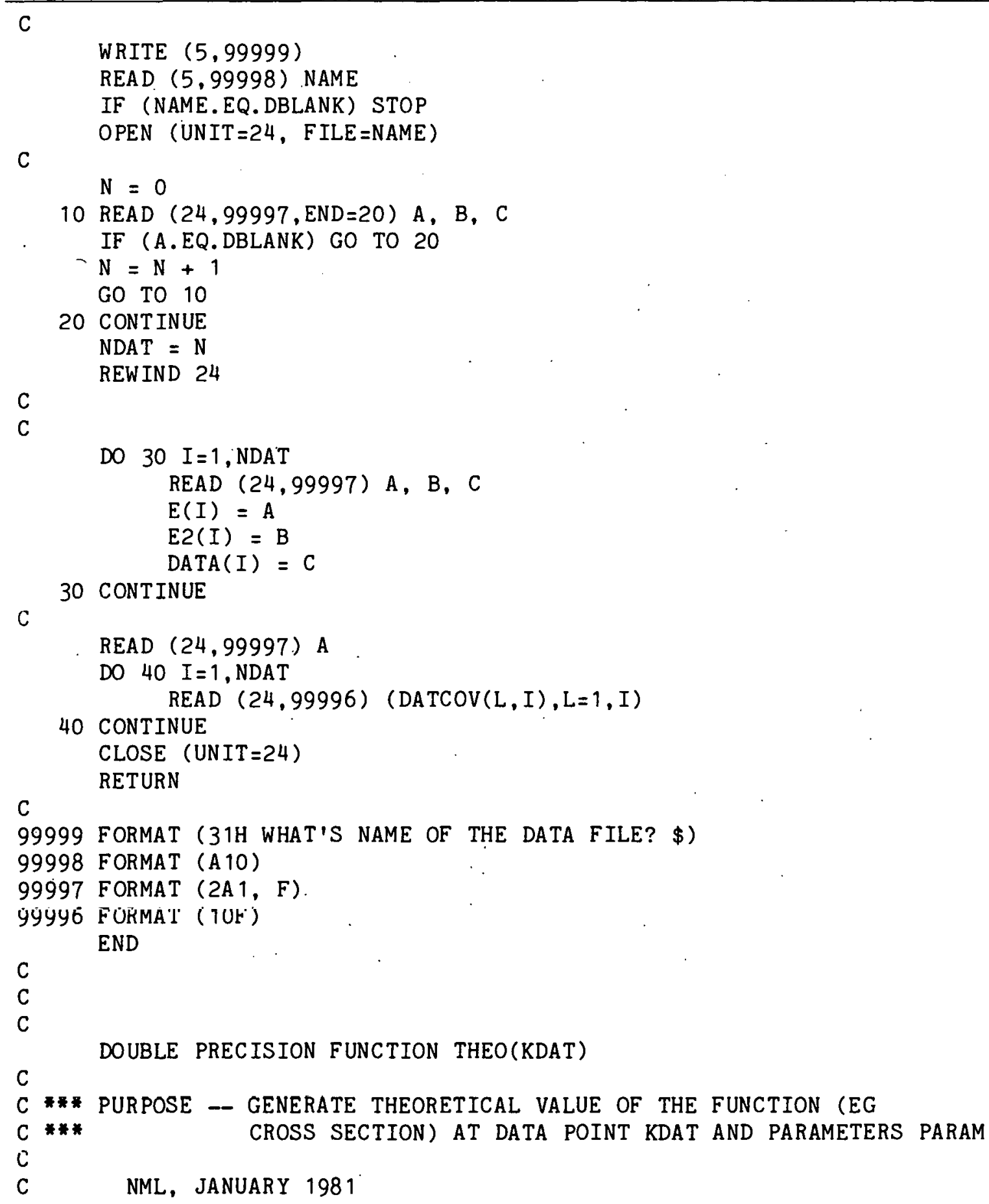




\section{IMPLICIT DOUBLE PRECISION (A-H,O-Z)}

COMMON /DAT/ E(51), E2(51), DATA(51), VARDAT(1326),

* EN(1326), TH(51), DUM(51), SIG(51)

COMMON /YRPAR/ PARAM(26), PARCOV $(26,26), \operatorname{YDUM}(26)$,

* IYdUM(26), IFPAR(26), IWHERE (26), NPARAM

DIMENSION ELMNT (3)

DATA ELMNT /1HA, $1 \mathrm{HB}, 1 \mathrm{HC} /$

DO $10 \quad I=1,3$

IF (E (KDAT).NE.ELMNT (I)) GO TO 10

10 CONT INUE

$$
\text { THEO }=\text { PARAM }(I)
$$

IF (E (KDAT).EQ.E2(KDAT)) GO TO 30

DO $20 \quad I=1,3$

IF (E2(KDAT). NE.ELMNT(I)) GO TO 20

20 CONTINUE

THEO $=$ THEO $/$ PARAM $(I)$

30 CONTINUE

RETURN

END

C

C

C

DOUBLE PRECISION FUNCTION DERIV(KDAT, KPAR)

$\mathrm{C}$

$C$ *** PURPOSE -- GENERATE DERIVATIVES FOR PARAMETER KPAR,

r.

$c$

C

C

NML, JANUIARY 1981

IMPLICIT DOUBLE PRECISION (A-H, O-Z)

COMMON /DAT/E(51), E2(51), DATA(51), VARDAT(1326),

* EN(1326), TH(51), DUM(51), SIG(51)

COMMON /YRPAR/ PARAM(26), PARCOV $(26,26), \operatorname{YDUM}(26)$,

* IYdUM(26), IFPAR(26), IWHERE(26), NPARAM

DIMENSION ELMNT ( 3 )

DATA ELMNT /1HA, 1 HB, 1HC/

C




Table V.2.2. (Continued)

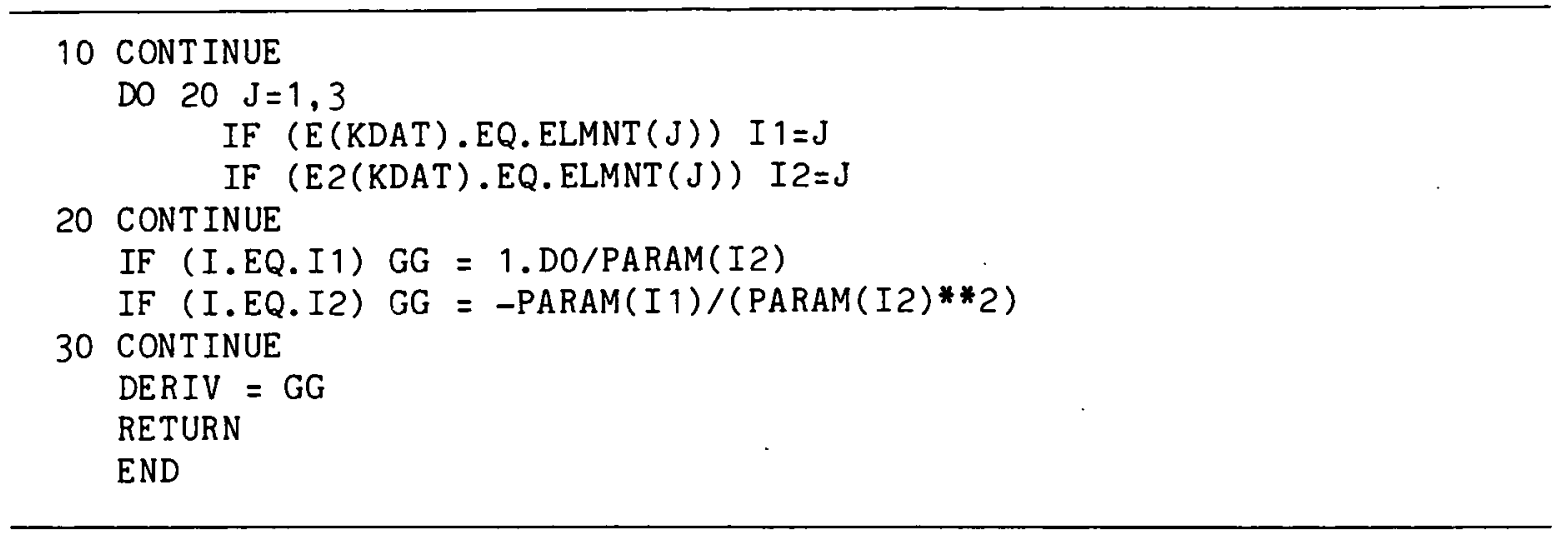


Table V.2.3. Modified Versions of Subroutines ØUTDAT, ØUTTH, ØUTG, and ØUTREL, for Use in Example 2 .

$\mathrm{C}$
$\mathrm{C}$
$\mathrm{C}$

SUBROUTINE OUTDAT

IMPLICIT DOUBLE PRECISION (A-H,O-Z)

COMMON /NUMBER/ NDAT, NPAR, ITER, ITMAX, CONVER

COMMON /PAR/ POLD(25). PARM(25). PDUM(25), VARPAR(325),

* VARNEW(325), IDUM(25)

COMMON /DAT/ E(51), E2(51), DATA(51), DATCOV(1326),

* EN(1326), TH(51), DUM(51), 3IG(51)

COMMON /BOTH/ G(51,25), $\operatorname{EMG}(51,25)$

DIMENSION IDDUM( 1 )

C

EQUIVALENCE(IDDUM( (1), SIG(1))

C

WRITE $(6,99999)$

II $=0$

DO $10 I=1, N D A T$

$I I=I I+I$

10 CONTINUE

$\operatorname{DUM}(I)=\operatorname{DSQRT}(\operatorname{DATCOV}(I I))$

C

WRITE $(6,99998)$

ç.

WRITE $(6,99997)$ (I,E(I),E2(I), DATA(I), DUM(I), I=1, NDAT)

II $=0$

IOFF $=0$

DO $30 \mathrm{I}=1$, NDAT

WU $\stackrel{J}{J}=1,1$

$I I=I I+1$

IF (I.EQ.J) GO TO 30

20 CONT INUE

IF (DATCOV(II).NE.U.DU) IUFF $=1 U F F+1$

30 CONT INUE

IF (IOFF, NE,O) CALL OUTV (DATCOV, DUM, IDDUM, NDAT) RETURN

C

99999 FORMAT (25HO****** INPUT DATA VALUES)

99998 FORMAT ( $48 \mathrm{HO}$ DATA POINT VALUE UNCERTAINTY)

99997 FORMAT (I5, 5X, A5, $\Lambda \mu, 2 \mathrm{~F} 1 \mu, 6$ )

END

C

C

C 
Table V.2.3. (Continued)

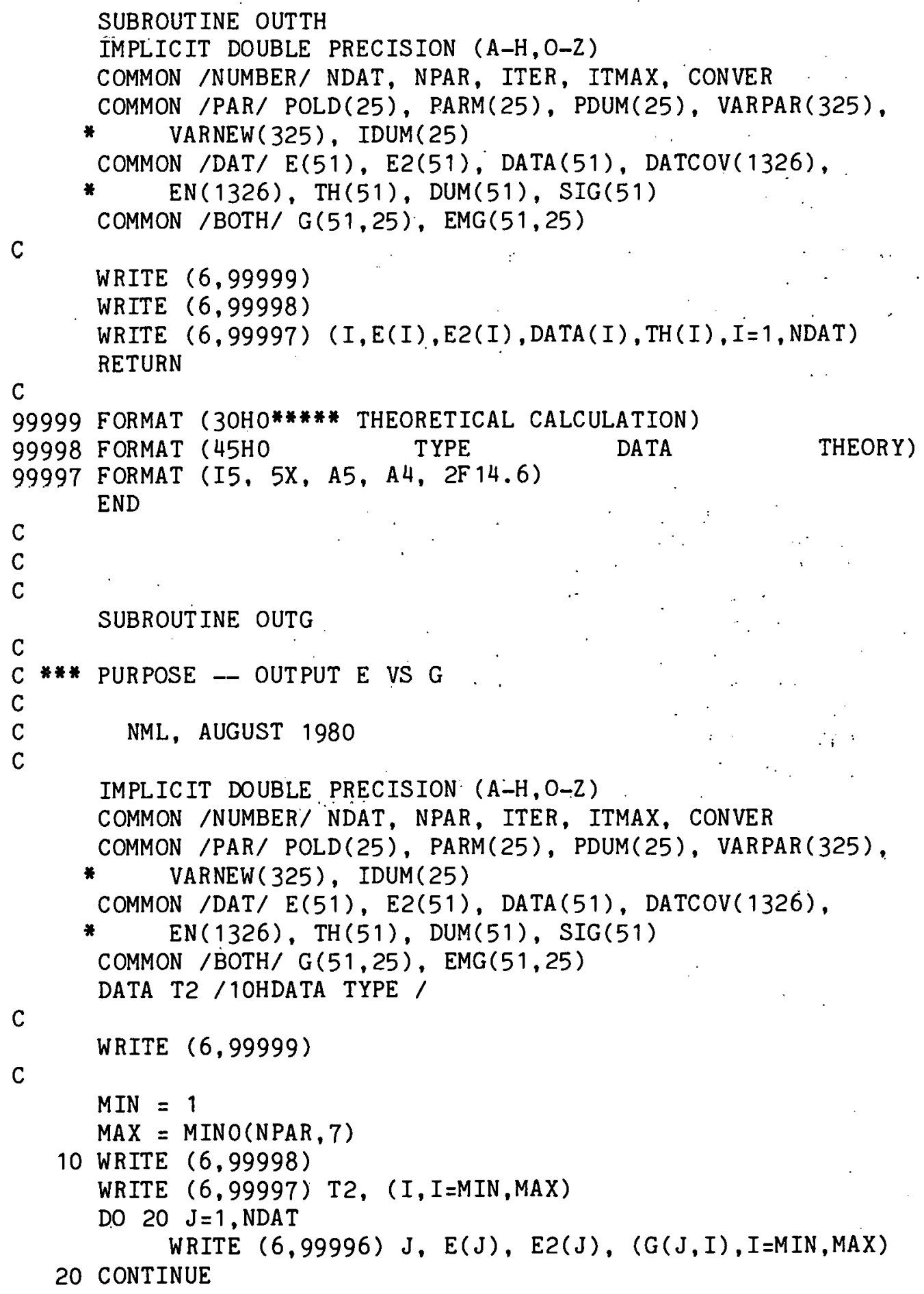


Table. V.2.3. (Continued)

C

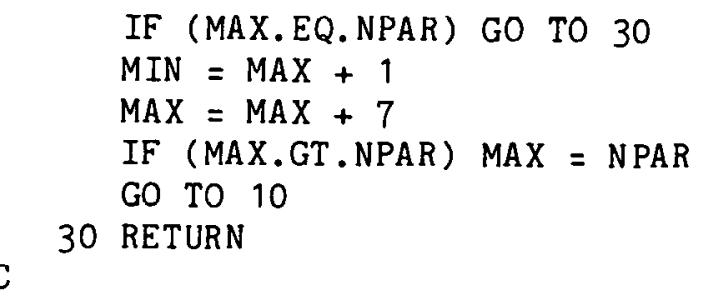

99999 FORMAT (27HO****** PARTIAL DERIVATTVES)

GYYY8 FURMAT (20X)

99997 FORMAT (10X, A 10, I10, GI 14)

99996 FORMAT (I4, 2X, JX, A5, A4, 2X, 7G 14.5)

END

C

C

C

SUBROUT INE OUTREL

IMPLICIT DOUBLE PRECISION (A-H,O-Z)

COMMON /NUMBER/ NDAT, NPAR, ITER, ITMAX, CONVER

COMMON /PAR/ POLD(25), PARM(25), PDUM(25), VARPAR(325),

* VARNEW(325), IDUM(25)

COMMON /DAT/E(51), E2(51), EXPT(51), VARDAT(1326),

* EN(1326), TH(51), DUM(51), SIG(51)

COMMON /BOTH/ G(51,25), $\operatorname{EMG}(51,25)$

DIMENSION FORMT (4)

DATA PL $/ 1 \mathrm{H}(/, \mathrm{PR} / 1 \mathrm{H}) /$

DATA FORMT /4OH $((1 \mathrm{X}, 4(\mathrm{~A} 1, \mathrm{I} 3, \mathrm{~A} 1,2 \mathrm{X}, 2 \mathrm{~A} 3,1 \mathrm{PG} 13.5,2 \mathrm{X})))$ /

C

DATA T1 /10HDATA TYPE /, T2 /1OHRESIDUAL /

C

WRITE $(6,99999)$

Gก TO 10

C

ENTRY OUTREB

C

WRITE $(6,99998)$

C

10 WRITE $(6.99997)(T 1, T P, T=1,4)$

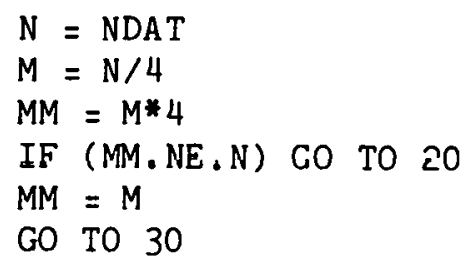


Table V.2.3. (Continued)

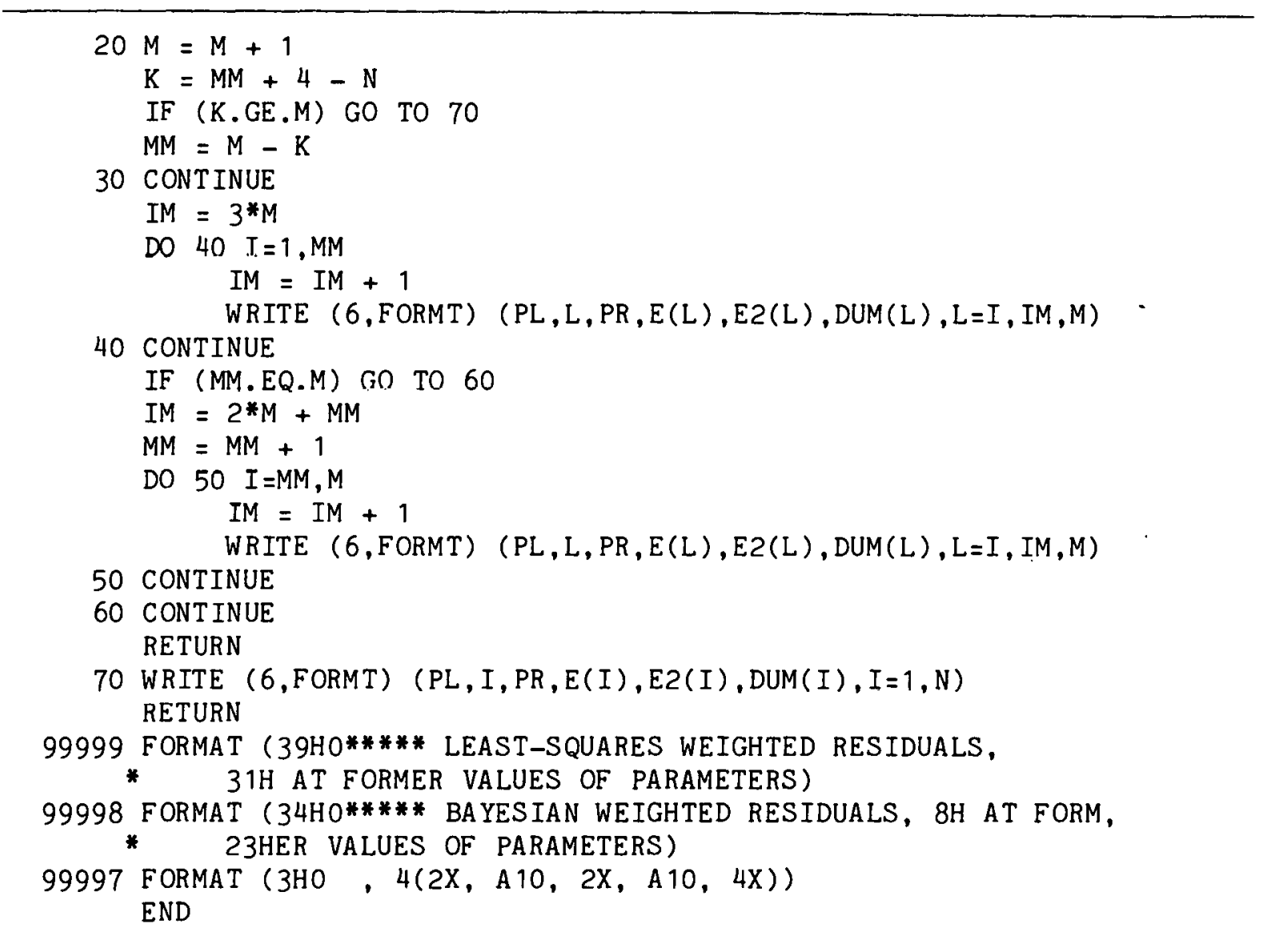


Table V.2.4. Teletype Commands and User Responses to Program Prompts for Example 2.

.EX BAYES, EX2, EX2OUT, DPPXX, DO4NML $\downarrow$

HOW MANY ITERATIONS? WHAT IS CONVERGENCE FRACTION? $5, .001 \downarrow$

DO YOU WISH TO USE AUTOMATIC NUMERICAL DERIVATIVES? $\mathrm{N} \downarrow$

WHAT'S NAME OF THE DATA FILE? EX21. DAT \&

WHAT'S NAME OF THE DATA FILE? EX22.DAT $\downarrow$

WHAT'S NAME OF THE DATA FILE? $\Perp$

STOP 
Table V.2.5. Output Resulting from the Use of Commands Given in Table V.2.4.

MAXIMUM NUMBER OF ITERATIONS IS 5

CONVERGENCE FACTOR IS 0.001000

******INPUT PARAMETER VALUES

$\begin{array}{lll} & \text { PARAMETER } & \text { UNCERTA INTY } \\ 1 & 10.000000 & 10.000000 \\ 2 & 12.000000 & 12.000000 \\ 3 & 17.000000 & 17.000000\end{array}$

****** INPUT DATA VALUES

$\begin{array}{ccccc} & \text { DATA } & \text { POINT } & \text { VALUE } & \text { UNCERTA INTY } \\ 1 & \text { A } & \text { A } & 10.300000 & 0.836660 \\ 2 & \text { B } & \text { A } & 1.200000 & 0.223607\end{array}$

STD. DEV. CORRELATION

$18.366600 \mathrm{D}-01 \quad 100$

2

$2 \quad 2.236068 \mathrm{D}-01 \quad 16 \quad 100$

***** THEORETICAL CALCULATION

\begin{tabular}{|c|c|c|c|c|}
\hline \multicolumn{3}{|c|}{ TYPE } & DATA & THEORY \\
\hline 1 & A & A & 10.300000 & 10.000000 \\
\hline 2 & B & A & 1.200000 & 1.200000 \\
\hline
\end{tabular}

****** PARTIAL DERIVATIVES

$\begin{array}{cccccc} & \text { DATA } & \text { TYPE } & 1 & 2 & 3 \\ 1 & \text { A } & \text { A } & 0.10000 D+01 & 0.00000 D+00 & 0.00000 D+00 \\ 2 & \text { B } & \text { A } & -0.12000 D+00 & 0.10000 D+00 & 0.00000 D+00\end{array}$

INTERMEDIATE RESULTS

$\begin{array}{lll} & \text { OLD PARAM } & \text { NEW PARAMETERS } \\ 1 & 10.000000 & 10.295236 \\ 2 & 12.000000 & 12.340715 \\ 3 & 17.000000 & 17.000000\end{array}$

***** THEORETICAL CALCULATION

\begin{tabular}{|c|c|c|c|c|}
\hline & \multicolumn{2}{|c|}{ TYPE } & DATA & THEORY \\
\hline & A & A & 10.300000 & 10.295236 \\
\hline 2 & B & A & 1.200000 & 1.19868 \\
\hline
\end{tabular}


Table V.2.5. (Continued)

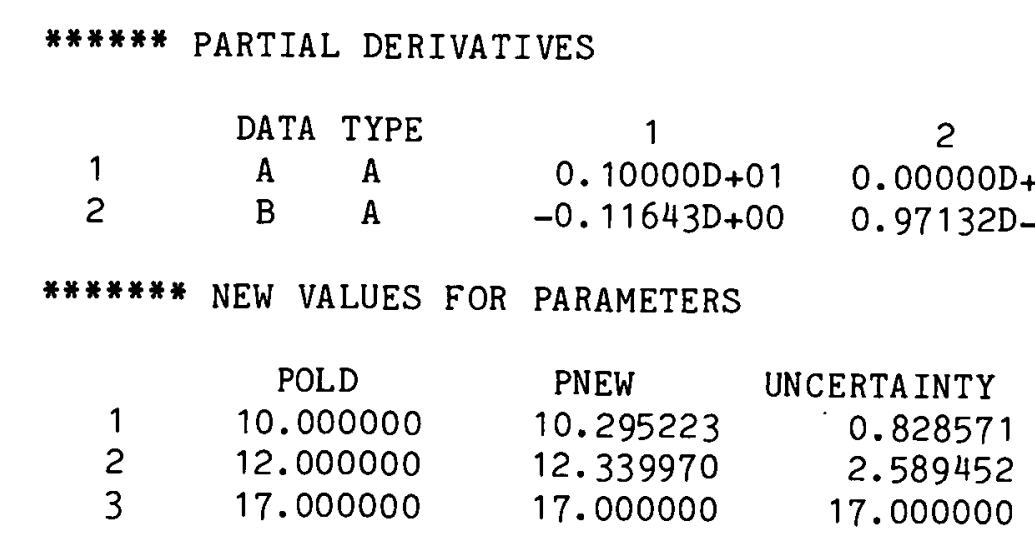

STD. DEV. CORRELATION

$\begin{array}{rrrrr}1 & 8.285711 \mathrm{D}-01 & 1 & 2 & 3 \\ 2 & 2.589452 \mathrm{D}+00 & 51 & 100 & \\ 3 & 1.700000 \mathrm{D}+01 & 0 & 0 & 100\end{array}$

****** INPUT DATA VALUES

$\begin{array}{ccccc} & \text { DATA } & \text { POINT } & \text { VALUE } & \text { UNCERTAINTY } \\ 1 & \text { B } & \text { B } & 11.500000 & 0.200000 \\ 2 & \text { A } & \text { B } & 0.800000 & 0.202043 \\ 3 & \text { C } & \text { B } & 1.400000 & 0.282843\end{array}$

STD. DEV. CORRELATION

$$
\begin{array}{rrrrr} 
& & 1 & 2 & 3 \\
2 & 2.000000 D-01 & 100 & & \\
3 & 2.828427 D-01 & 35 & 100 & \\
2.828427 D-01 & 18 & 38 & 100
\end{array}
$$

***** THEORETICAL CALCULATION

\begin{tabular}{|c|c|c|c|}
\hline & TYPE & DATA & THEORY \\
\hline 1 & B & 11.500000 & 12.339970 \\
\hline 2 & A & 0.800000 & 0.834299 \\
\hline 3 & C & 1.400000 & 1.377637 \\
\hline
\end{tabular}

****** PARTIAL DERIVATIVES

$\begin{array}{lccccc} & \text { DATA } & \text { TYPE } & 1 & 2 & 3 \\ 1 & \text { B } & \text { B } & 0.00000 D+00 & 0.10000 D+01 & 0.00000 D+00 \\ 2 & \text { A } & \text { B } & 0.81037 D-01 & -0.67609 D-01 & 0.00000 D+00 \\ 3 & \text { C } & \text { B } & 0.00000 D+00 & -0.11164 D+00 & 0.81037 D-01\end{array}$


Table V.2.5. (Continued)

INTERMEDIATE RESULTS

$\begin{array}{lll} & \text { OLD PARAM } & \text { NEW PARAMETERS } \\ 1 & 10.295223 & 10.126092 \\ 2 & 12.339970 & 11.525014 \\ 3 & 17.000000 & 16.526001\end{array}$

***** THEORETICAL CALCULATION

\begin{tabular}{lllrr} 
& \multicolumn{2}{c}{ TYPE } & \multicolumn{1}{c}{ DATA } & \multicolumn{1}{c}{ THEORY } \\
1 & B & B & 11.500000 & 11.525014 \\
2 & $\Lambda$ & $B$ & 0.800000 & 0.878619 \\
3 & C & B & 1.400000 & 1.433925
\end{tabular}

****** PARTIAL DERIVATIVES

$\begin{array}{cccccc} & \text { DATA } & \text { TYPE } & 1 & 2 & 3 \\ 1 & \text { B } & \text { B } & 0.00000 D+00 & 0.10000 D+01 & 0.00000 D+00 \\ 2 & \text { A } & \text { B } & 0.86768 D-01 & -0.76236 \mathrm{D}-01 & 0.00000 D+00 \\ 3 & \text { C } & \text { B } & 0.00000 D+00 & -0.12442 D+00 & 0.86768 D-01\end{array}$

***** INTERMEDIATE RESULTS

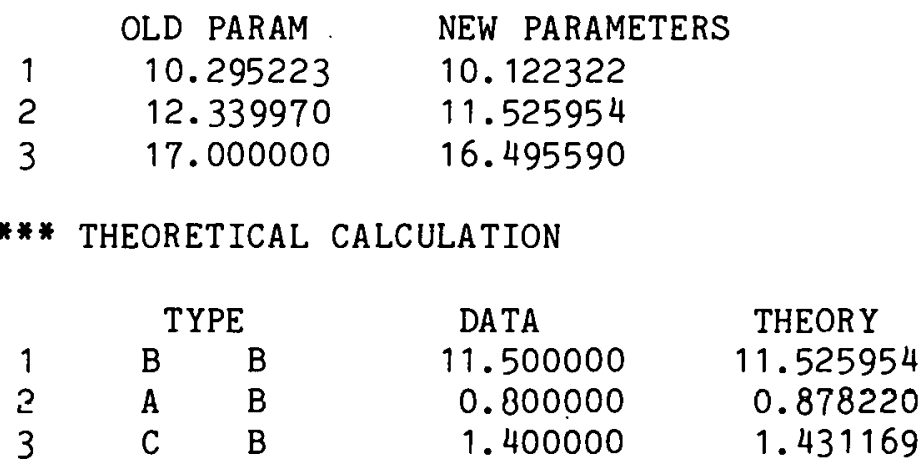

****** PARTIAL DERIVATIVES

$\begin{array}{cccccc} & \text { DATA } & \text { TYPE } & 1 & 2 & 3 \\ 1 & \mathrm{~B} & \mathrm{~B} & 0.00000 \mathrm{D}+00 & 0.10000 \mathrm{D}+01 & 0.00000 \mathrm{D}+00 \\ 2 & \mathrm{~A} & \mathrm{~B} & 0.86761 \mathrm{D}-01 & -0.76195 \mathrm{D}-01 & 0.00000 \mathrm{D}+00 \\ 3 & \mathrm{C} & \mathrm{B} & 0.00000 \mathrm{D}+00 & -0.12417 \mathrm{D}+00 & 0.86761 \mathrm{D}-01\end{array}$


Table V.2.5. (Continued)

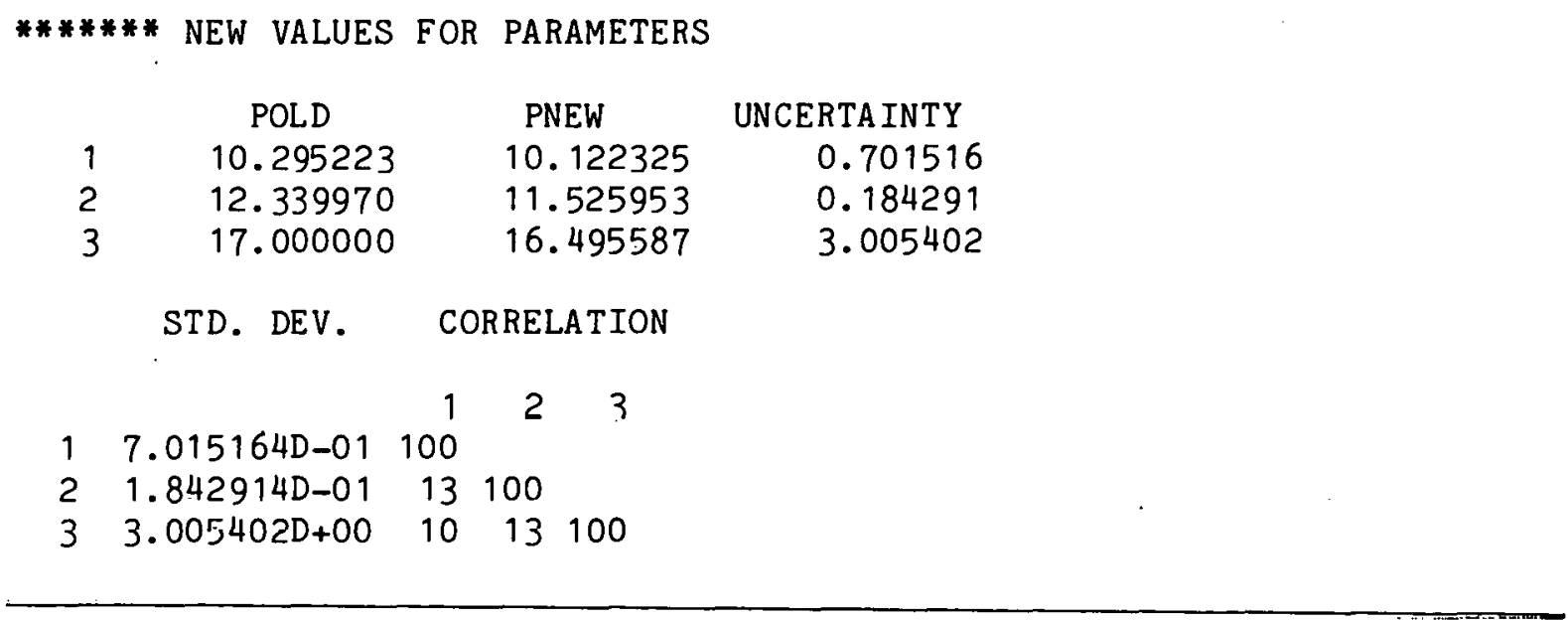


Table V.2.6. Data and Covariance Matrix for the Combination of the Two Data Sets Shown in Table V.2.1.

$\begin{array}{lllll}\mathrm{AA} & 10.3 & & & \\ \mathrm{BA} & 1.2 & & & \\ \mathrm{BB} & 11.50 & & & \\ \mathrm{AB} & 0.80 & & & \\ \mathrm{CB} & 1.40 & & & \\ & & & & \\ 0.7 & 0.03 & 0.0 & 0.0 & 0.0 \\ 0.03 & 0.05 & 0.0 & 0.0 & 0.0 \\ 0.0 & 0.0 & 0.04 & 0.02 & 0.01 \\ 0.0 & 0.0 & 0.02 & 0.08 & 0.03 \\ 0.0 & 0.0 & 0.01 & 0.03 & 0.08\end{array}$


Table V.2.7. Output Obtained by Including All Five Data Points Simultaneously.

MAXIMUM NUMBER OF ITERATIONS IS 5

CONVERGENCE FACTOR IS 0.001000

******INPUT PARAMETER VALUES

$\begin{array}{lll} & \text { PARAMETER } & \text { UNCERTAINTY } \\ 1 & 10.000000 & 10.000000 \\ 2 & 12.000000 & 12.000000 \\ 3 & 17.000000 & 17.000000\end{array}$

****** INPUT DATA VALUES

$\begin{array}{cccrc} & \text { DATA } & \text { POINT } & \text { VALUE } & \text { UNCERTAINTY } \\ 1 & \text { A } & \text { A } & 10.300000 & 0.836660 \\ 2 & \text { B } & \text { A } & 1.200000 & 0.223607 \\ 3 & \text { B } & \text { B } & 11.500000 & 0.200000 \\ 4 & \text { A } & \text { B } & 0.800000 & 0.282843 \\ 5 & \text { C } & \text { B } & 1.400000 & 0.282843\end{array}$

STD. DEV. CORRELATION

1 8. $3666 \cap \cap \cap-01100$

$\begin{array}{lllll}1 & 2 & 3 & 4 & 5\end{array}$

2 2.236068D-01 $16 \quad 100$

$32.000000 D-01 \quad 0 \quad 0 \quad 100$

$4 \quad 2.828427 \mathrm{D}-\mathrm{U} 1 \quad 0 \quad 0 \quad 35100$

$5 \quad 2.828427 \mathrm{D}-01 \quad 0 \quad 0 \quad 18 \quad 38 \quad 100$

***** INTERMEDIATE RESULTS

$\begin{array}{lcl} & \text { OLD PARAM } & \text { NEW PARAMETERS } \\ 1 & 10.000000 & 1 \mathrm{i} .119930 \\ 2 & 12.000000 & 11.525405 \\ 3 & 17.000000 & 16.493671\end{array}$

******* NEW VALUES FOR PARAMETERS

$\begin{array}{lccr} & \text { POLD } & \text { PNEW } & \text { UNCERTAINTY } \\ 1 & 10.000000 & 10.122885 & 0.705865 \\ 2 & 12.000000 & 11.526101 & 0.184283 \\ 3 & 17.000000 & 16.496059 & 3.005421\end{array}$

STD. DEV. CORRELATION

$\begin{array}{rrrrr} & & 1 & 2 & 3 \\ 2 & 7.058654 D-01 & 100 & & \\ 3 & 1.842831 D-01 & 13 & 100 & \\ & 3.005421 D+00 & 10 & 13 & 100\end{array}$




\section{Example 3. Background Subtraction}

The Problem:

Raw data points $X_{i}$ are independent, with uncertainties $\Delta X_{i}$. However, there is a known background $B$ with uncertainty $\Delta B$ which must be subtracted from the raw data. This background is independent of the data.

The First Solution:

There are at least two ways to properly treat the background subtraction. The first is to generate new "data" $D_{i}$ by subtracting the background explicitly, and find the covariance matrix $v_{i j}$ for this data. That is, we may set

$$
D_{i}=x_{i}-B
$$

so that changes in either $x_{i}$ or $B$ lead to changes in $D_{i}$ :

$$
\delta D_{i}=\delta X_{i}-\delta B
$$

The variance for $D_{i}$ is found by taking the expectation value of the square of this error, i.e.,

$$
v_{i i}=\left\langle(\delta D)^{2}\right\rangle=\left\langle\left(\delta X_{i}-\delta B\right)^{2}\right\rangle=\Delta X_{i}^{2}+\Delta B^{2}
$$

since $X_{i}$ and $B$ are assumed independent. The covariance between points $i$ and $j$ can similarly be found as

$$
v_{i j}=\left\langle\left(\delta X_{i}-\delta B\right)\left(\delta X_{j}-\delta B\right)\right\rangle
$$


For $i \neq j$, only the term $\langle\delta B \delta B\rangle$ remains. This term is the covariance of the background alone; thus the covariance $v_{i j}$ reduces to

$$
v_{i j}=\Delta B^{2}
$$

The Second Solution:

An alternative approach to the problem of background subtraction is lo treat raw data points $x_{i}$ as the data to be fit, and modify the theoretical calculations appropriately. That is, where in the f'irst approach we generated theoretical values $\mathrm{T}$, here we generate

$$
T^{\prime}=T+b
$$

where $b$ is a parameter of our model, and is input as the known value B with uncertainty $\Delta B$. The derivative $G$ associated with parameter $b$ is unity.

An important advantage of this approach is lial lie data point 3 remain uncorrelated. Thus a large data set can be broken into several smaller ones (to conform to computer limitations) and analyzed sequentially. Results will be equivalent to those which would be obtained if the entire set could be analyzed simultaneously. This is illustrated by the sample problem shown below, where we perform the calculation both simultaneously and sequentially.

\section{Specific Case:}

Artificially generated "raw data" are shown in Table V.3.1 (the PDP-10 file EX31.DAT). The background level was determined from an independent "measurement" to be approximately $B=40.17 \pm 6.77$. 
For the first method of solution, we wish to fit the adjusted data with a function of the form

$$
f(E, P)=P_{1} \exp \left\{-\left(E-P_{2}\right)^{2} / P_{3}^{2}\right\}
$$

remembering that the data have the covariance matrix given by Eqs. (V.3.3) and (V.3.5). User-supplied subroutines to accomplish this are stored in PDP-10 file EX31.F4, shown in Table V.3.2. Note that the raw data are read explicitly, and the background-subtracted data and adjusted data covariance matrix are generated within subroutine SETDAT.

Commands to execute this program and responses to program prompts are given in Table V.3.3, and the output file is listed in Table V.3.4. Note that the presence of off-diagonal elements of the data covariance matrix requires all data to be included simultaneously.

In the second method of solution, the functional form we wish to fit is

$$
f(E, P)=P_{1} \exp \left\{-\left(E-P_{2}\right)^{2} / P_{3}^{2}\right\}+P_{4}
$$

where the fourth parameter is input as the background level $40.166463 \pm$ 6.766185. User-supplied subroutines for this case are stored in PDP-10 file EX32.F4, shown in Table V.3.5. Execution commands are given in Table V.3.6, and output in Table V.3.7. Results for the first three parameters are exactly equivalent to those obtained via the first method; that this is to be expected is illustrated in Appendix A, Section 4, where it is demonstrated that adding a constant covariance matrix like that shown in Eqs. (V.3.4) and (V.3.5) is equivalent to adding a constant value to the theory as in Eq. (V.3.8). 
With the second method it is possible to analyze the data sequentially rather than simultaneously. That is, we can analyze the data from $E=25$ to $E=49$, e.g., and use the results of that analysis as input to the analysis of the remaining data. Execution commands for this sequential analysis are shown in Table V.3.8, and results are given in Table V.3.9.

Results obtained from such a sequential analysis are not expected to be exactly the same as those obtained from a simultaneous analysis, because the approximations built into the model are not exactly valid. Nevertheless, reasonable agreement between sequential and simultaneous analysis is usually obtained. In this example, the discrepancy between the two analyses, for each of the four paramelers, was less than $0.6 \%$ absolutc, or (more significantly) less than $7.0 \%$ of the corresponding uncertainty. Differences in the correlation matrix are more pronounced, though trends are given consistently.

For practical situations in which the large size of the data set prohibits simultaneous analysis, changing the order of the data subsets in a sequential analysis can be used for a consistency check. In this example, analyzing the high-energy region first and then the low-energy region gave results consistent with those quoted here. 
Table V.3.1. ORELA PDP-10 File EX31.DAT, Containing "Raw" Data Required for Example 3.

$\begin{array}{rrr}25.000000 & 30.032617 & 5.480202 \\ 26.000000 & 39.293188 & 6.268428 \\ 27.000000 & 37.558659 & 6.128512 \\ 28.000000 & 62.021808 & 7.875393 \\ 29.000000 & 33.491881 & 5.787217 \\ 30.000000 & 35.314806 & 5.942626 \\ 31.000000 & 59.671737 & 7.724748 \\ 32.000000 & 47.780402 & 6.912337 \\ 33.000000 & 55.474042 & 7.448090 \\ 34.000000 & 50.109183 & 7.078784 \\ 35.000000 & 57.132362 & 7.558595 \\ 36.000000 & 51.935085 & 7.206600 \\ 37.000000 & 67.476355 & 8.214399 \\ 38.000000 & 64.423848 & 8.026447 \\ 39.000000 & 69.447257 & 8.333502 \\ 40.000000 & 79.158297 & 8.897095 \\ 41.000000 & 86.357061 & 9.292850 \\ 42.000000 & 94.570995 & 9.724762 \\ 43.000000 & 77.289822 & 8.791463 \\ 44.000000 & 101.358525 & 10.067697 \\ 45.000000 & 82.501708 & 9.083045 \\ 46.000000 & 108.200675 & 10.401955 \\ 47.000000 & 114.508126 & 10.700847 \\ 48.000000 & 107.876942 & 10.386382 \\ 49.000000 & 130.520432 & 11.424554 \\ 50.000000 & 114.470710 & 10.699099 \\ 51.000000 & 112.498927 & 10.606551 \\ 52.000000 & 143.359819 & 11.973296 \\ 53.000000 & 130.125650 & 11.407263 \\ 54.000000 & 117.260513 & 10.828689 \\ 55.000000 & 112.144705 & 10.589840 \\ 56.000000 & 110.041392 & 10.490062 \\ 57.000000 & 111.031748 & 10.537160 \\ 58.000000 & 90.807915 & 9.529319 \\ 59.000000 & 91.758967 & 9.579090 \\ 60.000000 & 70.201249 & 8.378619 \\ 61.000000 & 78.406860 & 8.854765 \\ 62.000000 & 82.244825 & 9.068893 \\ 63.000000 & 83.963837 & 9.163178 \\ 64.000000 & 85.339459 & 9.237936 \\ 65.000000 & 67.236270 & 8.199773\end{array}$


Table V.3.1. (Continued)

\begin{tabular}{lll}
\hline 66.000000 & 63.828962 & 7.989303 \\
67.000000 & 64.729895 & 8.045489 \\
68.000000 & 64.914184 & 8.056934 \\
69.000000 & 57.713948 & 7.596970 \\
70.000000 & 51.214544 & 7.156434 \\
71.000000 & 36.063748 & 6.005310 \\
72.000000 & 47.804664 & 6.914092 \\
73.000000 & 41.833538 & 6.467885 \\
74.000000 & 39.249423 & 6.264936 \\
75.000000 & 31.293112 & 5.594025 \\
\hline
\end{tabular}


Table V.3.2. User-Supplied Subroutines for Example 3, First Method of Solution. These routines are stored on file EX31.F4 on the ORELA PDP-10.

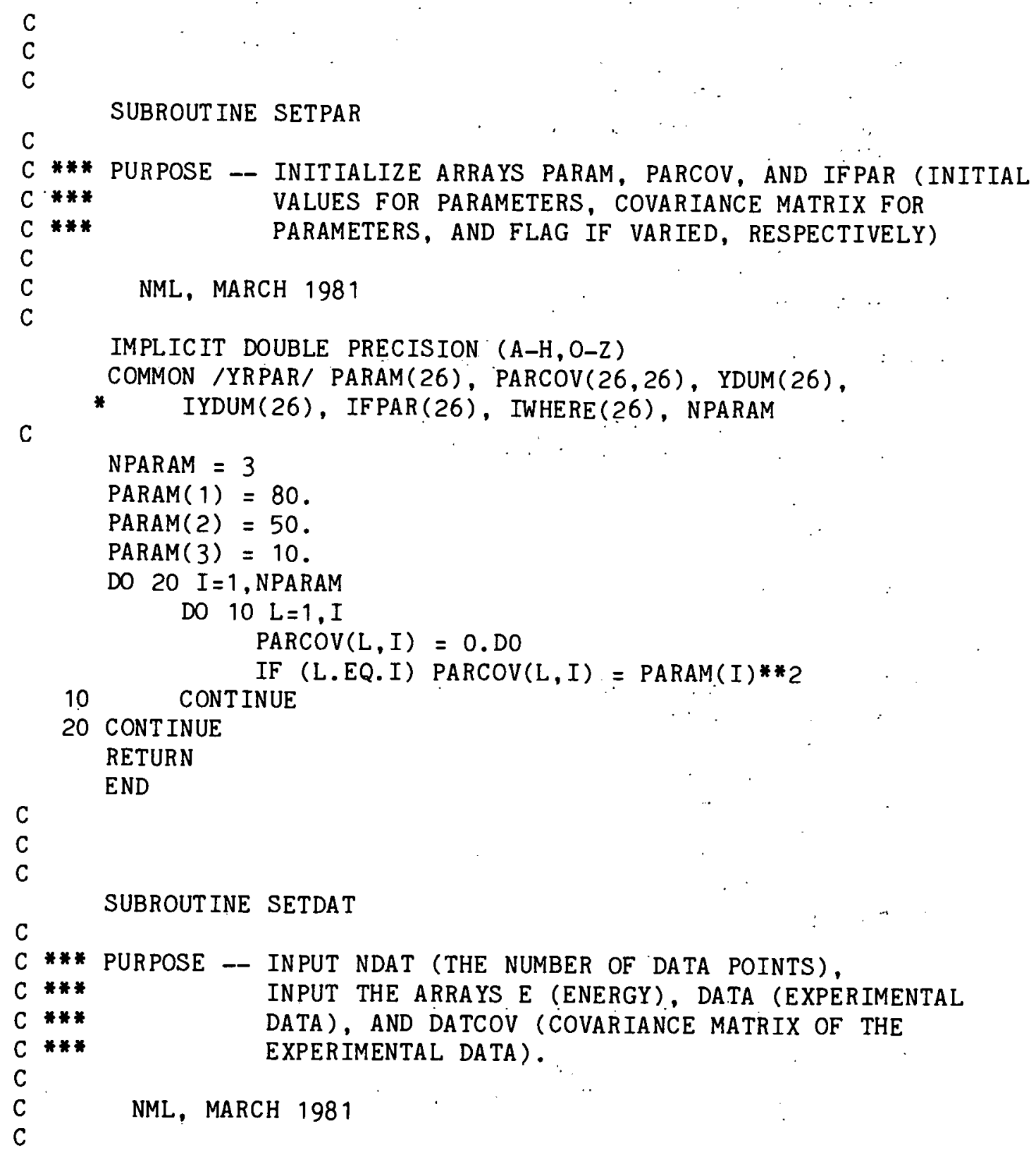


Tah1.e V.3.2. (Continued)

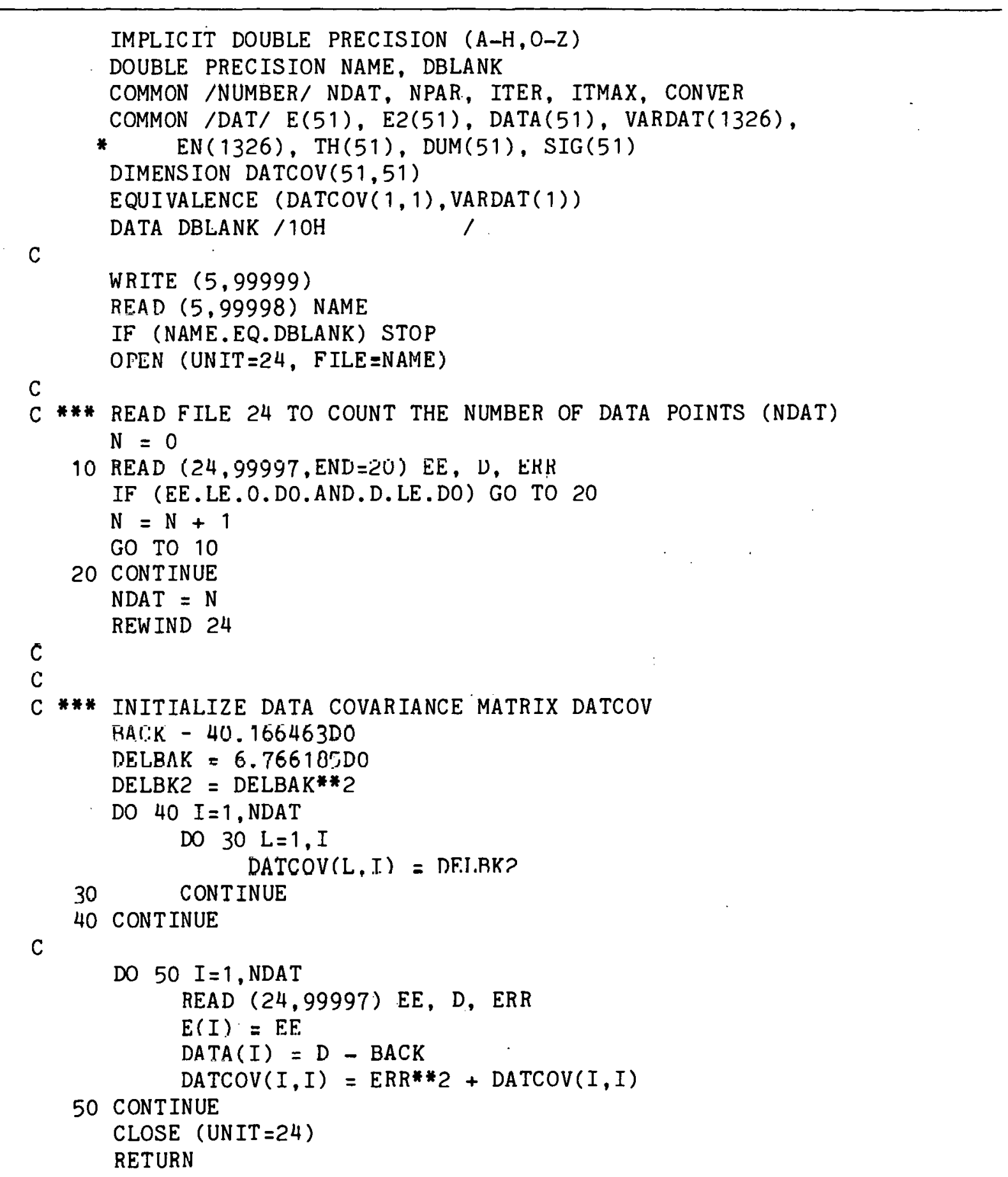


Table V.3.2. (Continued)

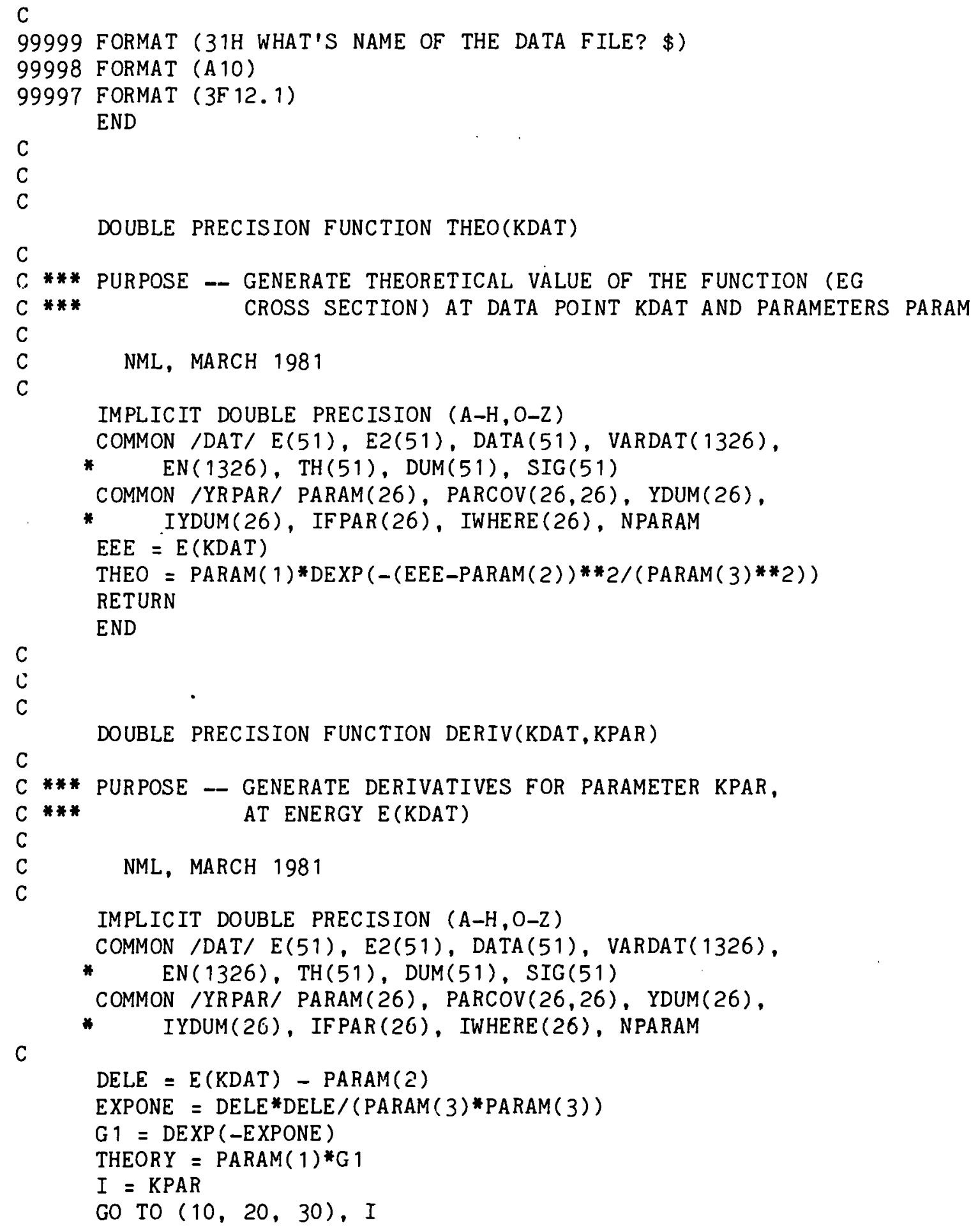


Table V.3.2. (Continued)

$10 \mathrm{GG}=\mathrm{G} 1$

GO TO 40

$20 \mathrm{GG}=2$. DO*THEORY*DELE/(PARAM(3)**2)

GO TO 40

30 GG $=2$. DO*THEOR Y*EXPONE/PARAM (3)

40 CONTINUE

DERIV = GG

RETURN

END 
Table V.3.3. Teletype Commands and User Responses to Program Prompts for Example 3, First Solution.

.EX BAYES, EX31, SHOW, DPPXX, DO4NML

HOW MANY ITERATIONS? WHAT IS CONVERGENCE FRACTION? $5, .001 \downarrow$

DO YOU WISH TO USE AUTOMATIC NUMERICAL DERIVATIVES?_- $\downarrow$

WHAT'S NAME OF THE DATA FILE? EX31.DAT $\downarrow$

WHAT'S NAME OF THE DATA FILE?

STOP 
Table V.3.4. Output Resulting From Use of Commands Shown in Table V.3.3.

MAXIMUM NUMBER OF ITERATIONS ISS 5

CONVERGENCE FACTOR IS 0.001000

******INPUT PARAMETER VALUES

$\begin{array}{lll} & \text { PARAMETER } & \text { UNCERTA INT } \\ 1 & 80.000000 & 80.000000 \\ 2 & 50.000000 & 50.000000 \\ 3 & 10.000000 & 10.000000\end{array}$

***** INTERMEDIATE RESULTS

$\begin{array}{lcl} & \text { OLD PARAM } & \text { NEW PARAMETERS } \\ 1 & 80.000000 & 76.833487 \\ 2 & 50.000000 & 51.298474 \\ 3 & 10.000000 & 12.660616\end{array}$

INTERMEDIATE RESULTS

$\begin{array}{lll} & \text { OLD PARAM } & \text { NEW PARAMETERS } \\ 1 & 80.000000 & 82.365721 \\ 2 & 50.000000 & 51.495437 \\ 3 & 10.000000 & 13.791187\end{array}$

***** INTERMEDIATE RESULTS

$\begin{array}{lll} & \text { ULD HAKAM } & \text { NEW PARAMETERS } \\ 1 & 80.000000 & 83.008461 \\ 2 & 50.000000 & 51.481651 \\ 3 & 10.000000 & 13.884043\end{array}$

******* NEW VALUES FOR PARAMETERS

$\begin{array}{lccr} & \text { POLD } & \text { PNEW } & \text { UNCERTAINTY } \\ 1 & 80.000000 & 83.017172 & 3.578796 \\ 2 & 50.000000 & 51.481154 & 0.346963 \\ 3 & 10.000000 & 13.889437 & 0.855672\end{array}$

STD. DEV. CORRELATION

$\begin{array}{rrrrr} & & 1 & 2 & 3 \\ 2 & 3 . S^{\prime} / 8796 D+00 & 100 & & \\ 3 & 3.469629 D-01 & -2 & 100 & \\ 3 & 8.556722 D-01 & 18 & -1 & 100\end{array}$


Table V.3.5: User-Supplied Subroutines for Example 3, Second Method for Solution. These routines are stored on file EX32.F4 on the ORELA PDP-10.

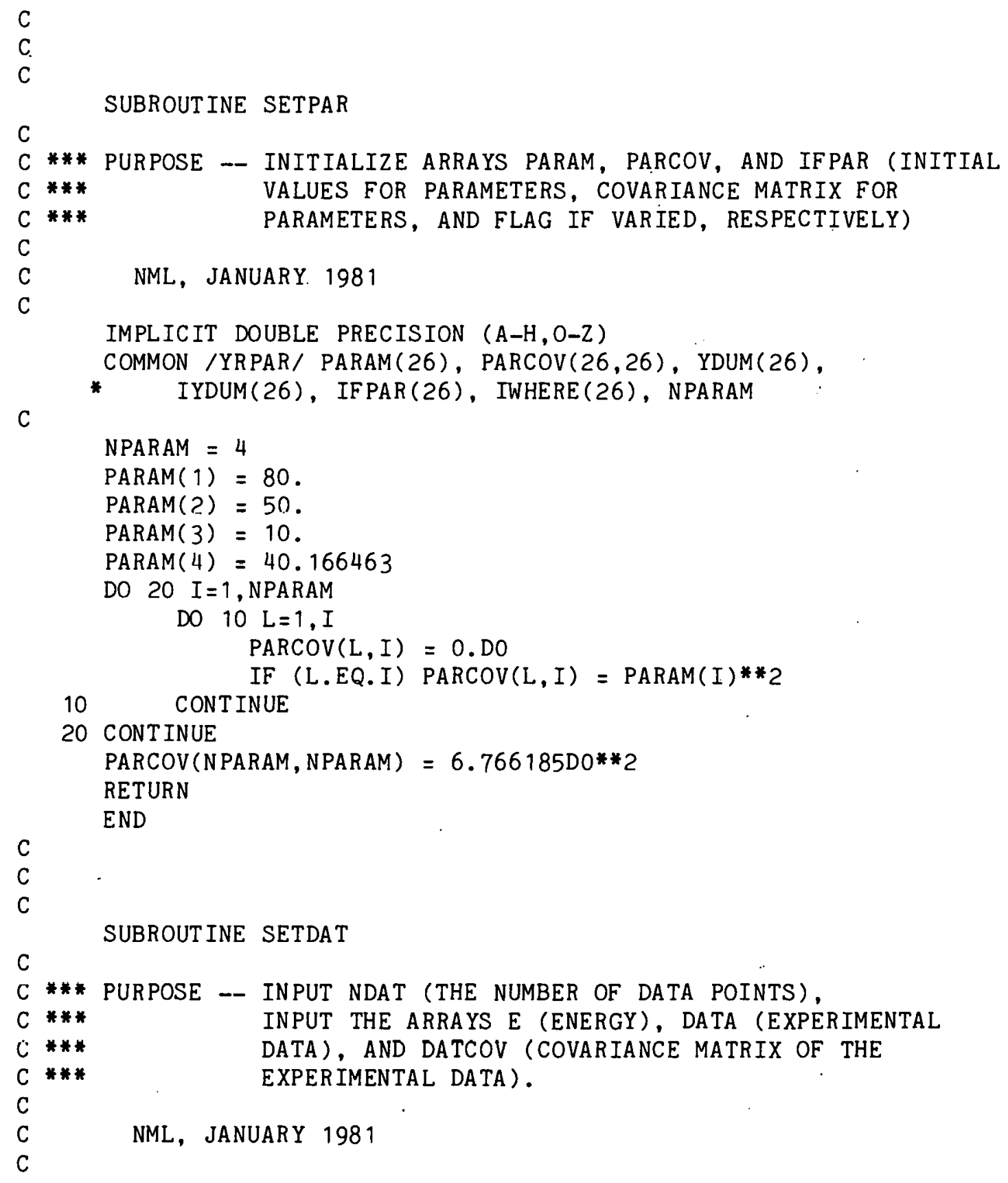


Table V.3.5. (Continued)

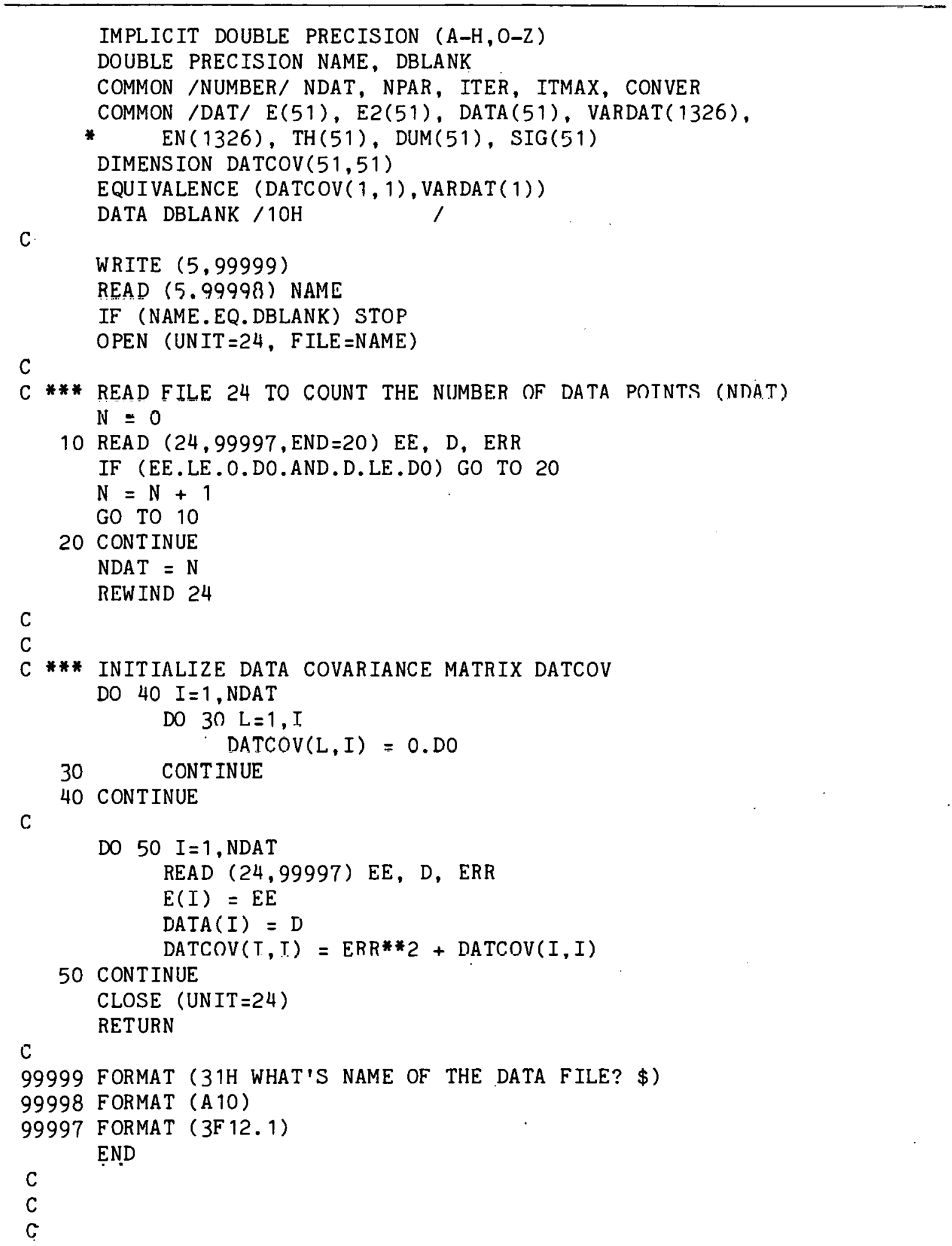


Table V.3.5. (Continued)

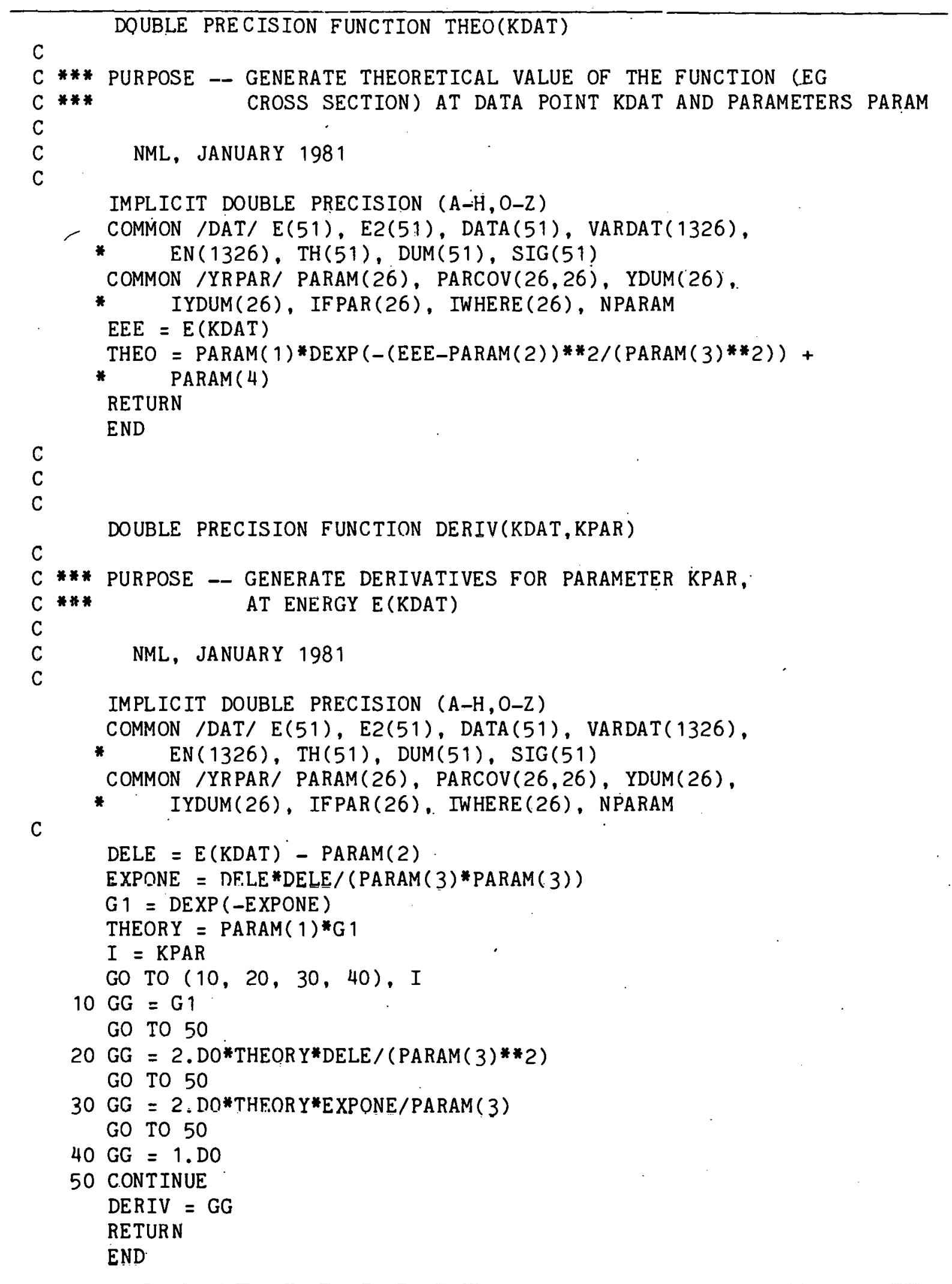


Table V.3.6. Teletype Commands and User Responses to Program Prompts for Example 3, Second Solution.

.EX BAYES, EX32, SHOW, DPPXX, D04NML *

HOW MANY ITERATIONS? WHAT IS CONVERGENCE FRACTION? $5, .001 \downarrow$

DO YOU WISH TO USE AUTOMATIC NUMERICAL DERIVATIVES? $\overline{\mathrm{N}} \downarrow$

WHAT'S NAME OF THE DATA FILE? EX31.DAT \&

WHAT'S NAME OF THE DATA FILE? \&

STOP 
Table V.3.7. Output Resulting From the Use of Commands Shown in Table V.3.6.

MAXIMUM NUMBER OF ITERATIONS IS 5

CONVERGENCE FACTOR IS 0.001000

******INPUT PARAMETER VALUES

$\begin{array}{lll} & \text { PARAMETER } & \text { UNCERTA INTY } \\ 1 & 80.000000 & 80.000000 \\ 2 & 50.000000 & 50.000000 \\ 3 & 10.000000 & 10.000000 \\ 4 & 40.166463 & 6.766185\end{array}$

***** INTERMEDIATE RESULTS

$\begin{array}{lll} & \text { OLD PARAM } & \text { NEW PARAMETERS } \\ 1 & 80.000000 & 76.833487 \\ 2 & 50.000000 & 51.298474 \\ 3 & 10.000000 & 12.660616 \\ 4 & 40.166463 & 39.996141\end{array}$

\section{INTERMEDIATE RESULTS}

$\begin{array}{lll} & \text { OLD PARAM } & \text { NEW PARAMETERS } \\ 1 & 80.000000 & 82.365721 \\ 2 & 50.000000 & 51.495437 \\ 3 & 10.000000 & 13.791187 \\ 4 & 40.166463 & 35.366567\end{array}$

INTERMEDIATE RESULTS

\begin{tabular}{|c|c|c|c|}
\hline & OLD PARAM & \multicolumn{2}{|c|}{ NEW PARAMETERS } \\
\hline 1 & 80.000000 & \multicolumn{2}{|c|}{83.008461} \\
\hline 2 & 50.000000 & \multicolumn{2}{|l|}{51.481651} \\
\hline 3 & 10.000000 & \multicolumn{2}{|l|}{13.884043} \\
\hline 4 & 40.166463 & \multicolumn{2}{|l|}{34.681893} \\
\hline & NEW VALUES FOR & \multicolumn{2}{|l|}{ PARAMETERS } \\
\hline & POLD & ENEW & UNCERTA INTY \\
\hline & 80.000000 & 83.017172 & 3.578796 \\
\hline & 50.000000 & 51.481154 & 0.346963 \\
\hline & 10.000000 & 13.889437 & 0.855672 \\
\hline & 40.166463 & 34.662382 & 3.004104 \\
\hline
\end{tabular}


Table V.3.7. (Continued)

STD. DEV. CORRELATION

$\begin{array}{rrrrrr} & & 1 & 2 & 3 & 4 \\ 2 & 3.578796 D+00 & 100 & & & \\ 2 & 3.469629 D-01 & -2 & 100 & & \\ 3 & 8.556722 D-01 & 18 & -1 & 100 & \\ 4 & 3.004104 D+00 & -54 & 3 & -84 & 100\end{array}$


Table V.3.8. Teletype Commands and User Responses to Program Prompt for Example.3, Second Solution, with Data Supplied Half at a Time.

.EX BAYES, EX32, SHOW, DPPXX, D04NML $\downarrow$

HOW MANY ITERATIONS? WHAT IS CONVERGENCE FRACTION? $5, .001 \downarrow$

DO YOU WISH TO USE AUTOMATIC NUMERICAL DERIVATIVES? $\mathrm{N} \downarrow$

WHAT'S NAME OF THE DATA FILE? EX31A.DAT $\downarrow$

WHAT'S NAME OF THE DATA FILE? EX31B.DAT $\downarrow$

WHAT'S NAME OF THE DATA FILE?

STOP 
Table V.3.9. Output Resulting From the Use of Commands Shown in Table V.3.8.

MAXIMUM NUMBER OF ITERATIONS IS 5 CONVERGENCE FACTOR IS 0.001000

******INPUT PARAMETER VALUES

$\begin{array}{llc} & \text { PARAMETER } & \text { UNCERTA INTY } \\ 1 & 80.000000 & 80.000000 \\ 2 & 50.000000 & 50.000000 \\ 3 & 10.000000 & 10.000000 \\ 4 & 40.166463 & 6.766185\end{array}$

***** INTERMEDIATE RESULTS

$\begin{array}{lll} & \text { OLD PARAM } & \text { NEW PARAMETERS } \\ 1 & 80.000000 & 95.888197 \\ 2 & 50.000000 & 55.419689 \\ 3 & 10.000000 & 16.079597 \\ 4 & 40.166463 & 36.777262\end{array}$

INTERMEdIATE RESULtS

$\begin{array}{lcc} & \text { OLD PARAM } & \text { NEW PARAMETERS } \\ 1 & 80.000000 & 94.066483 \\ 2 & 50.000000 & 51.597251 \\ 3 & 10.000000 & 15.730421 \\ 4 & 40.166463 & 35.171321 \\ & \end{array}$

$\begin{array}{lll} & \text { OLD PARAM } & \text { NEW FARAMETERS } \\ 1 & 80.000000 & 95.343956 \\ 2 & 50.000000 & 54.879020 \\ 3 & 10.000000 & 15.930085 \\ 4 & 110.166463 & 35.033138\end{array}$

***** INTERMEDIATE RESULTS

$\begin{array}{lll} & \text { OLD PARAM } & \text { NEW PARAMETERS } \\ 1 & 80.000000 & 94.718520 \\ 2 & 50.000000 & 54.732557 \\ 3 & 10.000000 & 15.818054 \\ 4 & 40.166463 & 35.113582\end{array}$


Table V.3.9. (Continued)

INTERMEDIATE RESULTS

$\begin{array}{lll} & \text { OLD PARAM } & \text { NEW PARAMETERS } \\ 1 & 80.000000 & 95.093282 \\ 2 & 50.000000 & 54.819004 \\ 3 & 10.000000 & 15.883230 \\ 4 & 40.166463 & 35.067593\end{array}$

******* NEW VALUES FOR PARAMETERS

$\begin{array}{lccr} & \text { POLD } & \text { PNEW } & \text { UNCERTA INTY } \\ 1 & 80.000000 & 94.879316 & 29.991130 \\ 2 & 50.000000 & 54.769427 & 6.467141 \\ 3 & 10.000000 & 15.845681 & 4.555806 \\ 4 & 40.166463 & 35.094206 & 4.367353\end{array}$

STD. DEV. CORRELATION

$\begin{array}{rrrrrr} & & 1 & 2 & 3 & 4 \\ 2 & 2.999113 D+01 & 100 & & & \\ 3 & 6.467141 D+00 & 97 & 100 & & \\ 4 & 4.555806 D+00 & 91 & 96 & 100 & \\ 4 & 4.367353 D+00 & -52 & -53 & -71 & 100\end{array}$

**** INTERMEDIATE RESULTS

$\begin{array}{lll} & \text { OLD PARAM } & \text { NEW PARAMETERS } \\ 1 & 94.879316 & 79.166133 \\ 2 & 54.769427 & 51.835727 \\ 3 & 15.845681 & 14.900612 \\ 4 & 35.094206 & 33.941739\end{array}$

\section{INTERMEDIATE RESULTS}

$\begin{array}{lll} & \text { OLD PARAM } & \text { NEW PARAMETERS } \\ 1 & 94.879316 & 82.362750 \\ 2 & 54.769427 & 51.457965 \\ 3 & 15.845681 & 13.7481162 \\ 4 & 35.094206 & 35.129103\end{array}$


Table V.3.9. (Continued)

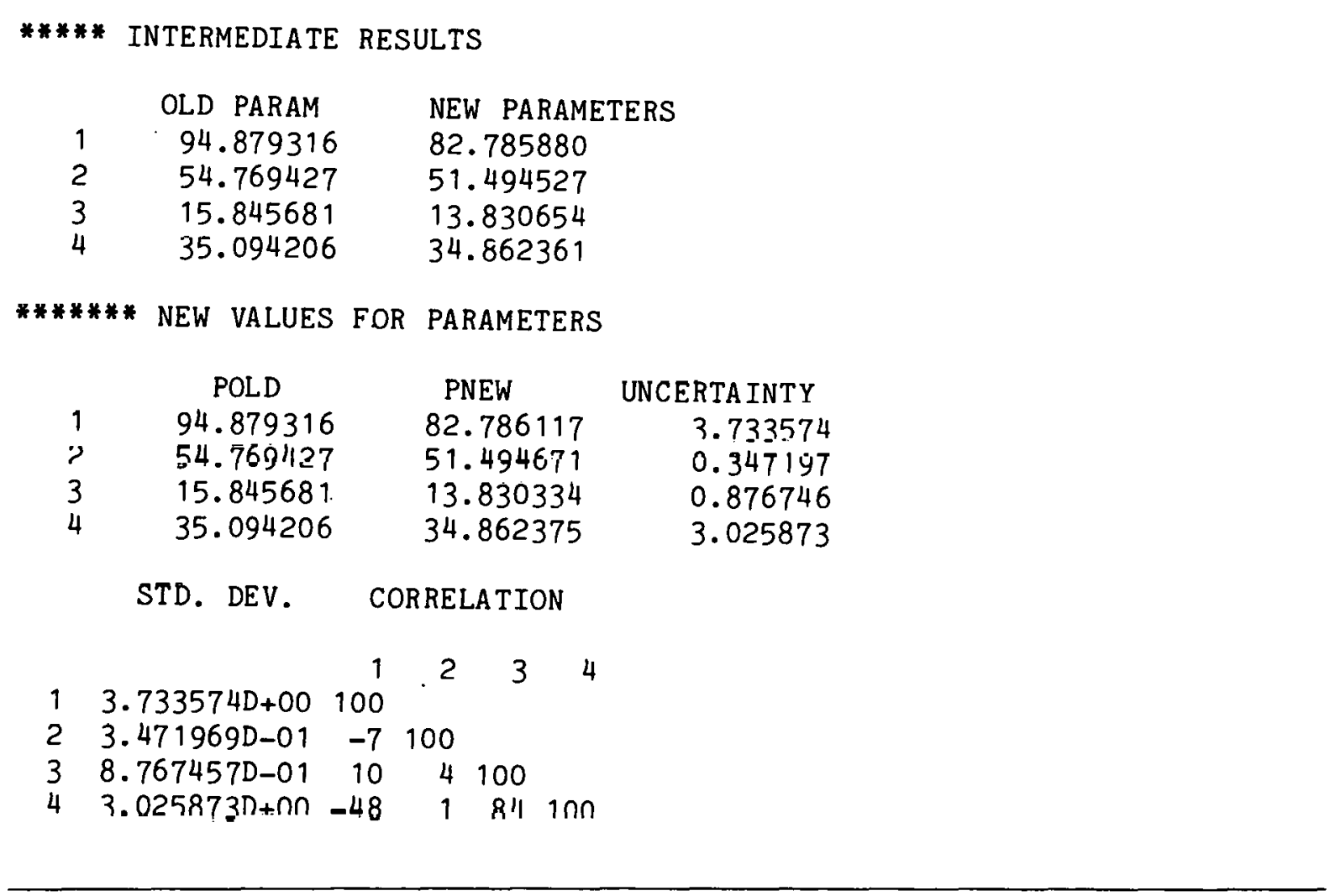




\section{Example 4. Normalization}

The Problem:

Data points $X_{i}$, with uncertainties $\Delta x_{i}$, are correct up to an overall normalization $\mathrm{N}$ with uncertainty $\Delta \mathrm{N}$. This normalization is independent of energy, and is measured independently from the experiment which produced the data points $X_{i}$.

The First Solution:

Again there are two ways to treat this problem. The first approach is to generate data $D_{i}$ as

$$
D_{i}=N X_{i}
$$

which gives changes in $D$ in terms of changes in $N$ or $X_{i}$ as

$$
\delta D_{i}=X_{i} \delta N+\dot{N} \delta X_{i}
$$

Then the variance on $D_{i}$ is given by

$$
\begin{aligned}
v_{i i} & =\left\langle\left(\delta D_{i}\right)^{2}\right\rangle \\
& =x_{i}^{2}\left\langle(\delta N)^{2}\right\rangle+N^{2}\left\langle\left(\delta x_{i}\right)^{2}\right\rangle \\
& =x_{i}^{2} \Delta N^{2}+N^{2} \Delta x_{i}{ }^{2}
\end{aligned}
$$

and the covariance between points $i$ and $j$ by

$$
v_{i j}=\left\langle\delta D_{i} \delta D_{j}\right\rangle=x_{i} x_{j} \Delta N^{2}
$$

since the data points $x_{i}$ are independent. 
The Second Solution:

The alternative approach is to keep $x_{i}$ as the data, and incorporate the normalization into the theory. That is, if $\mathrm{T}$ is the theoretical value calculated in the first approach, then here we have

$$
T^{\prime}=T / n
$$

where $\mathrm{n}$ is a model parameter which is initialized at the known value $\mathrm{N}$ with uncertainty $\Delta N$. The partial derivative $G$ of $T^{\prime}$ ' with respect to $n$ is

$$
G=-T / n^{2}=-T^{\prime} / n \text {, }
$$

and the partial derivatives with respect to the other parameters must be modified to give the derivative of $T^{\prime}$ rather than of $T$.

As in example 3, the second approach has the important advantage that correlations are not introduced into the data themselves. Thus a large data set can be broken into several smaller ones (to conform to computer limitations) and analyzed sequentially. Results will be equivalent to those which would be obtained if the entire set conld be analyzed sequentially. This is illustrated by the sample problem shown below, where we perform the calculation both simultaneously and sequentially.

\section{Specific Case:}

The artificially generated "raw data" used in this example are shown in Table V.4.1 (the PDP-10 file EX41.DAT). 
For the first method of solution, we wish to first adjust the data by a multiplicative constant whose value has been predetermined to be $1.14 \pm$ 0.10 , and then fit the adjusted data with a Breit-Wigner function of the form

$$
f(E, P)=\frac{\pi}{k^{2}} \frac{P_{2}^{2}}{\left(E-P_{1}\right)^{2}+\left(P_{2} / 2.0\right)^{2}}
$$

where $\mathrm{k}$ is the projectile momentum in the center of mass system. Usersupplied subroutines to accomplish this are stored in the PDP-10 file EX41.F4, shown in Table V.4.2. Note that the raw data are read explicitly, and the adjusted data (see Eq. (V.4.1)) and data covariance matrix (see Eqs. (V.4.3) and (V.4.4)) are generated within subroutine SETDAT.

Commands to execute this program and responses to program prompts are given in Table V.4.3, and the output file is listed in Table V.4.4. Note that the presence of off-diagonal elements of the data covariance matrix require all data to be included simultaneously.

In the second method of solution, the raw data is fit directly to a function of the form

$$
f(E, P)=\frac{1}{P_{3}} \frac{\pi}{k} \frac{P_{2}^{2}}{\left(E-P_{1}\right)^{2}+\left(P_{2} / 2.0\right)^{2}}
$$

where the third parameter is input as the predetermined multiplicative constant $1.14 \pm 0.10$. User-supplied subroutines for this case are stored in ORELA PDP-10 file EX42.F4, shown in Table V.4.5. Execution commands are given in Table V.4.6, and output in Table V.4.7.

For both solution methods, prior values of $P_{1}$ and $P_{2}$ are set at $120 . \pm$ 120. and $30 . \pm 30$. respectively, and the two parameters are not known to be correlated. 
Results for the first and second parameters agree with those obtained via the first method of solution to within three or more significant digits, or to within $25 \%$ of the uncertainties. Exact agreement is not expected, since the linear approximation is not strictly correct for multiplicative constants.

With the second method of solution it is possible to analyze the data sequentially rather than simultaneously. The data are divided into two subsets, file EX41A.DAT containing data from $E=100$ to $E=125$ and file EX41B.DAT containing the rest. Commands to analyze these subsets sequentially are shown in Table V.4.8, and the results given in Table V.4.9.

Agreement between parameter values for simultaneous vs sequential solutions is to within $3 \%$ of the corresponding uncertainty. This is better agreement than that obtained between the first and second solution methods (compare Tables V.4.4 and V.4.7). The correlation matrices consistently show that parameter pairs 1-2 and 1-3 are essentially unsorrièlated, wh1le the pair 2-3 are highly correlated.

For practical situations in which the large size of the data set prohibits simultaneous analysis, changing the order of the data sets in a sequential analysis can be used for a consistency check. In this example, analyzing the high-energy region first and then the low-energy region gives results similar with those quoted here, though the discrepancy between simultaneous and sequential results ranges as high as $13 \%$ of the uncertainty. 
Table V.4.1. ORELA PDP-10 File EX41.DAT, Containing "Raw" Data Used for Example 4.

Energy Data Absolute Uncertainty

$\begin{array}{lrl}100.000000 & 4.223518 & 0.205512 \\ 101.000000 & 4.466085 & 0.211331 \\ 102.000000 & 4.915435 & 0.221708 \\ 103.000000 & 5.394355 & 0.232258 \\ 104.000000 & 5.503246 & 0.234590 \\ 105.000000 & 6.116313 & 0.247312 \\ 106.000000 & 6.825470 & 0.261256 \\ 107.000000 & 7.921634 & 0.281454 \\ 108.000000 & 7.883934 & 0.280783 \\ 109.000000 & 7.861386 & 0.280382 \\ 110.000000 & 9.047163 & 0.300785 \\ 111.000000 & 9.291409 & 0.304818 \\ 112.000000 & 10.681179 & 0.326821 \\ 113.000000 & 12.041003 & 0.347001 \\ 114.000000 & 12.339183 & 0.351272 \\ 115.000000 & 13.292924 & 0.364595 \\ 116.000000 & 14.269995 & 0.377756 \\ 117.000000 & 15.627672 & 0.395319 \\ 118.000000 & 16.706080 & 0.408731 \\ 119.000000 & 16.959656 & 0.411821 \\ 120.000000 & 18.299793 & 0.427783 \\ 121.000000 & 18.533516 & 0.430506 \\ 122.000000 & 18.902473 & 0.434770 \\ 123.000000 & 18.480649 & 0.429891 \\ 124.000000 & 18.769973 & 0.433243 \\ 125.000000 & 18.380886 & 0.428729 \\ 126.000000 & 16.777637 & 0.409605 \\ 127.000000 & 16.465754 & 0.405780 \\ 128.000000 & 15.647785 & 0.395573 \\ 129.000000 & 14.189659 & 0.376692 \\ 130.000000 & 13.176671 & 0.362997 \\ 131.000000 & 12.202733 & 0.349324 \\ 132.000000 & 11.513750 & 0.339319 \\ 133.000000 & 10.142552 & 0.318474 \\ 134.000000 & 9.512503 & 0.308423 \\ 135.000000 & 8.488945 & 0.291358 \\ 136.000000 & 7.840551 & 0.280010 \\ 137.000000 & 6.427479 & 0.253525 \\ 138.000000 & 6.133853 & 0.247666 \\ 139.000000 & 5.827105 & 0.241394\end{array}$


Table V.4.1. (Continued)

$\begin{array}{ccc}\text { Energy } & \text { Data } & \text { Absolute } \\ 140.000000 & 5.353455 & 0.231375 \\ 141.000000 & 4.331043 & 0.208112 \\ 142.000000 & 4.382364 & 0.209341 \\ 143.000000 & 4.048990 & 0.201221 \\ 144.000000 & 3.694872 & 0.192220 \\ 145.000000 & 3.480069 & 0.186549 \\ 146.000000 & 3.182577 & 0.178398 \\ 147.000000 & 2.816217 & 0.167816 \\ 148.000000 & 2.787700 & 0.166964 \\ 149.000000 & 2.706788 & 0.164523 \\ 150.000000 & 2.402707 & 0.155007\end{array}$


Table V.4.2. User-Supplied Subroutines for the First Method of Solution for Example 4. These routines are stored on PDP-10 file EX41.F4.

C

$\mathrm{C}$

SUBROUTINE SETPAR

$\mathrm{C}$

C *** PURPOSE -- INITIALIZE ARRAYS PARAM, PARCOV, AND IFPAR (INITTAL VALUES FOR PARAMETERS, COVARIANCE MATRIX FOR

C

C

C

NML, MARCH 1981

IMPLICIT DOUBLE PRECISION (A-H,O-Z)

COMMON /YRPAR/ PARAM(26), PARCOV(26,26), YDUM(26),

* IYdum(26), IFPAR(26), IWHere(26), NPARAM

C

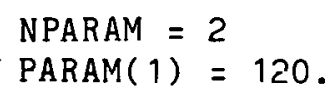
INPUT THE ARRAYS E (ENERGY), DATA (EXPERIMENTAL DATA), AND DATCOV (COVARIANCE MATRIX OF THE EXPERIMENTAL DATA).

NML, MARCH 1981

IMPLICIT DOUBLE PRECISION (A-H, O-Z)

DOUBLE PRECISION NAME, DBLANK

COMMON /NUMBER/ NDAT, NPAR, ITER, ITMAX, CONVER

COMMON /DAT/ E(51), E2(51), DATA(51), VARDAT(1326),

* EN(1326), TH(51), DUM(51), SIG(51)

DIMENSION DATCOV $(51,51)$

EQUIVALENCE (DATCOV $(1,1), \operatorname{VARDAT}(1)$ )

DA'TA DBLANK /10H 
Table V.4.2. (Continued)

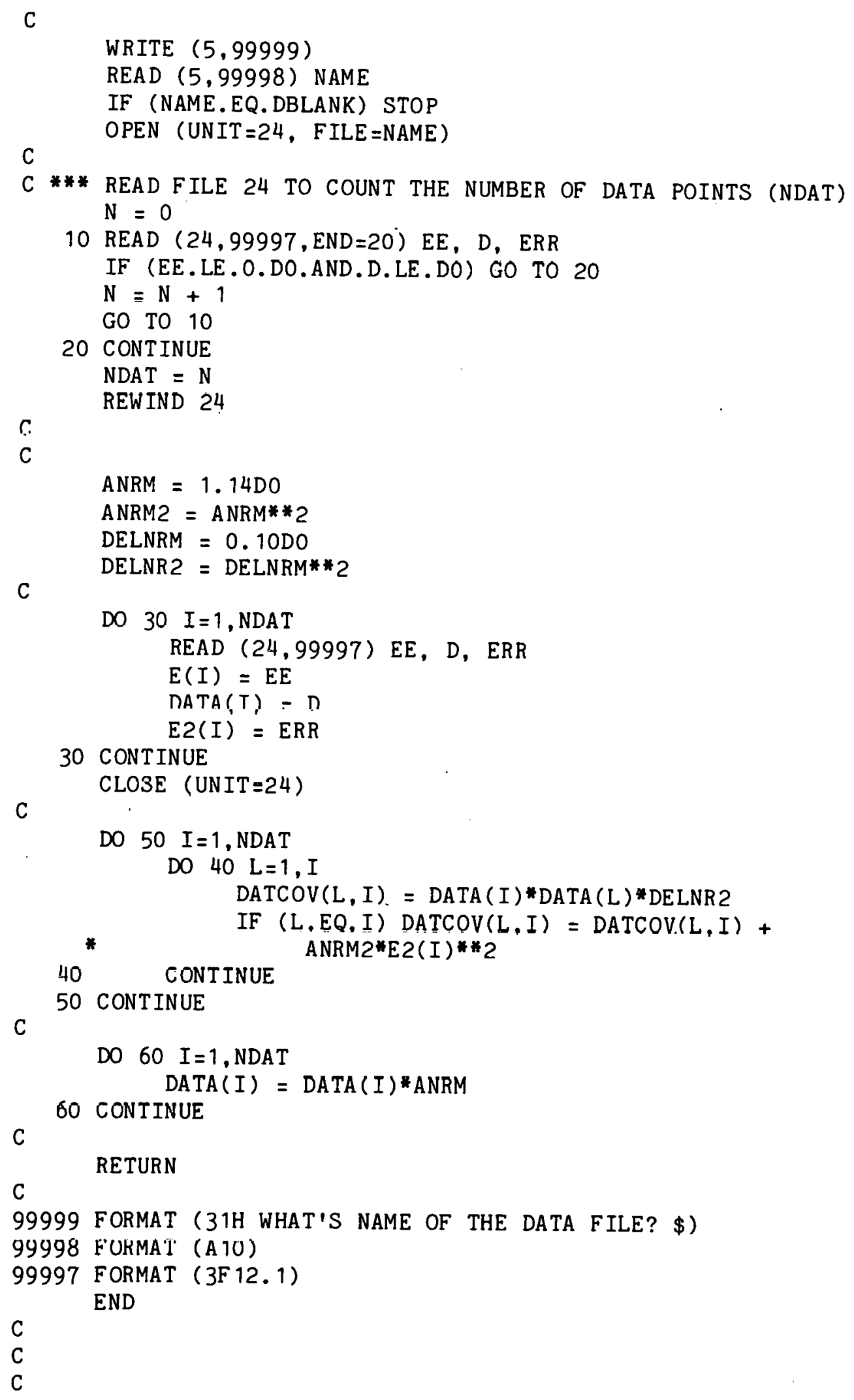


Table V.4.2. (Continued)

DOUBLE PRECISION FUNCTION THEO(KDAT)

C

C *** PURPOSE - GENERATE THEORETICAL VALUE OF THE FUNCTION (EG

$C * * *$ CROSS SECTION) AT DATA POINT KDAT AND PARAMETERS PARAM

C

C NML, MARCH 1981

c

IMPLICIT DOUBLE PRECISION (A-H,O-Z)

COMMON /DAT/ E(51), E2(5r), DATA(51), VARDAT(1326),

* EN(1326), TH(51), DUM(51), SIG(51)

COMMON /YRPAR/ PARAM(26), PARCOV $(26,26), \operatorname{YDUM}(26)$,

* IYDUM(26), IFPAR(26), IWHERE(26), NPARAM

DATA IN $10 /$

IF (IN.GT.0) GO TO 10

$A M=100$.

$C A Y=2.1968 E-4 *(A M /(A M+1.009))$

CAYS $=0.0314159 /$ CAY**2/1000.

IN $=1$

$10 \mathrm{EEE}=\mathrm{E}(\mathrm{KDAT})$

THEO $=($ CAYS/EEE $) *$ PARAM $(2) * * 2 /(($ EEE $-P A R A M(1)) * * 2+0.25 *$

* PARAM (2)**2)

RETURN

END

C

C.

C

DOUBLE PRECISION FUNCTION DERIV(KDAT, KPAR)

$\mathrm{C}$

C *** PURPOSE - GENERATE DERIVATIVES FOR PARAMETER KPAR,

$C * * *$ AT ENERGY E(KDAT)

C

C

C

NML, MAKCH $198 \%$

IMPLICIT DOUBLE PRECISION (A-H, O-Z)

COMMON /DAT/ E(51), E2(51), DATA(51), $\operatorname{VARDAT}(1326)$,

* EN(1326), TH(51), duM(51), SIG(51)

COMMON /YRPAR/ PARAM(26), PARCOV $(26,26), \operatorname{YDUM}(26)$,

* IYDUM(26), IFPAR(26), IWHERE(26), NPARAM

DATA IN $/ 0 /$

IF (IN.GT.0) GO TO 10

$A M=100$.

$C A Y=2.1968 E-4 *(A M /(A M+1.009))$

CAYS $=0.0314159 /$ CAY* $2 / 1000$.

C

$\mathrm{IN}=1$ 
Table V.4.2. (Continued)

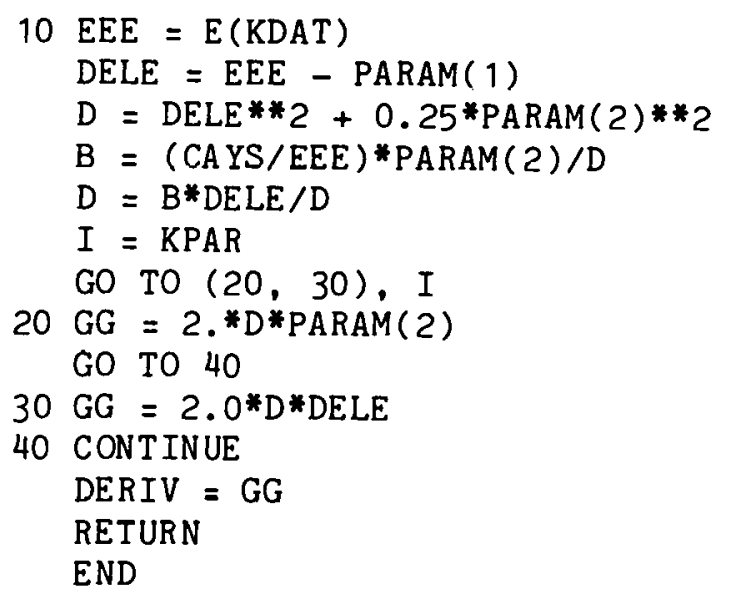


Table V.4.3. Teletype Commands and User Responses to Program Prompts for Example 4, First Method of Solution.

EX BAYES, EX41, SHOW,DPPXX,DO4NML $\downarrow$

HOW MANY ITERATIONS? WHAT IS CONVERGENCE FRACTION? 5,.001

DO YOU WISH TO USE AUTOMATIC NUMERICAL DERIVATIVES? $\mathbf{N} \downarrow$

WHAT'S NAME OF THE DATA FILE? EX41.DAT $\downarrow$

WHAT'S NAME OF THE DATA FILE? \&

STOP 
Table V.4.4. Output Resulting from the Use of Commands Given in Table V.4.3.

MAXIMUM NUMBER OF ITERATIONS IS 5 CONVERGENCE FACTOR IS 0.001000

******INPUT PARAMETER VALUES

$\begin{array}{crc} & \text { PARAMETER } & \text { UNCERTA INTY } \\ 1 & 120.000000 & 120.000000 \\ 2 & 30.000000 & 30.000000\end{array}$

****** INPUT DATA VALUES

$\begin{array}{rrrc} & \text { DATA POINT } & \text { VALUE } & \text { UNCERTAINTY } \\ 1 & 100.000000 & 1.814811 & 0.482980 \\ 2 & 101.000000 & 5.091337 & 0.507445 \\ 3 & 102.000000 & 5.603596 & 0.552717 \\ 4 & 103.000000 & 6.149565 & 0.600913 \\ 5 & 104.000000 & 6.273700 & 0.611864 \\ 6 & 105.000000 & 6.972597 & 0.673484 \\ 7 & 106.000000 & 7.781036 & 0.744697 \\ 8 & 107.000000 & 9.030663 & 0.054677 \\ 9 & 108.000000 & 8.987685 & 0.850896 \\ 10 & 109.000000 & 8.961980 & 0.848635 \\ 11 & 110.000000 & 10.313766 & 0.967517 \\ 12 & 111.000000 & 10.592206 & 0.991995 \\ 13 & 112.000000 & 12.176544 & 1.131233 \\ 14 & 113.000000 & 13.726743 & 1.267415 \\ 15 & 114.000000 & 14.066669 & 1.297272 \\ 16 & 115.000000 & 15.153933 & 1.392758 \\ 17 & 116.000000 & 16.267794 & 1.490564 \\ 18 & 117.000000 & 17.815546 & 1.626450 \\ 19 & 118.000000 & 19.044931 & 1.734371 \\ 20 & 119.000000 & 19.334008 & 1.759746 \\ 21 & 120.000000 & 20.861764 & 1.893845 \\ 27 & 171.000000 & 21.128208 & 1.917231 \\ 23 & 122.000000 & 21.548819 & 1.954147 \\ 24 & 123.000000 & 21.067940 & 1.911941 \\ 25 & 124.000000 & 21.397769 & 1.940890 \\ 26 & 125.000000 & 20.954210 & 1.901959 \\ 27 & 126.000000 & 19.126506 . & 1.741532 \\ 28 & 127.000000 & 18.770960 & 1.710321 \\ 29 & 128.000000 & 17.838475 & 1.628463 \\ 30 & 129.000000 & 16.176211 & 1.482523\end{array}$


Table V.4.4. (Continued)

$\begin{array}{llrl}31 & 130.000000 & 15.021405 & 1.381119 \\ 32 & 131.000000 & 13.911116 & 1.283610 \\ 33 & 132.000000 & 13.125675 & 1.214618 \\ 34 & 133.000000 & 11.562509 & 1.077277 \\ 35 & 134.000000 & 10.844253 & 1.014151 \\ 36 & 135.000000 & 9.677397 & 0.911561 \\ 37 & 136.000000 & 8.938228 & 0.846545 \\ 38 & 137.000000 & 7.327326 & 0.704739 \\ 39 & 138.000000 & 6.992592 & 0.675246 \\ 40 & 139.000000 & 6.642900 & 0.644423 \\ 41 & 140.000000 & 6.102939 & 0.596798 \\ 42 & 141.000000 & 4.937389 & 0.493828 \\ 43 & 142.000000 & 4.995895 & 0.499003 \\ 44 & 143.000000 & 4.615849 & 0.465364 \\ 45 & 144.000000 & 4.212154 & 0.429580 \\ 46 & 145.000000 & 3.967279 & 0.407843 \\ 47 & 146.000000 & 3.628138 & 0.377689 \\ 48 & 147.000000 & 3.210487 & 0.340456 \\ 49 & 148.000000 & 3.177978 & 0.337552 \\ 50 & 149.000000 & 3.085738 & 0.329309 \\ 51 & 150.000000 & 2.739086 & 0.298254\end{array}$


Table V.4.4. (Continued)

STD. DEV. CORRELATION

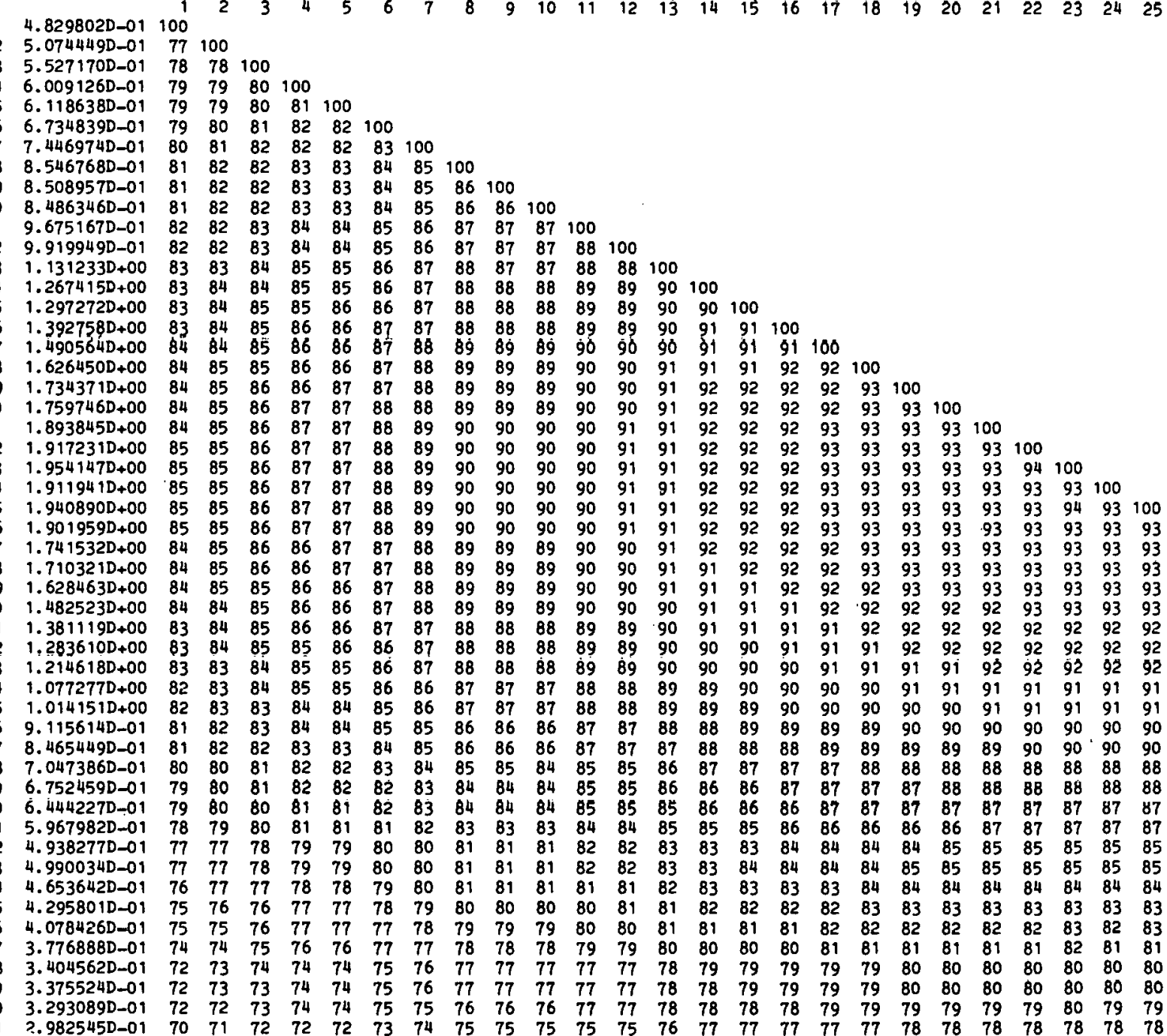


Table V.4.4. (Continued)

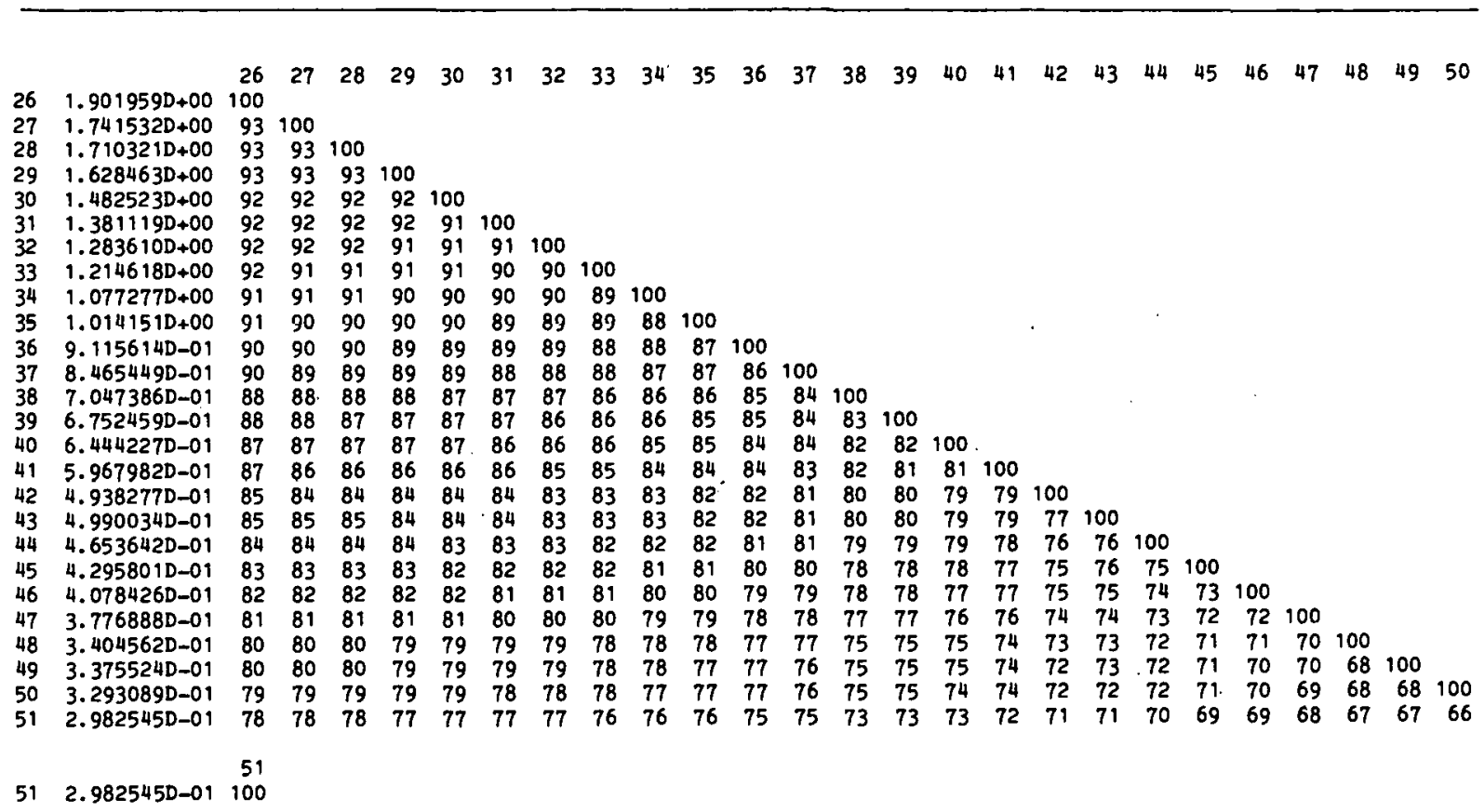

***** INTERMEDIATE RESULTS

$\begin{array}{ccc} & \text { OLD PARAM } & \text { NEW PARAMETERS } \\ 1 & 120.000000 & 123.522867 \\ 2 & 30.000000 & 23.859774\end{array}$

***** INTERMEDIATE RESULTS

$\begin{array}{ccc} & \text { OLD PARAM } & \text { NEW PARAMETERS } \\ 1 & 120.000000 & 123.221543 \\ 2 & 30.000000 & 22.601910\end{array}$

******* NEW VALUES FOR PARAMETERS

\begin{tabular}{ccrr} 
& POLD & \multicolumn{1}{c}{ PNEW } & UNCERTAINTY \\
1 & 120.000000 & 123.219438 & 0.065499 \\
2 & 30.000000 & 22.595304 & 0.189104
\end{tabular}

STD. DEV. CORRELATION
$16.549912 \mathrm{D}-02 \quad 100$
$21.891043 \mathrm{D}-013100$ 
Table V.4.5. User-Supplied Subroutines for the Second Method of Solution for Example 4. These routines are stored on PDP-10 file EX42.F4.

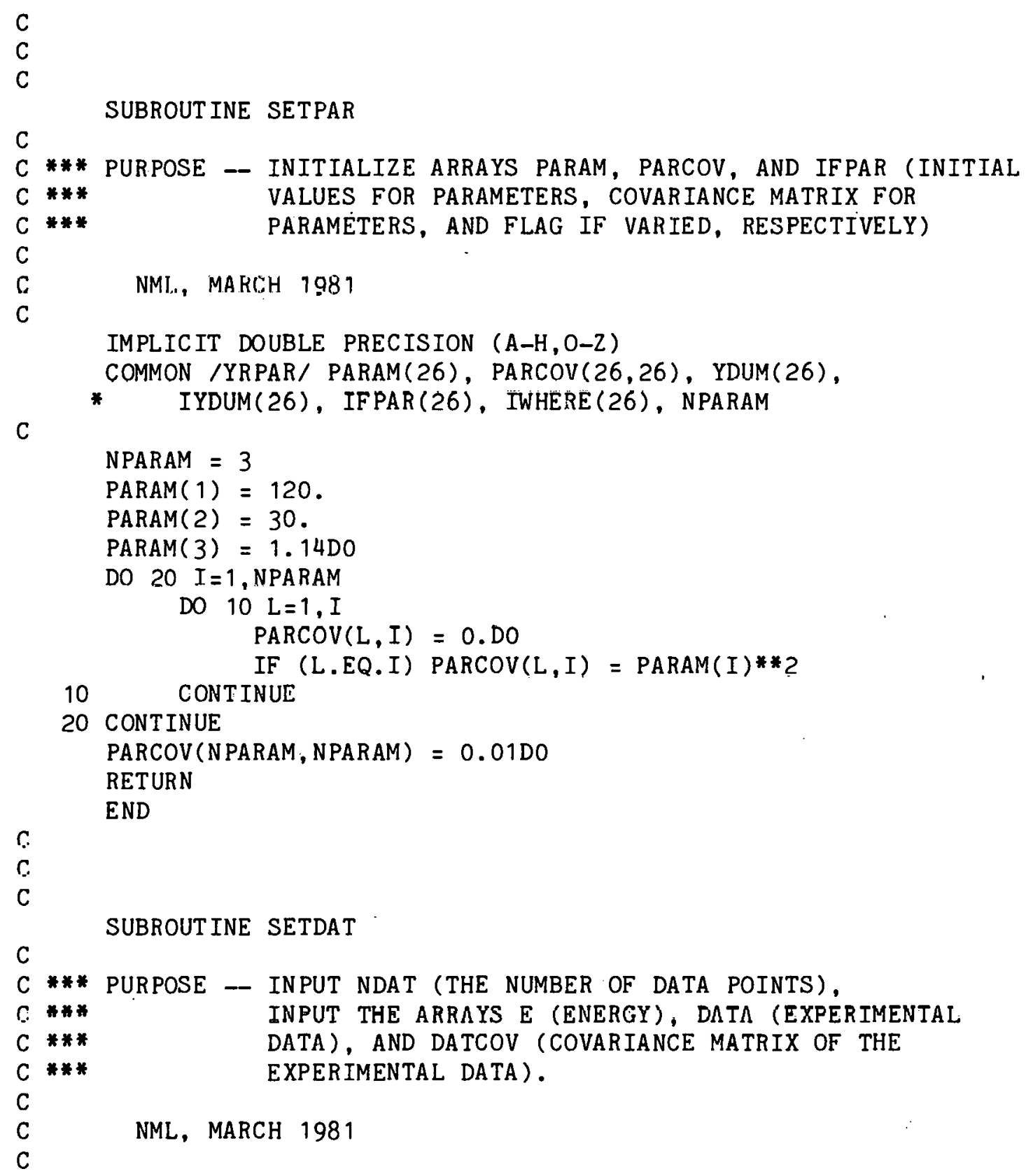
INPUT THE ARRAYS E (ENERGY), DATA (EXPERIMENTAL. 
Table V.4.5. (Continued)

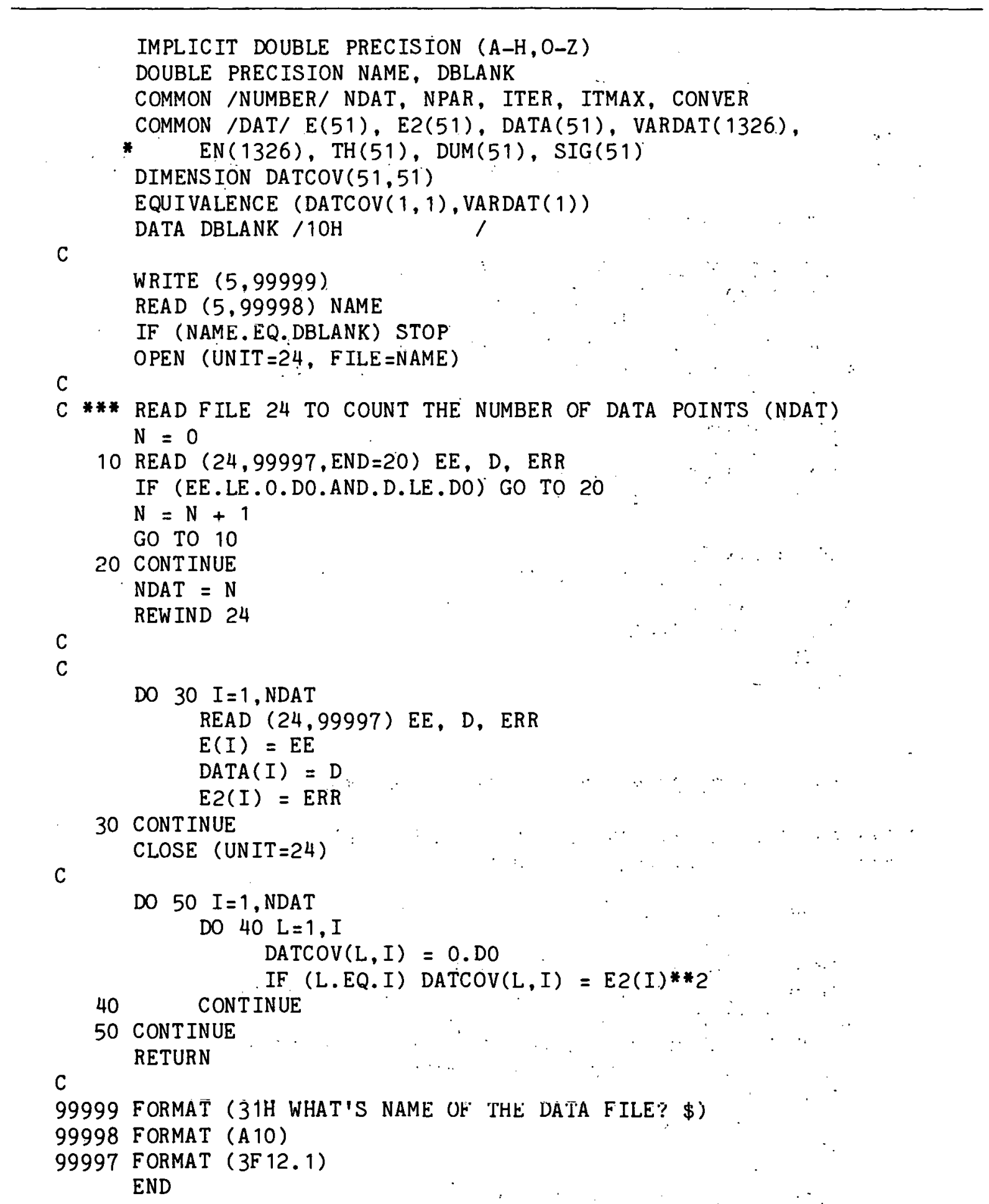


Table V.4.5. (Continucd)

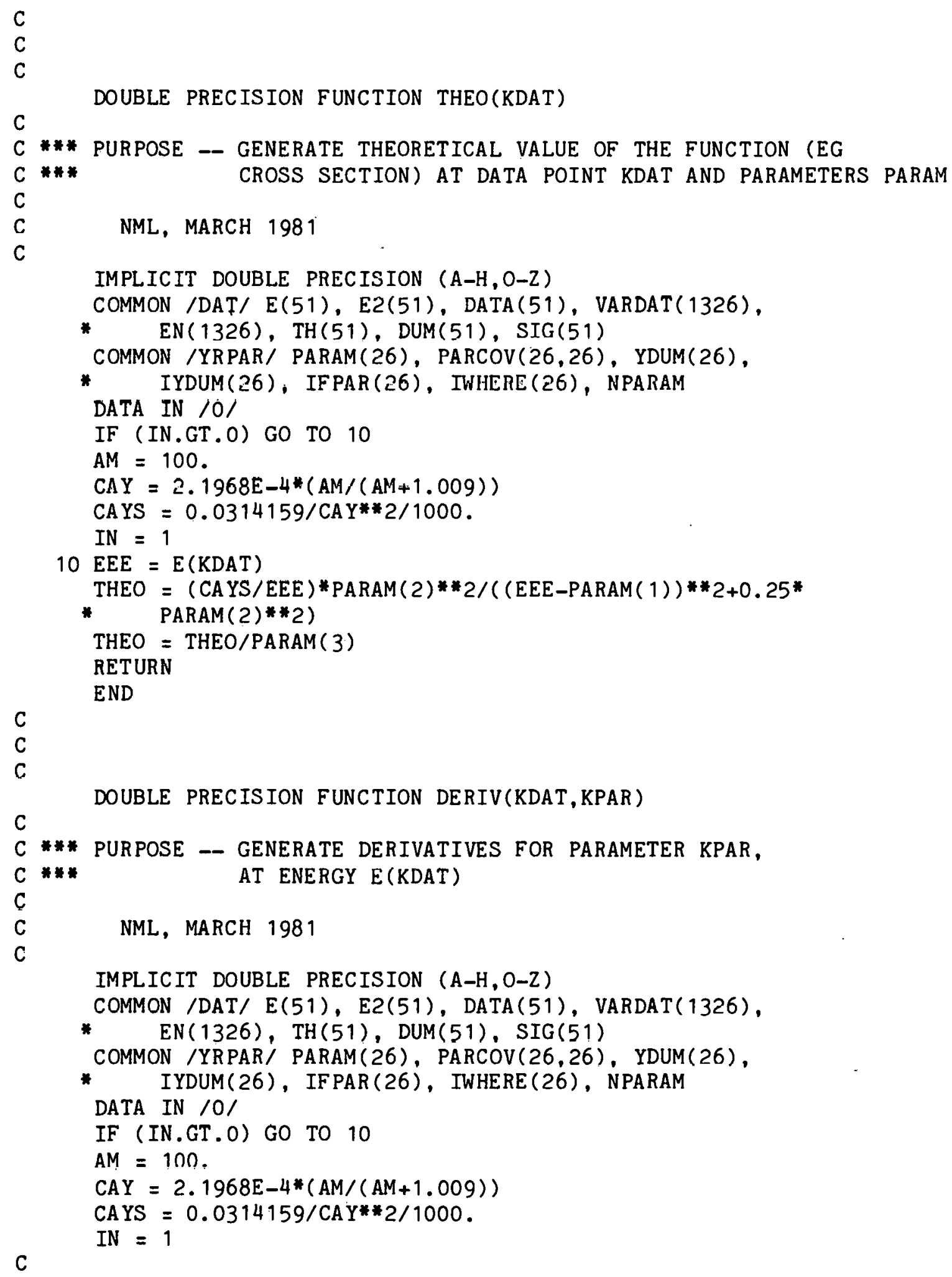


Table V.4.5. (Continued)

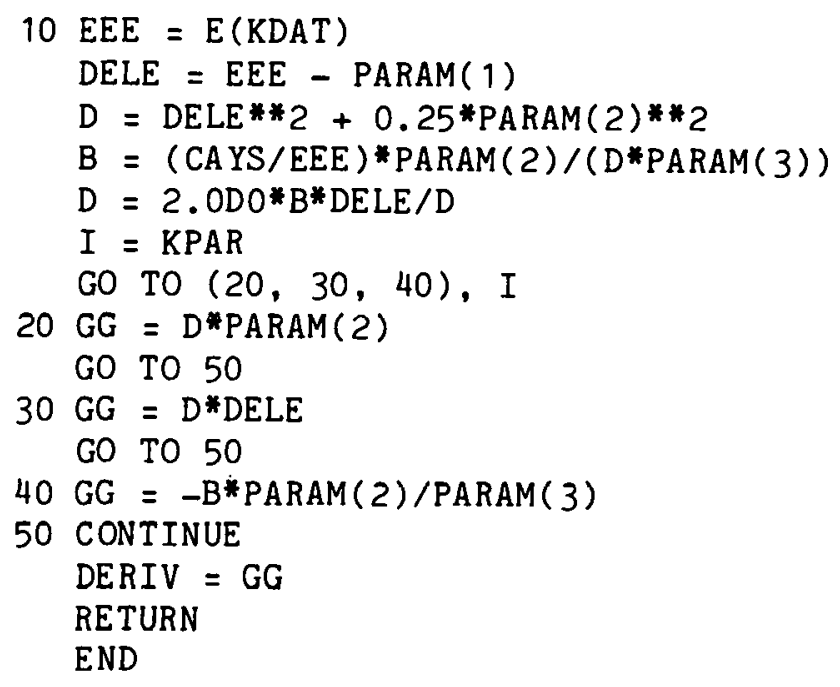


Table V.4.6. Teletype Commands and User Responses to Program Prompts for Example 4, Second Method of Solution.

.EX BAYES, EX42. SHOW, DPPXX, DO4NML $\downarrow$

HOW MANY ITERATIONS? WHAT IS CONVERGENCE FRACTION? $5.001 \downarrow$

DO YOU WISH TO USE AUTOMATIC NUMERICAL DERIVATIVES? $\mathbf{N} \downarrow$

WHAT'S NAME OF THE DATA FILE? EX41.DAT $\downarrow$

WHAT'S NAME OF THE DATA FILE? $!$

STOP 
Table V.4.7. Output Resulting from the Use of Commands Given in Table V.4.6.

MAXIMUM NUMBER OF ITERATIONS IS 5

CONVERGENCE FACTOR IS 0.001000

******INPUT PARAMETER VALUES

$\begin{array}{lrc} & \text { PARAMETER } & \text { UNCERTA INTY } \\ 1 & 120.000000 & 120.000000 \\ 2 & 30.000000 & 30.000000 \\ 3 & 1.140000 & 0.100000\end{array}$

***** INTERMEDIATE RESULTS

$\begin{array}{ccc} & \text { OLD PARAM } & \text { NEW PARAMETERS } \\ 1 & 120.000000 & 123.320330 \\ 2 & 30.000000 & 24.326760 \\ 3 & 1.140000 & 1.207887\end{array}$

***** INTERMEDIATE RESULTS

$\begin{array}{ccc} & \text { OLD PARAM } & \text { NEW PARAMETERS } \\ 1 & 120.000000 & 123.216831 \\ 2 & 30.000000 & 22.522077 \\ 3 & 1.140000 & 1.134500\end{array}$

***** INTERMEDIATE RESULTS

$\begin{array}{ccc} & \text { OLD PARAM } & \text { NEW PARAMETERS } \\ 1 & 120.000000 & 123.218900 \\ 2 & 30.000000 & 22.643774 \\ 3 & 1.140000 & 1.137689\end{array}$

******* NEW VALUES FOR PARAMETERS

\begin{tabular}{rrrr} 
& \multicolumn{1}{c}{ POLD } & \multicolumn{1}{c}{ PNEW } & UNCERTAINTY \\
1 & 120.000000 & 123.219184 & 0.065389 \\
2 & 30.000000 & 22.642567 & 0.188848 \\
3 & 1.140000 & 1.131635 & 0.008795
\end{tabular}

STD. DEV. CORRELATION

$\begin{array}{rrrrr}1 & 6.538899 D-02 & 1 & 2 & 3 \\ 2 & 1.888479 D-01 & 3 & 100 & \\ 3 & 8.195363 D-03 & -2 & 78 & 100\end{array}$


Table V.4.8. Teletype Commands and User Responses to Program Prompts for Example 4, Second Method of Solution, Where Subsets of the Data are Analyzed Sequentially.

.EX BA YES, EX42, SHOW, DPPXX, D04NML $\downarrow$ HOW MANY ITERATIONS? WHAT IS CONVERGENCE FRACTION? $5, .001 \downarrow$ DO YOU WISH TO USE AUTOMATIC NUMERICAL DERIVATIVES? WHAT'S NAME OF THE DATA FILE? EX41A.DAT $\downarrow$ WHAT'S NAME OF THE DATA FILE? EX41B.DAT $\downarrow$ WHAT'S NAME OF THE DATA FILE? $\downarrow$ STOP 
Table V.4.9. Output Resulting from the Use of Commands Given in Table V.4.8.

MAXIMUM NUMBER OF ITERATIONS IS 5

CON VERGENCE FACTOR IS 0.001000

******INPUT PARAMETER VALUES

$\begin{array}{ccc} & \text { PARAMETER } & \text { UNCERTAINTY } \\ 1 & 120.000000 & 120.000000 \\ 2 & 30.000000 & 30.000000 \\ 3 & 1.140000 & 0.100000\end{array}$

****** INPUT DATA VALUES

$\begin{array}{rrrc} & \text { DATA POINT } & \text { VALUE } & \text { UNCERTAINTY } \\ 1 & 100.000000 & 4.223518 & 0.205512 \\ 2 & 101.000000 & 4.466085 & 0.211 .331 \\ 3 & 102.000000 & 4.915435 & 0.221708 \\ 4 & 103.000000 & 5.394355 & 0.232258 \\ 5 & 104.000000 & 5.503246 & 0.234590 \\ 6 & 105.000000 & 6.116313 & 0.247312 \\ 7 & 106.000000 & 6.825470 & 0.261256 \\ 8 & 107.000000 & 7.921634 & 0.281454 \\ 9 & 108.000000 & 7.883934 & 0.280783 \\ 10 & 109.000000 & 7.861386 & 0.280382 \\ 11 & 110.000000 & 9.047163 & 0.300785 \\ 12 & 111.000000 & 9.291409 & 0.304818 \\ 13 & 112.000000 & 10.681179 & 0.326821 \\ 14 & 113.000000 & 12.041003 & 0.347001 \\ 15 & 114.000000 & 12.339183 & 0.351272 \\ 16 & 115.000000 & 13.292924 & 0.364595 \\ 11 & 116.000000 & 14.269995 & 0.377756 \\ 18 & 117.000000 & 15.627672 & 0.395319 \\ 19 & 118.000000 & 16.706080 & 0.408731 \\ 20 & 119.000000 & 16.959656 & 0.411821 \\ 21 & 120.000000 & 18.299793 & 0.427783 \\ 22 & 121.000000 & 18.533516 & 0.430506 \\ 23 & 122.000000 & 18.902473 & 0.434770 \\ 24 & 123.000000 & 18.480649 & 0.429891 \\ 25 & 124.000000 & 18.769973 & 0.433243 \\ 26 & 125.000000 & 18.380886 & 0.428729\end{array}$


Table V.4.9. (Continued)

INTERMEDIATE RESULTS

$\begin{array}{ccc} & \text { OLD PARAM } & \text { NEW PARAMETERS } \\ 1 & 120.000000 & 124.211134 \\ 2 & 30.000000 & 26.918133 \\ 3 & 1.140000 & 1.218049\end{array}$

***** TNTF.RMF.DTATF. RF.SIIT.TS

$\begin{array}{ccc} & \text { OLD PARAM } & \text { NEW PARAMETERS } \\ 1 & 120.000000 & 122.560816 \\ 2 & 30.000000 & 21.342463 \\ 3 & 1.1110000 & 1.147678\end{array}$

***** INTERMEDIATE RESULTS

$\begin{array}{ccc} & \text { OLD PARAM } & \text { NEW PARAMETERS } \\ 1 & 120.000000 & 122.923917 \\ 2 & 30.000000 & 22.193190 \\ 3 & 1.140000 & 1.142256\end{array}$

***** INTERMEDIATE RESULTS

$\begin{array}{ccc} & \text { OLD PARAM } & \text { NEW PARAMETERS } \\ 1 & 120.000000 & 122.944974 \\ 2 & 30.000000 & 22.202865 \\ 3 & 1.140000 & 1.140846\end{array}$

******* NEW VALUES FOR PARAMETERS

\begin{tabular}{rrrr} 
& POLD & \multicolumn{1}{c}{ PNEW } & UNCERTAINTY \\
1 & 120.000000 & 122.945288 & 0.220635 \\
2 & 30.000000 & $2 \mathrm{a} .203036$ & 0.355430 \\
3 & 1.140000 & 1.140832 & 0.010947
\end{tabular}

STD. DEV. CORRELATION

$\begin{array}{rrrrr} & & 1 & 2 & 3 \\ 2 & 2.206350 \mathrm{D}-01 & 100 & & \\ 3 & 3.554301 \mathrm{D}-01 & 75 & 100 & \\ 1.094666 \mathrm{D}-02 & -48 & 6 & 100\end{array}$


Table V.4.9. (Continued)

****** INPUT DATA VALUES

$\begin{array}{rrrr} & \text { DATA POINT } & \text { VALUE } & \text { UNCERTAINTY } \\ 1 & 126.000000 & 16.777637 & 0.409605 \\ 2 & 127.000000 & 16.465754 & 0.405780 \\ 3 & 128.000000 & 15.647785 & 0.395573 \\ 4 & 129.000000 & 14.189659 & 0.376692 \\ 5 & 130.000000 & 13.176671 & 0.362997 \\ 6 & 131.000000 & 12.202733 & 0.349324 \\ 7 & 132.000000 & 11.513750 & 0.339319 \\ 8 & 133.000000 & 10.142552 & 0.318474 \\ 9 & 134.000000 & 9.512503 & 0.308423 \\ 10 & 135.000000 & 8.488945 & 0.291358 \\ 11 & 136.000000 & 7.840551 & 0.280010 \\ 12 & 137.000000 & 6.427479 & 0.253525 \\ 13 & 138.000000 & 6.133853 & 0.247666 \\ 14 & 139.000000 & 5.827105 & 0.241394 \\ 15 & 140.000000 & 5.353455 & 0.231375 \\ 16 & 141.000000 & 4.331043 & 0.208112 \\ 17 & 142.000000 & 4.382364 & 0.209341 \\ 18 & 143.000000 & 4.048990 & 0.201221 \\ 19 & 144.000000 & 3.694872 & 0.192220 \\ 20 & 145.000000 & 3.480069 & 0.186549 \\ 21 & 146.000000 & 3.182577 & 0.178398 \\ 22 & 147.000000 & 2.816217 & 0.167816 \\ 23 & 148.000000 & 2.787700 & 0.166964 \\ 24 & 149.000000 & 2.706788 & 0.164523 \\ 25 & 150.000000 & 2.402707 & 0.155007\end{array}$

INTERMEDIATE RESULTS

$\begin{array}{ccc} & \text { OLD PARAM } & \text { NEW PARAMETERS } \\ 1 & 122.945288 & 123.215984 \\ 2 & 22.203036 & 22.656192 \\ 3 & 1.140832 & 1.138229\end{array}$

******* NEW VALUES FOR PARAMETERS

\begin{tabular}{rrrr} 
& \multicolumn{1}{c}{ POLD } & \multicolumn{1}{c}{ PNEW } & UNCERTAINTY \\
1 & 122.945288 & 123.217381 & 0.064962 \\
2 & 22.203036 & 22.644752 & 0.186979 \\
3 & 1.140832 & 1.137768 & 0.008168
\end{tabular}

STD. DEV. CORRELATION

$\begin{array}{rrrrr}1 & & 1 & 2 & 3 \\ 2 & 1.8669789 \mathrm{D}-02 & 100 & & \\ 3 & 8.168167 \mathrm{D}-03 & 5 & 100 & \\ & 1 & 78 & 100\end{array}$


Example 5. Angular Distribution

The Problem:

Find the coefficients in a Legendre expansion of an angular distribution which was generated from a physical model.

The Solution:

The theoretical values are given by the Legendre expansion

$$
\mathrm{T}(\theta)=\sum_{\ell=0}^{\mathrm{k}} \sqrt{\frac{2 \ell+1}{4 \pi}} \mathrm{P}_{\ell} \mathrm{Y}_{\ell 0}(\cos \theta)
$$

where $\mathrm{Y}_{\ell 0}(\mathrm{x})$ is the spherical harmonic with $\mathrm{m}=0$, equal to $\sqrt{\frac{2 \ell+1}{4 \pi}}$ times the Legendre polynomial of degree $l$. This expression is linear with respect to parameters $P_{\ell}$, the partial derivatives being given by $\sqrt{\frac{2 \ell+1}{4 \pi}} Y_{\ell 0}(\cos \theta)$.

Because the "data" points $D_{i}$ represent a calculated differential cross section, they are not independent. Rather, the integrated cross section is constant:

$$
\sigma=\rho \frac{\mathrm{d} \sigma}{\mathrm{d} \Omega} \mathrm{d} \Omega=\int_{0}^{2 \pi} \mathrm{d} \phi \int_{-1}^{1} \frac{\mathrm{d} \sigma}{\mathrm{d} \Omega}(\theta) \mathrm{d}(\cos \theta)
$$

Replacing the integral by a summation and $\frac{d \sigma}{d \Omega}\left(\theta_{i}\right)$ by $D_{i}$ gives

$$
\sigma=2 \pi \sum_{i} \bar{D}_{i} \sin \left(\theta_{i}\right)(\Delta \theta)_{i}
$$

This is a mathematical expression of the physical fact that the particle must appear at one, and only one, value of $\theta$. 
Small changes in data $D_{i}$ result in no change in $\sigma$ :

$$
0=\delta \sigma=2 \pi \sum_{i} \delta D_{i} \sin \theta_{i} \Delta \theta_{i}
$$

Multiplying by $\delta D_{j}$ and taking the expectation value give the following relationship for the covariance matrix elements $V_{i j}=\left\langle\delta D_{i} \quad \delta D_{j}\right\rangle$ :

$$
0=\sum_{i} v_{i j} \sin \theta_{i} \Delta \theta_{i}
$$

It is easy to see that the expression

$$
v_{i j}=\left(\Delta D_{i}\right)^{2} \delta_{i j}-\frac{\left(\Delta D_{i}\right)^{2} \sin \theta_{i} \Delta \theta_{i} \Delta \theta_{j} \sin \theta_{j}\left(\Delta D_{i}\right)^{2}}{\sum_{k}\left(\Delta D_{k} \sin \theta_{k} \Delta \theta_{k}\right)^{2}}
$$

satisfies the relationship $(V .5 .5)$, where $\Delta D_{i}$ is the measured uncertainty on $D_{i}$. In Appendix $A$ we demonstrate that this is in fact the only correct form. Note that this matrix is singular and thus has no inverse; leastsquares weighted residuals and $x^{2}$ must therefore not be evaluated here.

\section{Specific Case}

The "experimental data" used here are theoretical points resulting from a GENDA [PE67] fit to natural Calcium angular distribution data [HE82]. An arbitrary 5\% uncertainty $\Delta_{i}$ was assigned to each of the 44 data points $D_{i}$.

The data are listed in Table V.5.1. Starting values for the 21 parameters are given in Table V.5.2. User-supplied subroutines are shown in Table V.5.3. Execution commands are given in Table V.5.4. and output shown in Table V.5.5. No iteration is required for this problem, 
since the function shown in Eq. $(\mathrm{V} .5 .1)$ is linear in the parameters $\mathrm{P}_{\ell}$; nevertheless we have specified one iteration in order to obtain a listing of the theoretical cross section evaluated at the new parameter values.

Table V.5.6. shows the results which would be obtained if the data covariance matrix were naively set equal to

$$
v_{i j}=\left(\Delta D_{i}\right)^{3} \delta_{i j}
$$

Note that the differences between data and theory are more pronounced here, especially at forward angles. 
Table V.5.1. ØRELA PDP-10 File EX5.DAT, Containing Data for Example 5.

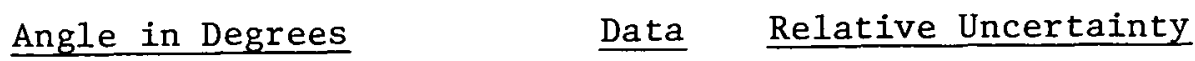
$0.4000 E+02$
$0.0000 \mathrm{E}+00 \quad 0.0000 \mathrm{E}+00 \quad 0.6118 \mathrm{E}+04 \quad 0.5000 \mathrm{E}+01$
$0.4000 E+01 \quad 0.0000 E+00 \quad 0.5665 E+04 \quad 0.5000 E+01$
$\begin{array}{llll}0.8000 E+01 & 0.0000 E+00 & 0.4481 E+04 & 0.5000 E+01\end{array}$
$0.1200 E+02 \quad 0.0000 E+00 \quad 0.2992 E+04 \quad 0.5000 E+01$
$0.1600 E+02 \quad 0.0000 E+00 \quad 0.1651 E+04 \quad 0.5000 E+01$
$0.2000 E+02 \quad 0.0000 E+00 \quad 0.7322 E+03 \quad 0.5000 E+01$
$0.2400 E+02 \quad 0.0000 E+00 \quad 0.2695 E+03 \quad 0.5000 E+01$
$0.2800 E+02 \quad 0.0000 E+00 \quad 0.1280 E+03 \quad 0.5000 E+01$
$0.3200 E+02 \quad 0.0000 E+00 \quad 0.1303 E+03 \quad 0.5000 E+01$
$0.3600 E+02 \quad 0.0000 E+00 \quad 0.1504 E+03 \quad 0.5000 E+01$
$0.4000 \mathrm{E}+02 \quad 0.0000 \mathrm{E}+00 \quad 0.1393 \mathrm{E}+03 \quad 0.5000 \mathrm{E}+01$
$0.4400 E+02 \quad 0.0000 E+00 \quad 0.1019 E+03 \quad 0.5000 E+01$
$0.4800 E+02 \quad 0.0000 E+00 \quad 0.6055 E+02 \quad 0.5000 E+01$
$0.5200 \mathrm{E}+02 \quad 0.0000 \mathrm{E}+00 \quad 0.3128 \mathrm{E}+02 \quad 0.5000 \mathrm{E}+01$
$0.5600 \mathrm{E}+02 \quad 0.0000 \mathrm{E}+00 \quad 0.1723 \mathrm{E}+02 \quad 0.5000 \mathrm{E}+01$
$0.6000 \mathrm{E}+02 \quad 0.0000 \mathrm{E}+00 \quad 0.1328 \mathrm{E}+02 \quad 0.5000 \mathrm{E}+01$
$0.6400 E+02 \quad 0.0000 E+00 \quad 0.1280 E+02 \quad 0.5000 E+01$
$0.6800 \mathrm{E}+02 \quad 0.0000 \mathrm{E}+00 \quad 0.1174 \mathrm{E}+02 \quad 0.5000 \mathrm{E}+01$
$0.7200 \mathrm{E}+02 \quad 0.0000 \mathrm{E}+00 \quad 0.9224 \mathrm{E}+01 \quad 0.5000 \mathrm{E}+01$
$0.7600 \mathrm{E}+02 \quad 0.0000 \mathrm{E}+00 \quad 0.6131 \mathrm{E}+01 \quad 0.5000 \mathrm{E}+01$
$0.8000 \mathrm{E}+02 \quad 0.0000 \mathrm{E}+00 \quad 0.3578 \mathrm{E}+01 \quad 0.5000 \mathrm{E}+01$
$\begin{array}{lllll}0.8400 E+02 & 0.0000 E+00 & 0.2070 E+01 & 0.5000 E+01\end{array}$
$0.8800 \mathrm{E}+02 \quad 0.0000 \mathrm{E}+00 \quad 0.1470 \mathrm{E}+01 \quad 0.5000 \mathrm{E}+01$
$0.9200 E+02 \quad 0.0000 E+00 \quad 0.1346 E+010.5000 E+01$
$0.9600 \mathrm{E}+02 \quad 0.0000 \mathrm{E}+00 \quad 0.1305 \mathrm{E}+01 \quad 0.5000 \mathrm{E}+01$
$0.1000 E+03 \quad 0.0000 E+00 \quad 0.1160 E+01 \quad 0.5000 E+01$
$0.1040 E+03 \quad 0.0000 E+00 \quad 0.9004 E+00 \quad 0.5000 E+01$
$0.1080 \mathrm{E}+03 \quad 0.0000 \mathrm{E}+00 \quad 0.6101 \mathrm{E}+00 \quad 0.5000 \mathrm{E}+01$
$0.1120 E+03 \quad 0.0000 E+00 \quad 0.3723 E+00 \quad 0.5000 E+01$
$0.1160 \mathrm{E}+03 \quad 0.0000 \mathrm{E}+00 \quad 0.2269 \mathrm{E}+00 \quad 0.5000 \mathrm{E}+01$
$\begin{array}{lllll}0.1200 E+03 & 0.0000 E+00 & 0.1672 E+00 & 0.5000 E+01\end{array}$
$0.1240 \mathrm{E}+03 \quad 0.0000 \mathrm{E}+00 \quad 0.1599 \mathrm{E}+00 \quad 0.5000 \mathrm{E}+01$
$\begin{array}{lllll}0.1280 \mathrm{E}+03 & 0.0000 \mathrm{E}+00 & 0.1687 \mathrm{E}+00 & 0.5000 \mathrm{E}+01\end{array}$
$\begin{array}{llll}0.1320 E+03 \quad 0.0000 E+00 & 0.1695 E+00 & 0.5000 E+01\end{array}$
$\begin{array}{lllll}0.1360 E+03 & 0.0000 E+00 & 0.1534 E+00 & 0.5000 E+01\end{array}$
$0.1400 E+03 \quad 0.0000 E+00 \quad 0.1235 E+00 \quad 0.5000 E+01$
$0.1440 \mathrm{E}+03 \quad 0.0000 \mathrm{E}+00 \quad 0.8725 \mathrm{E}-01 \quad 0.5000 \mathrm{E}+01$
$0.1480 \mathrm{E}+03 \quad 0.0000 \mathrm{E}+00 \quad 0.5286 \mathrm{E}-01 \quad 0.5000 \mathrm{E}+01$
$0.1520 \mathrm{E}+03 \quad 0.0000 \mathrm{E}+00 \quad 0.2753 \mathrm{E}-01 \quad 0.5000 \mathrm{E}+01$
$0.1560 E+03 \quad 0.0000 E+00 \quad 0.1780 E-010.5000 E+01$
$0.1600 E+03 \quad 0.0000 E+00 \quad 0.2879 E-01 \quad 0.5000 E+01$
$0.1640 E+03 \quad 0.0000 E+00 \quad 0.6171 E-01 \quad 0.5000 E+01$
$\begin{array}{llll}0.1680 E+03 & 0.0000 E+00 & 0.1112 E+00 & 0.5000 E+01\end{array}$
$\begin{array}{lllll}0.1720 \mathrm{E}+03 & 0.0000 \mathrm{E}+00 & 0.1648 \mathrm{E}+00 & 0.5000 \mathrm{E}+01\end{array}$
$0.1760 \mathrm{E}+03 \quad 0.0000 \mathrm{E}+00 \quad 0.2063 \mathrm{E}+00 \quad 0.5000 \mathrm{E}+01$
$\begin{array}{lllll}0.1800 E+03 & 0.0000 E+00 & 0.2220 E+00 & 0.5000 E+01\end{array}$ 
Table V.5.2. Starting Values for the Parameters for Example 5, Stored in File EX5.PAR.

1300. 1000. 800.600. 400. 200. 150. 100.

90. 80.70 .60 .55 .50 .45 .40 .

35. 30. 25. 20. 18. 15. 10. 8 .

5 . 
Table V.5.3. User-Supplied Subroutines for Example 5, Stored in File EX5.F4.

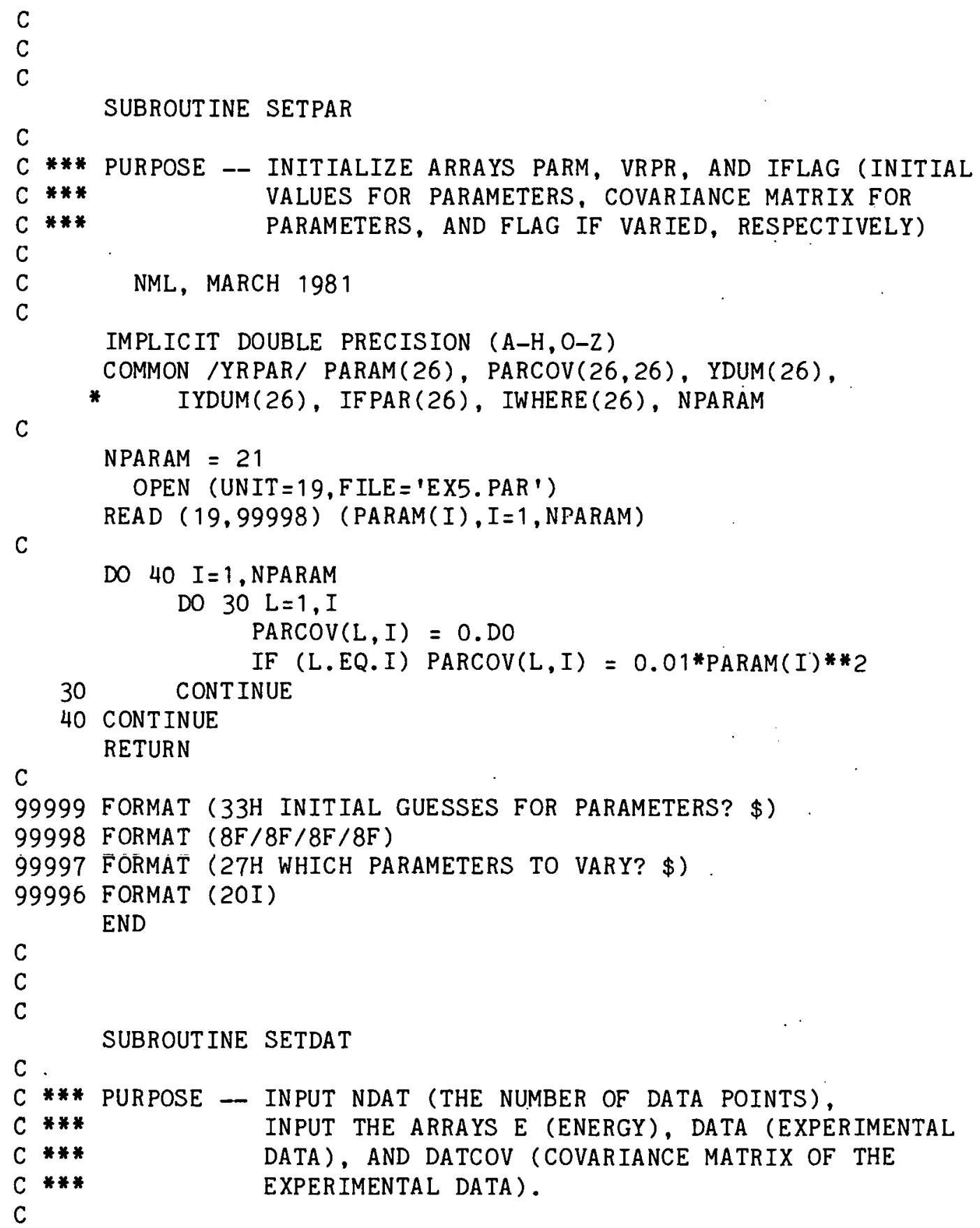


Table V.j.3. (Continued)

$\begin{array}{lll}C & \text { NML, MARCH } 1981\end{array}$

IMPLICIT DOUBLE PRECISION ( $\mathrm{A}-\mathrm{H}, \mathrm{O}-\mathrm{Z}$ )

DOUBLE PRECISION NAME, DBLANK

COMMON /NUMBER/ NDAT, NPAR, ITER, ITMAX, CONVER

COMMON /DAT/E(51), E2(51), DATA(51), VARDAT(1326),

* EN(1326), TH(51), DUM(51), SIG(51)

DIMENSIUN DATCUUV $(5 \%, 3 T)$

EQUIVALENCE (DATCOV $(1,1), \operatorname{VARDAT}(1))$

C

DATA LBLANK /TUH /, PI180/0.017453293DO/

WRITE $(5,99999)$

READ $(5,99998)$ NAME

IF (NAME.EQ.DBLANK) STOP

C

OPEN (UNIT $=24$, FILE $=$ NAME, ACCESS $=$ 'SEQIN $^{\prime}$ )

C

C

NDAT $=44$

C *** INITIALIZE DATA COVARIANCE MATRIX DATCOV

DO $40 I=1$, NDAT

DO $30 \mathrm{~L}=1, \mathrm{I}$

30 CONT INUE

$\operatorname{DACCUV}(L, I)=0.00$

C

40 CONTINUE

C *** READ FILE 24 TO OBTAIN ENERGY, DATA, AND UNCERTAINTIES,

$C * *$ SET COVARIANCE MATRIX

$\operatorname{READ}(24,99)$

99 FORMAT (1X)

SUM $=0.0$

DO $50 I=1$, NDAT

READ (24, 99997) EE, ABCD, D, ERR

$E(I)=E E$

$\operatorname{DATA}(I)=D$

$E R R=.01$

$\operatorname{DATCOV}(I, I)=(E R R * D) * 2$

EEEEE $=(E R R * D * D S I N(E E * P I 180)) * * 2$

$S U M=S U M+E E E E E$

50 CONTINUE

$E 2(I)=(E R R * D) * 2 * D S I N(E E * P I 180)$

CLOSE (UNIT $=24$ ) 
Table V.5.3. (Continued)

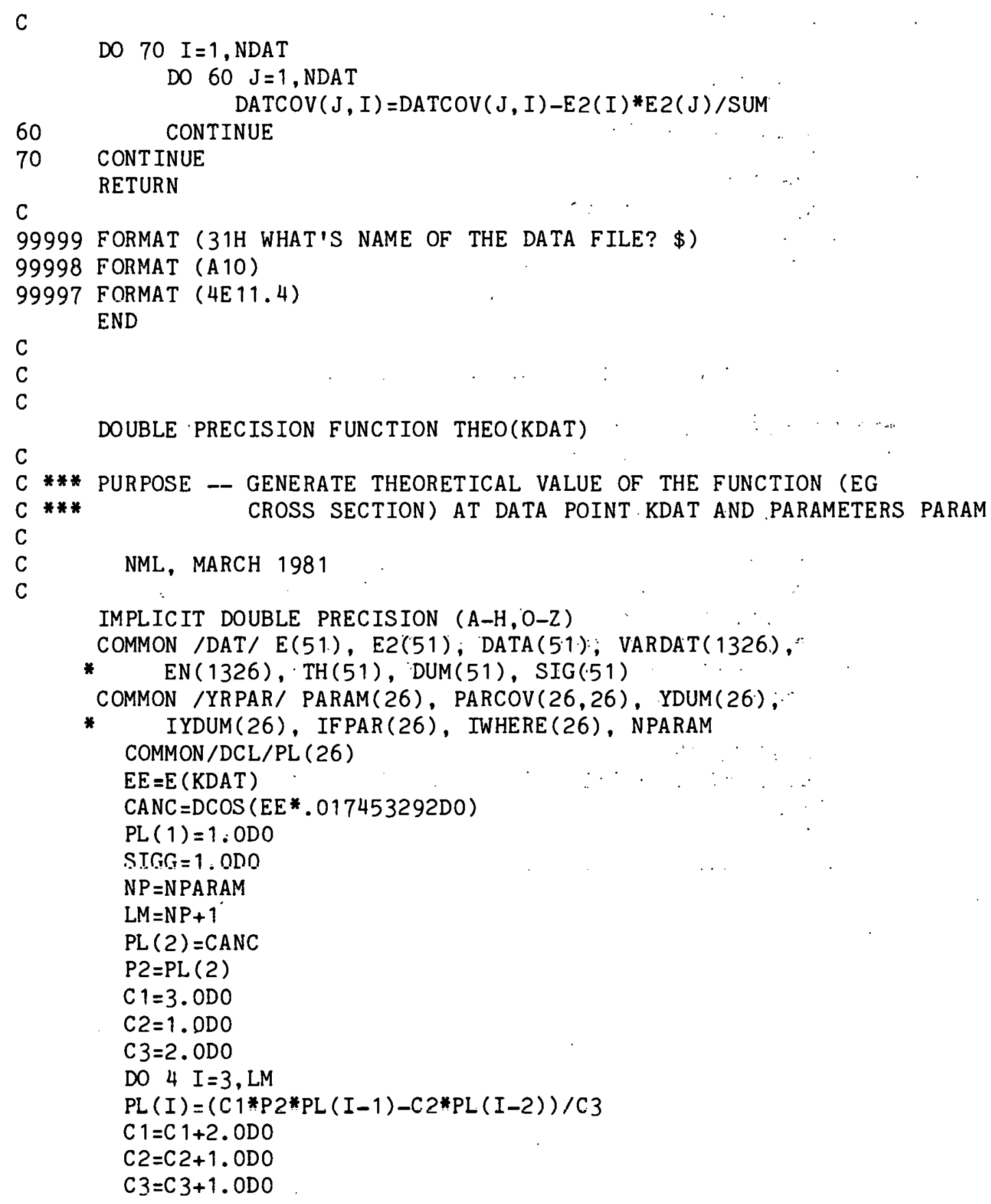


Täble V.5.3. (Continued)

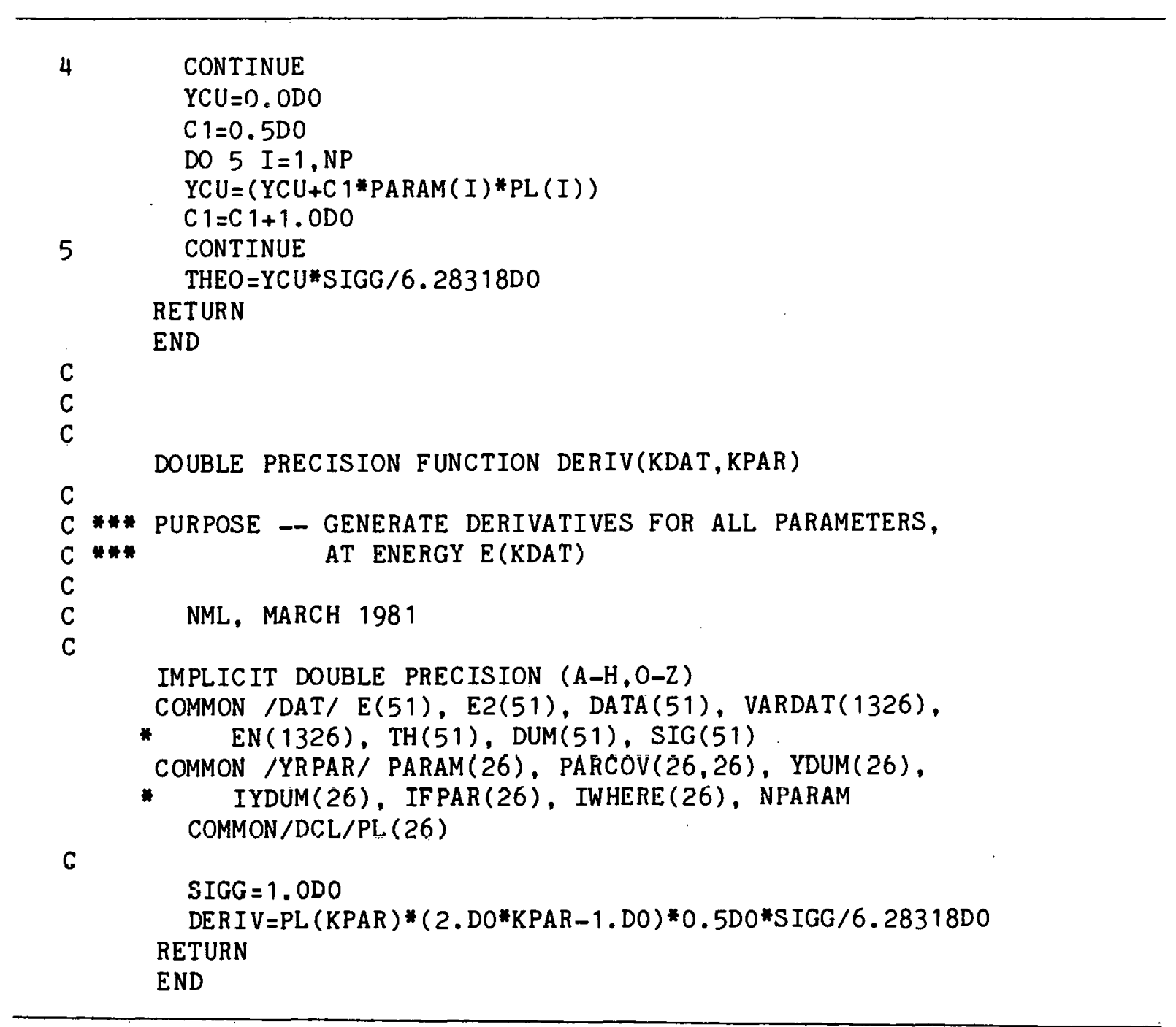


Table V.5.4. Teletype Commands and User Responses to Program Prompts for Example 5 .

.EX BAYES, EX5, SHOW, DPPXX, DO4NML $\downarrow$

HOW MANY ITERATIONS? WHAT IS CONVERGENCE FRACTION? $1,0 . \downarrow$

DO YOU WISH TO USE AUTOMATIC NUMERICAL DERIVATIVES? $\mathbb{N} \downarrow$

WHAT'S NAME OF THE DATA FILE? EX5.DAT $\downarrow$

WHAT 'S NAME OF THE DATA FILE? $\downarrow$

STOP 
Table V.J.5. Output Resulting from the Use of Commands Given in Table V.5.4.

MAXIMUM NUMBER OF ITERATIONS IS 1 CONVERGENCE FACTOR IS 0.000000

******INPUT PARAMETER VALUES

$\begin{array}{rrr} & \text { PARAMETER } & \text { UNCERTA INTY } \\ 1 & 1300.000000 & 130.000000 \\ 2 & 1000.000000 & 100.000000 \\ 3 & 800.000000 & 80.000000 \\ 4 & 600.000000 & 60.000000 \\ 5 & 400.000 n \cap 0 & 40.000000 \\ 6 & 200.000000 & 20.000000 \\ 7 & 150.000000 & 15.000000 \\ 8 & 100.000000 & 10.000000 \\ 9 & 90.000000 & 9.0 n n \cap n 0 \\ 10 & 80.000000 & 8.000000 \\ 11 & 70.000000 & 7.000000 \\ 12 & 60.000000 & 6.000000 \\ 13 & 55.000000 & 5.500000 \\ 14 & 50.000000 & 5.000000 \\ 15 & 45.000000 & 4.500000 \\ 10 & 40.000000 & 4.000000 \\ 17 & 35.000000 & 3.500000 \\ 18 & 30.000000 & 3.000000 \\ 19 & 25.000000 & 2.500000 \\ 20 & 20.000000 & 2.000000 \\ 21 & 18.000000 & 1.800000\end{array}$

INPUT DATA VALUES

$\begin{array}{rrrr} & \text { DATA POINI } & \text { VALUE } & \text { UNCEKTAINIY } \\ 1 & 0.000000 & 6118.000000 & 61.180000 \\ 2 & 4.000000 & 5665.000000 & 52.982656 \\ 3 & 8.000000 & 4481.000000 & 37.167439 \\ 4 & 12.000000 & 2992.000000 & 24.845156 \\ 5 & 16.000000 & 1651.000000 & 15.076195 \\ 6 & 20.000000 & 732.19994 \% & 7.135425 \\ 7 & 24.000000 & 269.500000 & 2.681979 \\ 8 & 28.000000 & 128.000000 & 1.278145 \\ 9 & 32.000000 & 130.299999 & 1.300506 \\ 10 & 36.000000 & 150.400000 & 1.499278 \\ 11 & 40.000000 & 139.299999 & 1.388513 \\ 12 & 44.000000 & 101.900000 & 1.016950 \\ 13 & 48.000000 & 60.550000 & 0.605008 \\ 14 & 52.000000 & 31.280000 & 0.312724\end{array}$


Table V.5.5. (Continued)

\begin{tabular}{rrrr}
\hline & & & \\
15 & 56.000000 & 17.230000 & 0.172286 \\
16 & 60.000000 & 13.280000 & 0.132793 \\
17 & 64.000000 & 12.800000 & 0.127993 \\
18 & 68.000000 & 11.740000 & 0.117394 \\
19 & 72.000000 & 9.224000 & 0.092237 \\
20 & 76.000000 & 6.131000 & 0.061309 \\
21 & 80.000000 & 3.578000 & 0.035780 \\
22 & 84.000000 & 2.070000 & 0.020700 \\
23 & 88.000000 & 1.470000 & 0.014700 \\
24 & 92.000000 & 1.346000 & 0.013460 \\
25 & 96.000000 & 1.305000 & 0.013050 \\
26 & 100.000000 & 1.160000 & 0.011600 \\
27 & 104.000000 & 0.900400 & 0.009004 \\
28 & 108.000000 & 0.610100 & 0.006101 \\
29 & 112.000000 & 0.372300 & 0.003723 \\
30 & 116.000000 & 0.226900 & 0.002269 \\
31 & 120.000000 & 0.167200 & 0.001672 \\
32 & 124.000000 & 0.159900 & 0.001599 \\
33 & 128.000000 & 0.168700 & 0.001687 \\
34 & 132.000000 & 0.169500 & 0.001695 \\
35 & 136.000000 & 0.153400 & 0.001534 \\
36 & 140.000000 & 0.123500 & 0.001235 \\
37 & 144.000000 & 0.087250 & 0.000872 \\
38 & 148.000000 & 0.052860 & 0.000529 \\
39 & 152.000000 & 0.027530 & 0.000275 \\
40 & 156.000000 & 0.017800 & 0.000178 \\
41 & 160.000000 & 0.028790 & 0.000288 \\
42 & 164.000000 & 0.061710 & 0.000617 \\
43 & 168.000000 & 0.111200 & 0.001112 \\
44 & 172.000000 & 0.164800 & 0.001648 \\
& & &
\end{tabular}


Table V.5.5. (Continued)

STD. DEV. CORRELATION

\begin{tabular}{|c|c|c|c|c|c|c|c|c|c|c|c|c|c|c|c|c|c|c|c|c|c|c|c|c|c|}
\hline & 1 & 2 & 3 & 4 & 5 & 6 & 7 & 8 & 9 & 10 & 11 & 12 & 13 & 14 & 15 & 16 & 17 & 18 & 19 & 20 & 21 & 22 & 23 & 24 & 25 \\
\hline $6.118000 D+01$ & 100 & & & & & & & & & & & & & & & & & & & & & & & & \\
\hline $5.298266 \mathrm{D}+01$ & 0 & 100 & & & & & & & & & & & & & & & & & & & & & & & \\
\hline $3.716744 D+01$ & 0 & -25 & 100 & & & & & & & & & & & & & & & & & & & & & & \\
\hline $2.484516 \mathrm{D}+01$ & 0 & -25 & -45 & 100 & & & & & & & & & & & & & & & & & & & & & \\
\hline $1.507620 D+01$ & 0 & -17 & -30 & -30 & 100 & & & & & & & & & & & & & & & & & & & & \\
\hline $7.135425 D+00$ & 0 & -9 & -10 & -15 & -10 & 100 & & & & & & & & & & & & & & & & & & & \\
\hline $2.681979 D+00$ & 0 & -4 & -7 & -7 & -4 & -2 & 100 & & & & & & & & & & & & & & & & & & \\
\hline $1.278145 \mathrm{D}+00$ & 0 & -2 & -4 & -4 & -2 & -1 & -1 & 100 & & & & & & & & & & & & & & & & & \\
\hline $1.300506 \mathrm{D}+00$ & 0 & -2 & -4 & -4 & -3 & -1 & -1 & 0 & 100 & & & & & & & & & & & & & & & & \\
\hline $1.499278 D+00$ & 0 & -3 & -5 & -5 & -4 & -2 & -1 & 0 & 0 & 100 & & & & & & & & & & & & & & & \\
\hline $1.3885130+00$ & 0 & -3 & -5 & -5 & -4 & -2 & -1 & 0 & 0 & -1 & 100 & & & & & & & & & & & & & & \\
\hline $1.016950 \mathrm{D}+00$ & 0 & -2 & -4 & -4 & -3 & -1 & -1 & 0 & 0 & -1 & -1 & 100 & & & & & & & & & & & & & \\
\hline $6.050080 D-01$ & 0 & -2 & -3 & -3 & -2 & -1 & 0 & 0 & 0 & 0 & 0 & 0 & 100 & & & & & & & & & & & & \\
\hline 7238D-01 & 0 & -1 & -1 & -1 & -1 & -1 & 0 & 0 & 0 & 0 & 0 & 0 & 0 & 100 & & & & & & & & & & & \\
\hline $1.722859 D-01$ & 0 & 0 & -1 & -1 & -1 & 0 & 0 & 0 & 0 & 0 & 0 & 0 & 0 & 0 & 100 & & & & & & & & & & \\
\hline $1.327930 \mathrm{D}-01$ & 0 & 0 & -1 & -1 & 0 & 0 & 0 & 0 & 0 & 0 & 0 & 0 & 0 & 0 & $\dot{0}$ & 100 & & & & & & & & & \\
\hline $1.279932 \mathrm{D}-01$ & 0 & 0 & -1 & -1 & 0 & 0 & 0 & 0 & 0 & 0 & 0 & 0 & 0 & 0 & 0 & 0. & 100 & & & & & & & & \\
\hline $1.173944 \mathrm{D}-01$ & 0 & 0 & -1 & -1 & 0 & 0 & 0 & 0 & 0 & 0 & 0 & 0 & 0 & 0 & 0 & 0 & 0 & 100 & & & & & & & \\
\hline $9.223715 \mathrm{D}-02$ & 0 & 0 & -1 & -1 & 0 & 0 & 0 & 0 & 0 & 0 & 0 & 0 & 0 & 0 & 0 & 0 & 0 & 0 & 100 & & & & & & \\
\hline 6. 130913D-02 & 0 & 0 & 0 & 0 & 0 & 0 & 0 & 0 & 0 & 0 & 0 & 0 & 0 & 0 & 0 & 0 & 0 & 0 & 0 & 100 & & & & & \\
\hline D-02 & 0 & 0 & 0 & 0 & 0 & 0 & 0 & 0 & 0 & 0 & 0 & 0 & 0 & 0 & 0 & 0 & 0 & 0 & 0 & 0 & 100 & & & & \\
\hline $196 \mathrm{D}-02$ & 0 & 0 & 0 & $u$ & $u$ & u & ن & u & 0 & 0 & 0 & 0 & 0 & 0 & 0 & 0 & 0 & 0 & 0 & 0 & 0 & 100 & & & \\
\hline $99 \mathrm{D}-02$ & 0 & 0 & 0 & 0 & 0 & 0 & 0 & 0 & 0 & 0 & 0 & 0 & 0 & 0 & 0 & 0 & 0 & 0 & 0 & 0 & 0 & 0 & 100 & & \\
\hline 5999D-02 & 0 & 0 & 0 & 0 & 0 & 0 & 0 & 0 & 0 & 0 & 0 & 0 & 0 & 0 & 0 & 0 & 0 & 0 & 0 & 0 & 0 & 0 & 0 & 100 & \\
\hline $1.304999 \mathrm{D}-02$ & 0 & 0 & 0 & 0 & 0 & 0 & 0 & 0 & 0 & 0 & 0 & 0 & 0 & 0 & 0. & 0 & 0 & 0 & 0 & 0 & 0 & 0 & 0 & 0 & 100 \\
\hline $9 D-02$ & 0 & 0 & 0 & 0 & 0 & 0 & 0 & 0 & 0 & 0 & 0 & 0 & 0 & 0 & 0 & 0 & 0 & 0. & 0 & 0 & 0 & 0 & 0 & 0 & 0 \\
\hline $9.003997 \mathrm{D}-03$ & 0 & 0 & 0 & 0 & 0 & 0 & 0 & 0 & 0 & 0 & 0 & 0 & 0 & 0 & 0 & 0 & 0 & 0 & 0 & 0 & 0 & 0 & 0 & 0 & 0 \\
\hline $9 D-03$ & 0 & 0 & 0 & 0 & 0 & 0 & 0 & 0 & 0 & 0 & 0 & 0 & 0 & 0 & 0 & 0 & 0 & 0 & 0 & 0 & 0 & 0 & 0 & 0 & 0 \\
\hline$D-03$ & 0 & 0 & 0 & 0 & 0 & 0 & 0 & 0 & 0 & 0 & 0 & 0 & 0 & 0 & 0 & 0 & 0 & 0 & 0 & 0 & 0 & 0 & 0 & 0 & 0 \\
\hline $2.269000 \mathrm{D}-03$ & 0 & 0 & 0 & 0 & 0 & 0 & 0 & 0 & 0 & 0 & 0 & 0 & 0 & 0 & 0 & 0 & 0 & 0 & 0 & 0 & 0 & 0 & 0 & 0 & 0 \\
\hline $1.672000 \mathrm{D}-03$ & 0 & 0 & 0 & 0 & 0 & 0 & 0 & 0 & 0 & 0 & 0 & 0 & 0 & 0 & 0 & 0 & 0 & 0 & 0 & 0 & 0 & 0 & 0 & 0 & \\
\hline $1.5990000-03$ & 0 & 0 & 0 & 0 & 0 & 0 & 0 & 0 & 0 & 0 & 0 & 0 & 0 & 0 & 0 & 0 & 0 & 0 & 0 & 0 & 0 & 0 & 0 & 0 & 0 \\
\hline $7000 D-03$ & 0 & 0 & 0 & 0 & 0 & 0 & 0 & 0 & 0 & 0 & 0 & 0 & 0 & $\dot{0}$ & 0 & 0 & 0 & 0 & 0 & 0 & 0 & 0 & 0 & 0 & \\
\hline $1.695000 \mathrm{D}-03$ & 0 & 0 & 0 & 0 & 0 & 0 & 0 & 0 & 0 & 0 & 0 & 0 & 0 & 0 & 0 & 0 & 0 & 0 & 0 & 0 & 0 & 0 & 0 & 0 & 0 \\
\hline $34000 D-03$ & 0 & 0 & 0 & 0 & 0 & 0 & 0 & 0 & 0 & 0 & 0 & 0 & 0 & 0 & 0 & 0 & 0 & 0 & 0 & 0 & 0 & 0 & 0 & 0 & 0 \\
\hline O00D-03 & 0 & 0 & 0 & 0 & 0 & 0 & 0 & 0 & 0 & 0 & 0 & 0 & 0 & 0 & 0 & 0 & 0 & 0 & 0 & 0 & 0 & 0 & 0 & 0 & 0 \\
\hline $50000-04$ & 0 & 0 & 0 & 0 & 0 & 0 & 0 & 0 & 0 & 0 & 0 & 0 & 0 & 0 & 0 & 0 & 0 & 0 & 0 & 0 & 0 & 0 & 0 & 0 & 0 \\
\hline 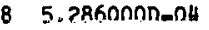 & 0 & 0 & 0 & 0 & 0 & 0 & 0 & 0 & 0 & 0 & 0 & 0 & 0 & 0 & 0 & 0 & 0 & 0 & 0 & 0 & 0 & 0 & 0 & 0 & 0 \\
\hline 10D-04 & 0 & 0 & 0 & 0 & 0 & 0 & 0 & 0 & 0 & 0 & 0 & 0 & 0 & 0 & 0 & 0 & 0 & 0 & 0 & 0 & 0 & 0 & 0 & 0 & 0 \\
\hline 00D-04 & 0 & 0 & 0 & 0 & 0 & 0 & u & 0 & $u$ & 0 & 0 & 0 & u & 0 & 0 & 0 & 0 & $\dot{0}$ & 0 & 0 & 0 & 0 & 0 & 0 & \\
\hline $2.879000 \mathrm{D}-04$ & 0 & 0 & 0 & 0 & 0 & 0 & 0 & 0 & 0 & 0 & 0 & 0 & 0 & 0 & 0 & 0 & 0 & 0 & 0 & 0 & 0 & 0 & 0 & 0 & 0 \\
\hline $6.171000 D-04$ & 0 & 0 & 0 & 0 & 0 & 0 & 0 & 0 & 0 & 0 & 0 & 0 & 0 & 0 & 0 & 0 & 0 & 0 & 0 & 0 & 0 & 0 & 0 & 0 & 0 \\
\hline 2000D-03 & 0 & 0 & 0 & 0 & 0 & 0 & 0 & 0 & 0 & 0 & 0 & 0 & 0 & 0 & 0 & 0 & 0 & 0 & 0 & 0 & 0 & 0 & 0 & 0 & 0 \\
\hline $.648000 \mathrm{D}-03$ & 0 & 0 & 0 & 0 & 0 & 0 & 0 & 0 & 0 & 0 & 0 & 0 & 0 & 0 & 0 & 0 & 0 & 0 & 0 & 0 & 0 & 0 & 0 & 0 & \\
\hline
\end{tabular}

$\begin{array}{lrrrrrrrrrrrrrrrrrrrr}26 & 1.159999 D-02 & 100 & 27 & 28 & 29 & 30 & 31 & 32 & 33 & 34 & 35 & 36 & 37 & 38 & 39 & 40 & 41 & 42 & 43 & 44\end{array}$ 
Table V.5.5. (Continued)

THEORETICAL CALCULATION

\begin{tabular}{rrrr} 
& ANGLE & DATA & \multicolumn{1}{c}{ THEORY } \\
1 & 0.000000 & 6118.000000 & 2989.568980 \\
2 & 4.000000 & 5665.000000 & 2667.003150 \\
3 & 8.000000 & 4481.000000 & 1936.630650 \\
4 & 12.000000 & 2992.000000 & 1269.171320 \\
5 & 16.000000 & 1651.000000 & 928.462798 \\
6 & 20.000000 & 732.199997 & 820.155669 \\
7 & 24.000000 & 269.500000 & 724.424120 \\
8 & 28.000000 & 128.000000 & 563.431033 \\
9 & 32.000000 & 130.299999 & 407.382153 \\
10 & 36.000000 & 150.400000 & 311.634125 \\
11 & 40.000000 & 139.299999 & 245.797290 \\
12 & 44.000000 & 101.900000 & 169.219584 \\
13 & 48.000000 & 60.550000 & 95.186277 \\
14 & 52.000000 & 31.280000 & 53.413273 \\
15 & 56.000000 & 17.230000 & 36.346632 \\
16 & 60.000000 & 13.280000 & 17.327535 \\
17 & 64.000000 & 12.800000 & -3.989127 \\
18 & 68.000000 & 11.740000 & -8.245897 \\
19 & 72.000000 & 9.224000 & 4.390171 \\
20 & 76.000000 & 6.131000 & 12.807627 \\
21 & 80.000000 & 3.578000 & 9.517585 \\
22 & 84.000000 & 2.070000 & 9.250757 \\
23 & 88.000000 & 1.470000 & 19.822928 \\
24 & 92.000000 & 1.346000 & 28.370874 \\
25 & 96.000000 & 1.305000 & 25.136642 \\
26 & 100.000000 & 1.160000 & 20.735484 \\
27 & 104.000000 & 0.900400 & 26.771720 \\
28 & 108.000000 & 0.610100 & 34.961570 \\
29 & 112.000000 & 0.372300 & 31.459558 \\
30 & 116.000000 & 0.226900 & 20.716708 \\
31 & 120.000000 & 0.167200 & 17.087411 \\
32 & 124.000000 & 0.159900 & 19.486326 \\
33 & 128.000000 & 0.168700 & 13.984942 \\
34 & 132.000000 & 0.169500 & -0.169745 \\
35 & 136.000000 & 0.153400 & -7.322895 \\
36 & 140.000000 & 0.123500 & -1.671079 \\
37 & 144.000000 & 0.087250 & 2.752042 \\
38 & 148.000000 & 0.052860 & -2.910797 \\
39 & 152.000000 & 0.027530 & -5.246524 \\
40 & 156.000000 & 0.017800 & 9.094583 \\
41 & 160.000000 & 0.028790 & 28.454175 \\
42 & 164.000000 & 0.061710 & 33.422376 \\
43 & 168.000000 & 0.111200 & 30.304037 \\
44 & 172.000000 & 0.164800 & 43.239372 \\
& & &
\end{tabular}


Table V.5.5. (Continued)

\section{INTERMEDIATE RESULTS}

$\begin{array}{cc}\text { OLD PARAM } & \text { NEW PARAMETERS } \\ 1300.000000 & 1321.849700 \\ 1000.000000 & 1226.239260 \\ 800.000000 & 1078.113730 \\ 600.000000 & 921.247207 \\ 400.000000 & 779.398097 \\ 200.000000 & 658.724348 \\ 150.000000 & 556.748930 \\ 100.000000 & 467.775757 \\ 90.000000 & 386.392693 \\ 80.000000 & 308.638560 \\ 70.000000 & 233.219483 \\ 60.000000 & 161.811183 \\ 55.000000 & 100.224253 \\ 50.000000 & 54.079274 \\ 45.000000 & 24.740608 \\ 40.000000 & 9.029796 \\ 35.000000 & 2.144524 \\ 30.000000 & -0.079910 \\ 25.000000 & -0.379305 \\ 20.000000 & -0.185724 \\ 18.000000 & -0.038155\end{array}$

THEORETICAL CALCULATION

\begin{tabular}{rrr} 
ANGLE & \multicolumn{1}{c}{ DATA } & \multicolumn{1}{c}{ THEORY } \\
0.000000 & 6118.000000 & 5683.096230 \\
4.000000 & 5665.000000 & 5298.620450 \\
8.000000 & 4481.000000 & 4277.620880 \\
12.000000 & 2992.000000 & 2953.220210 \\
16.000000 & 1651.000000 & 1704.105300 \\
20.000000 & 732.199997 & 796.223274 \\
24.000000 & 269.500000 & 303.118916 \\
28.000000 & 128.000000 & 134.635478 \\
32.000000 & 130.299999 & 129.051935 \\
36.000000 & 150.400000 & 152.883642 \\
40.000000 & 139.299999 & 144.937853 \\
44.000000 & 101.900000 & 106.138509 \\
48.000000 & 60.550000 & 61.881116 \\
52.000000 & 31.280000 & 31.156701 \\
56.000000 & 17.230000 & 17.167042 \\
60.000000 & 13.280000 & 13.486200 \\
64.000000 & 12.800000 & 12.919632 \\
68.000000 & 11.740000 & 11.692422 \\
72.000000 & 9.224000 & 9.169609 \\
76.000000 & 6.131000 & 6.154340
\end{tabular}


Table V.5.5. (Continued)

$\begin{array}{rrrr}21 & 80.000000 & 3.578000 & 3.614149 \\ 22 & 84.000000 & 2.070000 & 2.070820 \\ 23 & 88.000000 & 1.470000 & 1.459918 \\ 24 & 92.000000 & 1.346000 & 1.350166 \\ 25 & 96.000000 & 1.305000 & 1.314820 \\ 26 & 100.000000 & 1.160000 & 1.158798 \\ 27 & 104.000000 & 0.900400 & 0.894858 \\ 28 & 108.000000 & 0.610100 & 0.609327 \\ 29 & 112.000000 & 0.372300 & 0.374506 \\ 30 & 116.000000 & 0.226900 & 0.227078 \\ 31 & 120.000000 & 0.167200 & 0.166276 \\ 32 & 124.000000 & 0.159900 & 0.160360 \\ 33 & 128.000000 & 0.168700 & 0.169465 \\ 34 & 132.000000 & 0.169500 & 0.168931 \\ 35 & 136.000000 & 0.153400 & 0.152752 \\ 36 & 140.000000 & 0.123500 & 0.123735 \\ 37 & 144.000000 & 0.087250 & 0.087666 \\ 38 & 148.000000 & 0.052860 & 0.052764 \\ 39 & 152.000000 & 0.027530 & 0.027439 \\ 40 & 156.000000 & 0.017800 & 0.017875 \\ 41 & 160.000000 & 0.028790 & 0.028649 \\ 42 & 164.000000 & 0.061710 & 0.061781 \\ 43 & 168.000000 & 0.111200 & 0.111780 \\ 44 & 172.000000 & 0.164800 & 0.164213\end{array}$

******* NEW VALUES FOR PARAMETERS

\begin{tabular}{rrrr} 
& POLD & \multicolumn{1}{c}{ PNEW } & UNCERTAINTY \\
1 & 1300.000000 & 1321.849700 & 0.047574 \\
2 & 1000.000000 & 1226.239260 & 0.204550 \\
3 & 800.000000 & 1078.113730 & 0.475384 \\
4 & 600.000000 & 921.247207 & 0.745865 \\
5 & 400.000000 & 779.398097 & 0.944152 \\
6 & 200.000000 & 658.724348 & 1.046241 \\
7 & 150.000000 & 556.748930 & 1.073299 \\
8 & 100.000000 & 467.775757 & 1.069676 \\
9 & 90.000000 & 386.392693 & 1.066781 \\
10 & 80.000000 & 308.638560 & 1.065662 \\
11 & 70.000000 & 233.219483 & 1.051189 \\
12 & 60.000000 & 161.841183 & 1.009715 \\
13 & 55.000000 & 100.224253 & 0.935891 \\
14 & 50.000000 & 54.079274 & 0.830810 \\
15 & 45.000000 & 24.740608 & 0.699623 \\
16 & 40.000000 & 9.029196 & 0.550392 \\
17 & 35.000000 & 2.144524 & 0.394854 \\
18 & 30.000000 & -0.079910 & 0.248038 \\
19 & 25.000000 & -0.379305 & 0.127735 \\
20 & 20.000000 & -0.185724 & 0.047709 \\
21 & 18.000000 & -0.038155 & 0.009775
\end{tabular}


Table V.5.5. (Continued)

STD. DEV. CORRELATION

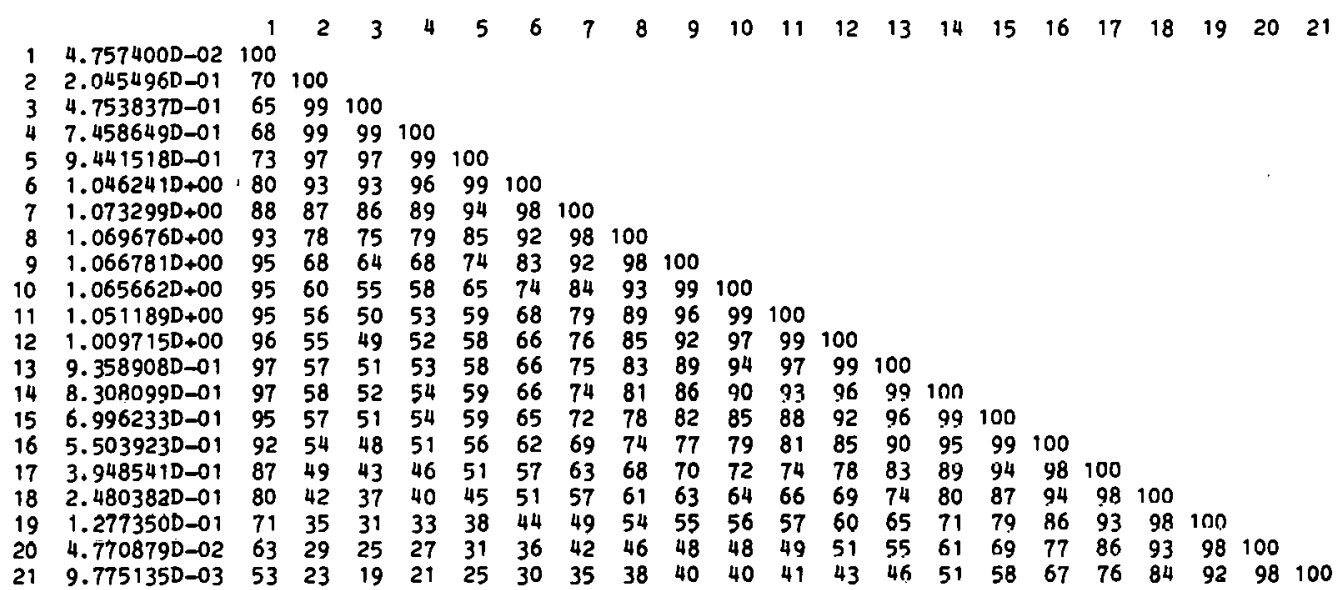


Table V.5.6. Results Which are Obtained for Example 5 by Assuming That the Data Covariance Matrix is Diagonal.

MAXIMUM NUMBER OF ITERATIONS IS 1

CONVERGENCE FACTOR IS 0.000000

******INPUT PARAMETER VALUES

$\begin{array}{rrr} & \text { PARAMETER } & \text { UNCERTA INTY } \\ 1 & 1300.000000 & 130.000000 \\ 2 & 1000.000000 & 100.000000 \\ 3 & 800.000000 & 80.000000 \\ 4 & 600.000000 & 60.000000 \\ 5 & 400.000000 & 40.000000 \\ 6 & 200.000000 & 20.000000 \\ 7 & 150.000000 & 15.000000 \\ 8 & 100.000000 & 10.000000 \\ 9 & 90.000000 & 9.000000 \\ 10 & 80.000000 & 8.000000 \\ 11 & 70.000000 & 7.000000 \\ 12 & 60.000000 & 6.000000 \\ 13 & 55.000000 & 5.500000 \\ 14 & 50.000000 & 5.000000 \\ 15 & 45.000000 & 4.500000 \\ 16 & 40.000000 & 4.000000 \\ 17 & 35.000000 & 3.500000 \\ 18 & 30.000000 & 3.000000 \\ 19 & 25.000000 & 2.500000 \\ 20 & 20.000000 & 2.000000 \\ 21 & 18.000000 & 1.800,000\end{array}$

****** INPUT DATA VALUES

$\begin{array}{rrrr} & \text { DATA POINT } & \text { VALUE } & \text { UNCERTAINTY } \\ 1 & 0.000000 & 6118.000000 & 61.180000 \\ 2 & 4.000000 & 5665.000000 & 56.650000 \\ 3 & 8.000000 & 4481.000000 & 44.810000 \\ 4 & 12.000000 & 2992.000000 & 29.920000 \\ 5 & 16.000000 & 1651.000000 & 16.510000 \\ 6 & 20.000000 & 732.199997 & 7.322000 \\ 7 & 24.000000 & 269.500000 & 2.695000 \\ 8 & 28.000000 & 128.000000 & 1.280000 \\ 9 & 32.000000 & 130.299999 & 1.303000 \\ 10 & 36.000000 & 150.400000 & 1.504000 \\ 11 & 40.000000 & 139.299999 & 1.393000 \\ 12 & 44.000000 & 101.900000 & 1.019000 \\ 13 & 48.000000 & 60.550000 & 0.605500 \\ 14 & 52.000000 & 31.280000 & 0.312800\end{array}$


Table V.5.6. (Continued)

$\begin{array}{rrrr}15 & 56.000000 & 17.230000 & 0.172300 \\ 16 & 60.000000 & 13.280000 & 0.132800 \\ 17 & 64.000000 & 12.800000 & 0.128000 \\ 18 & 68.000000 & 11.740000 & 0.117400 \\ 19 & 72.000000 & 9.224000 & 0.092240 \\ 20 & 76.000000 & 6.131000 & 0.061310 \\ 21 & 80.000000 & 3.578000 & 0.035780 \\ 22 & 84.000000 & 2.070000 & 0.020700 \\ 23 & 88.000000 & 1.470000 & 0.014700 \\ 24 & 92.000000 & 1.346000 & 0.013460 \\ 25 & 96.000000 & 1.305000 & 0.013050 \\ 26 & 100.000000 & 1.160000 & 0.011600 \\ 21 & 104.000000 & 0.900400 & 0.009004 \\ 28 & 108.000000 & 0.610100 & 0.006101 \\ 29 & 112.000000 & 0.372300 & 0.003723 \\ 30 & 116.000000 & 0.226900 & 0.002269 \\ 31 & 120.000000 & 0.167200 & 0.001672 \\ 32 & 124.000000 & 0.159900 & 0.001599 \\ 33 & 128.000000 & 0.168700 & 0.001687 \\ 34 & 132.000000 & 0.169500 & 0.001695 \\ 35 & 136.000000 & 0.153400 & 0.001534 \\ 36 & 140.000000 & 0.123500 & 0.001235 \\ 37 & 144.000000 & 0.087250 & 0.000872 \\ 38 & 148.000000 & 0.052860 & 0.000524 \\ 39 & 152.000000 & 0.027530 & 0.000275 \\ 40 & 156.000000 & 0.01 .7800 & 0.000178 \\ 41 & 160.000000 & 0.028790 & 0.000288 \\ 42 & 164.000000 & 0.061710 & 0.000617 \\ 43 & 168.000000 & 0.111200 & 0.001112 \\ 44 & 172.000000 & 0.164800 & 0.001648\end{array}$


Table V.5.6. (Continued)

THEORETICAL CALCULATION

\begin{tabular}{crr} 
ANGLE & \multicolumn{1}{c}{ DATA } & \multicolumn{1}{c}{ THEORY } \\
0.000000 & 6118.000000 & 2989.568980 \\
4.000000 & 5665.000000 & 2667.003150 \\
8.000000 & 4481.000000 & 1936.630650 \\
12.000000 & 2992.000000 & 1269.171320 \\
16.000000 & 1651.000000 & 928.462798 \\
20.000000 & 732.199997 & 820.155669 \\
24.000000 & 269.500000 & 724.424120 \\
28.000000 & 128.000000 & 563.431033 \\
32.000000 & 130.299999 & 407.382153 \\
36.000000 & 150.400000 & 311.634125 \\
40.000000 & 139.299999 & 245.797290 \\
44.000000 & 101.900000 & 169.219584 \\
48.000000 & 60.550000 & 95.186277 \\
52.000000 & 31.280000 & 53.413273 \\
56.000000 & 17.230000 & 36.346632 \\
60.000000 & 13.280000 & 17.327535 \\
64.000000 & 12.800000 & -3.989127 \\
68.000000 & 11.740000 & -8.245897 \\
72.000000 & 9.224000 & 4.390171 \\
76.000000 & 6.131000 & 12.807627 \\
80.000000 & 3.578000 & 9.517585 \\
84.000000 & 2.070000 & 9.250757 \\
88.000000 & 1.470000 & 19.822928 \\
92.000000 & 1.346000 & 28.370874 \\
96.000000 & 1.305000 & 25.136642 \\
00.000000 & 1.160000 & 20.735484 \\
104.000000 & 0.900400 & 26.771720 \\
08.000000 & 0.610100 & 34.961570 \\
12.000000 & 0.372300 & 31.459558 \\
16.000000 & 0.226900 & 20.716708 \\
20.000000 & 0.167200 & 17.087411 \\
24.000000 & 0.159900 & 19.486326 \\
28.000000 & 0.168700 & 13.984942 \\
32.000000 & 0.169500 & -0.169745 \\
36.000000 & 0.153400 & -7.322895 \\
110.000000 & 0.123500 & -1.671079 \\
44.000000 & 0.087250 & 2.752042 \\
48.000000 & 0.052860 & -2.910797 \\
52.000000 & 0.027530 & -5.246524 \\
56.000000 & 0.017800 & 9.094583 \\
60.000000 & 0.028790 & 28.454175 \\
64.000000 & 0.061710 & 33.422376 \\
68.000000 & 0.111200 & 30.304037 \\
72.000000 & 0.164800 & 43.239372
\end{tabular}


Table V.5.6. (Continued)

\begin{tabular}{rcc} 
***** & INTERMEDIATE & \multicolumn{1}{l}{ RESULTS } \\
& OLD PARAM & NEW PARAMETERS \\
1 & 1300.000000 & 1198.064340 \\
2 & 1000.000000 & 1106.591010 \\
3 & 800.000000 & 966.103235 \\
4 & 600.000000 & 819.332743 \\
5 & 400.000000 & 688.923587 \\
6 & 200.000000 & 580.115689 \\
7 & 150.000000 & 489.838187 \\
8 & 100.000000 & 412.102746 \\
9 & 90.000000 & 341.389800 \\
10 & 80.000000 & 273.657363 \\
11 & 70.000000 & 207.444345 \\
12 & 60.000000 & 144.181169 \\
13 & 55.000000 & 89.285390 \\
14 & 50.000000 & 48.247832 \\
15 & 45.000000 & 22.360252 \\
16 & 40.000000 & 8.612934 \\
17 & 35.000000 & 2.551308 \\
18 & 30.000000 & 0.442247 \\
19 & 25.000000 & -0.042787 \\
20 & 20.000000 & -0.053278 \\
21 & 18.000000 & -0.012243
\end{tabular}


Table V.5.6. (Continued)

THEORETICAL CALCULATION

\begin{tabular}{crr} 
ANGLE & \multicolumn{1}{c}{ DATA } & \multicolumn{1}{c}{ THEORY } \\
0.000000 & 6118.000000 & 5048.088970 \\
4.000000 & 5665.000000 & 4705.075650 \\
8.000000 & 4481.000000 & 3795.650560 \\
12.000000 & 2992.000000 & 2619.493660 \\
16.000000 & 1651.000000 & 1514.483990 \\
20.000000 & 732.199997 & 714.579119 \\
24.000000 & 269.500000 & 281.777897 \\
28.000000 & 128.000000 & 133.345951 \\
32.000000 & 130.299999 & 127.607557 \\
36.000000 & 150.400000 & 147.437007 \\
40.000000 & 139.299999 & 139.059753 \\
44.000000 & 101.900000 & 102.794300 \\
48.000000 & 60.550000 & 60.973860 \\
52.000000 & 31.280000 & 31.161281 \\
56.000000 & 17.230000 & 17.113929 \\
60.000000 & 13.280000 & 13.326732 \\
64.000000 & 12.800000 & 12.856083 \\
68.000000 & 11.740000 & 11.723842 \\
72.000000 & 9.224000 & 9.183613 \\
76.000000 & 6.131000 & 6.124223 \\
80.000000 & 3.578000 & 3.589190 \\
84.000000 & 2.070000 & 2.072684 \\
88.000000 & 1.470000 & 1.466087 \\
92.000000 & 1.346000 & 1.345410 \\
96.000000 & 1.305000 & 1.308775 \\
100.000000 & 1.160000 & 1.160301 \\
104.000000 & 0.900400 & 0.898703 \\
108.000000 & 0.610100 & 0.609401 \\
12.000000 & 0.372300 & 0.372860 \\
116.000000 & 0.226900 & 0.227087 \\
10.000000 & 0.167200 & 0.166911 \\
124.000000 & 0.159900 & 0.159955 \\
28.000000 & 0.168700 & 0.168979 \\
32.000000 & 0.169500 & 0.169360 \\
36.000000 & 0.153400 & 0.153223 \\
40.000000 & 0.123500 & 0.123514 \\
44.000000 & 0.087250 & 0.087373 \\
48.000000 & 0.057860 & 0.052847 \\
52.000000 & 0.027530 & 0.027501 \\
56.000000 & 0.017800 & 0.017821 \\
60.000000 & 0.028790 & 0.028754 \\
64.000000 & 0.061710 & 0.061725 \\
68.000000 & 0.111200 & 0.111349 \\
172.000000 & 0.164800 & 0.164654
\end{tabular}


Table V.5.6. (Cöntinued)

NEW VALUES FOR PARAMETERS

\begin{tabular}{rrrr} 
& POLD & \multicolumn{1}{c}{ PNEW } & UNCERTAINTY \\
1 & 1300.000000 & 1198.064340 & 3.954102 \\
2 & 1000.000000 & 1106.591010 & 3.827143 \\
3 & 800.000000 & 966.103235 & 3.609161 \\
4 & 600.000000 & 819.332743 & 3.339596 \\
5 & 400.000000 & 688.923587 & 3.040162 \\
6 & 200.000000 & 580.115689 & 2.720091 \\
7 & 150.000000 & 489.838187 & 2.391558 \\
8 & 100.000000 & 412.102746 & 2.075179 \\
9 & 90.000000 & 341.389800 & 1.790038 \\
10 & 80.000000 & 273.657363 & 1.544047 \\
11 & 70.000000 & 207.444345 & 1.335212 \\
12 & 60.000000 & 144.181169 & 1.156593 \\
13 & 55.000000 & 89.285390 & 0.998984 \\
14 & 50.000000 & 48.247832 & 0.851433 \\
15 & 45.000000 & 22.360252 & 0.703742 \\
16 & 40.000000 & 8.612934 & 0.550553 \\
17 & 35.000000 & 2.551308 & 0.395068 \\
18 & 30.000000 & 0.442247 & 0.248598 \\
19 & 25.000000 & -0.042787 & 0.128186 \\
20 & 20.000000 & -0.053278 & 0.047896 \\
21 & 18.000000 & -0.012243 & 0.009810
\end{tabular}

STR. DEV. SORRELETION

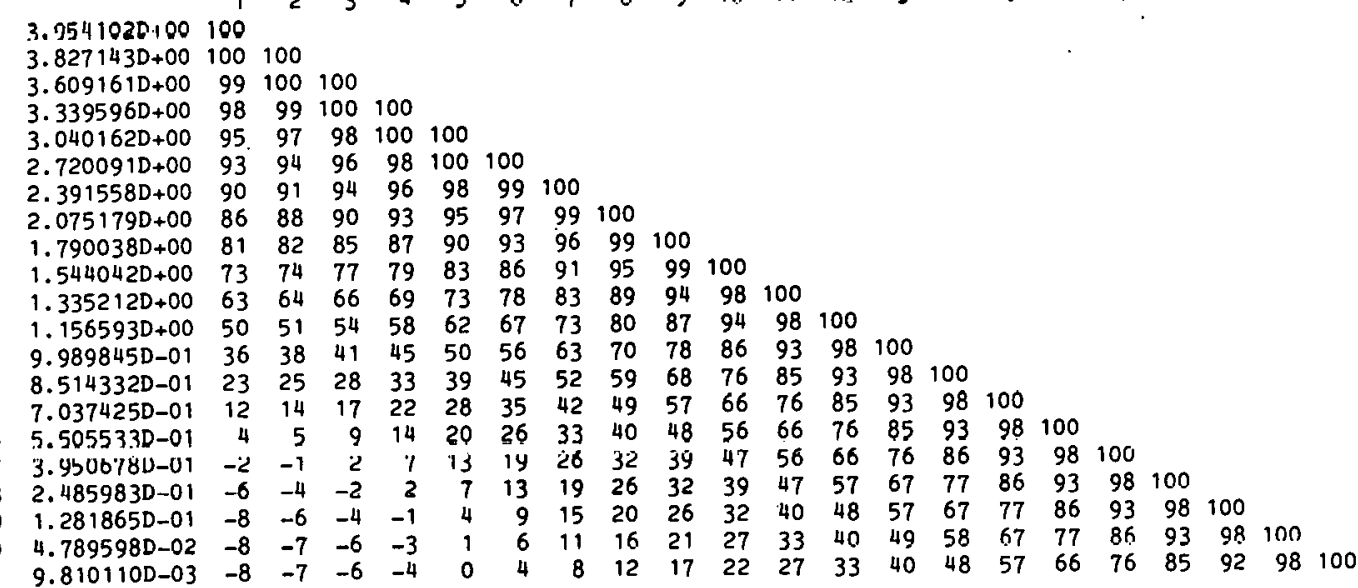




\section{THE COMPANION CODE LEAST}

For the benefit of users more familiar with least squares than with Bayes' method, a companion program LEAST has been developed to facilitate direct comparison of the two methods. LEAST differs from BAYES in two respects only: (1) Updated parameter values are obtained via solution of the least-squares equations (Eqs. (A30) and (A32)) rather than via Bayes' equations. (2) Sequential analyses of two or more data sets are not accepted, since every least-squares analysis assumes that there exists no prior information about the values of the parameters.

LEAST was designed to be totally compatible with BAYES, so that usersupplied subroutines and input for BAYES are correct for LEAST. Because input parameter covariance matrices are not required for least-squares analyses, they need not be provided in LEAST; if provided, they will be ignored.

Data covariance matrices, however, are required for least-squares analyses and must be provided. Off-diagonal elements are permitted in LEAST, unlike many least-squares solvers (e.g. LSFODF [WH79]; see also [PE80]). Sophisticated searching techniques are not employed in LEAST.

The examples from the previous section are reconsidered here, and those analyses which do not require the sequential feature of Bayes' equations and which do not involve singular data covariance matrices are repeated using least-squares. In all cases the user-supplied FøRTRAN and teletype commands and responses are identical to what is given in Section $V$, with the obvious substitution of LEAST for BAYES in the teletype commands, and omission of the request for a new data file. Only the output is shown here, in Tables VI. 1 through VI. 6. 
In most cases results from the least-squares analysis agree to within four or more significant digits with results obtained via Bayes' method. This is to be expected, since the input parameter uncertainties were set very large, in which limit Bayes' equations are equivalent to the leastsquares equations. The one notable exception is example 3, solution method 2 (Tables V.3.7 and VI.4), for which the agreement is no better than one significant digit. For the BAYES analysis, the prior information indicates that the input uncertainty on parameter number 4 is quite small; repeating the BAYES analysis with this uncertainty increased to 100.0 (i.e., assuming there is no prior information on that parameter) gives results which agree with those obtained from LEAST to three significant digits.

A FØRTRAN listing of the routines unique to LEAST (i.e., not shared by BAYES) is given in Appendix D. The code ZLEAST (not listed here) incorporates dynamic allocation of array storage in the same manner as ZBAYES (see Section IV.6). 
Table VI.1. Output from Least-Squares Analysis of Data Given in Example 1. (Compare with Table V.1.4.)

SOLVING LEAST SQUARES EQUATIONS. MAXIMUM NUMBER OF ITERATIONS IS 5

CON VERGENCE FACTOR IS 0.001000

***** LEAST-SQUARES WEIGHTED RESIDUALS AT FORMER VALUES OF PARAMETERS

ENERGY RESIDUAL

( 1) 10.0000

2) 11.0000

3) 12.0000

4) 13.0000

5) 14.0000

6) 15.0000

7) 16.0000

8) 17.0000

9) 18.0000

(10) 19.0000

(11) 20.0000

( 12) 21.0000
$1.68663 \mathrm{D}+00$

2. $55703 \mathrm{D}+00$

3. $46260 \mathrm{D}+00$

4. $32619 D+00$

$5.07585 \mathrm{D}+00$

$5.65895 \mathrm{D}+00$

$6.04957 D+00$

$6.24814 D+00$

$6.27507 \mathrm{D}+00$

$6.16229 D+00$

$5.94530 D+00$

$5.65768 \mathrm{D}+00$

\section{ENERGY}

( 13) 22.0000

( 14) 23.0000

( 15$) 24.0000$

(16) 25.0000

( 17) 26.0000

(18) 27.0000

( 19) 28.0000

( 20) 29.0000

( 21) 30.0000
RESIDUAL

$5.32793 \mathrm{D}+00$

4. $97849 \mathrm{D}+00$

4. $62581 \mathrm{D}+00$

4. $28129 \mathrm{D}+00$

3. $95227 \mathrm{D}+00$

3. $64301 \mathrm{D}+00$

3. $35564 \mathrm{D}+00$

3. $09076 \mathrm{D}+00$

2. $84799 \mathrm{D}+00$

INTERMEDIATE RESULTS

$\begin{array}{ccc} & \text { OLD PARAM } & \text { NEW PARAMETERS } \\ 1 & 1.000000 & 1.050000 \\ 2 & -25.000000 & -25.200000 \\ 3 & 300.000000 & 296.000001\end{array}$

***** LEAST-SQUARES WEIGHTED RESIDUALS AT FORMER VALUES OF PARAMETERS

ENERGY RESIDUAL

( 1) $10.0000-1.05414 D-01$

(2) $11.0000-1.31102 D-01$

(3) $12.0000-1.55817 \mathrm{D}-01$

(4) $13.0000-1.77458 \mathrm{D}-01$

( 5) $14.0000-1.94310 D-01$

(6) $15.0000-2.05365 \mathrm{D}-01$

( 7) $16.0000-2.10420 \mathrm{D}-01$

( 8) $17.0000-2.09966 \mathrm{D}-01$

( 9) $18.0000-2.04952 \mathrm{D}-01$

( 10) $19.0000-1.96518 \mathrm{D}-01$

( 11$) 20.0000-1.85791 \mathrm{D}-01$

( 12) $21.0000=1.73749 \mathrm{D}-01$

\section{ENERGY RESIDUAL}

( 13) $22.0000-1.61170 \mathrm{D}-01$

( 14) $23.0000-1.48624 \mathrm{D}-01$

( 15) $24.0000-1.36499 \mathrm{D}=01$

( 16) $25.0000-1.25038 D-01$

( 17$) 26.0000-1.14372 \mathrm{D}-01$

( 18) $27.0000-1.04557 \mathrm{D}-01$

( 19$) 28.0000-9.55968 \mathrm{D}-02$

( 20) $29.0000-8.74606 \mathrm{D}-\mathrm{C} 2$

( 21) $30.0000-8.00997 D-02$ 
Table VI.1. (Continued)

\section{INTERMEDIATE RESULTS}

$\begin{array}{ccc} & \text { OLD PARAM } & \text { NEW PARAMETERS } \\ 1 & 1.000000 & 1.048810 \\ 2 & -25.000000 & -25.200000 \\ 3 & 300.000000 & 296.000001\end{array}$

***** LEAST-SQUARES WEIGHTED RESIDUALS AT FORMER VALUES OF PARAMETERS

ENERGY RESIDUAL

( 1) $10.0000-5.96750 \mathrm{D}-05$

(2) $11.0000-7.43780 D-05$

(3) $12.0000-8.82044 D-05$

(4) $13.0000-1.00781 D-04$

( 5) $14.0000-1.10312 \mathrm{D}-04$

( 6) $15.0000-1.16280 D-04$

( 7) $16.0000-1.19279 D-04$

( 8) $17.0000-1.18910 \mathrm{D}-04$

( 9) $18.0000-1.16275 \mathrm{D}-04$

( 10) $19.0000-1.11483 D-04$

( 11 ) $20.0000-1.05250 \mathrm{D}-04$

( 12) $21.0000-9.84983 D-05$
ENERGY RESIDUAL

( 13) $22.0000-9.13200 \mathrm{D}-05$

(14) $23.0000-8.43045 \mathrm{D}-015$

( 15) $24.0000-7.74271 \mathrm{D}-05$

( 16) $25.0000-7.08651 \mathrm{D}-05$

( 17) $26.0000-6.47221 \mathrm{D}-05$

( 18) $27.0000-5.92667 \mathrm{D}-05$

(19) $28.0000-5.42286 \mathrm{D}-05$

( 20) $29.0000-4.96142 \mathrm{D}=05$

( 21) $30.0000-4.54124 \mathrm{D}-05$

******* NEW VALUES FOR PARAMETERS

$\begin{array}{cccr} & \text { POLD } & \text { PNEW } & \text { UNCERTAINTY } \\ 1 & 1.000000 & 1.048809 & 0.008328 \\ 2 & -25.000000 & -25.200000 & 0.638696 \\ 3 & 300.000000 & 296.000001 & 5.470518\end{array}$

STD. DEV. CORRELATION

$\begin{array}{rrrcc}1 & 8.327929 D-03 & 100 & 2 & 3 \\ 2 & 6.386963 \mathrm{D}-01 & -99 & 100 \\ 3 & 5.470518 D+00 & 96 & -99 \cdot & 100\end{array}$


Table VI.2. Output from Least-Squares Analysis of Combired Data Set for Example 2. (Compare with Table V.2.7.)

SOLVING LEAST SQUARES EQUATIONS.

MAXIMUM NUMBER OF ITERATIONS IS 5

CONVERGENCE FACTOR IS 0.001000

***** INTERMEDIATE RESULTS

$\begin{array}{lll} & \text { OLD PARAM } & \text { NEW PARAMETERS } \\ 1 & 10.000000 & 10.120099 \\ 2 & 12.000000 & 11.525184 \\ 3 & 17.000000 & 16.475995\end{array}$

******* NEW VALUES FOR PARAMETERS

$\begin{array}{lccr} & \text { POLD } & \text { PNEW } & \text { UNCERTAINTY } \\ 1 & 10.000000 & 10.123076 & 0.707745 \\ 2 & 12.000000 & 11.525885 & 0.184360 \\ 3 & 17.000000 & 16.479823 & 3.053504\end{array}$

STD. DEV. CORRELATION

$\begin{array}{rrrrr} & & 1 & 2 & 3 \\ 2 & 7.077446 D-01 & 100 & & \\ 3 & 1.843599 D-01 & 13 & 100 & \\ 3 & 3.053504 D+00 & 10 & 13 & 100\end{array}$


Table VI.3. Output from Least-Squares Analysis of Data Set for Example 3, First Method of Solution. (Compare with lable v.3.4.)

SOLVING LEAST SQUARES EQUATIONS.

MAXIMUM NUMBER OF ITERATIONS IS 5

CONVERGENCE FACTOR IS 0.001000

***** INTERMEDIATE RESULTS

$\begin{array}{lll} & \text { OLD PARAM } & \text { NEW PARAMETERS } \\ 1 & 80.000000 & 76.810304 \\ 2 & 50.000000 & 51.298677 \\ 3 & 10.000000 & 12.669581\end{array}$

***** INTERMEDIATE RESULTS

$\begin{array}{lll} & \text { OLD PARAM } & \text { NEW PARAMETERS } \\ 1 & 80.000000 & 82.379465 \\ 2 & 50.000000 & 51.495605 \\ 3 & 10.000000 & 13.817789\end{array}$

***** INTERMEDIATE RESULTS

$\begin{array}{lll} & \text { OLD PARAM } & \text { NFW PARAMETERS } \\ 1 & 80.000000 & 83.037786 \\ 2 & 50.000000 & 51.481371 \\ 3 & 10.000000 & 13.914404\end{array}$

\#\#H\#\#\#\# NEW VALŨE'S FUK YAKAME"I'ERS

$\begin{array}{lccr} & \text { POLD } & \text { PNEW } & \text { UNCERTAINTY } \\ 1 & 80.000000 & 83.046605 & 3.586875 \\ 2 & 50.000000 & 51.480844 & 0.347024 \\ 3 & 10.000000 & 13.920079 & 0.861652\end{array}$

STD. DEV. CORRELATION

$\begin{array}{rrrrr} & & 1 & 2 & 3 \\ 2 & 3.586875 D+00 & 100 & & \\ 3 & 3.470243 D-01 & -2 & 100 & \\ 3 & 8.616517 D-01 & 18 & -2 & 100\end{array}$


Table VI.4. Output from Least-Squares Analysis of Data Set for Example 3, Second Method of Solution. (Compare with Table VI.3.7.)

SOLVING LEAST SQUARES EQUATIONS.

MAXIMUM NUMBER OF ITERATIONS IS 5

CONVERGENCE FACTOR. IS 0.001000

***** INTERMEDIATE RESULTS

$\begin{array}{lll} & \text { OLD PARAM } & \text { NEW PARAMETERS } \\ 1 & 80.000000 & 76.817676 \\ 2 & 50.000000 & 51.298678 \\ 3 & 10.000000 & 12.672309 \\ 4 & 40.166463 & 39.967020\end{array}$

***** INTERMEDIATE RESULTS

$\begin{array}{lll} & \text { OLD PARAM } & \text { NEW PARAMETERS } \\ 1 & 80.000000 & 82.843214 \\ 2 & 50.000000 & 51.494127 \\ 3 & 10.000000 & 14.016209 \\ 4 & 40.166463 & 34.514574\end{array}$

INTERMEDIATE RESULTS

$\begin{array}{lll} & \text { OLD PARAM } & \text { NEW PARAM } \\ 1 & 80.000000 & 83.997927 \\ 2 & 50.000000 & 51.474992 \\ 3 & 10.000000 & 14.274148 \\ 4 & 40.166463 & 33.101852\end{array}$

***** INTERMEDIATE RESULTS

$\begin{array}{lll} & \text { OLD PARAM } & \text { NEW PARAMETERS } \\ 1 & 80.000000 & 84.081284 \\ 2 & 50.000000 & 51.472523 \\ 3 & 10.000000 & 14.314622 \\ 4 & 40.166463 & 32.948571\end{array}$


Table VI.4. (Continued)

******* NEW VALUES FOR PARAMETERS

$\begin{array}{lccr} & \text { POLD } & \text { PNEW } & \text { UNCERTAINTY } \\ 1 & 80.000000 & 84.089851 & 3.829384 \\ 2 & 50.000000 & 51.472090 & 0.345052 \\ 3 & 10.000000 & 14.320542 & 0.982562 \\ 4 & 40.166463 & 32.928753 & 3.653031\end{array}$

STD. DEV , CORRELATION

$\begin{array}{rrrrrr} & & 1 & 2 & 3 & 4 \\ 2 & 3.829384 D+00 & 100 & & & \\ 2 & 3.450518 D-01 & -3 & 100 & & \\ 3 & 9.025019 D=01 & 34 & -2 & 100 & \\ 4 & 3.653031 D+00 & -64 & 4 & -88 & 100\end{array}$


Table VI.5. Output for Least-Squares Analysis of Data Set for Example 4, First Method of Solution. (Compare with Table V.4.4.)

SOLVING LEAST SQUARES EQUATIONS.

MAXIMUM NUMBER OF ITERATIONS IS 5

CONVERGENCE FACTOR IS 0.001000

***** INTERMEDIATE RESULTS

$\begin{array}{ccc} & \text { OLD PARAM } & \text { NEW PARAMETERS } \\ 1 & 120.000000 & 123.522848 \\ 2 & 30.000000 & 23.859483\end{array}$

***** INTERMEDIATE RESULTS

$\begin{array}{ccc} & \text { OLD PARAM } & \text { NEW PARAMETERS } \\ 1 & 120.000000 & 123.221544 \\ 2 & 30.000000 & 22.601618\end{array}$

******* NEW VALUES FOR PARAMETERS

\begin{tabular}{lcrr} 
& POLD & \multicolumn{1}{c}{ PNEW } & UNCERTAINTY \\
1 & 120.000000 & 123.219435 & 0.065499 \\
2 & 30.000000 & 22.595013 & 0.189108
\end{tabular}

STD. DEV. CORRELATION

$\begin{array}{rrrr} & & 1 & 2 \\ 2 & 6.549897 D-02 & 100 & \\ 1.891082 D-01 & 3 & 100\end{array}$


Table VI.6. Output from Least-Squares Analysis of Data Set for Example 4, Second Method of Solution. (Compare with Table V.4.7.)

SOLVING LEAST SQUARES EQUATIONS. MAXIMUM NUMBER OF ITERATIONS IS 5 CONVERGENCE FACTOR IS 0.001000

***** INTERMEDIATE RESULTS

$\begin{array}{ccc} & \text { OLD PARAM } & \text { NEW PARAMETERS } \\ 1 & 120.000000 & 123.319824 \\ 2 & 30.000000 & 24.335206 \\ 3 & 1.140000 & 1.208207\end{array}$

***** INTERMEDIATE RESULTS

$\begin{array}{ccc} & \text { OLD PARAM } & \text { NEW PARAMETERS } \\ 1 & 120.000000 & 123.216864 \\ 2 & 30.000000 & 22.519767 \\ 3 & 1.140000 & 1.134418\end{array}$

***** INTERMEDIATE RESULTS

$\begin{array}{ccc} & \text { NLD PARAM } & \text { NEW PARAMETERO } \\ 1 & 120.000000 & 123.218895 \\ 2 & 30.000000 & 22.643222 \\ 3 & 1.140000 & 1.137664\end{array}$

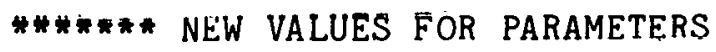

\begin{tabular}{lrrr} 
& POLD & \multicolumn{1}{c}{ PNEW } & UNCERTAINTY \\
1 & 120.000000 & 123.219183 & 0.065387 \\
2 & 30.000000 & 22.641993 & 0.189234 \\
3 & 1.140000 & 1.137609 & 0.008223
\end{tabular}

STD. DEV. CORRELATION

$\begin{array}{rrrrr} & & 1 & 2 & 3 \\ 2 & 6.538734 \mathrm{D}=02 & 100 & & \\ 3 & 1.892344 \mathrm{D}-01 & 3 & 100 & \\ 3 & 8.222874 \mathrm{D}-03 & -2 & 78 & 100\end{array}$




\section{SUMMARY}

This technical memorandum was prepared primarily as a guide for the experimentalist who wishes to use Bayes' method as an aid in data analysis. The five examples presented in Sections $V$ and VI were chosen because they typify the kinds of problems encountered in neutron physics studies at ORELA. Nevertheless, the method has far broader applicability; Bayes' method could be used wherever traditional least-squares' methods are now being used, and should be used wherever prior information about parameter values is available. It is the author's hope that this report has offered some insight into the proper use of Bayes' method, and that the reader is inspired to employ Bayes' method in his own research. 
THIS PAGE

WAS INTENTIONALLYY

LEFT BLANK 


\section{REFERENCES}

D079 J. J. Dongarra, C. B. Moler, J. R. Bunch and G. W. Stewart, LINPACK Users' Guide, SIAM (1979).

GA73 A. Gandini, "Nuclear Data and Integral Measurements Correlations for Fast Reactors," Part I and II, Comitato Nazionale Energia Nucleare, Casaccia, Italy (1973), RT/FI(73)5 and 22 (1973).

HE80 D. M. Hetrick and C. Y. Fu, "GLUCS: A Generalized Least-Squares Program for Updating Cross-Section Evaluations with Correlated Data Sets", ORNL/TM-7341, ENDF-303, October 1980.

HE82 D. M. Hetrick, C. Y. Fu and D. C. Larson, to be published.

LA80 N. M. Larson and F. G. Perey, "User's Guide for SAMMY: A Computer Model for Multilevel R-matrix Fits to Neutron Data Using Bayes' Equations", ORNL/TM-7485, ENDF-297, November 1980.

MA80 J. H. Marable, C. R. Weisbin, and G. de Saussure, "Combination of Differential and Integral Data", in "Sensitivity and Uncertainty Analysis of Reactor Performance Parameters", to be published in Adv. Nucl. Sci. and Technology, Plenum Press, editor Martin Becker.

NAG Numerical Algorithms Group (USA) Inc., 1250 Grace Court, Downers Grove, Illinois 60516 - USA. Telephone (312)971-2337.

PE67 F. G. Perey, computer code GENØA, ORNL, unpublished (1967).

PE79 F. G. Perey, lecture notes "Introduction to Probability Theory and Applications to Neutron and Reactor Physics Problems", unpublished.

PE80 R. W. Peelle, "Uncertainty in the Nuclear Data Used for Reactor Calculations", in "Sensitivity and Uncertainty Analysis of Reactor Performancc Parameters", to be publizhed in Adv. Nucl. 3oi. and Technology, Plenum Press, editor Martin Becker.

PE82 F. G. Perey, submitted to Phys. Rev. A.

RA82 Radiation Shielding Information Center, Oak Ridge National Laboratory, P. O. Box X, Oak Ridge, TN 37830 .

WH79 D. M. Wharton and D. K. Olsen, "LSFøDF: A Generalized Nonlinear Least-Squares Fitting Program for. Use with ORELA ODF Files", ORNL/TM-6545, December 1978. 
THIS PAGE

WAS INTENTIONALLY LEFT BLANK 
APPENDIX A

ALGEBRAIC DETAILS 
THIS PAGE

WAS INTENTIONALLY

LEFT BLANK 
This appendix presents algebraic details which would obscure the broad understanding of our method, were they to be presented in the text. Included are the derivation of Bayes' equations from Bayes' theorem, development of an appropriate iteration scheme for Bayes' theorem, derivation of least-squares equations from Bayes' equations; proof that a constant covariance matrix is equivalent to a coherent data correction, and derivation of the correct covariance matrix for angular distribution data.

\section{Deriving Bayes' Equations}

In Section II, we state that Bayes' equations may be derived directly from Bayes' theorem,

$$
p(P \mid D X) \propto p(P \mid X) p(D \mid P X) .
$$

provided the three basic assumptions are met. These assumptions are:

i) the prior pdf is a joint normal. That is, the pdf for the parameters, prior to consideration of the data $D$, is

$$
p(P \mid X) \propto \exp \left\{-1 / 2(P-\bar{P})^{t_{M}-1}(P-\bar{P})\right\}
$$

ii) the likelihood function is a joint normal. That is, the pdf for the experimental data is

$$
p(D \mid P X) \propto \exp \left\{-1 / 2(D-T)^{t} V^{-1}(D-T)\right\}
$$

where $T$ is a function of the parameter $P$.

iii) the true value is a linear function of the parameters. That is, a Taylor expansion of the theoretical values around the prior expectation values of the parameters truncates after the linear term:

$$
T=T+G(P-\bar{P})
$$


where the sensitivity matrix $G$ is defined by

$$
G_{i k}=\frac{\partial T_{i}}{\partial P_{k}} \mid \quad P=\bar{P}
$$

and the theoretical value $\overline{\mathrm{T}}_{i}$ (i.e., $\overline{\mathrm{T}}$ for data point $i$ ) is also evaluated at $P=\bar{P}$.

Given these three assumptions, the posterior $\operatorname{pd} p(P \mid D X)$ is also a joint normal distribution and may be written

$$
p(P \mid D X) \propto \exp \left\{-1 / 2\left(P-\bar{P}^{\prime}\right)^{t}\left(M^{\prime}\right)^{-1}\left(P-\bar{P}^{\prime}\right)\right\} .
$$

Substituting Eq. (A2) through (A6) into Eq. (A1) and equating the exponents yield, in matrix form,

$$
\begin{aligned}
\left(P-\bar{P}^{\prime}\right)^{t}\left(M^{\prime}\right)^{-1}\left(P-\bar{P}^{\prime}\right)+Y & =(P-\bar{P})^{t} M^{-1}(P-\bar{P}) \\
& +[D-\bar{T}-G(P-\bar{P})]^{t} V^{-1}[D-T-G(P-\bar{P})]
\end{aligned}
$$

where $Y$ represents the normalization constant and is independent of $P$. Setting $P-\bar{P}=P-\bar{P}^{\prime}+\bar{P}^{\prime}-\bar{P}$ in Eq. (A7), and rearranging terms, we obtain

$$
\begin{aligned}
\left(P-\bar{P}^{\prime}\right)^{t}\left(M^{\prime}\right)^{-1}\left(P-\bar{P}^{\prime}\right)+Y & =\left(P-\bar{P}^{\prime}\right)^{t}\left(M^{-1}+G^{t} V^{-1} G\right)\left(P-\bar{P}^{\prime}\right) \\
& +\left(P-\bar{P}^{\prime}\right)^{t}\left[\left(M^{-1}+G^{t} V^{-1} G\right)\left(\bar{P}^{\prime}-\bar{P}\right)-G^{t} V^{-1}(D-\bar{T})\right] \\
& +\left[\left(\bar{P}^{\prime}-\bar{P}\right)^{t}\left(M^{-1}+G^{t} V^{-1} G\right)-(D-T)^{t} V^{-1} G\right]\left(P-\bar{P}^{\prime}\right) \\
& +\left(\bar{P}^{\prime}-\bar{P}\right)^{t} M^{-1}\left(\bar{P}^{\prime}-\bar{P}\right) \\
& +\left[D-\bar{T}-G\left(\bar{P}^{\prime}-\bar{P}\right)\right]^{t} V^{-1}\left[D-\bar{T}-G\left(\bar{P}^{\prime}-\bar{P}\right)\right] .
\end{aligned}
$$

Because Eq. (A8) must hold for all values of $P$, we may equate lerms quadratic, linear, or constant in $\left(P_{-}-\bar{P}^{\prime}\right)$. Equating the quadratic terms gives Bayes' equation for updating the covariance matrix:

$$
\left(M^{\prime}\right)^{-1}=M^{-1}+G^{t} V^{-1} G
$$


Multiplying both sides by $M$ on the left and $M^{\prime}$ on the right yields

$$
M^{\prime}=\left[1+M G^{t} V^{-1} G\right]^{-1} M
$$

Using the identity $X^{-1}=(Z X)^{-1} Z$ with $Z=G^{t}(N+V)^{-1} G$, substituting $N$ for $G M G^{t}$, and rearranging give

$$
M^{\prime}=\left[G^{t}\left\{(N+V)^{-1}\left(1+N V^{-1}\right)\right\} G\right]^{-1} G^{t}(N+V)^{-i}(M .
$$

The quantity in curly brackets in Eq. (A11) is equal to $\mathrm{V}^{-1}$; making that substitution and introducing the identity $\mathrm{V}^{-1} \mathrm{~V}=\mathrm{I}$ into that equation give

$$
M^{\prime}=\left[G^{t} V^{-1} G\right]^{-1} G^{t} V^{-1} V(N+V)^{-1} G M \text {. }
$$

Algebraic manipulation then y1elds

$$
M^{\prime}=\left[G^{t} V^{-1} G\right]^{-1} G^{t} V^{-1} G M-\left[G^{t} V^{-1} G\right]^{-1} G^{t} V^{-1} G M G^{t}(N+V)^{-1} G M
$$

which reduces to

$$
M^{\prime}=M-M G^{t}(N+V)^{-1} G M
$$

This is exactly Bayes' equation for updating the covariance matrix, Eq. (II.9). Explicitly, this equation may be written

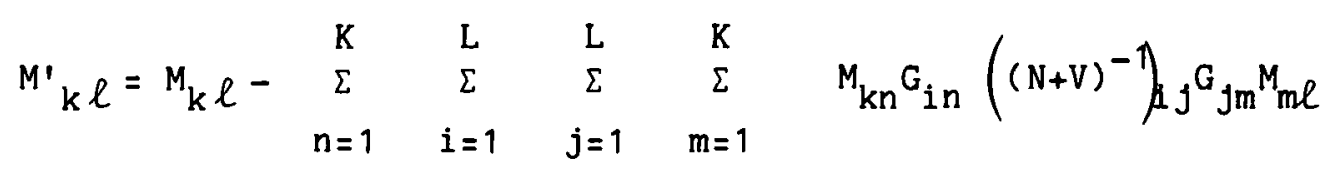

where $N$ is given by

$$
N_{i j}=\sum_{k=1}^{K} \sum_{=1}^{K} \quad G_{i k}{ }^{M} \ell^{G} j \ell .
$$


To obtain Bayes' equation for updating the parameter values, we equate the linear terms of $\mathrm{Eq}$. (A8). Since the left-hand side of that equation has no terms linear in $\left(P_{-} \bar{P}^{\prime}\right)$, the coefficient of $\left(P_{-} \bar{P}^{\prime}\right)$ on the right-hand side must be zero. That is,

$$
\left(M^{-1}+G^{t} V^{-1} G\right)\left(\bar{P}^{\prime}-\bar{P}\right)=G^{t} V^{-1}(D-\bar{T})
$$

From Eq. (A9), Lhe first quantity on the left is just (M') ${ }^{-1}$; we therefore Ilulliply both sides of Eq. (A17) by M', using Eq. (A14), and obtain

$$
\bar{P}^{\prime}-\bar{P}=\left(M-M G^{t}(N+V)^{-1} G M\right) G^{t} V^{-1}(D-T)
$$

which reduees to

$$
\bar{P}^{\prime}-\bar{P}=M G^{t}(N+V)^{-1}(D-T) .
$$

Explicitly, this equation is

$$
\bar{P}_{k}^{\prime}=\bar{P}_{k}+\sum_{\ell=1}^{K} \sum_{i=1}^{L} \sum_{j=1}^{L} \quad M_{k \ell} G_{i \ell}\left((N+V)^{-1}\right){ }_{i j}\left(D_{j}-\bar{T}_{j}\right)
$$

Finally, we note that the constant term in Eq. (A8) may be specified using Eq. (A19) to give

$Y=(D-T){ }^{t}\left[(N+V)^{-1} G M G^{t}(N+V)^{-1}+\left(1-(N, V)^{-1} N\right) V^{-1}\left(1-N(N+V)^{-1}\right)\right](D-T)$

which reduces to

$$
Y=(D-\bar{T})^{t}(N+V)^{-1}(D-\vec{T})
$$




\section{Iteration Scheme}

The linearity hypothesis, i.e., the assumption that the Taylor expansion of the theoretical values around the prior expectation value truncates after the linear term, is in general only approximately true. Therefore, the parameter values $\bar{P}$ ' resulting from application of Bayes' equations are also only approximately correct. To obtain more accurate values, the Taylor expansion. Eq. (A4), may be performed not around $\bar{P}$ but around the new (intermediate) values $\bar{P}^{(n)}$, where $n$ represents the $n$th iteration and $\overline{\mathrm{P}}^{(0)}=\overline{\mathrm{P}}$ :

$$
T \simeq \bar{T}^{(n)}+G^{(n)}\left(P-\bar{P}^{(n)}\right)
$$

Here the sensitivity matrix $G^{(n)}$ and the theoretical values $T^{(n)}$ are evaluated at $P=\bar{P}^{(n)}$. With Eq. (A23) for T, the formula analogous to Eq. (A7) is

$$
\begin{aligned}
\left(P-\bar{P}^{(n+1)}\right)^{t}\left(M^{(n+1)}\right)^{-1}\left(P-\bar{P}^{(n+1)}\right)+Y=(P-\bar{P})^{t} M^{-1}(P-\bar{P}) \\
\quad+\left[D-\bar{T}^{(n)}-G^{(n)}\left(P-\bar{P}^{(n)}\right)\right]^{t} V^{-1}\left[D-\bar{T}^{(n)}-G^{(n)}\left(P-\bar{P}^{(n)}\right)\right]
\end{aligned}
$$

Setting $P$ equal to $P-\bar{P}^{(n+1)}+\bar{P}^{(n+1)}$ everywhere in the right-hand side of Eq. (A24) gives the formula analogous to Eq. (A8) with $\overline{\mathrm{T}}$ in that expression replaced by $\bar{T}^{(n)}+G^{(n)}\left(\bar{P}-\bar{P}^{(n)}\right)$, and $G$ by $G^{(n)}$. The iterative form of Bayes' equations follow immediately:

$$
\begin{aligned}
& \bar{P}^{(n+1)}=\bar{P}+M G^{(n) t}\left(N^{(n)}+V\right)^{-1}\left(D-T^{(n)}-G^{(n)}\left(\bar{P}-\bar{P}^{(n)}\right)\right) \\
& M^{(n+1)}=M-M G^{(n) t}\left(N^{(n)}+V\right)^{-1} G^{(n)} M
\end{aligned}
$$

where

$$
N^{(n)}=G^{(n)} \dot{G}^{(n) t}
$$




\section{Derivation of Least-Squares from Bayes' Equations}

The equivalence of the least-squares method with Bayes' equations in the limit of large $M$ (i.e., in the extreme case where there is no prior knowledge of the values of the parameters) is best demonstrated by considering Eq. (A17):

$$
\left(M^{-1}+G^{t} V^{-1} G\right)\left(\bar{P}^{\prime}-\bar{P}\right)=G^{t} V^{-1}(D-T)
$$

or, in the iterative form,

$$
\begin{aligned}
\left(M^{-1}\right. & \left.+G^{(n) t} V^{-1} G^{(n)}\right)\left(\bar{P}^{(n+1)}-\bar{P}\right) \\
& =G^{(n) t} V^{-1}\left(n=\bar{T}^{(n)}-G^{(n)}\left(\bar{P}-\bar{P}^{(n)}\right)\right)
\end{aligned}
$$

For large $M$, the term $G^{t} V^{-1} G$ overwhelms $M^{-1}$, and this equation reduces immediately to

$$
\vec{P}^{(n+1)}=\bar{P}^{(n)}+\left(G^{(n) t} V^{-1} G^{(n)}\right)^{-1} G^{(n) t} V^{-1}\left(D-\bar{T}^{(n)}\right)
$$

which is the well-known least-squares formula.

Similarly, parameter uncertainties and covariances can be found from the iterative form of $\mathrm{Eq} .(\mathrm{Ag})$ :

$$
\left(M^{(n+1)}\right)^{-1}=M^{-1}+G^{(n) t} V^{-1} G^{(n)}
$$

which reduces to.

$$
M^{(n+1)}=\left(G^{(n) t} V^{-1} G^{(n)}\right)^{-1}
$$


in the limit of large M. In least-squares applications, the quoted covariance matrix is usually the value given in Eq. (A32), scaled by $x^{2} / d$, where

$$
x^{2}=\left(D-\bar{T}^{(n)}\right)^{t} V^{-1}\left(D-T^{(n)}\right)
$$

and $d$ is the number of degrees of freedom in the problem ( $d=$ number of data points minus number of parameters). In the LEAST program described in this manual, no such scaling is performed.

\section{Use of Data Covariances to Indicate Coherent Data Corrections}

In Example V.3 we saw computational proof that a constant term added to the data covariance matrix is equivalent to a constant, coherent correction to the theory. For a mathematical proof, we begin by writing the covariance matrix in the form

$$
V=\bar{V}+A A^{t}
$$

where $\bar{V}$ is the original covariance matrix, and $A$ is a column matrix whose elements are zero nutside the range where the correction is to be applied, and constant inside the range. Bayes' equations require the inverse of $N+\bar{V}+A A^{t}$, which is equivalent to

$$
\left(N+\bar{V}+A A^{t}\right)^{-1}=(N+\bar{V})^{-1}\left[1-\frac{1}{1+A^{t}(N+\bar{V})^{-1} A} A A^{t}(N+\bar{V})^{-1}\right]
$$


as can be verified by multiplying the right-hand side by $\left(N+\bar{V}+A A^{t}\right)$. Substitution of this expression into the first of Bayes' equations (Eq. (A19) or Eq. (II.8)) gives

$$
\bar{P}^{\prime}=\bar{P}+M G^{t}(N+\bar{V})^{-1}(D-\Delta T-\bar{T})
$$

where the correction term $\Delta \mathrm{T}$ is given by

$$
\Delta T=\frac{1}{1+A^{L}(N+\bar{V})^{-1} A} A A^{t}(N+\bar{V})^{-1}(D \cdot \bar{T})
$$

Thus, the presence of an additive constant term ( $A A^{t}$ ) in the data covariance matrix is equivalent to a coherent correction to the theory or. equivalently, to the data. Also, note that if the elements of column matrix A are not zero or constant, Eqs. (A36) and (A37) remain valid, but the correction term $\Delta$ varies from point to point.

\section{Covariance Matrix for Differential Cross Sections}

In Example V.5, Eq. (V.5.6) was stated to be the correct form for the covariance matrix for angular distribution data. Here we present a proof that this form is in fact correct.

Let $p$ be the probability that a particle is scattered to within $d \Omega$ of position $(\theta, \phi)$. (Azimuthal symmetry io oosumed.) Then $p$ is given by

$$
p=\frac{d \sigma / d \Omega d(\cos \theta) d \phi}{\sigma}
$$


Discretizing gives the probability for finding the particle at $\theta_{i}$ as

$$
p_{i}=\frac{2 \pi D_{i} \sin \theta_{i} \Delta \theta_{i}}{\sigma}
$$

Perey [PE79] has shown that the covariance matrix for the $p_{i}$ is given by

$$
\left\langle\delta p_{i} \quad \delta p_{j}\right\rangle=\frac{p_{i} \delta_{i j}-p_{i} p_{j}}{N}
$$

where $\mathrm{N}$ may be viewed as a normalization constant related to the duration of the experiment. Using Eq. (A39) to replace both $\delta p_{i}$ and $p_{i}$ in Eq. (A40) gives

$$
\begin{aligned}
& \frac{2 \pi}{\sigma}\left\langle\delta D_{i} \delta D_{j}>\sin \theta_{j} \sin \theta_{i} \Delta \theta_{i} \Delta \theta_{j}\right. \\
= & \frac{2 \pi}{\sigma N} D_{i} \sin \theta_{i} \Delta \theta_{i} \delta_{i j}-\left(\frac{2 \pi}{\sigma}\right)^{2} \frac{1}{N} D_{i} \sin \theta_{i} \Delta \theta_{i} D_{j} \sin \theta_{j} \Delta \theta_{j}
\end{aligned}
$$

Therefore the covariance between data $D_{i}$ and data $D_{j}$ is $\left\langle\delta D_{i} \delta D_{j}\right\rangle$, or

$$
v_{i j}=\frac{D_{i}}{N \sin \theta_{i} \Delta \theta_{i}} \delta_{i j}-\frac{\frac{D_{i} \sin \theta_{i} \Delta \theta_{i}}{N \sin \dot{\theta}_{i} \Delta \theta_{i}} \frac{D_{j} \sin \theta_{j} \Delta \theta_{j}}{N i n \theta_{j} \Delta \theta_{j}}}{\frac{\sigma}{2 \pi N}}
$$

Using Eq. $(\mathrm{V}, 5,3), \frac{\sigma}{2 \pi \mathrm{N}}$ can be written as

$$
\frac{\sigma}{2 \pi N}=\sum_{i} \frac{D_{i}}{N \sin \theta_{i} \Delta \theta_{i}} \quad\left(\sin \theta_{i} \Delta \theta_{i}\right)^{2}
$$


If we now identify

$$
\frac{D_{i}}{N \sin \theta_{i} \Delta \theta_{i}}
$$

as the square of the uncertainty with which $D_{i}$ is measured, Eqs. (A42) and (A43) become

$$
V_{i j}=\left(\Delta D_{i}\right)^{2} \delta_{i j}-\frac{\left(\Delta D_{i}\right)^{2} \sin \theta_{i} \Delta \theta_{i}\left(\Delta D_{j}\right)^{2} \sin \theta_{j} \Delta \theta_{j}}{\sum_{k}\left(\Lambda n_{k} \sin \theta_{k} \Delta \theta_{k}\right)^{2}}
$$

which is identical to Eq. (V.5.6). 
APPENDIX B

NOTATION USED IN BAYES 


\section{THIS PAGE : \\ WAS INTENTIONALLY \\ LEFT BLANK}


NOTATION USED IN BAYES

FDRTRAN Name

(Dimensions, if

Applicable)

Symbol Used

in Text

Meaning

AUTØ

flag which, when equal to 'Y', indicates that the automatic numerical derivative option is in effect

CØNVER

convergence fraction; if no parameter changes more than this fraction of its former value, iteration ceases

DATA(NDATMX)

D

experimental data points

DATCØV (NDATMX, NDATMX)

V

covariance matrix for the
data

DUM( NDATMX)

dummy array for temporary storage

E (NDATMX)

first independent variable (often, energy)

E2 (NDATMX)

second independent variable

EMG (NDATMX, NPARMX)

$M G^{(n) t}$

$\operatorname{EN}(m)$, where $m=$

$N^{(n)}+V$

NDATMX* $(\operatorname{NDATMX}+1)) / 2$

G(NDATMX, NPARMX)

$G^{(n)}$

HBASE

fractional step size for generating numerical derivatives automatically

IDUM(NTARMX)

dummy array

IF PAR (NNPARM)

flag which is set to 1 if parameter is to be varied, 0 if not 


\begin{tabular}{|c|c|c|}
\hline $\begin{array}{l}\text { FØRTRAN Name } \\
\text { (Dimensions, if } \\
\text { Applicable) }\end{array}$ & $\begin{array}{l}\text { Symbol Used } \\
\text { in Text }\end{array}$ & Meaning \\
\hline ITMAX & & $\begin{array}{l}\text { maximum number of iterations } \\
\text { allowed }\end{array}$ \\
\hline ITER & & current iteration number \\
\hline IWHERE (NNPARM) & & bookkeeper \\
\hline IYDUM( NN PARM) & & dummy array \\
\hline NDAT & $\mathrm{L}$ & $\begin{array}{l}\text { number of experimental data } \\
\text { points }\end{array}$ \\
\hline NDATMX & & array dimensions for data \\
\hline NNPARM & & $\begin{array}{l}\text { array dimensions for } \\
\text { parameters (complete set, } \\
\text { varied and fixed) }\end{array}$ \\
\hline NPARAM & & $\begin{array}{l}\text { total number of parameters } \\
\text { (both varied and fixed) }\end{array}$ \\
\hline NPAR & $\mathrm{K}$ & $\begin{array}{l}\text { nimber of varied paramelers } \\
\text { ror lhe problen }\end{array}$ \\
\hline NPARMX & & $\begin{array}{l}\text { array dimensions for varied } \\
\text { parameters }\end{array}$ \\
\hline$P \wedge R \Lambda M(N N P \Lambda R M)$ & & $\begin{array}{l}\text { initial cotimatc for the } \\
\text { complete set of parameters }\end{array}$ \\
\hline PARC $\varnothing V$ (NNPARM, NNPARM) & & $\begin{array}{l}\text { initial estimate for the } \\
\text { covariance matrix for the } \\
\text { complete set of parameters }\end{array}$ \\
\hline PARM(N PARMX) & $\bar{p}(n)$ & $\begin{array}{l}\text { current values of varied } \\
\text { parameters }\end{array}$ \\
\hline PARM (N PARMX) & $\overline{\mathrm{P}}^{(n+1)}$ & $\begin{array}{l}\text { updated values of varied } \\
\text { parameters }\end{array}$ \\
\hline
\end{tabular}




\begin{tabular}{|c|c|c|}
\hline $\begin{array}{l}\text { FøRTRAN Name } \\
\text { (Dimensions, if } \\
\text { Applicable) }\end{array}$ & $\begin{array}{l}\text { Symbol Used } \\
\text { in Text }\end{array}$ & Meaning \\
\hline PARVAR (NPARMX, NPARMX) & M & $\begin{array}{l}\text { temporary storage for } \\
\text { parameter covariance } \\
\text { matrix }\end{array}$ \\
\hline PDUM(NPARMX) & & $\begin{array}{l}\text { dummy array for temporary } \\
\text { storage }\end{array}$ \\
\hline$P \oslash L D(N P A R M X)$ & $\overline{\mathrm{P}}$ & $\begin{array}{c}\text { initial estimate for value } \\
\text { of varied parameters }\end{array}$ \\
\hline $\mathrm{RC} \oslash \mathrm{ND}$ & & $\begin{array}{l}\text { condition number determined } \\
\text { by the matrix solution } \\
\text { routine DPPC } \emptyset \text {; if very } \\
\text { small, matrix is nearly } \\
\text { singular }\end{array}$ \\
\hline SIG (NDATMX) & & $\begin{array}{l}\text { reciprocal of the square- } \\
\text { root of the diagonal } \\
\text { element of EN, used in } \\
\text { scaling of matrix } \\
\text { manipulations }\end{array}$ \\
\hline $\mathrm{TH}(\mathrm{NDATMX})$ & $\bar{T}^{(n)}$ & $\begin{array}{l}\text { theoretical values for data } \\
\text { points, evaluated at } \\
\text { parameter values } \overline{\mathrm{P}}\end{array}$ \\
\hline $\begin{array}{l}\operatorname{VARDAT}(m), \text { where } \\
m \equiv(\operatorname{NDATMX}(\operatorname{NDATMX}+1)) / 2\end{array}$ & $\mathrm{v}$ & $\begin{array}{l}\text { data covariance matrix in } \\
\text { crunched form }\end{array}$ \\
\hline $\begin{array}{l}\operatorname{VARPAR}(m), \text { where } \\
\qquad \mathrm{m}=\left(\operatorname{NPARM} \mathrm{X}^{*}(\mathrm{NPARMX}+1)\right) / 2\end{array}$ & M & $\begin{array}{l}\text { parameter covariance matrix } \\
\text { in crunched form }\end{array}$ \\
\hline $\begin{array}{l}\operatorname{VARNEW}(m), \text { where } \\
\qquad \mathrm{m}=\left(\mathrm{NPARM} \mathrm{X}^{*}(\mathrm{NPARMX}+1)\right) / 2\end{array}$ & $M^{(n+1)}$ & $\begin{array}{l}\text { updated parameter covariance } \\
\text { matrix }\end{array}$ \\
\hline
\end{tabular}




\section{THIS PAGE}

\section{WAS INTENTIONALLY LEFT BLANK}


APPENDIX $C$

FØRTRAN LISTING OF BAYES MAIN PROGRAM AND OTHER ROUTINES 
THIS PAGE

\section{WAS INTENTIONALLY \\ LEFT BLANK}









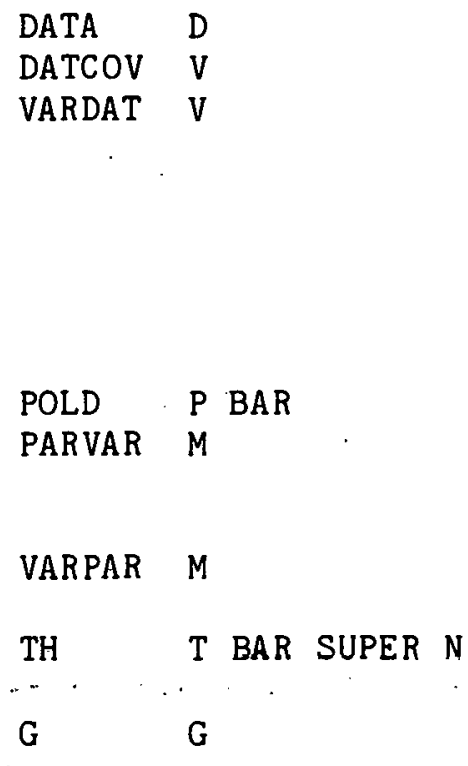

DATA NDATMX $/ 51 /$, NPARMX $/ 25 /$, NNPARM/26/

DATA YES /1HY/
EXPER IMENTAL DATA

DATA COVARIANCE MATRIX

COVARIANCE MATRIX FOR DATA, STORED

IN TRIANGULAR FORM AS

$$
\begin{array}{rrrrllllll}
1 & 2 & 4 & 7 & \ldots & \text { OR } & 1 & & & \\
3 & 5 & 8 & & & 2 & 3 & & \\
& 6 & 9 & & & & 4 & 5 & 6 & \\
& 10 & & & & 7 & 8 & 9 & 10 \\
& & & & & & &
\end{array}
$$

INITIAI. ESTIMATE OF PARAMETERS ESTIMATE OF COVARIANCE MATRIX FOR PARAMETERS, 3TORED IN REGULAR MATRIX FORM STIMATE OF COVARIANCE MATRIX FOR PARAMETERS, STORED IN TRIANGULAR FORM TALUE FOR DATA, EVALUATED RESPECT TO PARAMETERS; EVALUATED AT ENERGY E AND AT CURRENT VAI.UF. OF PARAMETERS, STORED AS G(NDAT, NPAR) NTERMEDIATE (OR CURRENT) VALUES OF

\section{PARAMETERS}

NEW VALUES FOR PARAMETER COVARIANCES 
C

C

CALL OUTALL (JJPAR, JJDAT, JJTH, JJG, JJREL, JJCHL, * JJREB, JJCHB, JJGMG)

C

C

C

C

WRITE $(5,99999)$

READ $(5,99998)$ ITMAX, CONVER

WRITE $(6,99997)$ ITMAX, CONVER

WRITE $(5,99996)$

READ $(5,99995)$ AUTO

C

IF (AUTO.NE.YES) GO TO 10

WRITE $(5,99994)$,

READ $(5,99993)$ HBASE

C

WRITE $(6,99992)$. HBASE

C

10 CALL PPARAM(NNPARM)

C

C

C

C

IF (NPAR.GT.NPARMX) GO TO 40

IF (JJPAR) CALL OUTPAR

INPUT TO OUTPAR -- PARM, VARPAR

OUTPAR WRITES OUT PARAMETERS, COVARIANCE MATRIX

IF (JJPAR .AND. NPAR.LT.NPARAM) CALL OUTYPR INPUT TO OUTYPR -- PARAM, PARCOV, IF PAR

OUTYPR WRITES OUT COMPLETE LIST OF PARAMETERS AND COVARIANCE MATRIX

20 CALL SETDAT

C

C

CALL FIXV

OUTPUT FROM SETDAT - NDAT,E, DATA, VARDAT

INPUT TO FIXV - DATCOV (STORED IN VARDAT AND EN) OUT PUT FROM FIXV - VARDAT

IF (NDAT.GT.NDATMX) GO TO 50

IF (JJDAT) CALL OUTDAT

INPUT TO OUTDAT - NDAT, E, DATA, VARDAT

OUTDAT WRITES OUT DATA, COVARIANCE MATRIX

ITER $=0$ 
C c

C

C

C

C

C

C

C

C

C

C

C

C

C

C

C

C

$\mathrm{C}$

C

C

C

C

C

C

ITER $=$ ITER +1

c

c

C

C

C

40 WRITE $(5,99991)$ NPAR, NPARMX STOP

C

50 WRITE $(5,99990)$ NDAT, NDATMX STOP

IF (JJTH) CALL OUTTH

IF ( JJG) CALL OUTG

IF (ITER.LT.ITMAX) CALL OUTP1

IF (ITER.EQ. ITMAX) CALL OUTP2

CALL UPDATE

CALL RESTRT

GO TO 20

THEORY' GENERATES THE FUNCTION AND ITS DERIVATIVES

INPUT TO THEORY -- NPAR, NDAT, PARM, E

OUT PUT FROM THEORY - TH, G

INPUT TO OUTTH - NDAT,E, DATA, TH

OUTTH PRINTS THEORY (TH) AND DATA (DATA) VS ENERGY (E)

INPUT TO OUTG -- NPAR, NDAT,E,G

OUTG PRINTS PARTIAL DERIVATIVES AT PARM

CALL NEWPAR (JJREL, JJCHL, JJREB, JJCHB, JJGMG)

INPUT TO NEWPAR -- POLD, PARM, VARPAR, DATA, VARDAT, TH

OUT PUT FROM NEWPAR -- PARM (UPDATED), VARNEW

ALSO USED BY NEWPAR - EMG, EN, DUM, SIG, PDUM

INPUT TO OUTP1 -- POLD, PARM

INPUT TO OUTP2 -- POLD, PARM, VARNEW

INPUT TO UPDATE -- PARM, VARPAR, TWHERE

OUT PU'I FROM UPDATE -- PARAM, PARCOV, UPDATED ALSO

IF (ITER.EQ. ITMAX .AND. NPAR.LT.NPARAM) CALL OUTYPR

INPUT TO OUTYPR - PAKAM, PARCOV, IFPAR

FOR MORE DATA TO BE INCORPORATED 
C

99999 FORMAT (42H HOW MANY ITERATIONS? WHAT IS CONVERGENCE,

* 11H FRACTION? \$)

99998 FORMAT (I, F)

99997 FORMAT (32H MAXIMUM NUMBER OF ITERATIONS IS, I3/7H CONVER,

* 16HGENCE FACTOR IS , F 10.6)

99996 FORMAT (39H DO YOU WISH TO USE AUTOMATIC NUMERICAL,

* 14H DERIVATIVES? \$)

99995 FORMAT (A 1)

99994 FORMAT (42H WHAT IS FRACTION DIFFERENCE FOR AUTOMATIC, * 13H DERIVATIVE? \$)

99993 FORMAT (F)

99992 FORMAT (36H AUTOMATIC DERIVATIVE USES STEP SIZE, F10.5)

99991 FORMAT (9H YOU WANT, I5, 21H BUT ARE ALLOWED ONLY, I5,

* 17H parameter values. $/ 28 \mathrm{H}$ change in commons /Par/ and,

* $8 \mathrm{H} / \mathrm{BOTH} /$, , 35H AND IN SUBROUT INES PPARAM AND OLDP)

99990 FORMAT (9H YOU WANT, I5, 21H BUT ARE ALLOWED ONLY, I5,

* 13H Data values./30H CHange in COMmons /DAT/ AND ,

* 42H/BOTH/, AND IN SUBROUTINES SETDAT AND FIXV)

END

C

$\mathrm{C}$

$\mathrm{C}$

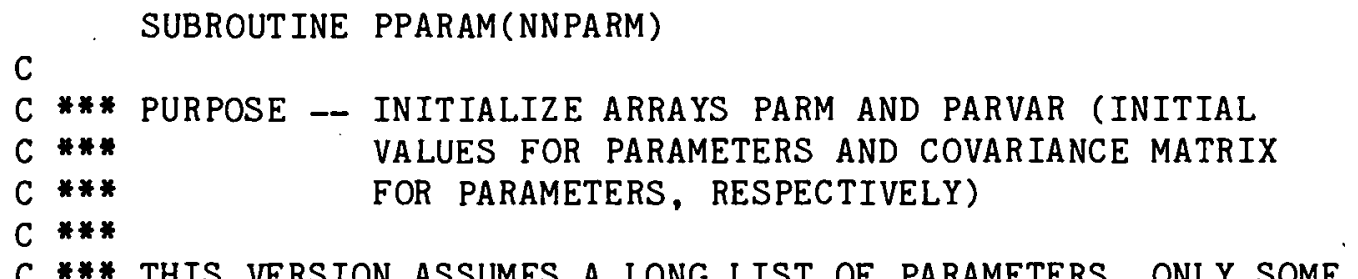

C*** THIS VERSION ASSUMES A LONG LIST OF PARAMETERS, ONLY SOME

$C * * *$ THE COVARIANCE MATRIX OF THE WHOLE LIST IS STORED

C*** IN PARCOV, AND THE MATRIX ELEMENTS OF IFPAR ARE

$C * * * \quad$ ZERO IF THAT PARAMETER IS NOT TO BE VARIED,

$c * * * \quad$ AND ONE IF IT IS TO BE VARIED. THESE ARRAYS ARE

$C * * *$ FOUND IN COMMON/YRPAR/, ALONG WITH THE ARRAY

$C * * *$

C

C

C NML, JANUARY 1981

C

IMPLICIT DOUBLE PRECISION (A-H,O-Z)

COMMON /NUMBER/ NDAT, NPAR, ITER, ITMAX, CONVER

COMMON /PAR/ POLD(25), PARM(25), PDUM(25), VARPAR(325),

* VARNEW(325), IDUM(25)

DIMENSION PARVAR $(25,25)$

EQUIVALENCE (PARVAR $(1,1), \operatorname{VARPAR}(1)$ )

COMMON /YRPAR/ PARAM(26), PARCOV(26,26), YDUM(26),

* IYDUM(26), IFPAR(26), IWHERE (26), NPARAM 


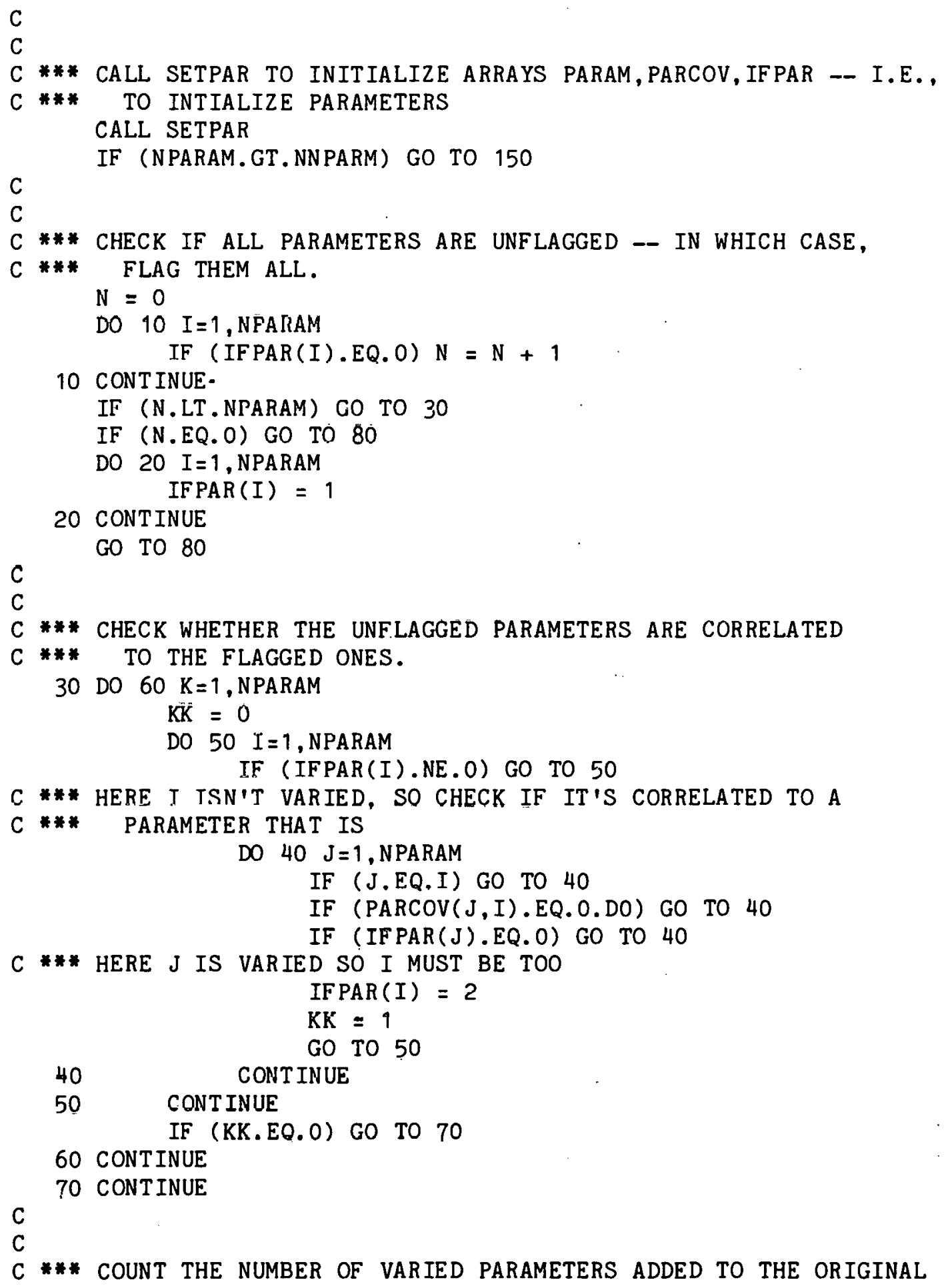


$c$

C*** LIST. ALSO INITIALIZE PARM AND IWHERE.

80 IPAR $=0$

$\mathrm{JPAR}=0$

DO $90 I=1$, NPARAM

IF (IFPAR(I).EQ.0) GO TO 90

$I P A R=I P A R+1$

PARM (IPAR) = PARAM(I)

IWHERE (IPAR) = I

IF (IFPAR(I).EQ.2) JPAR = JPAR + 1

C

90 CONTINUE

IF (JPAR.NE.0) WRITE $(6,99999)$ JPAR

$\mathrm{C}$

C *** ORGANIZE COVARIANCE MATRIX

NPAR = IPAR

IPAR $=0$

DO $110 \quad I=1$, NPARAM

IF (IFPAR(I).EQ.0) GO TO 110

$I P A R=I P A R+1$

$\mathrm{JPAR}=0$

DO $100 \mathrm{~J}=1$, NPARAM

IF (IFPAR(J).EQ.0) GO TO 100

$J P A R=J P A R+1$

100

PARVAR (JPAR, IPAR) $=\operatorname{PARCOV}(J, I)$

110 CONT INUE

C

C *** INITIALIZE POLD

DO $120 \quad I=1$, NPAR

$\operatorname{POLD}(I)=\operatorname{PARM}(I)$

120 CONTINUE

$c$

C *** REARRANGE STORAGE OF VARPAR TO USE ONLY LOWER TRIANGULAR

IL $=0$

DO $140 I=1$, NPAR

DO $130 \mathrm{~L}=1, \mathrm{I}$

$I \bar{L}=I \dot{L}+1$

$\operatorname{VARPAR}(I L)=\operatorname{PARVAR}(L, I)$

130 CONTINUE

140 CONTINUE

RETURN

C

150 WRITE $(5,99998)$ NPARAM

WRITE $(6,99998)$ NPARAM

STOP

C

99999 FORMAT (46HONUMBER OF ADDITIONAL PARAMETERS WHICH MUST BE,

* $1 \mathrm{H}$, 38HVARIED BECAUSE OF COVARIANCE MATRIX IS, I5)

99998 FORMAT ( $9 \mathrm{H}$ YOU WANT, I5, 21H BUT ARE ALLOWED ONLY, I5,

* 17Hparameter values. $128 \mathrm{H}$ change every arRay in commo,

* $\quad 1 \mathrm{HN}, 8 \mathrm{H} /$ YRPAR/.)

END 


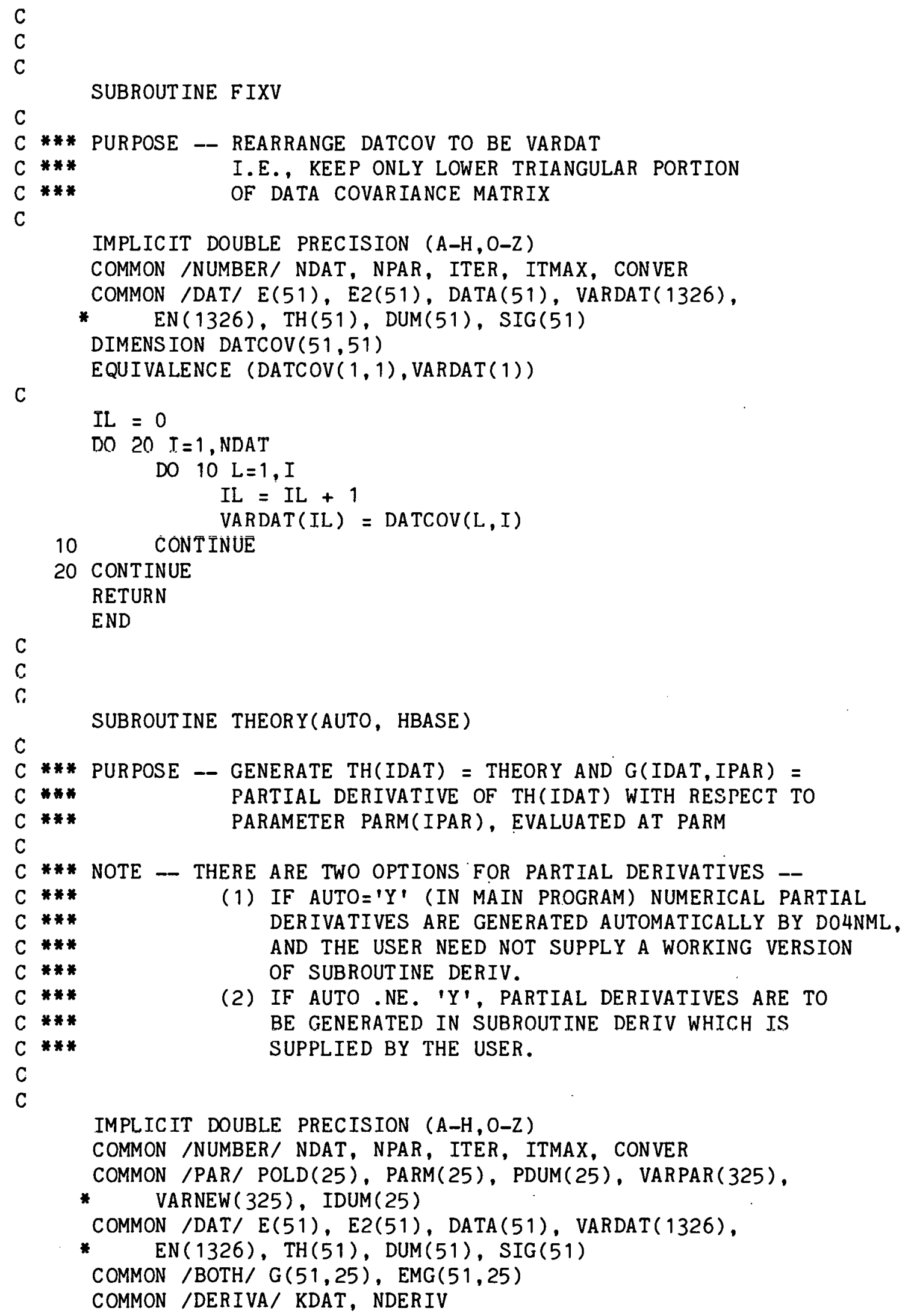




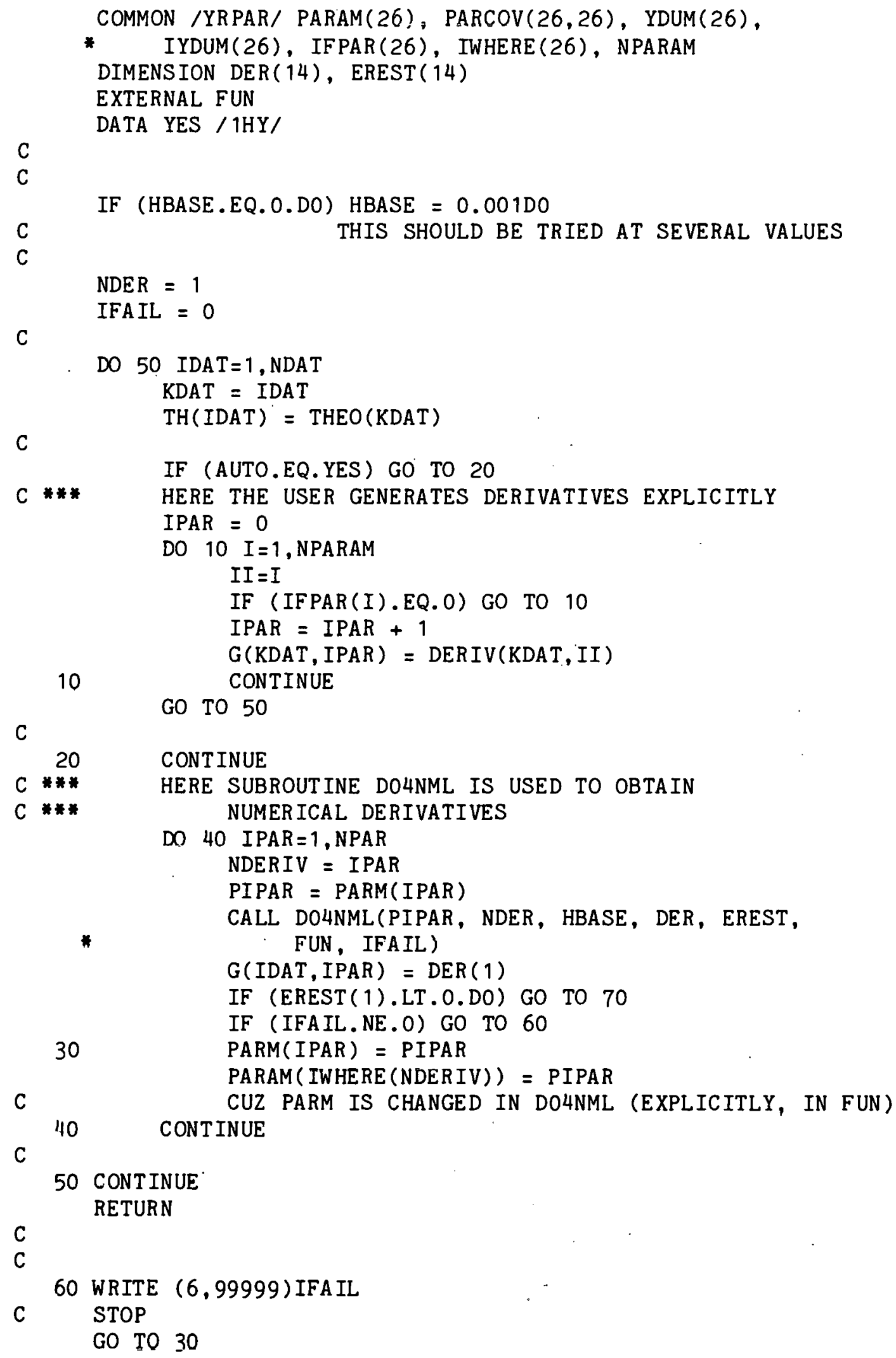




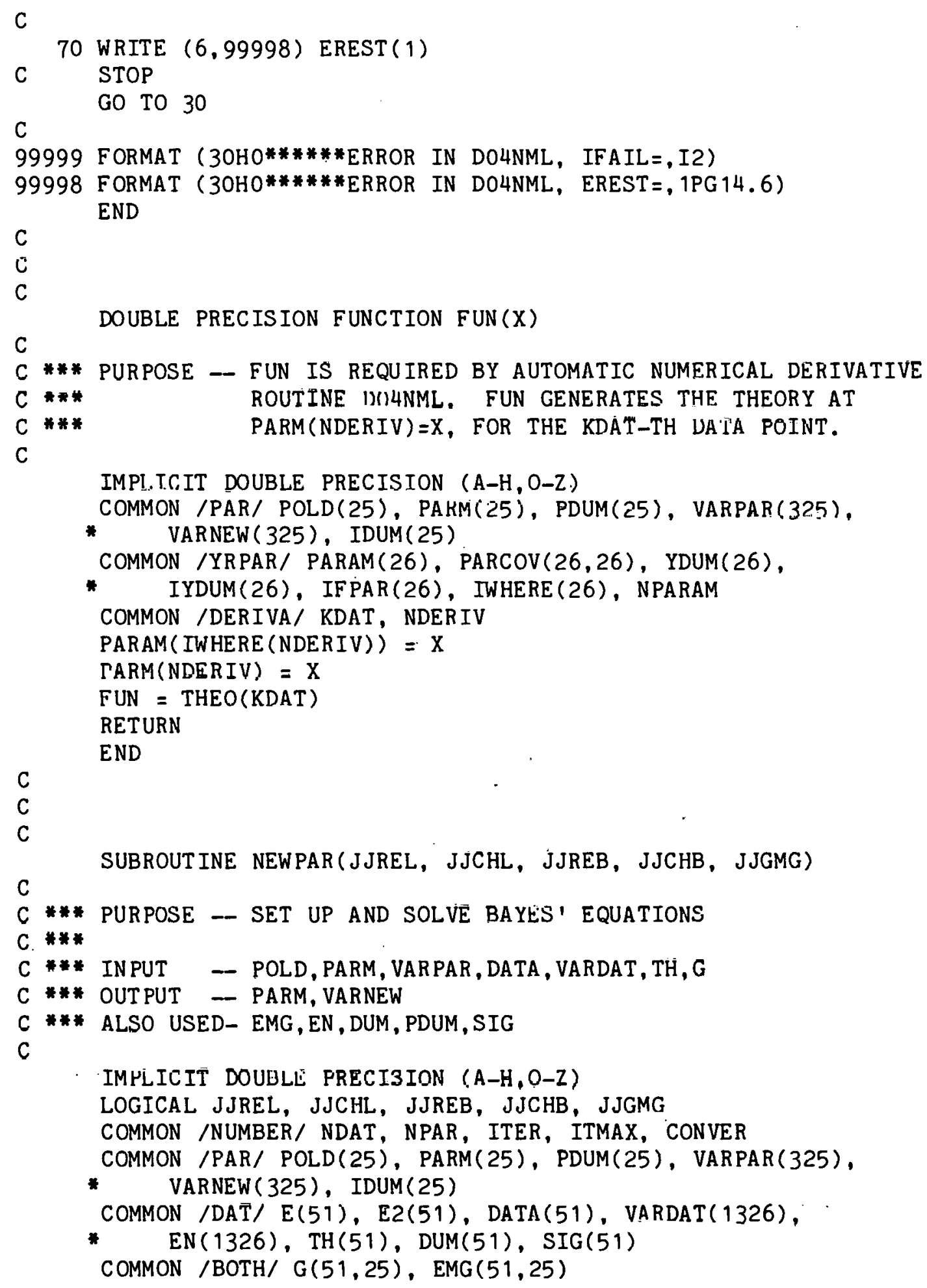




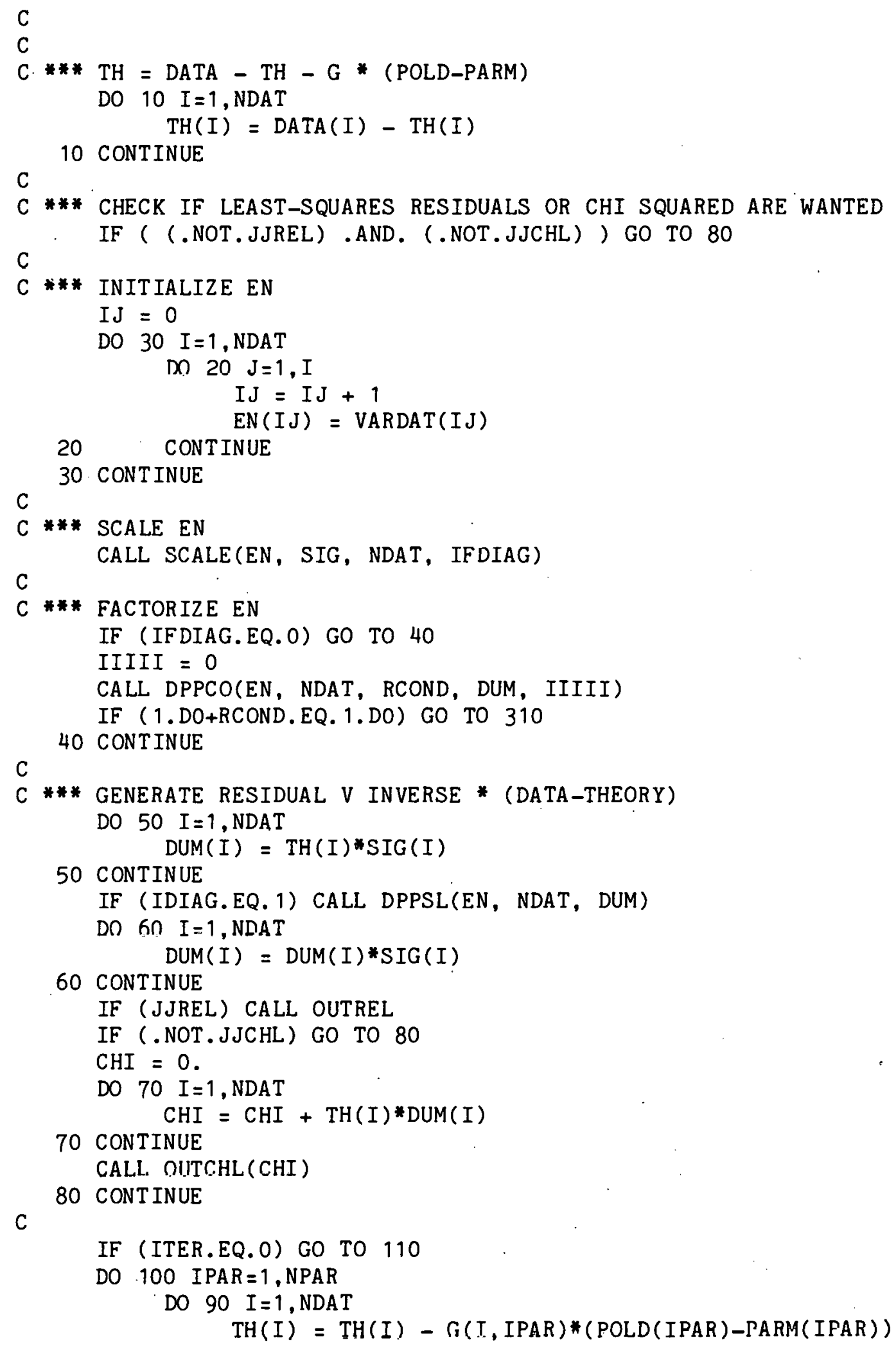




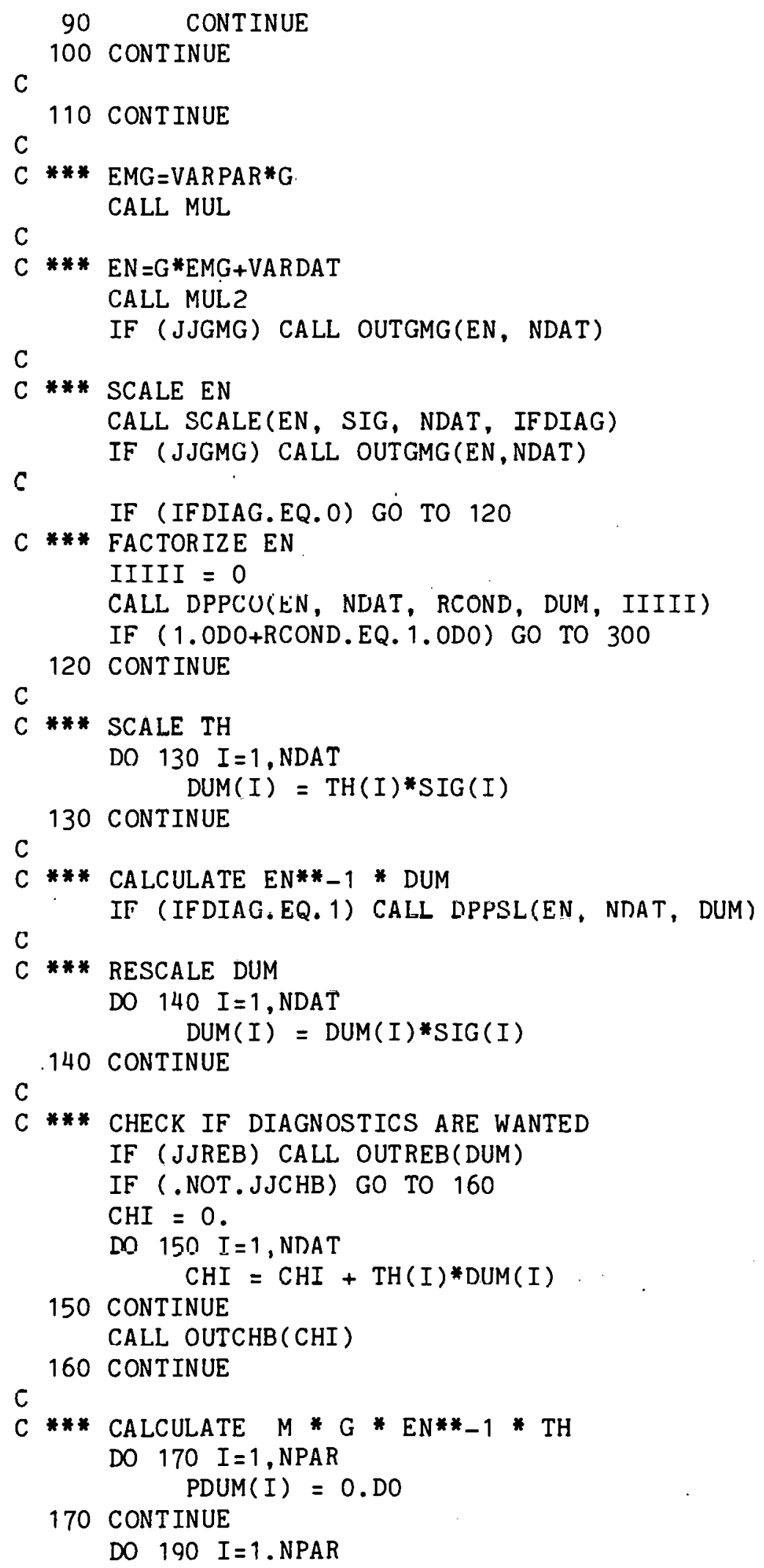









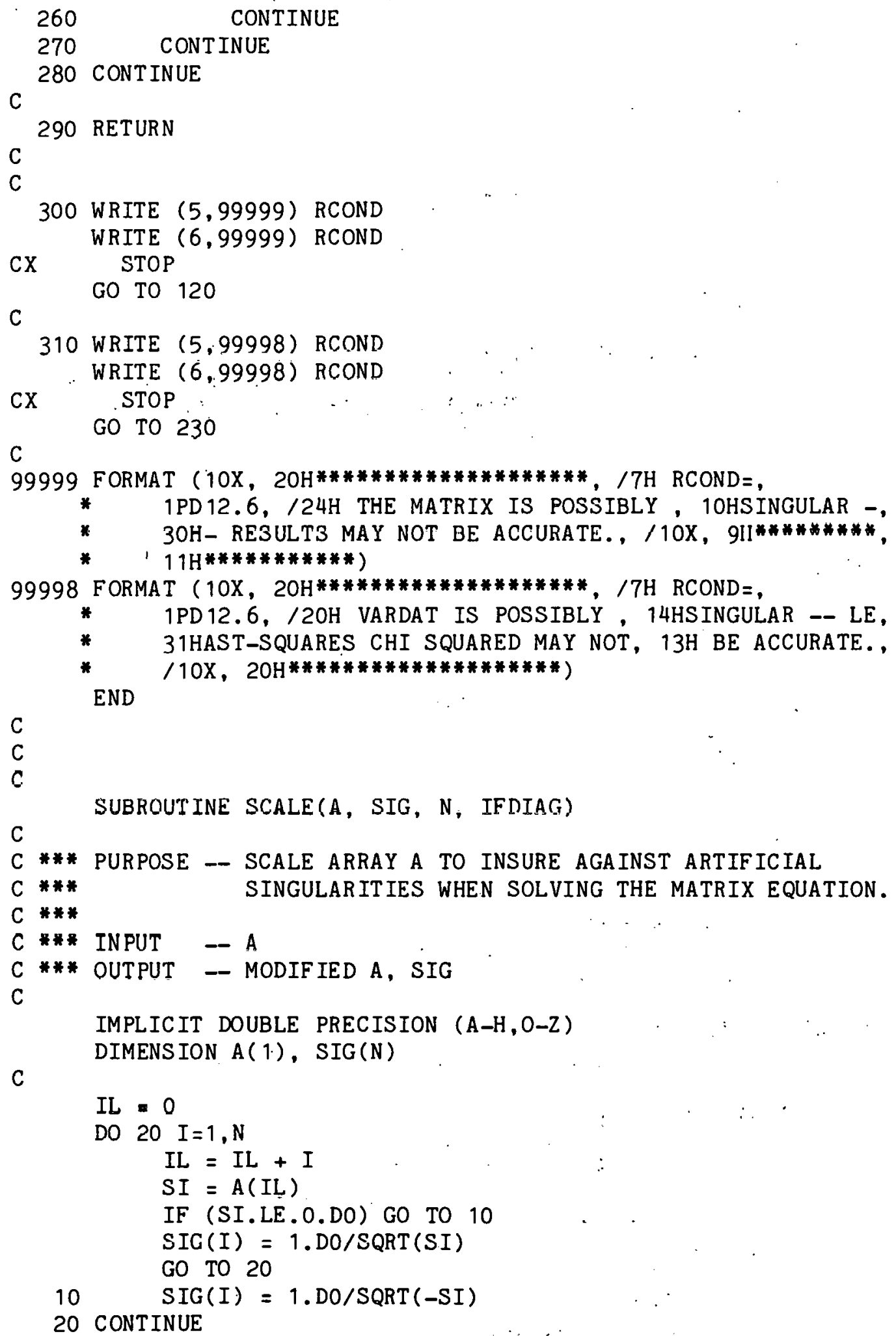


C

IFDIAG $=0$

$\mathrm{IL}=0$

DO $40 I=1, N$

$S I=S I G(I)$

DO $30 \mathrm{~L}=1, \mathrm{I}$

$I L=I L+1$

IF (I.NE.L .AND. A(IL),NE. O.DO) IFDIAG = 1

30

$A(I L)=A(I L) * S I * S I G(L)$

C

40 CONTINUE

RETURN

END

$\mathrm{C}$

C

C

SUBROUT INE MUL

$\mathrm{C}$

C *** PURPOSE -- GENERATE EMG(IDAT, IPAR) = (SUM OVER JPAR)

$C * * *$

C *** G(IDAT, JPAR) *

VARPAR (JPAR AND IPAR)

$\mathrm{C}$

IMPLICIT DOUBLE PRECISION (A-H,O-Z)

COMMON /NUMBER/ NDAT, NPAR, ITER, ITMAX, CONVER

COMMON /PAR/ POLD(25), PARM(25), PDUM(25), VARPAR(325),

* VARNEW(325), IDUM(25)

COMMON/BOTH/ G(51,25), EMG $(51,25)$

C

C

$\mathrm{JK}=0$

DO $60 \mathrm{~J}=1$, NPAR

DO $10 \mathrm{~L}=1$, NDAT

$\operatorname{EMG}(\mathrm{L}, \mathrm{J})=0 . \mathrm{DO}$

10 CONT INUE

DO $50 \mathrm{~K}=1$, NPAR

IF (J.GE.K) GO TO 20

$K J=\left(K^{*}(K-1)\right) / 2+J$

$E M=\operatorname{VARPAR}(K J)$

GO - TO 30

20

$\mathrm{JK}=\mathrm{JK}+1$

$\mathrm{EM}=\operatorname{VARPAR}(\mathrm{JK})$

30

CONTINUE

IF (EM.EQ.O.DO) GO TO 50

DO $40 \mathrm{~L}=1$, NDAT

40

$\operatorname{EMG}(\mathrm{L}, \mathrm{J})=\operatorname{EMG}(\mathrm{L}, \mathrm{J})+\mathrm{EM}^{*} \mathrm{G}(\mathrm{L}, \mathrm{K})$

50 CONTINUE

60 CONTINUE

RETURN

END 







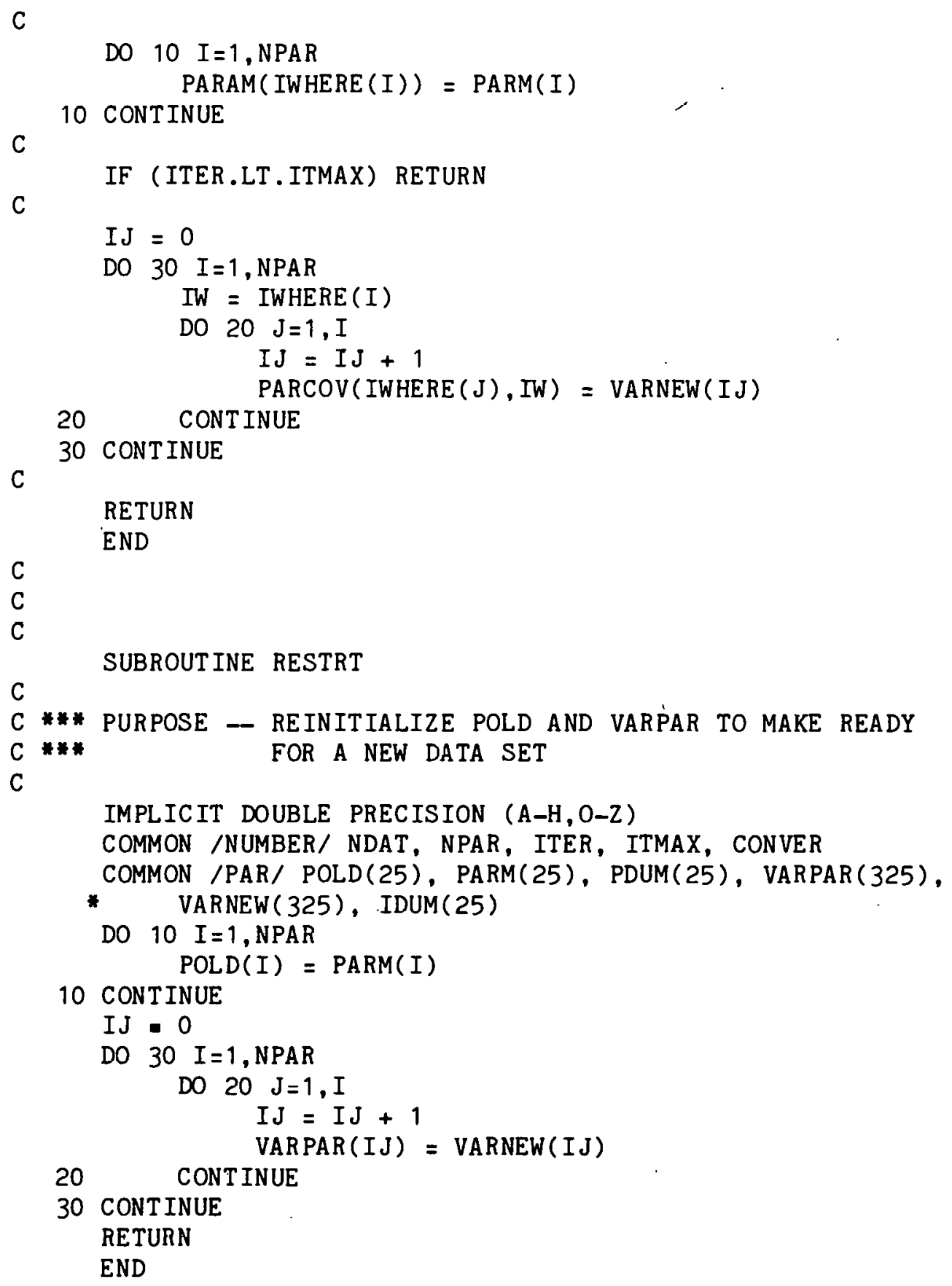


THIS PAGE

\section{WAS INTENTIONALLY \\ LEFT BLANK}


APPENDIX D

FøRTRAN LISTING OF ROUTINES UNIQUE TO PROGRAM LEAST 


\section{THIS PAGE \\ WAS INTENTIONALLY \\ LEFT BLANK}


C

C

C

C

C

C

C

C

C

C

C

C

C

C

C

C

C

C

c

C

C

C

C

C

C

C

C

C

C

C

C

C

C

C

C

C

C

C

C
PROGRAM LEAST

PROGRAM TO SOLVE LEAST SQUARES EQUATIONS FOR UPDATING PARAMETER VALUES BASED ON INPUT DATA AND APPROPRIATE THEORY (TO BE PROVIDED BY THE USER)

N.M.LARSON, JANUARY 1981

INPUT TO LEAST PROGRAM IS ON UNIT 5(TELETYPE) -- THE PROGRAM WILL PROMPT YOU BY ASKING APPROPRIATE QUESTIONS.

OUTPUT FROM LEAST IS ON UNIT 6.

FOR LEAST METHOD : SOLVE THESE EQUATIONS

( $P$ BAR SUPER $N+1)-(P$ BAR SUPER $N$ )

$=$ ( $G$ TRANSPOSE * V INVERSE * G) INVERSE *

$G$ TRANSPOSE * V INVERSE *

( D - ( T BAR SUPER N)

AND

$(M$ SUPER $N+1)=(G$ TRANSPOSE * V INVERSE * G) INVERSE

NOTATION IS AS FOLLOWS --

FORTRAN THEORETICAL NAME NAME

E

E2

NDAT

NPAR

DATA D

DATCOV V
MEANING

ENERGY, OR FIRST INDEPENDENT

PARAMETER

SECOND INDEPENDENT PARAMETER

NUMBER OF DATA POINTS

NUMBER OF PARAMETERS TO BE VARIED

EXPERIMENTAL DATA

DATA COVARIANCE MATRIX 
VARDAT V

POLD P BAR

TH T BAR SUPER N

G G

PARM P BAR SUPER

PARM P BAR SUPER $\mathrm{N}+1$

VARNEW M SUPER $\mathrm{N}+1$
COVARIANCE MATRIX FOR DATA, STORED

IN TRIANGULAR FORM AS

$\begin{array}{llllllll}1 & 2 & 4 & 7 & \ldots & \text { OR } 1\end{array}$

$358 \quad 23$

$69 \quad 456$

$10 \quad 78910$

...

INITIAL ESTIMATE OF PARAMETERS

THEORETICAL VALUE FOR DATA, EVALUATED

AT CURRENT VALUE OF PARAMETERS

PARTIAL DERIV OF (TH) WITH

RESPECT TO PARAMETERS, EVALUATED

AT ENERGY E $\Lambda$ ND $\Lambda T$ CURRENT VALUE

OF PARAMETERS, STORED AS G(NDAT,NPAR)

INTERMEDIATE (OR CURRENT) VALUIES OF

PARAMETERS

NEW VALUES OF PARAMETERS

NEW VALUES FOR PARAMETER COVARIANCES

$\mathrm{C}$

$\mathrm{C}$

C

IMPLICIT DOUBLE PRECISION (A-H,O-Z)

LOGICAL JJPAR, JJDAT, JJTH, JJG, JJREL, JJCHL,

* JJREB, JJCHB, JJGMG

C

COMMON /NUMBER/ NDAT, NPAR, ITER, ITMAX, CONVER

COMMON /PAR/ POLD(25), PARM(25), PDUM(25), VARPAR(325),

* VARNEW(325), IDUM(25)

C. *** $f(1)(11 *(11,1)) /$ ?

$\mathrm{C}$

COMMON /DAT/ E(51), E2(51), DATA(51), $\operatorname{VARDAT}(1326)$,

* EN(1326), TH(51), DUM(51), SIG(51)

C *** $1326=(51 *(51+1)) / 2$

C

COMMON /BOTH/ $G(51,25), \operatorname{EMG}(51,25)$

$c$

COMMON /YRPAR/ PARAM(26), $\operatorname{PARCOV}(26,26), \operatorname{YDUM}(26)$,

* IYdUM(20), IFPAR(20), IWHERE(26), NPARAM.

C

DATA NDATMX /51/, NPARMX /25/, NNPARM/ 26/

DATA YES /1HY/

C

C

CALL OUTALL(JJPAR, JJDAT, JJTH, JJG, JJREL, JJCHL,

* JJREB, JJCHB, JJGMG) 
C

WRITE $(5,99999)$

WRITE $(6,99999)$

WRITE $(5,99998)$

READ $(5,99997)$, ITMAX, CONVER

C

WRITE $(6,99996)$ ITMAX, CONVER

WRITE $(5,99995)$

READ $(5,99994)$ AUTO

IF (AUTO.NE.YES) GO TO 10

C

WRITE $(5,99993)$

READ $(5,99992)$ HBASE

C

WRITE $(6,99991)$ HBASE

C

10 CALL PPARAM(NNPARM)

C

OUTPUT FROM PPARAM -- NPAR, PARM, PARAM, POLD, NPARAM

IF (NPAR.GT.NPARMX) GO TO 30

CALL SETDAT

OUTPUT FROM SETDAT -- NDAT,E, DATA, VARDAT

CALL FIXV

C

C

$\mathrm{C}$

C

IF (NDAT.GT.NDATMX) GO TO 40

IF ( JJDAT) CALL OUTDAT

INPUT TO OUTDAT - NDAT,E, DATA, VARDAT

C

OUTDAT WRITES OUT DATA, COVARIANCE MATRIX

$\mathrm{C}$

$\mathrm{C}$

ITER $=0$

20 CALL THEORY(AUTO, HBASE)

C

THEORY GENERATES THE FUNCTION AND ITS DERIVATIVES

INPUT - TO THEORY - NPAR, NDAT, PARM, E

OUTPUT FROM THEORY -- TH,G

IF (JJTH) CALL OUTTH

INPUT TO OUTTH -- NDAT, E, DATA, TH

C

$\mathrm{C}$

$\mathrm{C}$

$\mathrm{C}$

OUTTH PRINTS THEORY (TH) AND DATA (DATA) VS ENERGY (E)

IF ( JJG) CALL OUTG

INPUT TO OUTG -- NPAR, NDAT,E,G

OUTG PRINTS PARTIAL DERIVATIVES AT PARM 


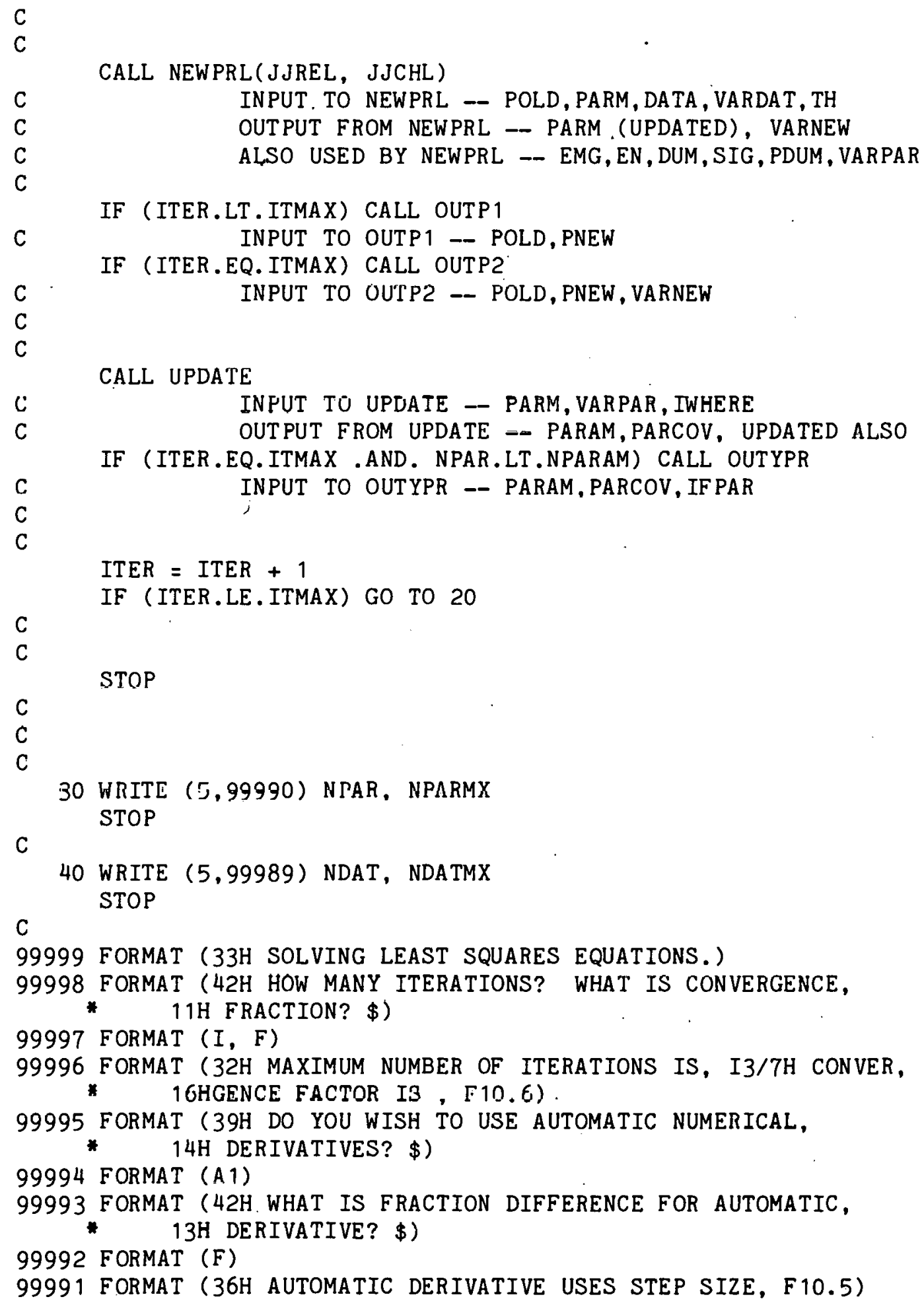




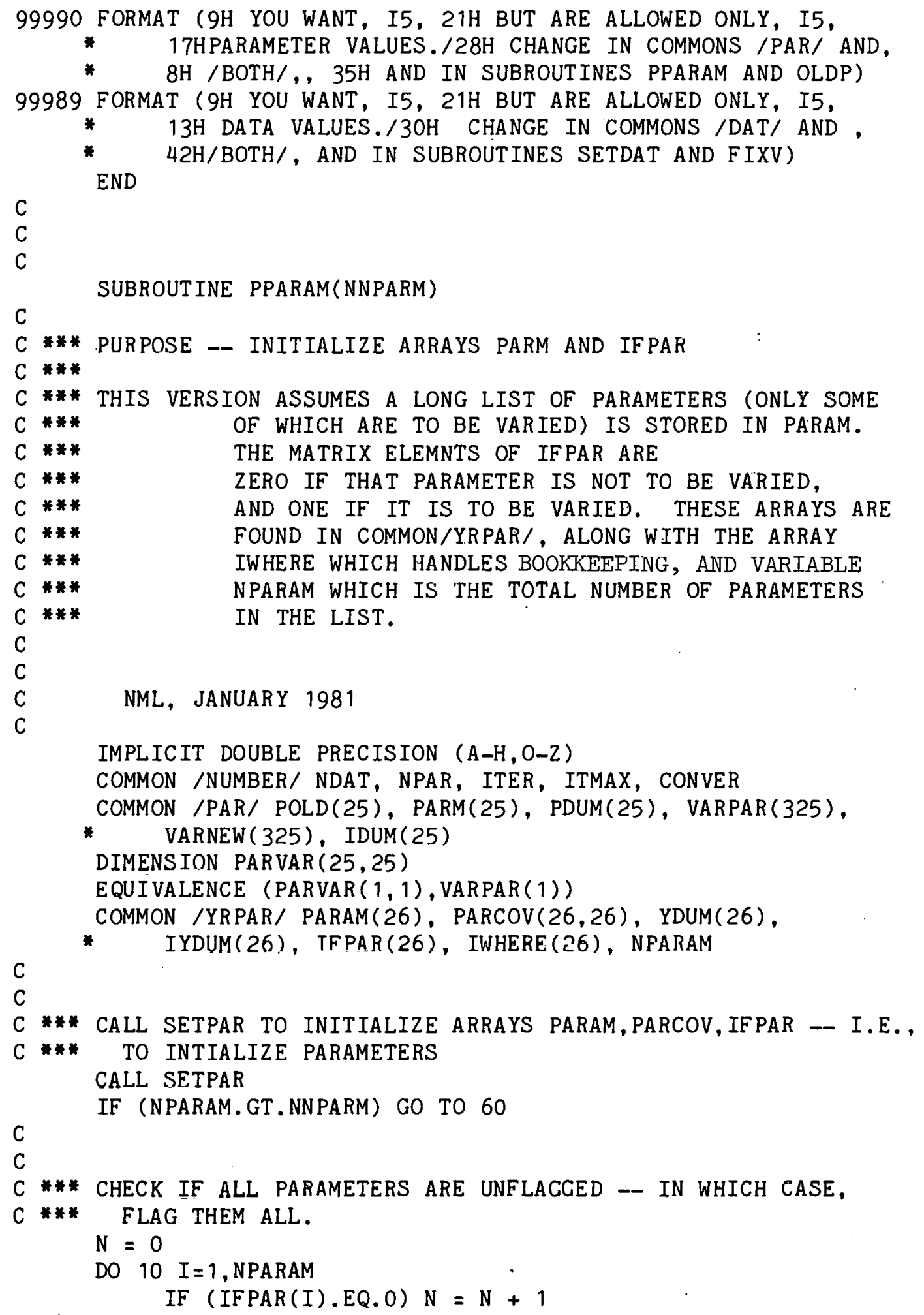




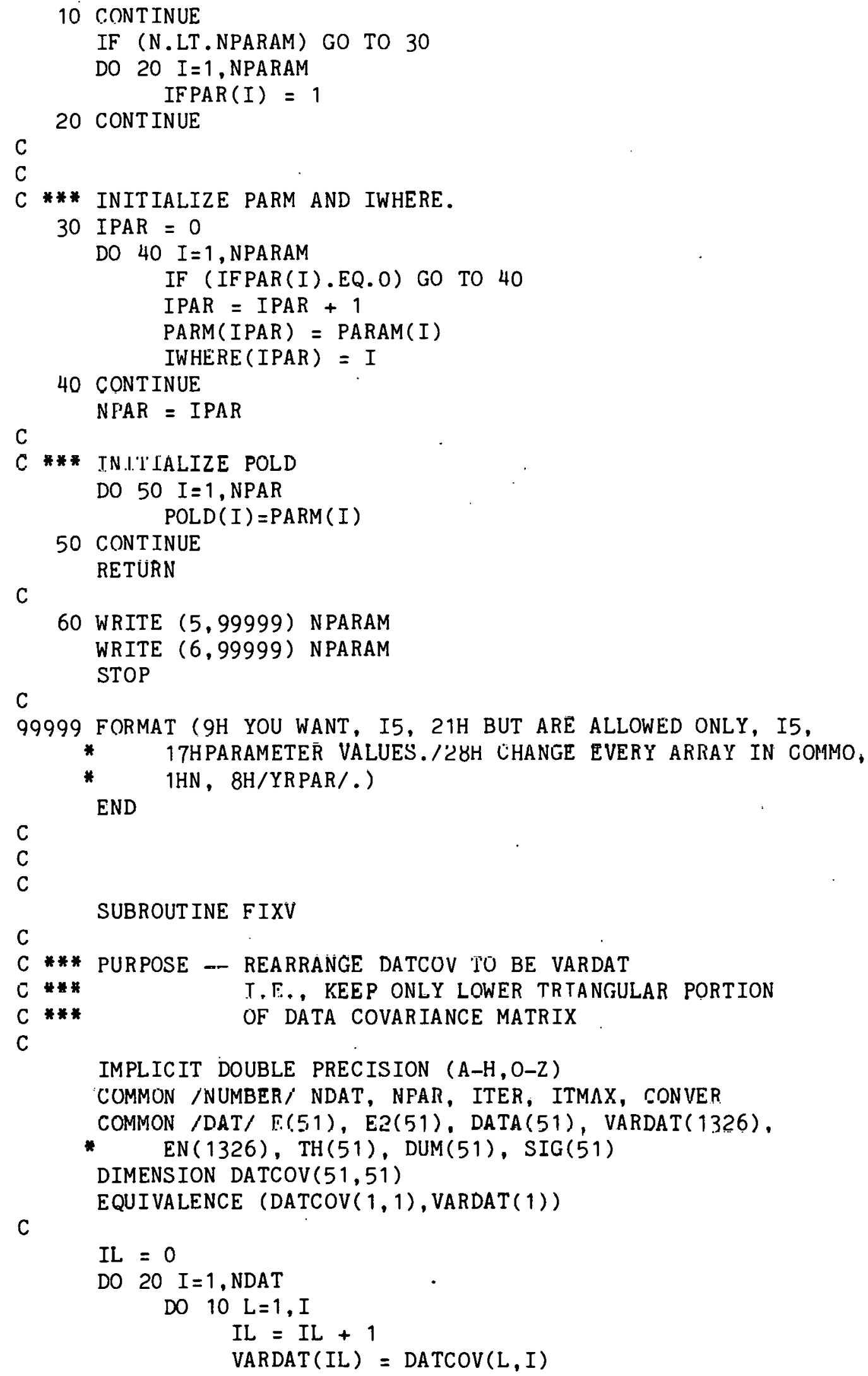

$I L=0$

DO $20 \quad I=1, N D A T$

DO $10 \mathrm{~L}=1, \mathrm{I}$

$I L=I L+1$

$\operatorname{VARDAT}(I L)=\operatorname{DATCOV}(L, I)$ 


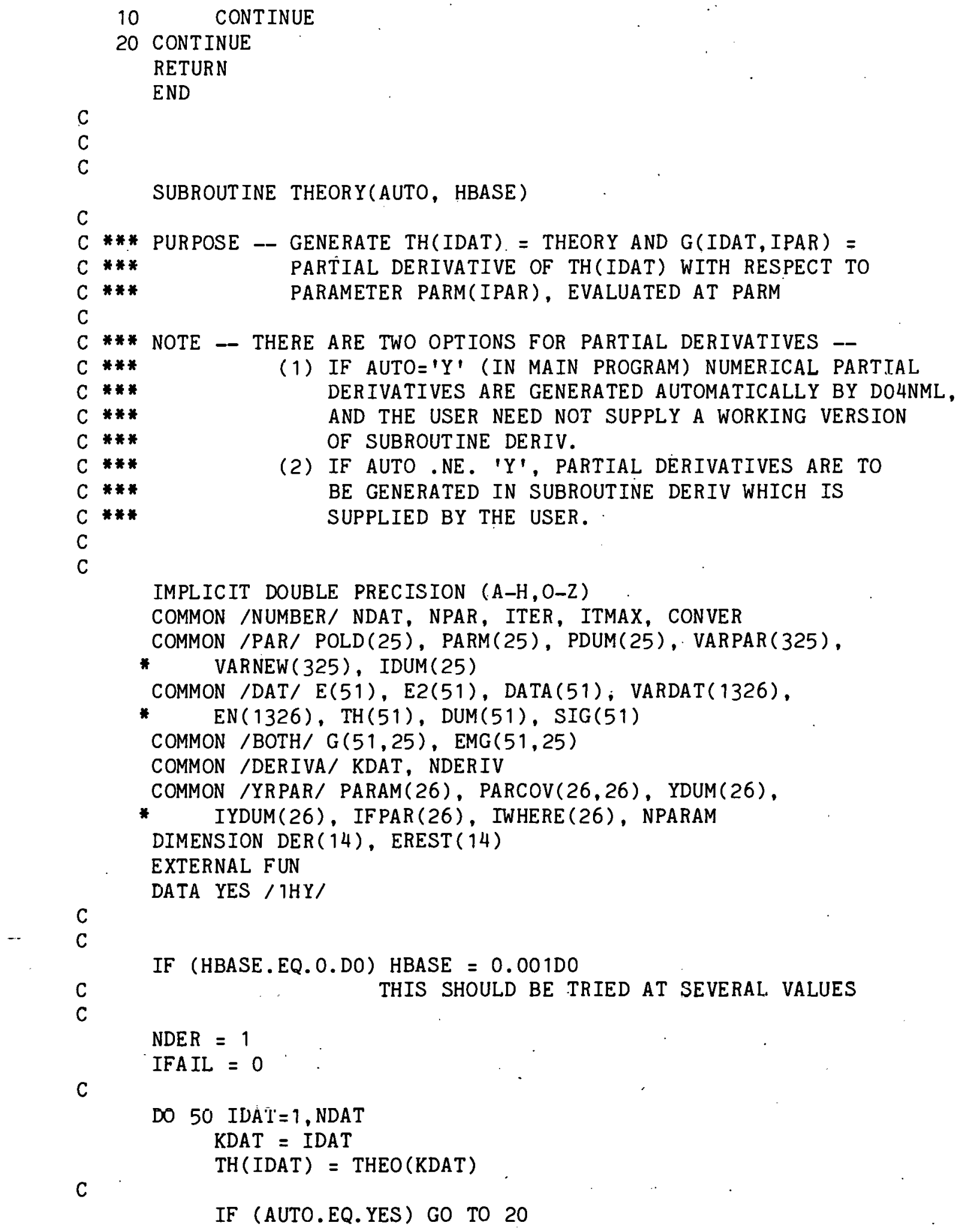




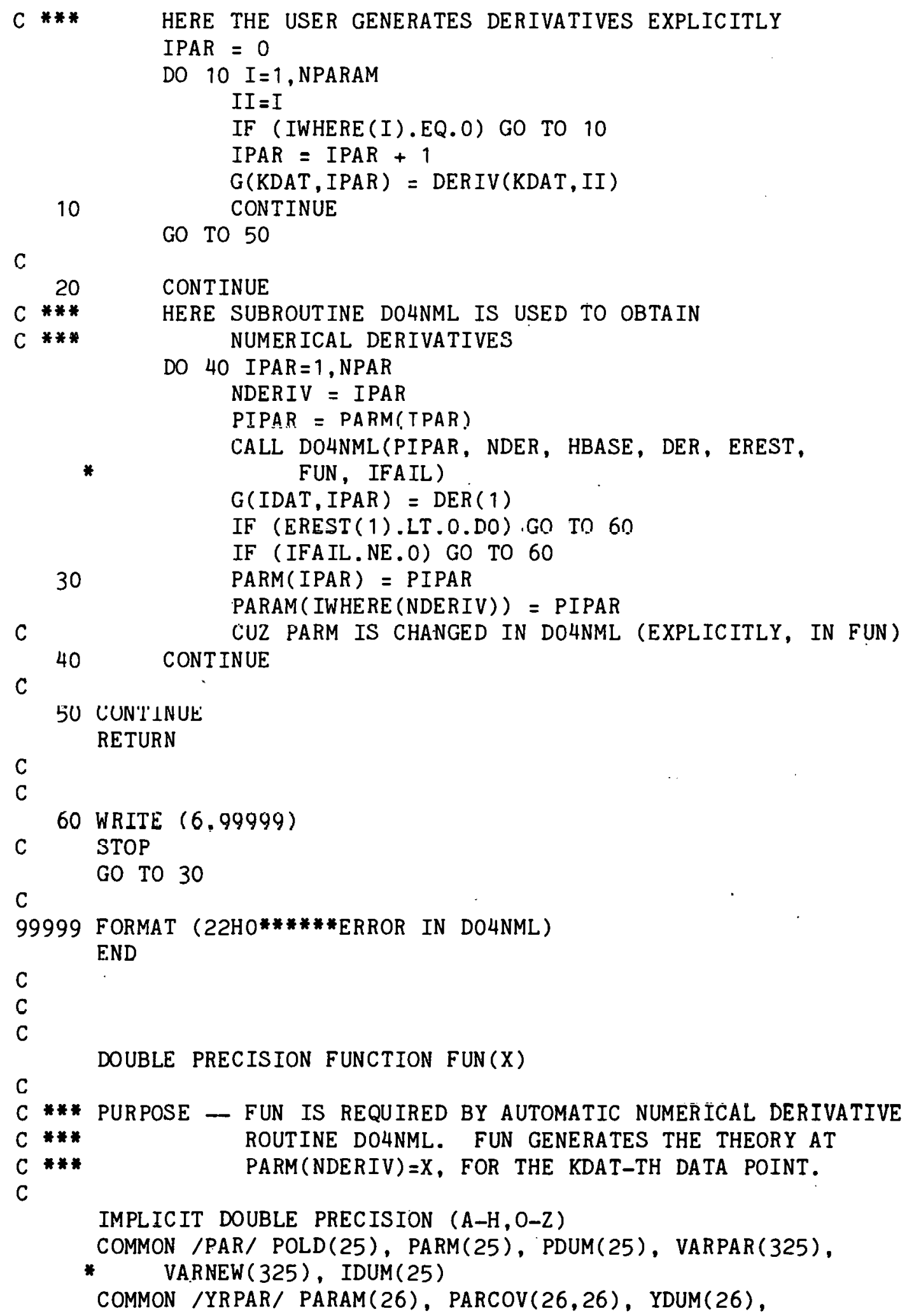




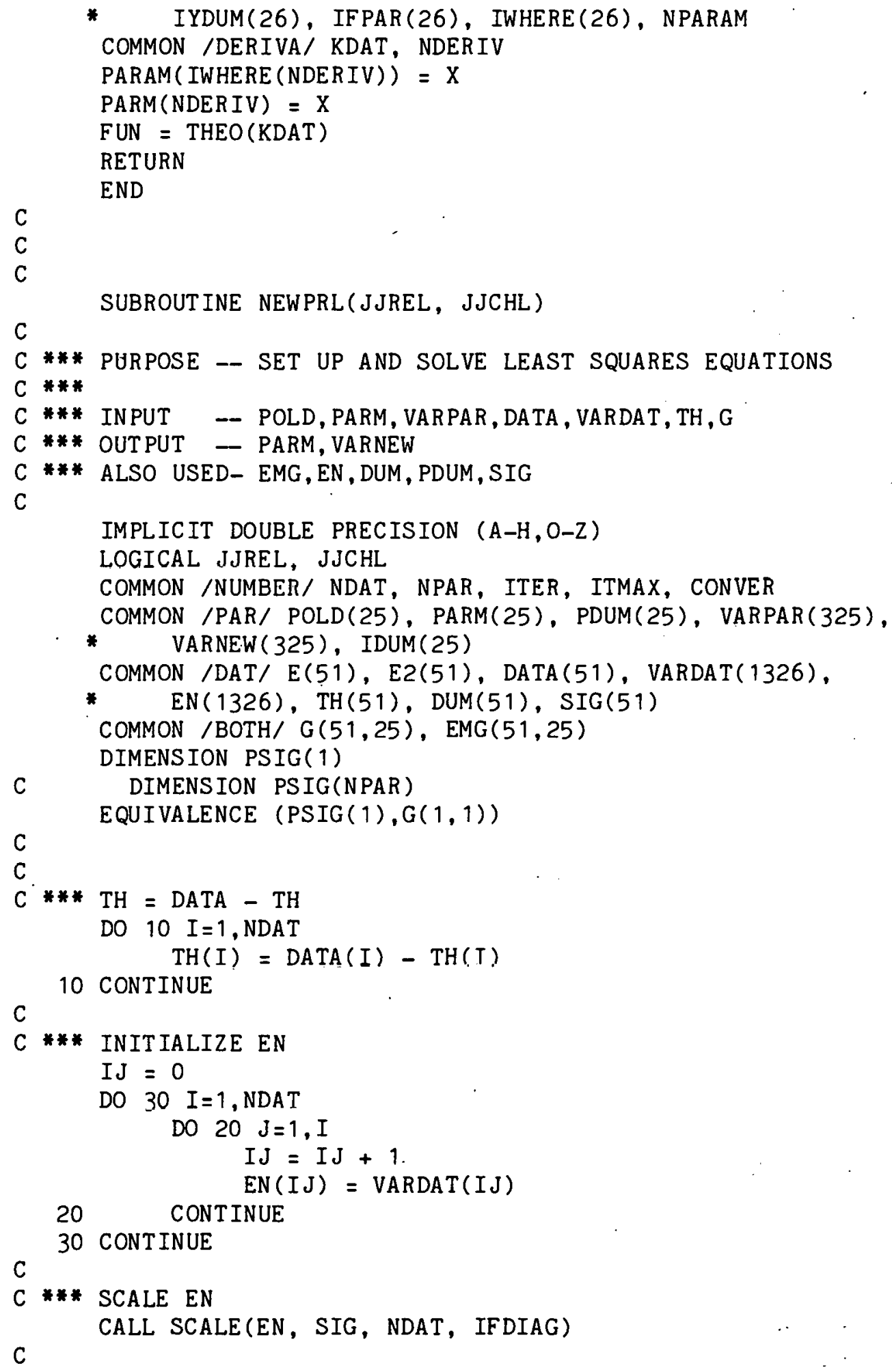




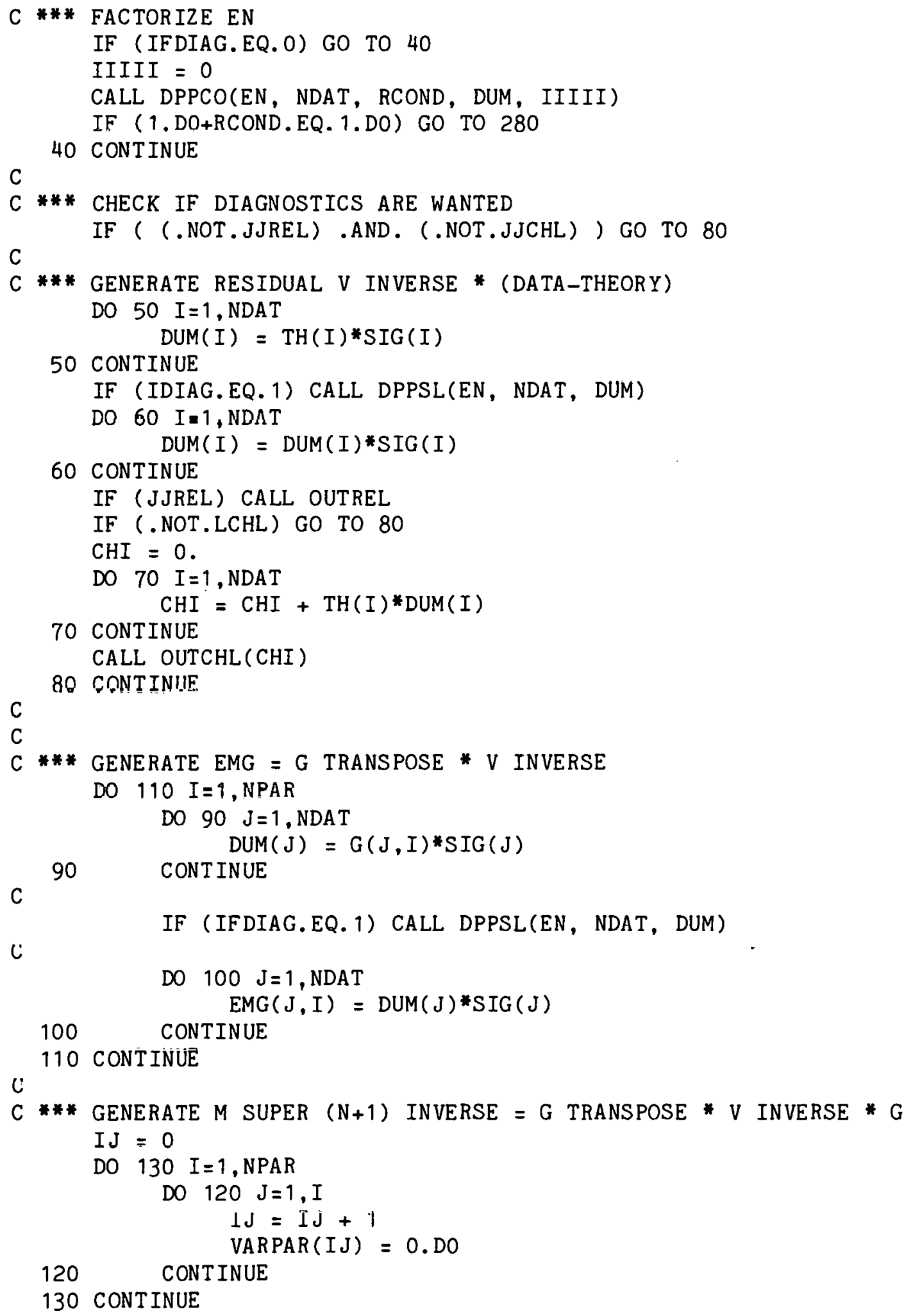


C

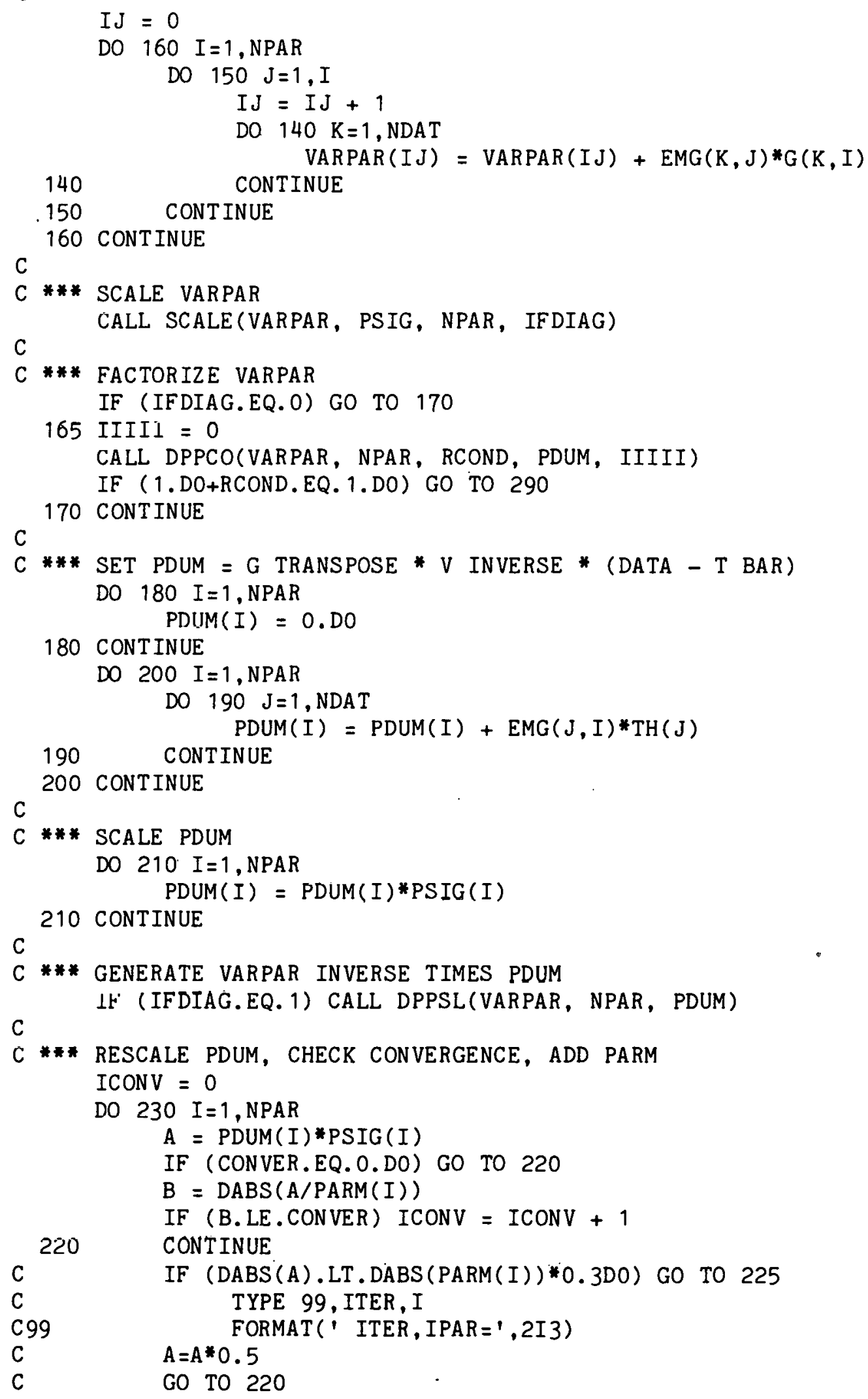




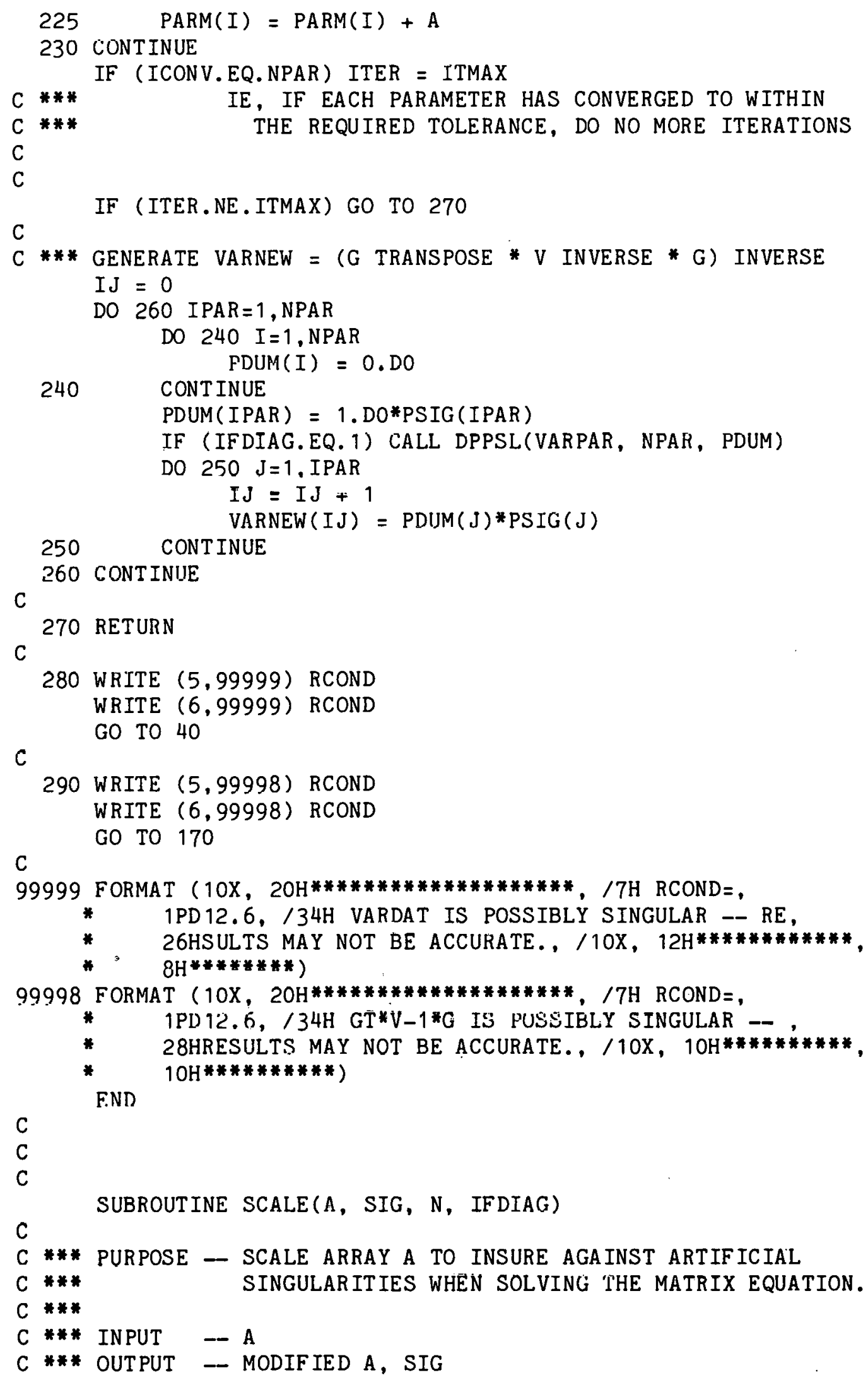


C

IMPLICIT DOUBLE PRECISION (A-H,O-Z)

DIMENSION A(1), SIG(N)

C

$\mathrm{IL}=0$

DO $20 \quad I=1, N$

$I L=I \dot{L}+I$

$S I=A(I L)$

IF (SI.LE.0.DO) GO TO 10

$\operatorname{SIG}(I)=1 . \mathrm{DO} / \mathrm{SQRT}(\mathrm{SI})$

GO TO 20

10

$\mathrm{SIG}(\mathrm{I})=1 . \mathrm{DO} / \mathrm{SQRT}(-\mathrm{SI})$

C

20 CONTINUE

$$
\text { IFDIAG }=0
$$

$\mathrm{IL}=0$

DO $40 I=1, N$

$S I=S I G(I)$

DO $30 \mathrm{~L}=1, \mathrm{I}$

$I L=I L+1$

IF (I.NE.L .AND. A(IL).NE.0.DO) IFDIAG $=1$

30 $A(I L)=A(I L) * S I * S I G(L)$

40 CONT INUE

C

RETURN

END

C

C

C

SUBROUT INE UPDATE.

$\mathrm{C}$

C *** PURPOSE -- UPDATE THE ARRAYS PARAM AND PARCOV TO AGREE WITH

$C * * *$

C **** NEW VALUES GENERATED IN NEWPAR, AND STORED IN PARM AND VARNEW

C NML, JANUARY 1981

$\mathrm{C}$

IMPLICIT DOUBLE PRECISION (A-H,O-Z)

COMMON /NUMBER/ NDAT, NPAR, ITER, ITMAX, CONVER

COMMON /PAR/ POLD(25), PARM(25); PDUM(25), VARPAR(325),

* VARNEW(325), IDUM(25)

COMMON /YRPAR/ PARAM(26), PARCOV(26,26), YDUM(26),

C

* IYDUM(26), IFPAR(26), IWHERE(26), NPARAM

DO $10 \quad I=1$, NPAR

$\operatorname{PARAM}(\operatorname{IWHERE}(I)$ ) = PARM(I)

10 CONT INUE 


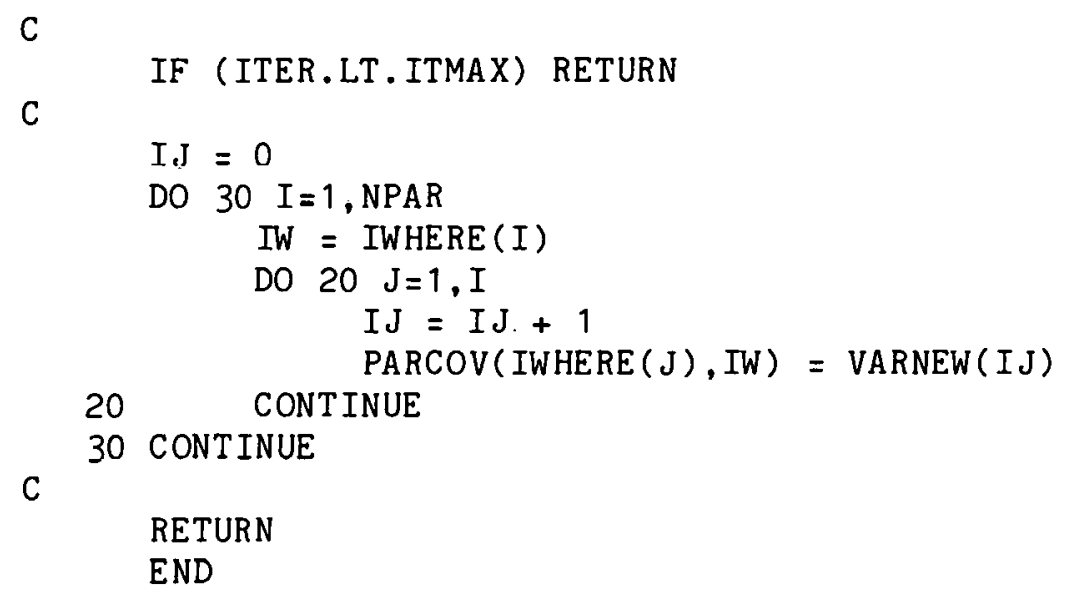


APPENDIX E

FØRTRAN LISTING OF OUTPUT ROUTINES 
THIS PAGE

\section{WAS INTENTIONALLY LEFT BLANK}




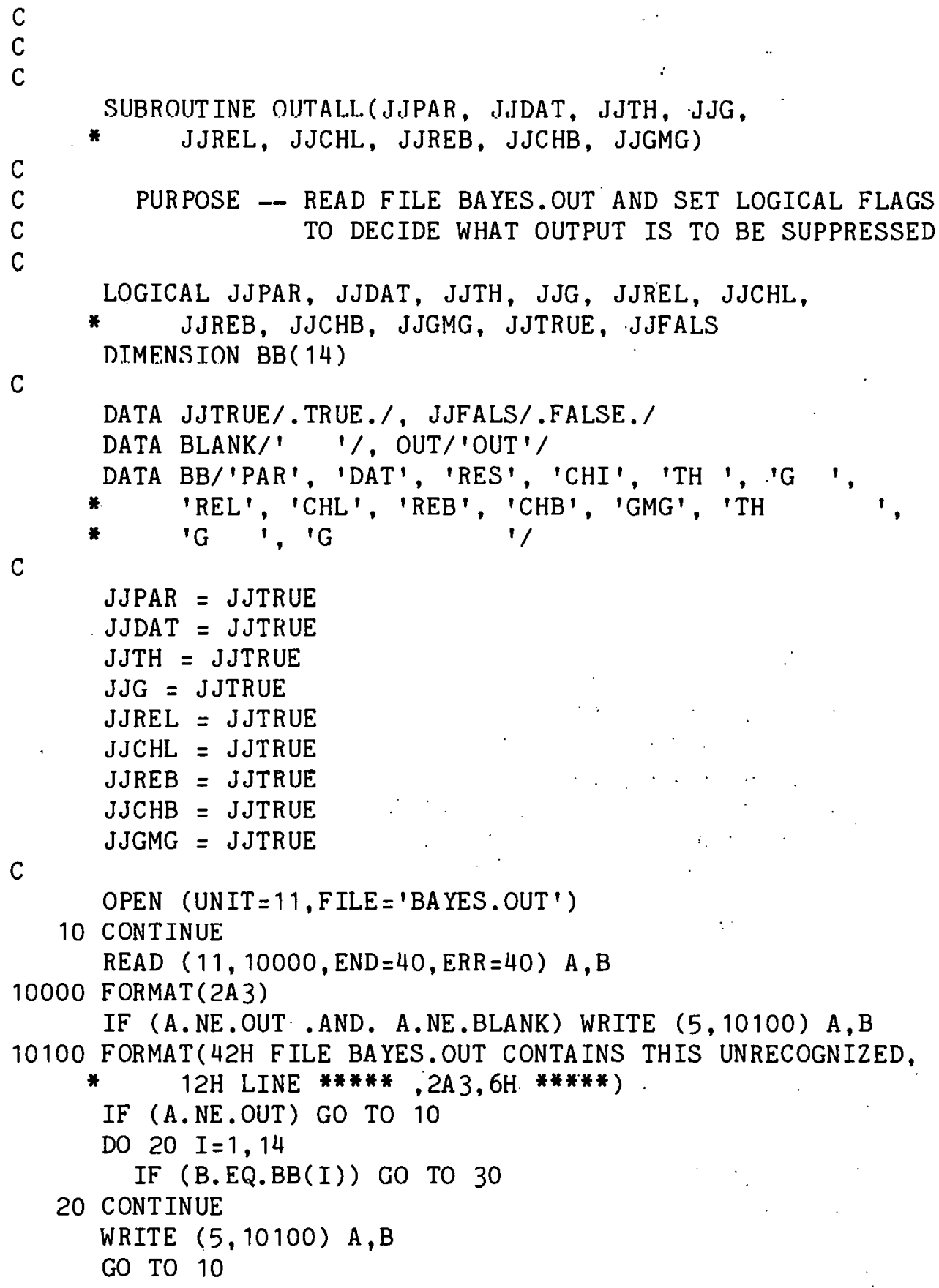


30 CONTINUE

IF (I.EQ. 1) JJPAR = JJFALS

IF (I.EQ. 2) JJDAT = JJFALS

IF (I.EQ.3) JJREL = JJFALS

IF (I.EQ. 3) JJREB = JJFALS

IF (I.EQ. 4) JJCHL = JJFALS

IF (I.EQ.4) JJCHB = JJFALS

IF (I.EQ.5) JJTH = JJFALS

IF (I.EQ.6) JJG = JJFALS

IF (I.EQ.7) JJREL = JJFALS

IF (I.EQ.8) JJCHL = JJFALS

IF (I.EQ. 9) JJREB = JJFALS

IF (I. EQ. 10) JJCHB = JJFALS

IF (I.EQ. 11) JJGMG = JJFALS

IF (I.EQ. 12) JJTH = JJFALS

IF (I.EQ.13) JJG = JJFALS

IF. (I.EQ. 14) JJG = JJFALS

GO TO 10

40 RETURN

END

C

$\mathrm{C}$

C

SUBROUT INE OUTPAR

IMPLICIT DOUBLE PRECISION (A-H, O-Z)

COMMON /NUMBER/ NDAT, NPAR, ITER, ITMAX, CONVER

COMMON /PAR/ POLD(25), PARM(25), PDUM(25), VARPAR(325),

* VARNFW(325), IDUM(25)

COMMON /DAT/ E(51), E2(51), DATA(51), VARDAT(1326),

* EN(1326), TH(51), DUM(51), SIG(51)

C

COMMON /BOTH/ G(51,25), EMG $(51,25)$

C

WRITE $(6,99999)$

II $=0$

DO $10 I=1$, NPAR

$I I=I I+I$

$\operatorname{PDUM}(I)=\operatorname{ISQRT}(\operatorname{VARPAR}(I I))$

10 CONT INUE

C

WRITE $(6,99998)$

WRITE $(6,99997)$ (I,PARM (I), PDÚM (I), I=1, NPAR)

C

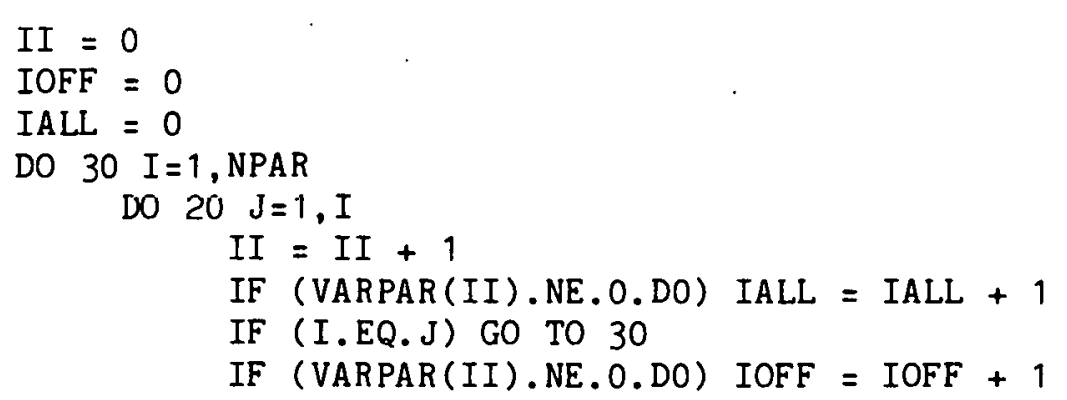




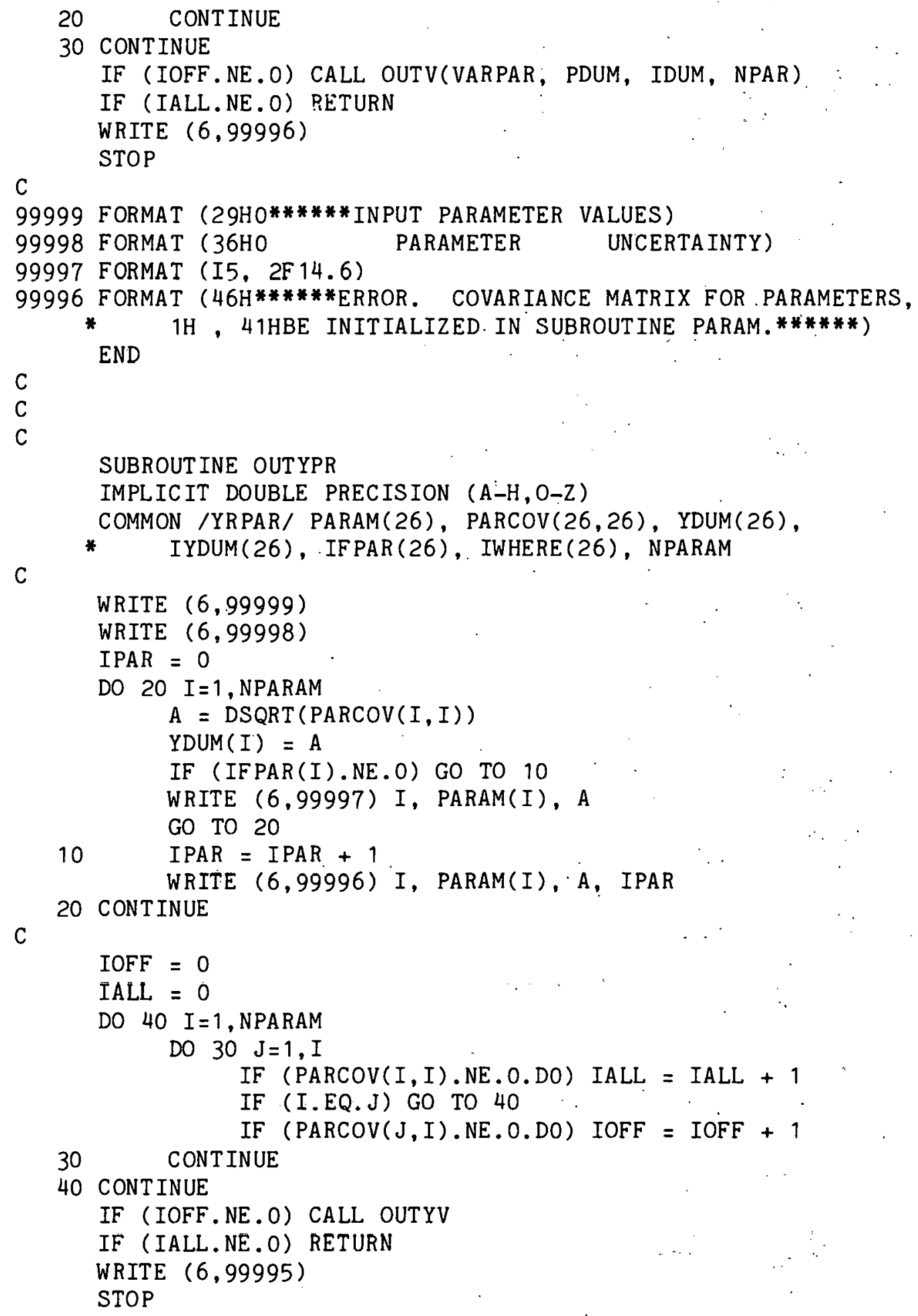


C

99999 FORMAT (40H0******COMPLETE LIST OF PARAMETER VALUES)

99998 FORMAT (36H0 PARAMETER UNCERTAINTY, 6H V,

* 22HAR IEd PARAMETER NUMBER)

99997 FORMAT (I5, 2F 14.6)

99996 FORMAT (I5, 2F 14.6, I 10)

99995 FORMAT (46H******ERROR. COVARIANCE MATRIX FOR PARAMETERS, * $1 \mathrm{H}$, 44HMUST BE INITIALIZED IN SUBROUTINE SETPAR.***, END

$\mathrm{C}$

$\mathrm{C}$

$\mathrm{C}$

SUBROUT INE OUTDAT

IMPLICIT DOUBLE PRECISION (A-H,O-Z)

COMMON /NUMBER/ NDAT, NPAR, ITER, ITMAX, CONVER

COMMON /PAR/ POLD(25), PARM(25), PDUM(25), VARPAR(325),

* VARNEW( 325$), \operatorname{IDUM}(25)$

COMMON IDAT/ E(51), E2(51). DATA(b1), VARDAT(1326),

* EN(1326), TH(51), DUM(51), SIG(51)

COMMON /BOTH/ $G(51,25)$, $\operatorname{EMG}(51,25)$

DIMENSION IDDUM( 1 )

EQUIVALENCE (IDDUM( 1),SIG(1))

C

WRITE $(6,99999)$

C

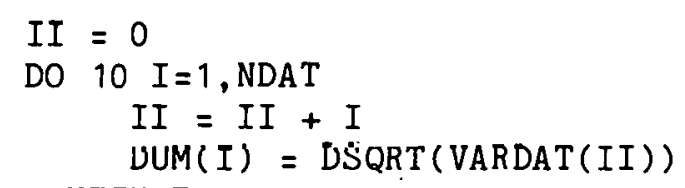

C

10 CONTINUE

WRITE $(6,99998)$

WRTTE $(6,99997)\left(I, E(I), \operatorname{DATA}(I), \operatorname{DUM}(I), I=1, N \cup A I^{\prime}\right)$

C

II $=0$

IOFF $=0$

DO $30 I=1, N D A T$

DC $20 \mathrm{~J}=1, \mathrm{I}$

$I I=I I+1$

IF (I.EQ.J) GO TO 30

IF (VARDAT (II).NE.O.DO) IOFF = IOFF + 1

20 CONTINUE

30 CONTINIIE

IF (IOFF.NE.0) CALL OUTV(VARDAT, DUM, IDDUM, NDAT)

RETURN

C

99999 FORMAT (25HO****** INPUT DATA VALUES)

99998 FORMAT (46HO DATA POINT VALUE UNCERTAIN,

* 2HTY)

99997 FORMAT (I5, 3F 14.6)

END 
C
C
C

SUBROUTINE OUTTH

IMPLICIT DOUBLE PRECISION (A-H,O-Z)

COMMON /NUMBER/ NDAT, NPAR, ITER, ITMAX, CONVER

COMMON /PAR/ POLD(25), PARM(25), PDUM(25), VARPAR(325),

* VARNEW(325), $\operatorname{IDUM}(25)$

COMMON /DAT/ E(51), E2(51), DATA(51), VARDAT(1326),

* $\operatorname{EN}(1326), \mathrm{TH}(51), \operatorname{DUM}(51), \operatorname{SIG}(51)$

C

COMMON /BOTH/ $\mathrm{G}(51,25), \operatorname{EMG}(51,25)$

WRITE $(6,99999)$

WRITE $(6,99998)$

WRITE $(6,99997)(I, E(I), \operatorname{DATA}(I), T H(I), I=1, N D A T)$

RETURN

C

99999 FORMAT (30H0***** THEORETICAL CALCULATION)

99998 FORMAT (45HO ENERGY DATA

99997 FORMAT (I5, 3F 14.6)

END

$\mathrm{C}$

C

C

SUBROUTINE OUTG

$\mathrm{C}$

C *** PURPOSE -- OUTPUT E VS G

$\mathrm{C}$

C NML, AUGUST 1980

C

IMPLICIT DOUBLE PRECISION (A-H,O-Z)

COMMON /NUMBER/ NDAT, NPAR, ITER, ITMAX, CONVER

COMMON /PAR/ POLD(25), PARM(25), PDUM(25), VARPAR(325),

* VARNEW(325), IDIM(25)

COMMON /DAT/E(51), E2(51), DATA(51), VARDAT(1326),

* EN(1326), TH(51), DUM(51), SIG(51)

COMMON /BOTH/ $G(51,25)$, EMG $(51,25)$

C

DATA T2 /10H ENERGY /

C

WRITE $(6,99999)$

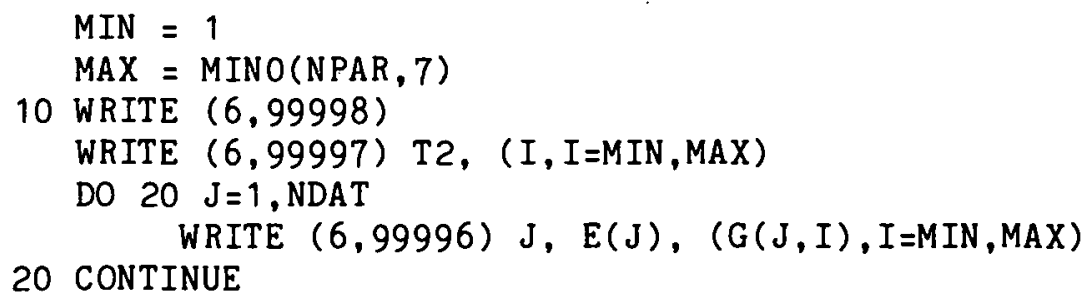


C

IF (MAX.EQ.NPAR) GO TO 30

MIN $=$ MAX + 1

$\operatorname{MAX}=\operatorname{MAX}+7$

IF (MAX.GT.NPAR) MAX = NPAR

GO TO 10

C

30 RETURN

99999 FORMAT (27HO****** PARTIAL DERIVATIVES)

99998 FORMAT (20X)

99997 FORMAT (10X, A 10, I10, 6I 14)

99996 FORMAT (I4, 2X, 1PG 14.6, 2X, 7G 14.5)

END

l

C

C

SUBROUT INE OUTP 1

IMPLICIT DOUBLE PRECISION (A-H,O-Z)

COMMON /NUMBER/ NDAT, NPAR, ITER, ITMAX, CONVER

COMMON /PAR/ POLD(25), PARM(25), PDUM(25), VARPAR(325),

* VARNEW(325), IDUM(25)

COMMON /DAT/ E(51), E2(51), DATA(51), VARDAT(1326),

* EN(1326), TH(51), DUM(51), SIG(51)

C

COMMON /BOTH/ G(51,25), $\operatorname{EMG}(51,25)$

WRITE $(6,99999)$

WRIIE $(6,99998)$

C

DO $10 I=1, N P A R$

WRITE $(6,99997)$ I, POLD(I), PARM(I)

10 CONTINUE

RETURN

C

99999 FORMAT (27HO***** INTERMEDIATE RESULTS)

99998 FORMAT $(38 \mathrm{HO}$
99997 FORMAT $(\mathrm{I5}, 5 \mathrm{~F} 14.6)$

END

C

C

r.

SUBROITTNE OUTP2

IMPLICIT DOUBLE PRECISION (A-H,O-Z)

COMMON /NUMBER/ NDAT, NPAR, ITER, ITMAX, CONVER

COMMON /PAR/ POLD(25), PARM(25), PDUM(25), $\operatorname{VARPAR}(325)$,

* VARNEW(325), IDUM(25)

COMMON /DAT/ E(51), E2(51), DATA(51), VARDAT(1326),

* EN(1326), TH(51), DUM(51), SIG(51)

C

COMMON /BOTH/ G(51,25), EMG $(51,25)$ 
WRITE $(6,99999)$

C

$$
\begin{aligned}
& I I= 0 \\
& D O \quad 10 I=1, N P A R \\
& I I=I I .+I \\
& \\
&\text { PDUM }(I)=\text { DSQRT (VARNEW }(I I))
\end{aligned}
$$

C

10 CONTINUE

WRITE $(6,99998)$

WRITE $(6,99997)(I, \operatorname{POLD}(I), \operatorname{PARM}(I), \operatorname{PDUM}(I), I=1, N \vdash \wedge(R)$

C

II $=0$

IOFF $=0$

DO $30 I=1$, NPAR

DO $20 \mathrm{~J}=1, \mathrm{I}$

$I I=I I+1$

IF (I.EQ.J) GO TO 30

20

IF (VARNEW(II),NE.O.DO) IOFF $=$ IOFF +1

30 CONTINUE

IF (IOFF.NE.0) CALL OUTV(VARNEW, PDUM, IDUM, NPAR)

RETURN

C

99999 FORMAT (34H0******* NEW VALUES FOR PARAMETERS)

99998 FORMAT (46HO

POLD

PNEW

UNCERTA INTY)

99997 FORMAT (I5, 3F 14.6)

END

$\mathrm{C}$

$\mathrm{C}$

C

SUBROUT INE OUTV (V, S, IC, N)

C

C *** PURPOSE -- OUTPUT TRIANGULAR VARIANCE V AS STD. DEV. AND CORRELATI

$\mathrm{C}$

C NML, AUGUST 1980

C

IMPLICIT DOUBLE PRECISION (A-H,O-Z)

DIMENSION $V(1), S(N), I C(N)$

$\mathrm{C}$

C

WRITE $(6,99999)$

C

$\mathrm{NN}=0$

MANY $=25$

$M=N / M A N Y$

$M M=M *$ MANY

IF (MM.NE.N) $M=M+1$

IMIN $=1-$ MANY

IMAX $=$ MINO(MANY,N) 


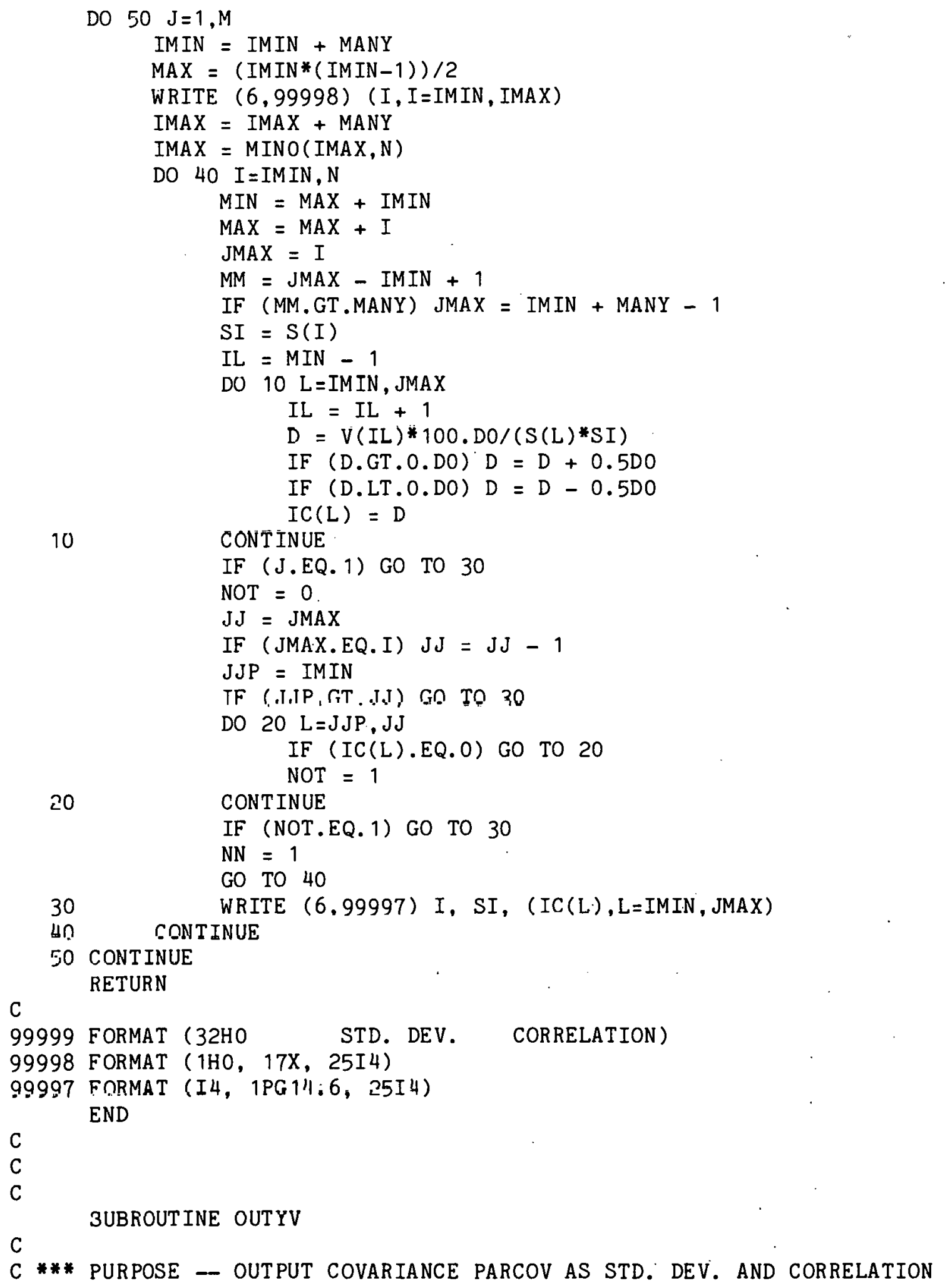




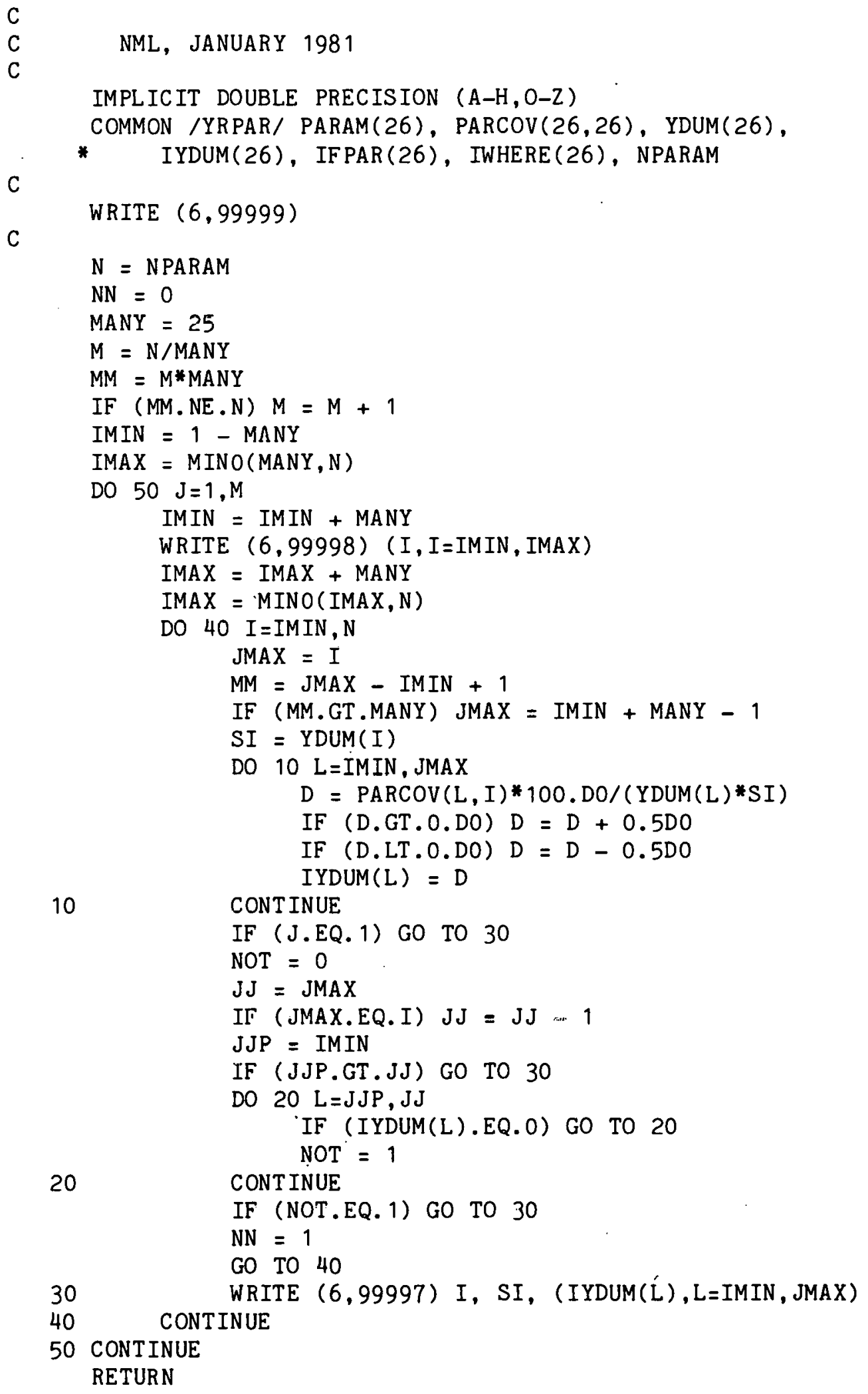




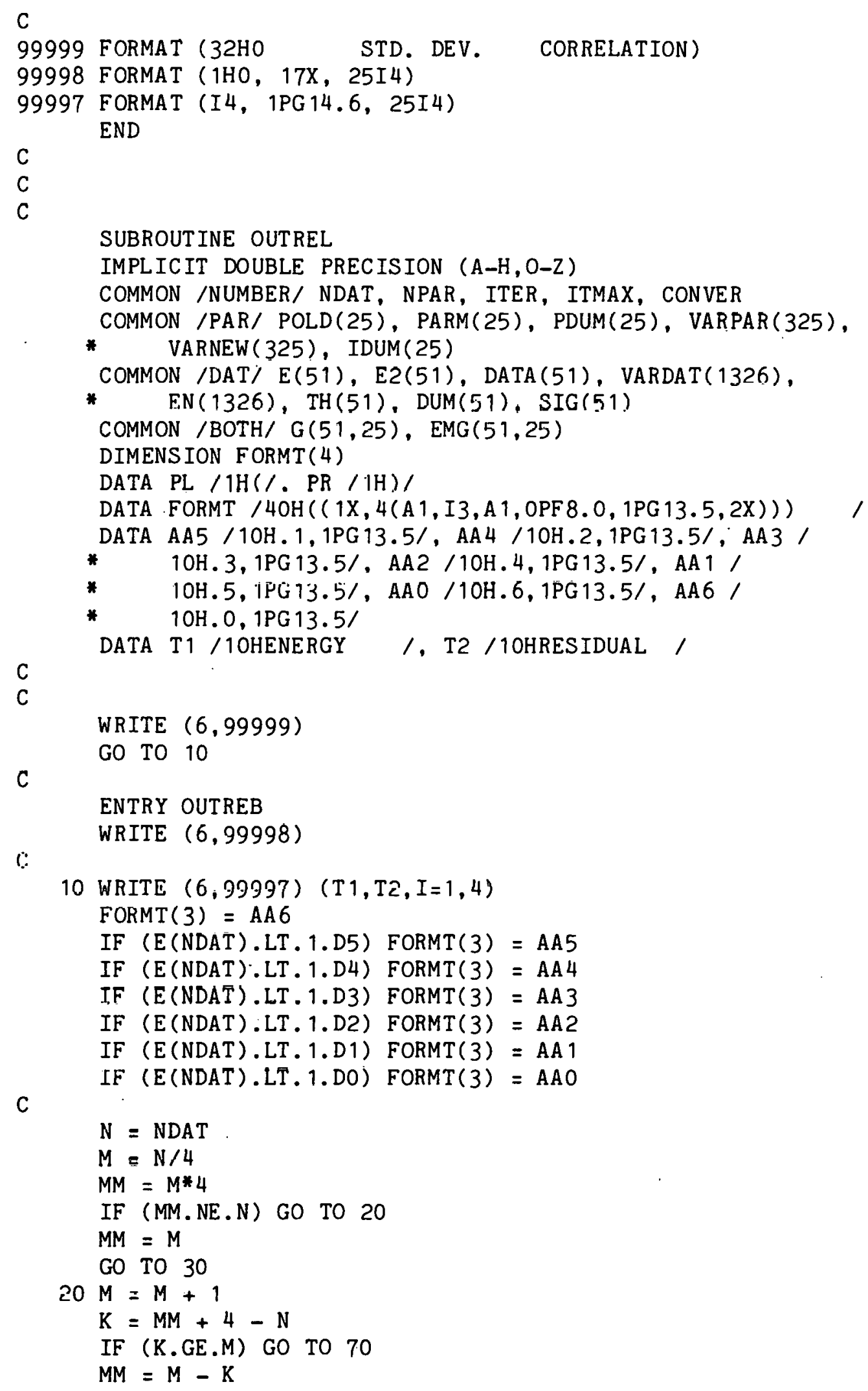


30 CONTINUE

$I M=3 * M$

DO $40 \quad I=1, M M$

$I M=I M+1$

WRITE $(6, F O R M T)(P L, L, P R, E(L), D U M(L), L=I, I M, M)$

40 CONTINUE

IF (MM.EQ.M) GO TO 60

$I M=2 * M+M M$

$M M=M M+1$

DO $50 \quad I=M M, M$

$I M=I M+1$

WRITE $(6, F O R M T)(P L, L, P R, E(L), D U M(L), L=I, I M, M)$

50. CONTINUE

60 CONTINUE

RETURN

70 WRITE (6,FORMT) (PL, I, PR, E (I), DUM(I), I=1,N)

RETURN

99999 FORMAT (39H0***** LEAST-SQUARES WEIGHTED RESIDUALS,

* 31H aT Former VALUES of PARAMETERS)

99998 FORMAT (34H0***** BAYESIAN WEIGHTED RESIDUALS, 8H AT FORM, * 23HER VALUES OF PARAMETERS)

99997 FORMAT (3HO, $4(2 X, A 10,2 X, A 10,4 X))$

END

$\mathrm{C}$

C

C

SUBROUT INE OUTCHL ( $C H I$ )

IMPLICIT DOUBLE PRECISION ( $\mathrm{A}-\mathrm{H}, \mathrm{O}-\mathrm{Z}$ )

COMMON /NUMBER/ NDAT, NPAR, ITER, ITMAX, CONVER

WRITE $(6,99999)$ CHI

$\mathrm{N}=$ NDAT - NPAR

IF (N.LE. O) RETURN

$\mathrm{CHI}=\mathrm{CHI} / \mathrm{DFLOAT}(\mathrm{N})$

WRITE $(6,99998)$ CHI

C RETURN

ENTRY OUTCHB(CHI)

WRITE $(6,99997)$ CHI

$\mathrm{N}=$ NDAT - NPAR

IF (N.LE.0) RETURN

$\mathrm{CHI}=\mathrm{CHI} / \mathrm{DFLOAT}(\mathrm{N})$

WRITE $(6,99998)$ CHI

C

RETURN

99999 FORMAT (42H0***** LEAST-SQUARES CHI SQUARED AT FORMER,

* 24H VALUES OF PARAMETERS IS, F 15.6)

99998 FORMAT (45HOCHI SQUARED DIVIDED BY DEGREES OF FREEDOM IS,

* F 15.6)

99997 FORMAT (37H0**** BAYESIAN CHI SQUARED AT FORMER,

* 24H VAlUES OF PARAMETERS IS, F15.6)

END 


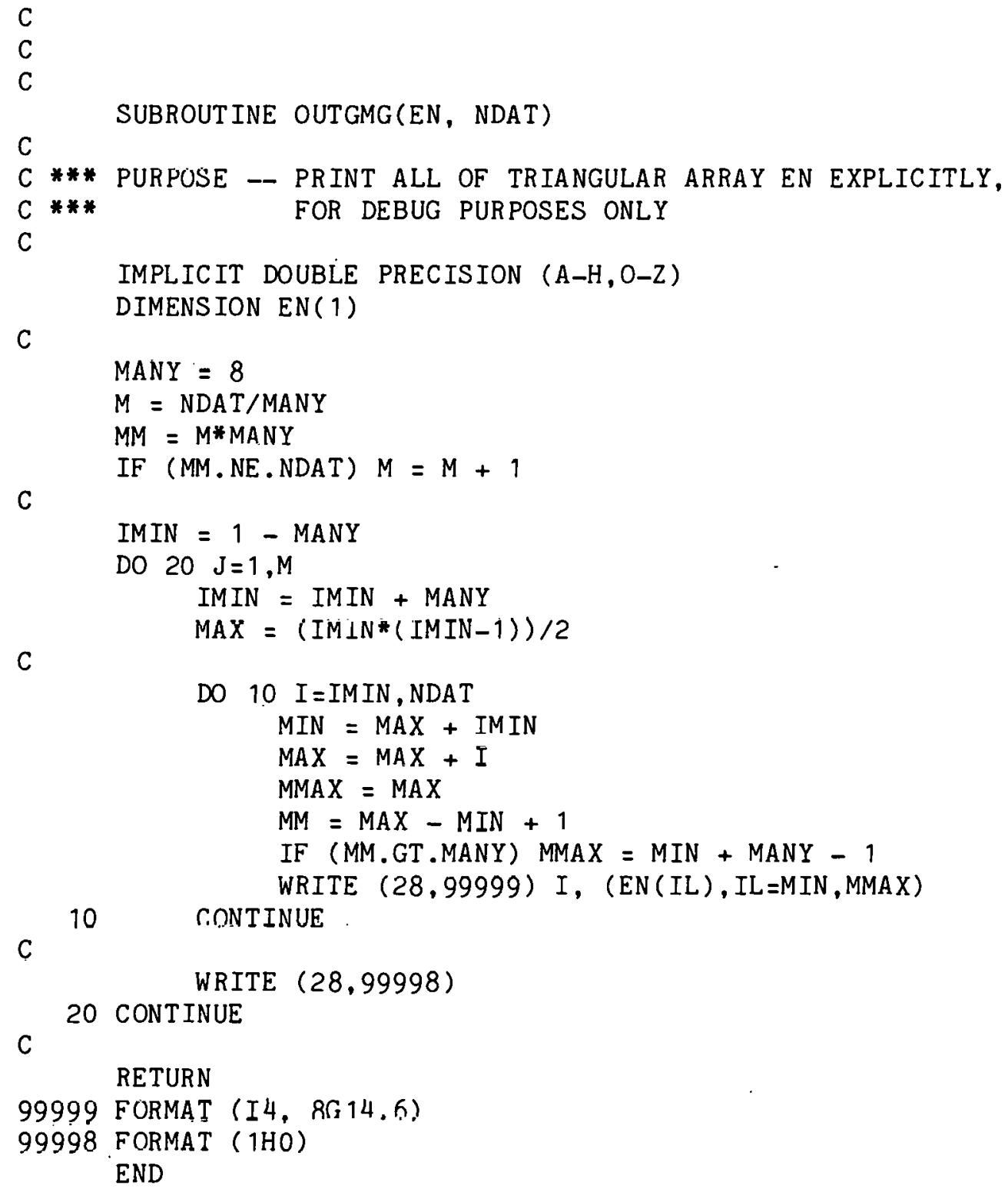


ORNL/TM-8185

ENDF -323

INTERNAL DISTRIBUTION

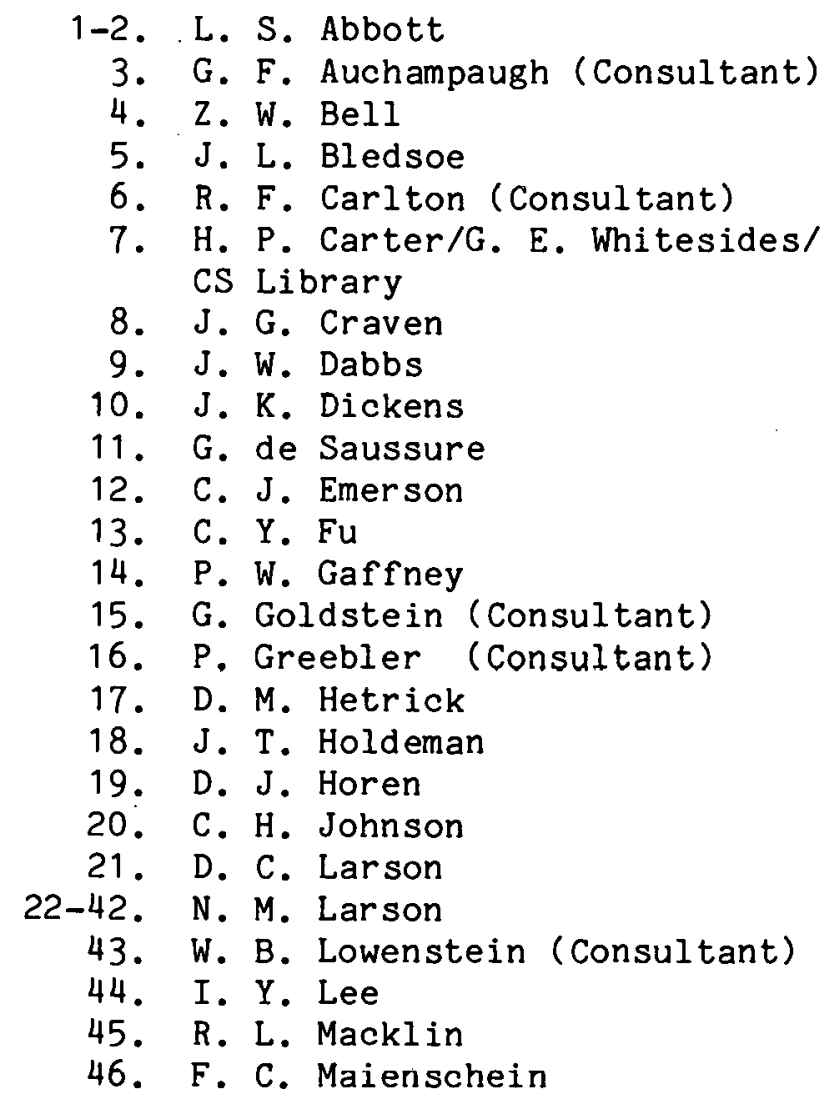

47. B. F. Maskewitz

48. G. S. McNeilly

49. P. S. Meszaros

50. S. Y. Ohr

51. D. K. Olsen

52. R. W. Peelle

53. C. M. Perey

54. F. G. Perey

55. R. B. Perez

56. S. Raman

57. M. Rhoades-Brown

58. R. Satchler

59. R. O. Sayer

60. A. L. Sjoreen

61. R. E. Uhrig (Consultant)

62. L. W. Weston

63. R. Wilson (Consultant)

64. R. Winters (Consultant)

65. Central Research Library

66. K-25 Plant Library

67. ORNL Y-12 Technical Library Document Reference Section

68-69. Laboratory Records Department

70. ORNL Patent office

71. Laboratory Records (RC)

\section{EXTERNAL DISTRIBUTION}

72. Pedro Andreo, Servicio de Fisica, Depto. de Radiologia, Hospital Clinico Universitario, Avda. Gomez Laguna, s/n., Zarágoza-9, ESPANA (Spain).

73. Allan D. Carlson, Neutron Measurements and Research, U.S. Department of Commerce, National Bureau of Standards, Washington, DC 20234.

74. Chief, Mathematics and Geoscience Branch, DOE, Washington, DC 20545.

75. DOE Oak Ridge Operations, Reactor Division, P. O. Box E, Oak Ridge, TN 37830.

76. DOE Division of Reactor Research and Development, Washington, DC 20545.

77. J. C. Garth, RADC/ESR, Hanscom Air Force Base, MA 01731. 
78. J. A. Lorenc, Nuclear Design Engineer, Nuclear Studies and Safety Department, 700 University Avenue, Toronto, Ontario M5G 1X6.

79. D. W. Muir, MS-B243, Los Alamos National Laboratory, Los Alamos, NM 87545.

80. J. N. Rogers, Division 8324, Sandia Laboratories, Livermore, CA 94550 .

81. Office of Assistant Manager for Energy Research and Development, Department of Energy, Oak Ridge Operations, Oak Ridge, TN 37830.

82-264. For distribution as shown in TID-4500 Distribution Category UC-79d, Liquid Metal Fast Breeder Reactor Physics - Base (60 copies - ENDF distribution). 